\title{
WestVirginiaUniversity
}

THE RESEARCH REPOSITORY @ WVU

Graduate Theses, Dissertations, and Problem Reports

2014

\section{Stem cell matrix and cartilage regeneration}

Jingting Li

West Virginia University

Follow this and additional works at: https://researchrepository.wvu.edu/etd

\section{Recommended Citation}

$\mathrm{Li}$, Jingting, "Stem cell matrix and cartilage regeneration" (2014). Graduate Theses, Dissertations, and Problem Reports. 394.

https://researchrepository.wvu.edu/etd/394

This Dissertation is protected by copyright and/or related rights. It has been brought to you by the The Research Repository @ WVU with permission from the rights-holder(s). You are free to use this Dissertation in any way that is permitted by the copyright and related rights legislation that applies to your use. For other uses you must obtain permission from the rights-holder(s) directly, unless additional rights are indicated by a Creative Commons license in the record and/ or on the work itself. This Dissertation has been accepted for inclusion in WVU Graduate Theses, Dissertations, and Problem Reports collection by an authorized administrator of The Research Repository @ WVU.

For more information, please contact researchrepository@mail.wvu.edu. 


\author{
Jingting Li \\ Dissertation submitted to the School of Medicine \\ at West Virginia University
}

in partial fulfillment of the requirements for the degree of

\author{
Doctor of Philosophy in \\ Exercise Physiology \\ Ming Pei, M.D., Ph.D., Chair \\ Stephen E. Alway, Ph.D. \\ John M. Hollander, Ph.D. \\ Emidio E. Pistilli, Ph.D. \\ Yon Rojanasakul, Ph.D. \\ Division of Exercise Physiology \\ Morgantown, West Virginia \\ 2014
}

Keywords: Mesenchymal stem cells, Nucleus pulposus, Decellularized extracellular matrix, Chondrogenesis

Copyright 2014 Jingting Li 


\section{Abstract \\ STEM CELL MATRIX AND CARTILAGE REGENERATION Jingting Li}

Cartilage defects caused by injuries of the knee affect about 900,000 Americans annually, resulting in more than 200,000 surgical procedures. Cartilage repair remains a major challenge due to its limited healing capacity. Current cell-based therapy using autologous chondrocyte implantation has been developed for decades and promising results have been observed in clinic. However, the shortage of autologous chondrocytes and their uncertain long-term effectiveness have led researchers to find alternative solutions. Stem cells from various tissues have been shown to be potential sources of chondrocytes. Among them, synovium-derived stem cells (SDSCs) have been suggested as tissue-specific stem cells for chondrogenesis. However, a major obstacle challenging the cartilage tissue engineering is cell senescence, which is due mainly to extensive ex vivo passaging and elderly donors. A reconstructed ex vivo microenvironment that can maintain or enhance stemness is urgently needed for facilitating largescale tissue engineering. To facilitate ex vivo expansion, the conventional methods for stem cell expansion were extensively investigated. We first compared the influence of low- and highseeding density on human SDSC stemness during ex vivo expansion. Low-density seeding expansion yielded SDSCs with enhanced proliferative and multi-differentiation capacities compared to high-density seeding though it was not highly efficient. Downregulation of ERK1/2 and JNK and upregulation of p38 might be attributed to the retained "stemness" under low-density expansion. We next compared the impact of hypoxia, fibroblast growth factor-2 (FGF-2) supplementation and a novel approach of SDSC-deposited decellularized extracellular matrix (DECM) on SDSC stemness. DECM expansion enhanced greater SDSC proliferation while retaining stem cell characteristics, compared to FGF-2 supplementation alone. The combination of hypoxia, FGF-2 and DECM contributed to the highest cell number in SDSC expansion, indicating their synergistic effects. Although the chondrogenic index was comparable between DECM expansion and FGF-2 supplementation, which were much higher than expansion on plastic flask alone, the observations that FGF-2 induced hypertrophic marker genes suggested the superiority of DECM in enhancing SDSC self-renewal while retaining stemness. Other potential cell sources for depositing DECM were also evaluated. We found that, besides SDSCs, adipose- or urine-derived stem cells and dermal fibroblasts could also deposit the DECM, which could enhance SDSC self-renewal and chondrogenic potential without concomitantly enhancing adipogenic and osteogenic potentials. These findings suggest that, given an optimal DECM substrate, the chondrogenic potential within the tissue-specific SDSC could be substantially 
enhanced. We further characterized human fetal synovial fibroblasts as fetal SDSCs as they possessed the multi-lineage differentiation capacities and mesenchymal stem cell surface marker expression. Fetal SDSC-derived DECM expansion not only increased cell number and enhanced chondrogenic potential; it also lowered SDSC senescence marker expression while enhancing MSC marker expression compared to expansion on plastic flasks alone. As cell senescence is a limiting factor for tissue regeneration, we then investigated whether the DECM derived from fetal SDSCs referred to as a young stem cell microenvironment could be used for rejuvenating adult SDSC. We found that fetal SDSC-derived DECM (FE) was superior to adult SDSC-deposited DECM (AE) in promoting SDSC proliferation and chondrogenic potential. Further investigation revealed that unique proteins in FE might be responsible for the rejuvenation effect and advantageous proteins in $\mathrm{AE}$ might contribute to differentiation more than proliferation. Compared to $A E$, the lower elasticity of FE yielded expanded SDSCs with lower elasticity, which could be responsible for the enhancement of chondrogenic differentiation. MAPK and noncanonical Wnt signals were also actively involved in DECM-mediated SDSC rejuvenation. The young and healthy microenvironment provided by fetal SDSCs could serve as a "fountain of youth" for adult SDSC rejuvenation. Finally, we tested whether the DECM expansion system would also be beneficial to the chondrocyte-like nucleus pulposus cell (NPC) rejuvenation from human herniated discs and whether fetal DECM was superior to adult DECM. Although both SDSC and NPC deposited DECMs (SECM and NECM) significantly enhanced NPC proliferation, only NECM expanded NPCs manifested the increased redifferentiation capacities after chondrogenic induction. NECM was better than SECM in functioning as an expansion system in vitro by promoting NPC proliferation and redifferentiation. In conclusion, we have demonstrated that the DECM deposited by human primary cells or stem cells serves as an ex vivo expansion system for maintaining self-renewal and differentiation potential, which could greatly benefit the future generation of cell-based therapy for cartilage and intervertebral disc regeneration. 


\section{ACKNOWLEDGEMENTS}

The present work would not have been possible without the help of the following people.

Foremost, I want to thank Dr. Ming Pei for giving me the opportunity to study this Integrated Biomedical Science PhD program at West Virginia University. Without his scientific perspectives and support, I would not have finished this thesis. He is always available for all my questions and providing helpful scientific advice when necessary during this work. His genuine enthusiasm for work sets good role model for me and motives me to go beyond my limits.

Furthermore, I would like to thank all my committee members from the West Virginia University. Thank you to Dr. Stephen Alway and Dr. John Hollander for providing me guidance and useful advice during my study in Exercise Physiology. Further thanks go to Dr. Yon Rojanasakul and Dr. Emidio Pistilli for always being so supportive and helpful during participation of committee meetings.

I would also like to thank all members of the Department of Exercise Physiology and Department of Orthopaedics at West Virginia University for providing me such a nice study and working atmosphere. They are not only colleagues but also friends. Special thanks go to Nina Clovis, Suzanne Danley and Vince Kish for maintaining our lab in good condition, helping with animal studies and biomechanical tests.

My deep appreciation goes to Sudjit Luanpitpong, the best roommate, a forever friend and an admiring colleague. I learned the most invaluable things from her. She is the best example of "work like you don't need the money, love like you have never been hurt and dance like nobody is watching". I treasured every second that we have spent together. She makes me feel that I am not alone. Without her unconditional support, I would not be able to get to this point. The past five years with her were the happiest moments of my life. I cannot tell you how lucky I feel to have her in my life. To Michelle Luo, we may not contact each other as often but thank her for being there for me during my most needed times.

My sincere thanks go to my parents Mr. Lasheng Li and Mrs. Hong Liu, for always supporting and believing in me, for planting the confidence in me that all things turn out well eventually, for allowing me to follow my dreams and for traveling so far from China to attend my graduation ceremony. Thank you all so much! 


\section{TABLE OF CONTENTS}

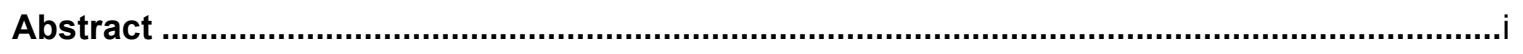

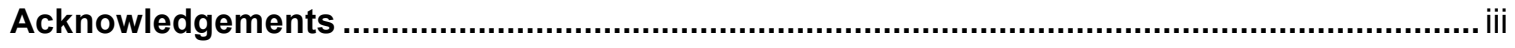

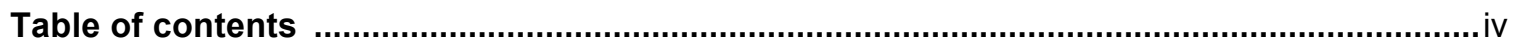

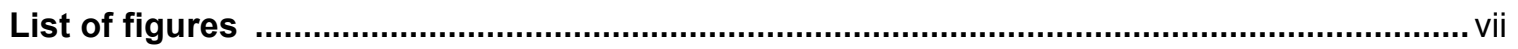

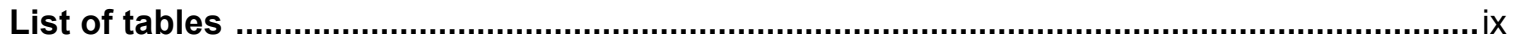

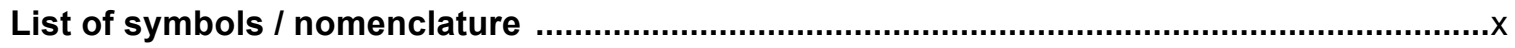

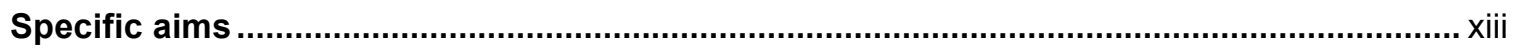

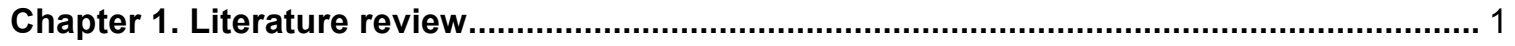

1.1 Current status of cartilage defect and intervertebral disc degeneration ...................... 1

1.1.1 Cartilage biology and intervertebral disc biology ........................................... 1

1.1.2 Degenerative joint and disc disease ........................................................... 3

1.1.3 Cartilage defect and disc degeneration .................................................... 4

1.2 Current treatments for cartilage defect and disc degeneration................................ 5

1.2.1 Conservative treatments and autologous chondrocyte implantation .................. 5

1.2.2 Current therapeutic strategies for nucleus pulposus regeneration ..................... 7

1.3 Current efforts and challenges of cartilage engineering ........................................ 7

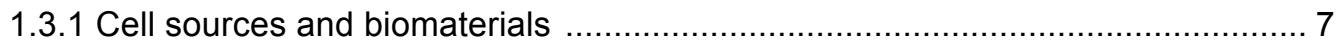

1.3.2 Challenges of cell senescence ….......................................................... 9

1.4 Potential contribution of DECM to cartilage regeneration......................................... 12

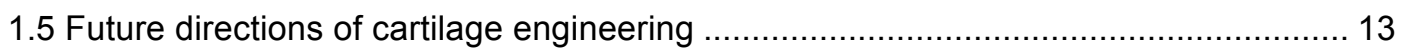

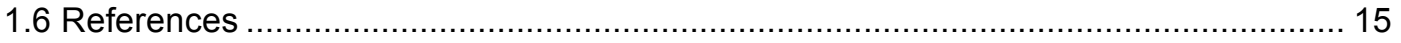

Chapter 2. Low-density expansion protects human synovium-derived stem cell from

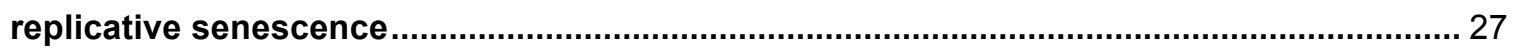

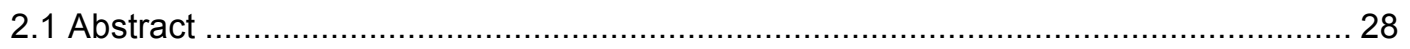

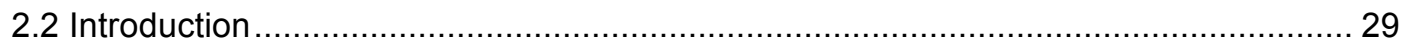

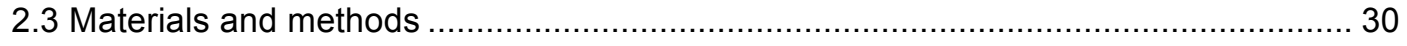

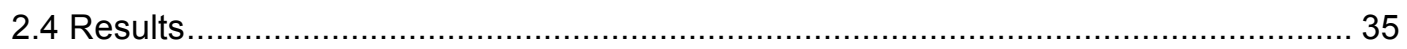

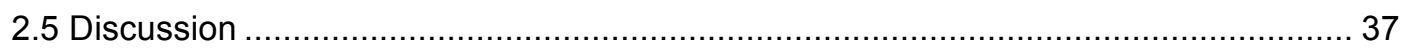

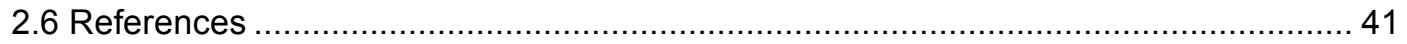

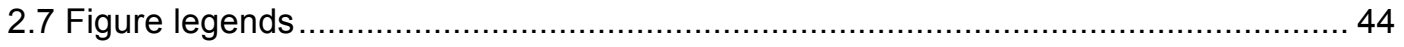


Chapter 3. Optimization of an in vitro three-dimensional microenvironment to reprogram synovium-derived stem cell for cartilage tissue engineering …......................................... 52

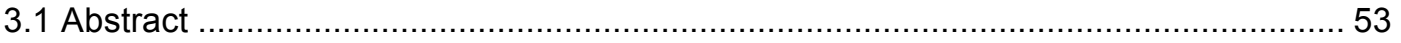

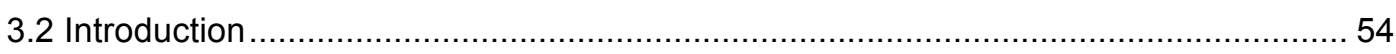

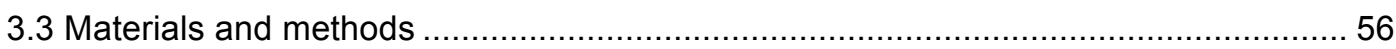

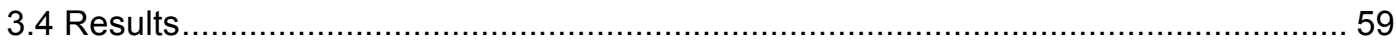

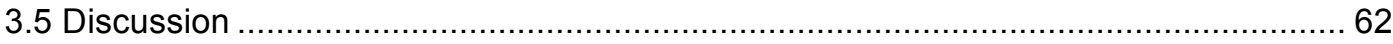

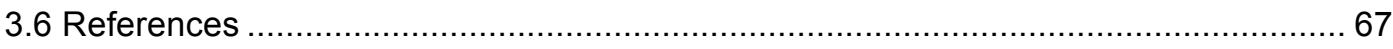

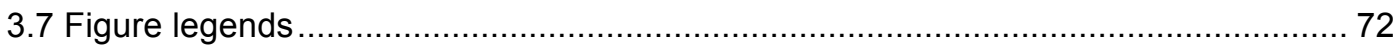

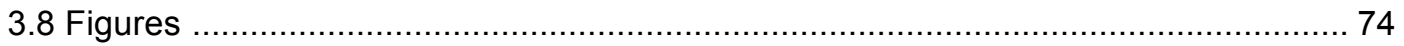

Chapter 4. Probing the role of decellularized matrix for enhancing human synovium-

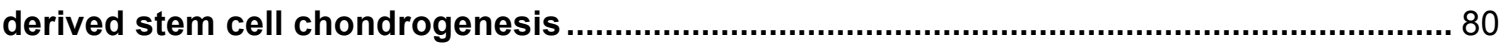

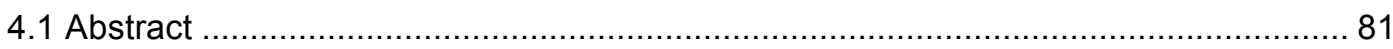

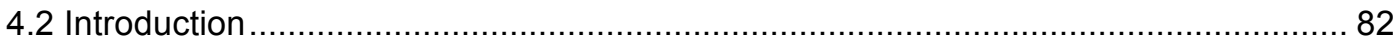

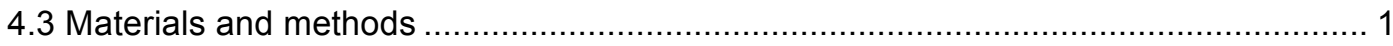

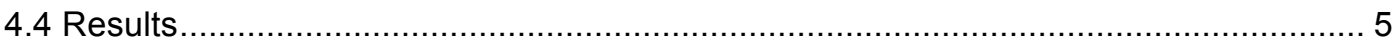

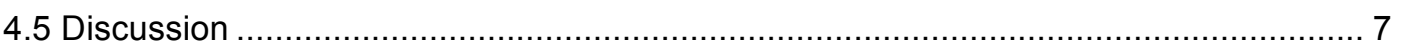

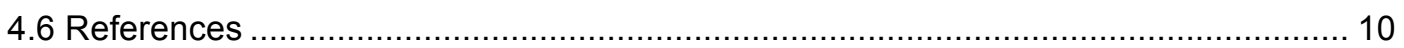

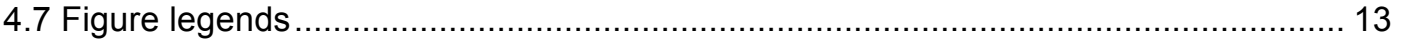

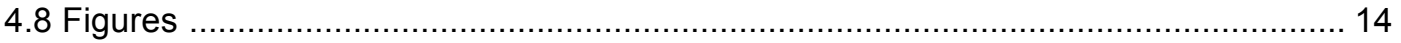

Chapter 5. Creation of an in vitro microenvironment to enhace human fetal synovium-

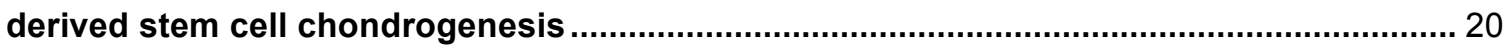

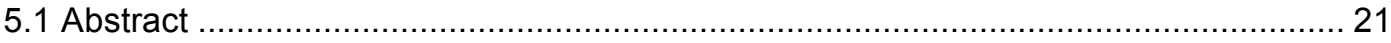

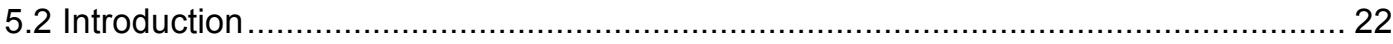

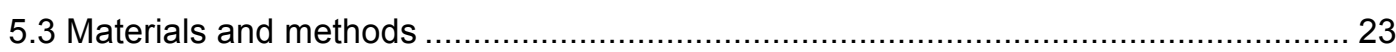

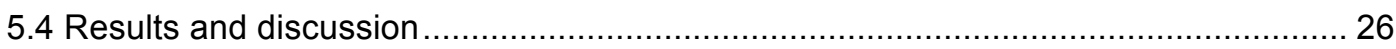

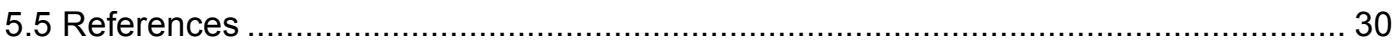

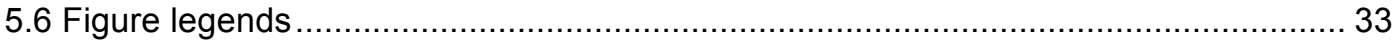

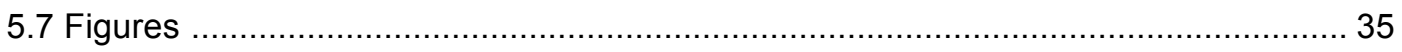

Chapter 6. Rejuvenation of chondrogenic potenial in a young stem cell microenvironment

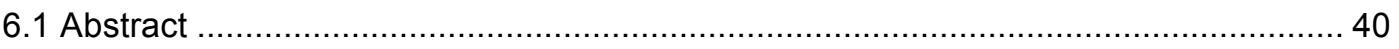

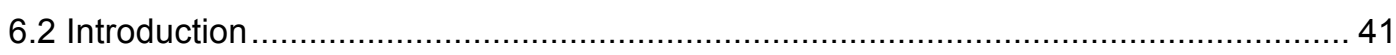

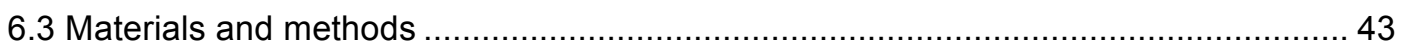

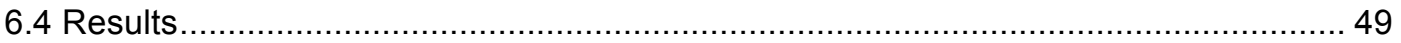




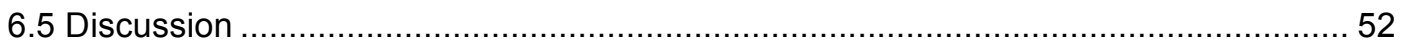

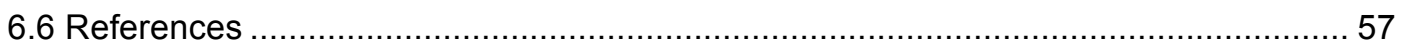

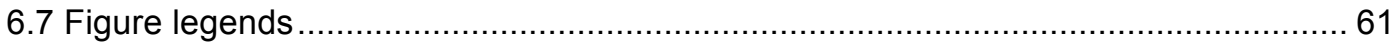

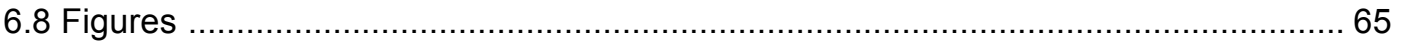

Chapter 7. A comparison in rejuvenation of human nucleus pulpous cells from herniated disc by synovium-derived stem cells and nucleus pulposus cells deposited tissue-specific

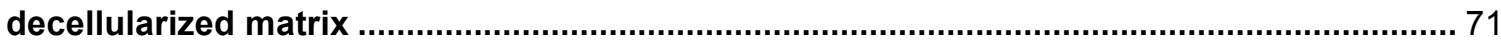

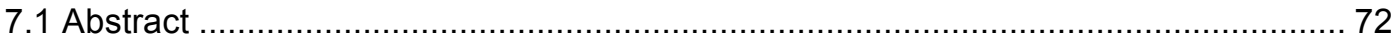

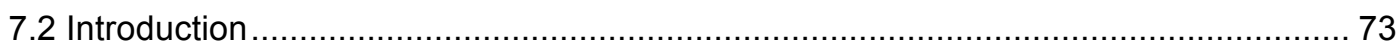

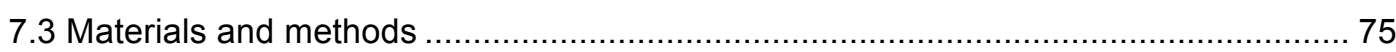

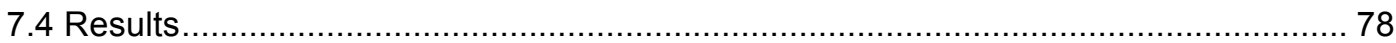

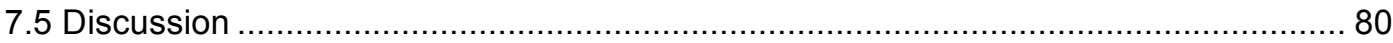

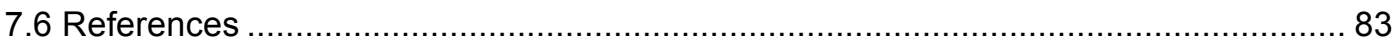

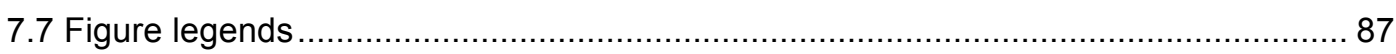

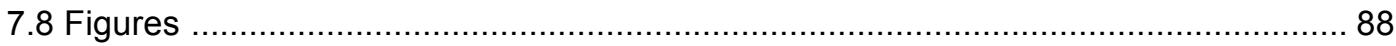

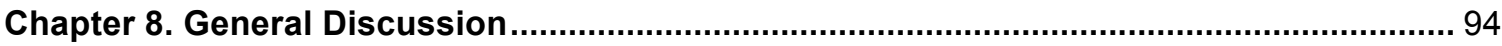

8.1 SDSC is a tissue-specific stem cell for chondrogenesis......................................... 94

8.2 Reconstruction and optimization of DECM based ex vivo expansion system for

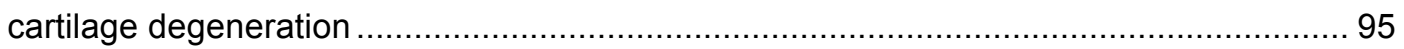

8.3 Biophysical and biochemical explanations of DECM............................................... 98

8.4 Signaling pathways involved in rejuvenating effect of DECM ............................... 100

8.5 DECM: a potential in vitro model of epigenetic application for cartilage regeneration 102

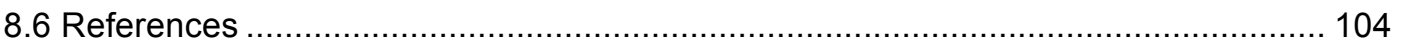




\section{LIST OF FIGURES}

\section{Chapter 1}

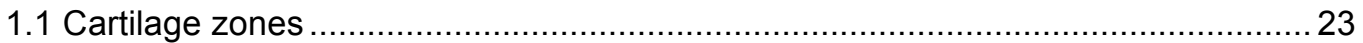

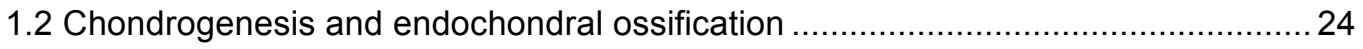

1.3 Resemblance between synovial joint and intervertebral disc .............................. 25

1.4 Senescence-associated signaling pathways in chondrogenic differentiation .......... 26

\section{Chapter 2}

2.1 Cell morphology, number, and size changes at different seeding density ..............46

2.2 MSC marker expression, $\mathrm{PI}$ and apoptosis changes at different seeding density ... 47

2.3 Chondrogenic markers protein level changes after different density seeding ..........48

2.4 Chondrogenic markers mRNA level changes after different density seeding.......... 49

2.5 Cell seeding density affects expanded cell osteogenic and adipogenic potential.... 50

2.6 Expression of $\mathrm{p} 21$, caveolin-1 and MAPK signaling changes at either density ........51

\section{Chapter 3}

3.1 SDSC morphology in preparation of ECM and expansion .................................. 74

3.2 Cell number counted after expansion and followed by pellet culture....................... 75

3.3 Histology and immunohistochemistry of SDSC pellets .......................................... 76

3.4 Biochemical analysis for DNA and GAG contents in SDSC pellets ........................77

3.5 Chondrogenic marker genes expression in SDSC pellets .................................... 78

3.6 Hypertrophic marker genes expression in SDSC pellets ..................................... 79

\section{Chapter 4}

4.1 DECMs expansion enhanced SDSC proliferation.................................................. 98

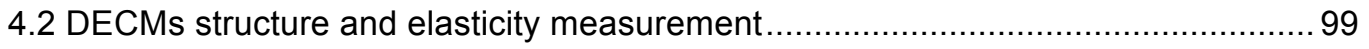

4.3 Biochemical analysis of sulfated GAG and DNA contents ................................. 100

4.4 Histology and immunostaining for chondrogenic markers in pellets ....................... 101

4.5 Chondrogenic and hypertrophic marker genes expression in pellets ..................... 102

4.6 Adipogenic and osteogenic potential was analyzed in expanded SDSCs .............. 103

\section{Chapter 5}

5.1 Characterization of multi-lineage differentiation capacity of hfSF ..... 119

5.2 Effect of extracellular matrix on hfSF expansion and anti-senescence .................. 120

5.3 Assessment of expanded hfSF chondrogenic differentiation at the protein level .... 121 


\section{Chapter 6}

6.1 Enhanced proliferation and anti-apoptotic on ECM-expanded ASDSCs ................ 149

6.2 Contribution of ECM structure and composition to ASDSC rejuvenation ................ 150

6.3 FE promoted expanded ASDSCs' early chondrogenic differentiation ..................... 151

6.4 Potential mechanisms underlying ECM-mediated ASDSC rejuvenation ................. 152

6.5 FE promoted expanded ASDSCs' later chondrogenic differentiation ...................... 153

6.6 Promoted adipogenesis expanded ASDSC ECM pretreatment............................. 154

\section{Chapter 7}

7.1 Cell morphology of NPC during expansion on plastic flasks or SECMs ................ 172

7.2 Cell morphology of NPC during expansion on plastic flasks or NECMs ................. 173

7.3 Mesenchymal stem cell surface markers analysis by flow cytometry ..................... 174

7.4 Histology and immunostaining of ECMs pre-expanded NPCs pellets .................... 175

7.5 Biochemistry analysis for GAG and DNA content in ECMs expanded NPCs .......... 176

7.6 Hypertrophic, catabolic metaboism and senescence gene markers expression ..... 177 


\section{LIST OF TABLES}

\section{Chapter 1}

1.1 Advantages and disadvantages of various cell sources

\section{Chapter 3}

3.1 TaqMan-customized chondrogenic marker gene primers and probes................73

\section{Chapter 6}

6.1 Select ECM and ECM interacting proteins identified in FE and $\mathrm{AE}$...... 147 


\section{LIST OF SYMBOLS / NOMENCLATURE}

\begin{tabular}{|c|c|}
\hline 2D & Two-dimensional \\
\hline $3 \mathrm{D}$ & Three-dimensional \\
\hline $\mathrm{ACl}$ & Autologous chondrocyte implantation \\
\hline $\mathrm{ACl}-\mathrm{C}$ & Collagen-covered $\mathrm{ACl}$ \\
\hline ACl-P & Periosteal-based ACl \\
\hline $\mathrm{AE}$ & ASDSC-derived DSCM \\
\hline AF & Annulus fibrosus \\
\hline ALP & Alkaline phosphatase \\
\hline ASCs & Adipose-derived stem cells \\
\hline ASDSC & Adult SDSCs \\
\hline BMP & Bone morphogenetic protein \\
\hline BMSCs & Bone marrow derived mesenchymal stem cells \\
\hline CEP & Cartilaginous end-plates \\
\hline Col I & Type I collagen \\
\hline Col II & Type II collagen \\
\hline Col X & Type $X$ collagen \\
\hline DAB & 3,3'-diaminobenzidine \\
\hline DCFH-DA & 2',7'-dichlorofluorescein-diacetate \\
\hline DE & DF-derived DECM \\
\hline DECM & Decellularized extracellular matrix \\
\hline DFs & Dermal fibroblasts \\
\hline DMMB & Dimethylmethylene blue \\
\hline DSCM & Decellularized stem cell matrix \\
\hline ECM & Extracellular matrix \\
\hline ESCs & Embryonic stem cells \\
\hline ERK & Extracellular signal regulated kinase \\
\hline FACS & Fluorescence-activated cell sorting \\
\hline FAK & Focal adhesion kinase \\
\hline FBS & Fetal bovine serum \\
\hline $\mathrm{FE}$ & FSDSC-derived DECM \\
\hline FGF & Fibroblast growth factor \\
\hline FITC & Fluorescein isothiocyanate \\
\hline FSDSC & Fetal SDSC \\
\hline GAGs & Glycosaminoglycans \\
\hline
\end{tabular}




\begin{tabular}{|c|c|}
\hline HGF & Hepatocyte growth factor \\
\hline HIF & Hypoxia-inducible factor \\
\hline HfSF & Human fetal synovial fibroblast \\
\hline IGF1 & Insulin-like growth factor-1 \\
\hline IL & Interleukin \\
\hline iPSC & Induced pluriopotent stem cell \\
\hline IVD & Intervertebral disc \\
\hline JNK & C-Jun $\mathrm{NH}_{2}$-terminal kinase \\
\hline LBP & Low back pain \\
\hline LPL & Lipoprotein lipase \\
\hline $\mathrm{MACl}$ & Matrix associated $\mathrm{ACl}$ \\
\hline MAPK & Mitogen activated protein kinase \\
\hline MFI & Median fluorescent intensity \\
\hline MMP & Matrix metalloproteinases \\
\hline MSCs & Mesenchymal stem cells \\
\hline NCs & Notochordal cells \\
\hline NECM & NPC-derived DECM \\
\hline NPC & Nucleus pulposus cells \\
\hline OA & Osteoarthritis \\
\hline $\mathrm{OCN}$ & Osteocalcin \\
\hline OCT4 & Octamer-binding transcription factor 4 \\
\hline PBS & Phosphate buffered saline \\
\hline PCR & Polymerase chain reaction \\
\hline PDSC & Periosteum-derived stem cell \\
\hline PGs & Proteoglycans \\
\hline PGA & Poly glycolic acid \\
\hline $\mathrm{PI}$ & Proliferation index \\
\hline PI3K & Phosphatidylinositol 3-kinase \\
\hline PKC & Protein kinase $\mathrm{C}$ \\
\hline PPARY & Peroxisome proliferator-activated receptor gamma \\
\hline RA & Rheumatoid arthritis \\
\hline ROS & Reactive oxygen species \\
\hline RUNX2 & Runt domain transcription factor \\
\hline SDSCs & Synovium-derived stem cells \\
\hline SECM & SDSC-derived DECM \\
\hline SEM & Scanning electron microscope \\
\hline SIRT1 & Sirtuin1 \\
\hline
\end{tabular}




$\begin{array}{ll}\text { SOX9 } & \text { SRY (sex determining region Y)-box } \\ \text { SPP1 } & \text { Secreted phosphoprotein type 1 } \\ \text { SSEA4 } & \text { Stage specific embryonic antigen } 4 \\ \text { TGF } \beta & \text { Transforming growth factor } \beta \\ \text { TNF } & \text { Tumor necrosis factor } \\ \text { UE } & \text { USC-derived DECM } \\ \text { USCs } & \text { Urine-derive stem cells } \\ \text { VEGF } & \text { Vascular endothelial growth factor }\end{array}$




\section{SPECIFIC AIMS}

Cartilage defects caused by injuries to the knee affect about 900,000 Americans annually, resulting in more than 200,000 surgical procedures. ${ }^{1}$ Cartilage repair remains a major challenge due to its limited healing capacity. Current cell-based therapy using autologous chondrocyte implantation $(\mathrm{ACl})$ has been developed for decades and promising results have been observed in clinic. ${ }^{2 ; 3}$ However, the shortage of autologous chondrocytes and their uncertain long-term effectiveness have led researchers to find alternative solutions. Stem cells from various tissues have been shown to be potential sources of chondrocytes. Among them, the synovium-derived stem cell (SDSC) has been suggested as a the tissue-specific stem cell for chondrogenesis. ${ }^{4}$ However, a major obstacle challenging the cartilage tissue engineering is cell senescence, which is due mainly to extensive ex vivo passaging and elderly donors. ${ }^{5}$ A reconstructed ex vivo microenvironment that can maintain or enhance stemness is urgently needed for facilitating largescale tissue engineering.

Recently many studies have suggested that decellularized tissue matrix provides a threedimensional structure with biochemical and biomechanical cues to facilitate tissue and organ regeneration. Previous work have demonstrated that porcine SDSC derived stem cell matrix could be decellularized (DECM) and serve as a substrate that can significantly enhance cell proliferation and facilitate chondrogenesis. ${ }^{6}$ However, it remains unclear if this DECM system could be successfully translated into human primary cells.

Based on these exciting data and our preliminary novel data along with the urgent clinical need for cartilage regeneration, we hypothesized that (i) DECM as a novel expansion system is superior to conventional methods in maintaining SDSC stemness and facilitatating chondrogenesis; (ii) Young DECM derived from fetal SDSCs can rejuvenate adult stem cells and restore their self-renewal and chondrogenic differentiation potentials; and (iii) Young DECM expansion system could also be applied to rejuvenate chondrocyte-like nucleus pulposus cells (NPCs) from herniated discs toward higher proliferation and redifferentiation potentials.

Our long-term goal was to develop an efficient in vitro expansion system with proliferation and chondrogenic differentiation rejuvenating capacities, which can provide a large quantity of high quality cells for cartilage engineering. The potential impact of this study is that the optimization of ex vivo stem cell protocols with decellularized extracellular matrix for maintaining stemness and facilitating chondrogenesis will provide high quality and a large quantity of cells for $\mathrm{ACl}$. The 
understanding of the rejuvenation mechanism by matrixes will advance the knowledge of cartilage regeneration and benefit the development of better treatment for cartilage defect.

The objectives of this dissertation were to: (1) investigate the effect of conventional methods (seeding density, low oxygen, growth factor) and the novel DECM expansion system on SDSCs for facilitating chondrogenesis and explore the potential cell sources of DECM; (2) characterize the rejuvenating effect of fetal SDSCs deposited young DECM on adult SDSCs and its potential mechanisms; (3) apply the young DECM expansion system to the rejuvenation of primary NPC from herniated human discs. The central hypothesis was that DECM deposited by human primary cells or stem cells can serve as ex vivo expansion system for cartilage regeneration. The following three specific aims and correspondent hypothesis are described as below.

\section{Specific Aims:}

Specific aim 1: Demonstrate that DECM is superior to conventional methods as an expansion system in maintaining SDSC stemness and facilitating chondrogenesis.

1.1 Investigate the effect of seeding density, hypoxia, fibroblast growth factor-2 (FGF-2) and DECM on SDSC expansion and chondrogenic differentiation.

Hypothesis 1.1: We hypothesized that low density seeding can enhance SDSC self-renewal and chondrogenic differentiation. Hypoxia, FGF-2 and DECM deposited by SDSCs in combination or alone can increase the proliferative and chondrogenic differentiation potentials in SDSCs.

1.2 Investigate whether DECM derived from sources including SDSCs, dermal fibroblasts, adipose and urine-derived stem cell can reprogram SDSCs.

Hypothesis 1.2: We hypothesized that DECMs derived from SDSCs, dermal fibroblasts, adipose and urine-derived stem cells can reprogram SDSCs toward more proliferation and stemness, especially chondrogenesis.

Specific aim 2: Characterize the rejuvenation effect of young DECM on adult SDSCs towards proliferation and chondrogenesis.

2.1 Characterize fetal synovium fibroblasts as fetal SDSCs and investigate its deposited DECM. 
Hypothesis 2.1: We hypothesized that fetal synovium fibroblasts contain fetal SDSCs due to the capacity to express MSC markers and undergo multi-lineage differentiation.

2.2 Examine the rejuvenation effect from young DECM on adult SDSCs by comparing SDSCs expanded on either young or old DECM through evaluating their self-renewal and chondrogenic differentiation potentials.

Hypothesis 2.2: We hypothesized that young DECM deposited by fetal SDSCs can rejuvenate adult SDSCs towards proliferation and chondrogenesis.

Specific aim 3: Investigate the rejuvenation effect of primary NPCs from herniated human discs using young or adult DECMs deposited by SDSCs and NPCs.

3.1 Investigate whether human fetal or adult SDSC deposited DECM can rejuvenate NPCs from herniated intervertebral discs.

Hypothesis 3.1: We hypothesized that DECM derived from fetal or adult SDSCs can enhance proliferative and/or chondrogenic potentials.

3.2 Investigate whether human fetal or adult NPC derived DECM can enhance NPC proliferation and redifferentiation potentials.

Hypothesis 3.2: We hypothesized that DECM derived from fetal or adult NPCs can enhance proliferative and/or chondrogenic potentials. 


\section{REFERENCES}

1. Cole BJ, Frederick RW, Levy AS, et al. Management of a 37 year-old man with recurrent knee pain. J. Clin. Outcomes. Manag. 1999;6:46-57.

2. Lewis PB, McCarty LP, Kang RW, et al. Basic science and treatment options for articular cartilage injuries. J Orthop Sports Phys Ther. 2006;36:717-27.

3. Vasiliadis HS, Wasiak J. Autologous chondrocyte implantation for full thickness articular cartilage defects of the knee. Cochrane Database Syst Rev. 2010;10:CD003323.

4. Jones BA, Pei M. Synovium-derived stem cells: a tissue-specific stem cell for cartilage engineering and regeneration. Tissue Eng Part B Rev. 2012;18:301-11.

5. Li J, Pei M. Cell senescence: a challenge in cartilage engineering and regeneration. Tissue Eng Part B Rev. 2012;18:270-87.

6. He F, Chen X, Pei M. Reconstruction of an in vitro tissue-specific microenvironment to rejuvenate synovium-derived stem cells for cartilage tissue engineering. Tissue Eng Part $A$. 2009;15:3809-21. 


\section{CHAPTER 1:LITERATURE REVIEW}

\subsection{Current Status of Cartilage Defect and Intervertebral Disc Degeneration}

\subsubsection{Cartilage Biology and Intervertebral Disc Biology}

Articular cartilage is a unique, hypocellular, and avascular tissue, made mostly of extracellular collagens and proteoglycans (PGs). It allows for a smooth gliding of articulating surfaces of a joint in order to withstand high loads during a lifetime. The structural integrity of the articular cartilage is essential to perform physical activity throughout life.

Different types of cartilage tissue are present throughout the body at various sites. According to the histological classification, there are hyaline, elastic, and fibrocartilage depending on their molecular composition. ${ }^{1}$ Hyaline articular cartilage is formed by the chondrocytes $(\sim 5 \%$ of the cartilage wet weight and $<10 \%$ of the cartilage tissue volume) surrounded by an intricate network of extracellular matrix (ECM). The cartilage matrix is rich in PGs $(\sim 10 \%)$ (mostly aggrecan, but also decorin, biglycan, and fibromodulin) and collagen fibrils ( 15\%) (mostly type-ll collagen, but also type-IX, -XI, -VI, and -XIV collagens) and a number of additional molecules for stabilization (link protein, cartilage oligomeric matrix protein, fibronectin, tenascin). ${ }^{2-4}$ Normal hyaline articular cartilage contains about $70-80 \%$ water mainly bound to PGs, but a proportion of which can move freely for joint lubrication and for nutrition of the chondrocytes. Adult hyaline articular cartilage is avascular and aneural tissue that does not possess a lymphatic drainage. The chondrocytes thus derive oxygen and nutrition from the synovial fluid by diffusion.

The cartilage ( 2-5 $\mathrm{mm}$ thick) is structurally divided in three zones (Figure 1.1), each with a unique cell morphology and collagen fibers that depend on the expression of specific molecules. The superficial/tangential zone ( 10-20\%) contains flattened chondrocytes (at the highest density and expressing lubricin essential for lubrication) and fibers parallel to the surface. The intermediate/ transitional zone $(\sim 40-60 \%)$ is formed of round-shaped cells and oblique, less organized fibers. The deep/basal zone ( $30 \%)$ (Including the calcified zone) also contains roundshaped cells (at the lowest density) and fibers, both in vertical columns perpendicular to the surface. The specific organization of articular cartilage and the embedded chondrocytes result from complex developmental processes in which the joints are formed during embryogenesis. ${ }^{5}$

This process is called endochondral ossification (Figure 1.2), and can be divided into four steps: chondrogenesis from early mesenchymal condensations, chondrocyte differentiation and hypertrophy, mineralization of the matrix and invasion of bone cells, and finally, the definitive formation of bone. Chondrogenesis is the first step in endochondral ossification and is based on 
strongly regulated events that comprise condensation of mesenchymal chondroprogenitor cells, differentiation into chondrocytes, and the patterning of chondrofying tissues into skeletal structures. The composition of ECM changes during the differentiation of mesenchymal cells into chondrocytes. The expression of collagen I decreases, chondrocytes start producing collagen II, $\mathrm{IX}$, and $\mathrm{XI}$ as well as aggrecan, link protein, and Gla protein. This composition of cartilage is largely retained in adult articular cartilage. In those parts of the embryonic cartilage in which cartilage is replaced by bone, chondrocytes differentiation further and become hypertrophic expressing collagen $X$. The invasion of blood vessels from the perichondrium indicated the vascularization of cartilage and the beginning of bone formation. ${ }^{5 ; 6}$ The ECM gets mineralized in part by hypertrophic chondrocytes, and through the coordinated action of mineralizing osteoblasts and bone resorbing osteoclasts that migrate into the remodeling cartilage.

The chondrocytes exist at low oxygen tension, especially those in the deep/basal zone. In normal adult cartilage, the chondrocytes do not show proliferative activity and the network of type-II collagen fibers is extremely stable, with a half-life of several years, and also the turnover of aggrecan is not excessive (months to years), ${ }^{2}$ making cartilage a very consistent tissue. This results in a limited ability of cartilage to self-heal after trauma and degenerative disease. ${ }^{7}$

Nevertheless, the adult chondrocytes are capable of adjusting the metabolic (structural and functional) cartilage homeostasis by regulating the balance of ECM components (synthesis versus degradation) depending on the (complex) presence and influence of various factors including the composition of the matrix itself, mechanical loads, local hormones, growth factors (transforming growth factor beta - TGF- $\beta$, insulin-like growth factor I - IGF-I, the bone morphogenetic proteins 2 and 7 - BMP-2, -7), and cytokines (interleukin 1 - IL-1, tumor necrosis factor alpha - TNF- $\alpha$ ), disease (osteoarthritis - OA) or injury, and aging. ${ }^{2 ; 8}$ The chondrocytes respond for instance to mechanical forces by interactions between their cell surface integrins and the components of the matrix or to local factors (hormones, growth factors, cytokines) by interactions with specific cell surface receptors. As a consequence, these cells can either secrete matrix molecules or the enzymes that degrade them (matrix metalloproteinase's - MMPs, aggrecanases) by undergoing phenotypic changes. ${ }^{2 ; 9-11}$

Intervertebral disc (IVD) stabilizes the spine by anchoring adjacent vertebral bodies to each other; at the same time allowing movement between vertebrae, which gives the spine its flexibility, and they absorb and distribute loads applied to the spine. With increasing age they undergo striking changes in volume, shape, structure, and composition that decrease motion and alter the mechanical properties of the spine. Like other connective tissues, discs consist of a sparse population of cells and an abundant ECM formed by an elaborate framework of macromolecules 
filled with water. The cells synthesize the macromolecules and then maintain and repair the framework created from these molecules. The integrity and mechanical properties of the IVD depend on the macormolecules and their interactions with water. Due to lack of blood supply in the mature disc, the cells rely on the ability of nutrients and wastes to move through the matrix. Transport of these molecules through the matrix depends on the composition and organization of the macromolecular framework, and the matrix water content, which is largely determined by the PG concentration. ${ }^{12}$

The IVD is part of an anatomic unit that includes the nucleus pulposus (NP) located centrally, the annulus fibrosus (AF) located peripherally, and the cartilaginous end-plates (CEP) with their associated capillary beds both cranially and caudally. The healthy AF comprises concentric layers of predominantly type I collagen fibrils, which serve as a boundary containing the inner NP. The healthy NP tissue is characterized by high PG and water content within a loose collagen network. It has a sparse, heterogeneous population of cells responsible for maintaining the matrix. The negatively charged ECM retains between $66-86 \%$ water, ${ }^{13}$ which permits distribution of and resistance to spinal loads while sustaining disc height.

Interestingly, articular cartilage in synovial joints bears a lot of resemblance to NP (Figure 1.3). But the NP is not a viable option due to a lack of precursors, high susceptibility to degeneration, and various other pathologies. In contrast, synovial lining has a highly robust adult stem cell population that exhibits a great capacity for both cartilage and NP repair and may be suitable for NP regeneration. A recent comprehensive review also suggested the potential of using synovium derived stem cells (SDSCs) as a source for NP regeneration. ${ }^{14}$

\subsubsection{Degenerative Joint and Disc Disease}

$\mathrm{OA}$ is the most common and highly prevalent degenerative joint diseases in which articular cartilage integrity is compromised. It affects more than $20 \%$ of American adults and $10 \%$ of men older than 60 develop OA. It is highly associated with age and characterized by a change in chondrocyte behavior that leads to elevated production of proteolytic enzymes, such as MMP13, and consequently to cartilage damage and loss of joint function. The current understanding about $\mathrm{OA}$ is that it is a disease of the entire joint and not only a pathological degradation of articular cartilage. Inflammation of synovial membrane causes release of chondrotoxic proteins leading to cartilage destruction. Typical $\mathrm{OA}$ is characterized by areas of poorly delineated defects. Untreated cartilage defects resulting from trauma or osteochondritis dissecans tend to predispose patients to the development of OA. Current treatments are focused on symptomatic relief but they lack efficacy to control the progression of this disease, which is a leading cause of disability. The pharmacological interventions that address chronic pain are insufficient, and no proven structure- 
modifying therapy is available. ${ }^{9}$ With the progress of defining the molecular mechanisms involved in the initiation and progression of $\mathrm{OA}$, the effective disease-modifying drugs is being developing. Cell-based therapy and novel approaches using mesenchymal stem cells (MSCs) as an alternative cell source to chondrocytes are currently on trial. ${ }^{15 ; 16}$ Patients suffering from degenerative diseases such as $\mathrm{OA}$ are the main group that will benefit from successful cartilage regeneration. ${ }^{17}$

Rheumatoid arthritis (RA) is an autoimmune disease that results in a chronic, systematic inflammatory disorder that affects many tissues and organs, but principally attacks flexible joints. During RA pathogenesis, proinflammatory cytokines present in the rheumatoid synovial fluid activated MMP secretion by chondrocytes, synoviocytes and increase pericellular degradation of these cells. Cartilage degeneration is the result of the action of MMP. To date, the goal of treatment in RA is to reduce joint inflammation and pain, maximize joint function, and prevent joint destruction and deformity.

Degenerative disc disease is the degeneration of one or more IVD of the spine, also called degenerative disc disorder. It is a disease of aging and can cause severe chronic pain and greatly affects the quality of one's life. Current treatments are predominantly conservative or, less commonly, surgical; in many cases there is no clear diagnosis and therapy is considered inadequate.

Aging is the accumulation of changes in a person over time. It affects every organ to a different degree. Aged chondrocytes are less responsive to mechanical and inflammatory stimulus. Their protein secretion has been altered, as evidenced by decreased anabolic activity and increased production of proinflammatory cytokines and matrix-degrading enzymes. The above changes make cartilage more susceptible to damage and can lead to the early onset of OA and other degenerative diseases. Age also has an influence on cell properties when using autologous chondrocytes. $^{18}$

\subsubsection{Cartilage Defects and Disc Degeneration}

Age-related degeneration of articular cartilage and IVD is the most common causes of pain and disability in middle-aged and older people. ${ }^{19 ; 20} \mathrm{OA}$, trauma, and metabolic disorders of the subchondral bone, such as osteonecrosis or osteochondritis dissecans are the primary causes of cartilage defects accompanied with degeneration. ${ }^{21}$ Cartilage is vulnerable to traumatic injury; due to its avascular nature, inability to access MSCs, and the irreversible aging process, the ability of cartilage to self-heal is disappointing. In 1000 knee arthroscopies, $61 \%$ of the knee joints had cartilage defects; $44 \%$ of them were due to OA, $28 \%$ were due to focal cartilage defects, and 
$2 \%$ were due to osteochondritis dissecans. ${ }^{22}$ Patients with symptomatic cartilage defects often report pain, swelling, joint locking, stiffness, and clicking. Symptoms may cause significant functional impairment, often limiting one's ability to work, play sports, and perform activities of daily living.

Symptomatic disc degeneration is thought to be a significant contributor to low back pain (LBP), which is estimated to trigger between $2.8 \%{ }^{23}$ and $5 \%{ }^{24}$ of health-care visits in the United States. The overall cost of LBP exceeds $\$ 100$ billion/year in the United States alone, when considering both direct costs and indirect costs, such as lost wages and productivity. ${ }^{25}$ The lumbar spine disc degeneration begins earlier in life than degeneration of any other connective tissue in the human body, often by the second decade. ${ }^{19 ; 26-28}$ As degeneration progresses, the IVD becomes less able to efficiently absorb physiological loads, resulting in load transfer to adjacent vertebral bodies leading to end plate changes, osteophyte formation, and trabecular microfractures. ${ }^{29}$ Degenerative fissures in the lamellae of the AF coalesce ${ }^{30}$ leads to a lack of structural integrity, which may allow heriniation of the central NP material.

During development, the immature NP arises from the embryonic notochord and remains populated with notochordal cells (NCs). ${ }^{31}$ These large, highly-vacuolated, and metabolically active cells produce a high PG content matrix in addition to providing regulatory cues for surrounding cells. ${ }^{32-34}$ With age and degeneration, NP undergoes extensive changes in terms of matrix composition and cell population. Initial signs of degeneration present around the first decade of life along with a decline in $\mathrm{NCs},{ }^{26}$ though it is still unclear whether the decline is due to the continued differentiation of NCs into chondrocyte-like NPs or due to the programmed death (apoptosis) of the resident cells with invasion by cells from CEP or AFs, both of which together with NP consist IVD. ${ }^{35-37}$ Degeneration of NP results in a transition from the gelatinous healthy tissue to a more fibrous structure that is unable to provide mobility to the spine and allows complex motion. The consequent altered transmission of spinal loads can ultimately lead to disc failure.

\subsection{Current Treatments for Cartilage Defect and Disc Degeneration}

\subsubsection{Conservative Treatments and Autologous Chondrocyte Implantation}

The first step in the management of articular cartilage lesion is always conservative treatment, which typically begins with the use of medications or nutritional supplements including acetaminophen, nonsteroidal anti-inflammatory drugs, and glucosamine and chondroitin sulfate. These medications may help decrease the symptoms of articular cartilage lesion, but they are generally of limited benefit to relatively young and active patients. Although physical therapy 
helps optimize extremity strength and flexibility, it is not highly effective in reducing the symptoms associated with cartilage defect.

Current surgical methods of managing chondral defects include palliative treatment with arthroscopic debridement and lavage, reparative treatment with marrow-stimulation and restorative treatment, including osteochondroal grafting, total joint arthroplasty and autologous chondrocyte implantation (ACl). The first generation of $\mathrm{ACl}$ was introduced in 1987 and published in $1994 .^{38}$ The procedure involves harvesting autologous chondrocytes from non-weight bearing aspects of the knee. Chondrocytes are then isolated by collagenase digestion and expanded in vitro. During a second surgery, the cartilage defect is debrided up to the healthy edges and covered with an autologous periosteal patch, taken from the medial tibia. Finally, the suspension of healthy autologous cultured chondrocytes is directly injected into the chondral defect under the periosteal patch. Despite significant improvements and positive clinical reports, the adoption of periosteal based $\mathrm{ACl}(\mathrm{ACl}-\mathrm{P})$ has been limited partly owing to post-operative complications such as cell leaking and periosteal-related hypertrophy.

The second generation of $\mathrm{ACl}$ is known as collagen-covered $\mathrm{ACl}(\mathrm{ACl}-\mathrm{C})$ and is characterized by the application of a bioabsorbable collagen membrane in place of the periosteal flap. The chondrocytes are cultured with collagen membrane for several weeks; the membrane is then cut to the correct size and shape of the cartilage defect. Despite $\mathrm{ACl}-\mathrm{C}$ showing similar clinical improvements and fewer complications, cutting and repeated manipulation of the seeded membrane may result in the loss of critical chondrocytes. A modified $\mathrm{ACl}-\mathrm{C}$ technique has been developed in which expanded chondrocytes are applied to the collagen membrane after it has been cut to size, reducing the risk of viable cell loss while retaining the ease and speed of the technique. However, ACI-C still suffers from technical problems such as insufficient mechanical stability, uncertain cell distribution within the defect, and the necessity of an intact cartilage shoulder surrounding the defect.

The third generation of $\mathrm{ACl}$ is tissue-engineered matrices seeded with autologous chondrocytes; it is called matrix associated/induced $\mathrm{ACl}(\mathrm{MACl})$. Cultured autologous chondrocytes are directly seeded onto biodegradable collagen type I/III membrane or allowed to penetrate into a threedimensional (3D) scaffold or fleece prior to intra-articular implantation. The cell carrier based $\mathrm{MACl}$ technique procedure was recently reviewed by Brittberg. ${ }^{39}$ Several commercially available products have been developed and marketed in Europe, such as MACI ${ }^{2}$, Hyalograft $\circledast \mathrm{C}$, Novocart $₫ 3 D$, and BioSeed $\AA-C$ etc. ${ }^{40}$ The widely adopted $M A C I \circledast$ used in routine orthopaedic practice is the only third-generation cell carrier that is currently being evaluated in a randomized, controlled trial to meet European regulations for marketing approval and potentially those of other 
countries. $\mathrm{MACl}$ minimizes donor site morbidity by avoiding the harvest and implantation of a periosteal flap. The 3D cultures that $\mathrm{MACl}$ can provide also solve the problem of chondrocyte dedifferentiation during expansion and serve as a barrier to fibroblast invasion.

\subsubsection{Current Therapeutic Strategies for Nucleus Pulposus Regeneration}

Conservative treatments of acute and/or chronic LBP, such as bed rest, anti-inflammatory medications, and physical therapy, have been proved ineffectual. The most popular surgical options are still discectomy followed by fusion. Despite the many reports of good to excellent outcomes with this method, long-term adverse biomechanical consequences to adjacent functional spinal unit need to be concerned. ${ }^{41}$

Regenerative strategies over the past decades have advanced significantly, but a number of hurdles remain before a clinical treatment can be widely accepted. Autologous transplantation techniques are among the earliest tissue engineering strategies and recently have demonstrated promise for long-term articular cartilage repair in humans. ${ }^{42}$ Due to a number of similarities between cartilage and the NP tissue, the autologous paradigm has been extended to disc repair. After promising results in canine models, ${ }^{43}$ the Euro Disc randomized trial found that, two years after surgery, patients maintained increased pain reduction and decreased loss of tissue hydration. ${ }^{44}$ However, the results of this strategy may be limited due the reliance on a population of cells with a deteriorated capacity due to the degenerative process. Procurement of cells is also difficult, in part due to the high incidence of apoptosis, ${ }^{45}$ which reduces an already sparse cell population. This issue is further complicated by the extensive passaging procedure required to obtain sufficient numbers of cells for in vivo implantation. When passaged in monolayer, NP cells (NPCs) are known to proliferate slowly ${ }^{46}$ and undergo increasing dedifferentiation. ${ }^{47-49}$ Cells from degenerated NP also become increasingly senescent which makes them minimally responsive to growth factor or cytokine stimulation; the cells display increased catabolic metabolism characterized by the increased production of matrix degrading enzymes. ${ }^{50-53}$

\subsection{Current Efforts and Challenges of Cartilage Tissue Engineering}

\subsubsection{Cell Sources and Biomaterials for Cartilage Engineering}

Without doubt, autologous chondrocytes are the idea cell source for repairing cartilage. Unfortunately, the use of autologous chondrocytes is fraught with unsolved challenges, such as the loss of chondrocyte markers and dedifferentiation in culture during expansion, potential cell leakage, uneven cell distribution in 3D space, potential donor site morbidity (complications of donor site healing), shortage of chondrocytes due to limited cell number from biopsy, short lifespan of chondrocytes, lack of uniformity of in vitro expanded chondrocytes from laboratory to 
laboratory, and low cell quality from aged patients.

Two broad types of stem cells in mammals include embryonic stem cells (ESCs), which are isolated from the inner cell mass of blastocysts and adult stem cells, which are found in various tissues. ESCs possess the capability to self-renewal and to differentiate into all types of cells. However, its application in humans are restricted by ethical issues. Adult stem cells were first discovered in bone marrow and other accessible sources such as adipose, blood, skin, and urine. The most frequently investigated adult stem cells for cartilage tissue engineering is bone marrow, adipose, synovium-derived stem cells (SDSC). The tissue-specificity of SDSC as a stem cell for cartilage regeneration has been recently reviewed. ${ }^{54}$

Other candidate cell sources are also promising. Fetal stem cells located in the organs of fetuses, are not immortal but highly proliferative and multipotent. Recently, induced pluripotent stem cells (iPSCs) have been developed by reprogramming human somatic cells, providing a more abundant and ethical-feasible source of progenitor cells that also possess the capacity of generating all types of human cells. ${ }^{55}$ However, the low efficiency of reprogramming terminally differentiated cells into iPSCs has remained a major obstacle that prevents the wide application of this technology in practical use. (Table 1.1)

\begin{tabular}{|c|c|c|}
\hline Cell type & Advantages & Disadvantages \\
\hline $\begin{array}{l}\text { Autologous } \\
\text { chondrocyte }\end{array}$ & $\begin{array}{l}\text { Native phenotype } \\
\text { Minimal risk of immunological } \\
\text { problem }\end{array}$ & $\begin{array}{l}\text { Small initial cell number } \\
\text { De-differentiation on expansion }\end{array}$ \\
\hline $\begin{array}{l}\text { Allogeneic } \\
\text { chondrocyte }\end{array}$ & $\begin{array}{l}\text { Larger cell number } \\
\text { Off-the-shelf solution }\end{array}$ & $\begin{array}{l}\text { Limited donor availability } \\
\text { Risk of disease transmission }\end{array}$ \\
\hline $\begin{array}{l}\text { Fetal } \\
\text { mesenchymal } \\
\text { stem cell }\end{array}$ & $\begin{array}{l}\text { Strong potential to produce large } \\
\text { numbers } \\
\text { Off-the-shelf solution }\end{array}$ & $\begin{array}{l}\text { Limited donor availability } \\
\text { Risk of diease transmission } \\
\text { Potential ethical considerations }\end{array}$ \\
\hline $\begin{array}{l}\text { Adult } \\
\text { mesenchymal } \\
\text { stem cell }\end{array}$ & $\begin{array}{l}\text { Potential to produce large numbers } \\
\text { Various harvest sites } \\
\text { Additional paracrine signaling } \\
\text { potential }\end{array}$ & $\begin{array}{l}\text { Potential for hypertrophy } \\
\text { Heterogeneous population of } \\
\text { cells } \\
\text { Stable and reproducible } \\
\text { differentiation still problematic }\end{array}$ \\
\hline $\begin{array}{l}\text { Induced } \\
\text { pluripotent stem } \\
\text { cells }\end{array}$ & $\begin{array}{l}\text { Large source of patient specific cells } \\
\text { Multiple cell types can be produced }\end{array}$ & $\begin{array}{l}\text { Stable and reproducible } \\
\text { differentiation still problematic } \\
\text { Potential for teratoma }\end{array}$ \\
\hline Embryonic stem & Off-the-shelf solution & Stable and reproducible \\
\hline
\end{tabular}




\begin{tabular}{|l|l|l|}
\hline cells & Multiple cell types can be produced & $\begin{array}{l}\text { differentiation still problematic } \\
\text { Potential for teratoma }\end{array}$ \\
& Ethical considerations
\end{tabular}

Table 1.1 Advantages and disadvantages of various cell sources.

Scaffolds made of natural biomaterials, such as collagen and hyaluronic acid, can maintain the expression of aggrecan and type-Il collagen in chondrocytes. For instance, collagen has been intensively studied as a natural polymer with respect to cartilage tissue engineering. Chondrocytes cultured within collagen gels preserve their phenotype and glycosaminoglycan (GAG) production for as long as six weeks in culture ${ }^{56}$ Matrices and membranes derived from collagen also stimulate chondrocytes to produce new collagen. ${ }^{57}$ Hyaluronan, a highly concentrated component in the ECM of articular cartilage, is also a good candidate for biodegradable and biocompatible scaffold material. Chondrocytes cultured with chemical crosslinking hyaluronan scaffold express more chondrogenic markers, type-II collagen, aggrecan, and less type-I collagen. ${ }^{58}$ Other natural polymers derived from ECM used in cartilage engineering as 3D culture systems include fibrin glue, alginate, agarose, chitosan, chondroitin sulfate, gelatin, and silk fibroin. ${ }^{59}$

\subsubsection{Challenges of Cell Senescence in Cartilage Engineering}

Adult stem cell based therapies present great potentials for cartilage regeneration. However, cell senescence remains a big challenge for large scale ex vivo expansion and maintenance of MSC stemness. It is known that intrinsic and extrinsic factors are involved in the process of cell senescence. The intrinsic mechanism is called the Hayflick limit. ${ }^{60}$ Most somatic cell types reach cell-cycle arrest after a characteristic number of population doublings, which is also referred to as "cellular or replicative senescence". In humans, cell-cycle arrest is typically reached after 20 to 100 cell population doublings. It prevents cells from immortalization and suppresses oncogenesis. However, it also limits the goal of large-scale ex vivo cell expansion as required for cartilage regeneration and tissue engineering applications. Although it is possible to overcome the Hayflick limit by genetically modifying cells, for instance, transfecting human articular chondrocytes with the human telomerase gene ${ }^{61}$ such manipulations are regarded as potentially dangerous in the context of tissue engineering. On the other hand, extrinsic factor-associated senescence, also called stress-induced senescence, is considered more premature, as it can halt cell growth before the Hayflick limit is reached. Theoretically, through modifying the culture conditions and minimizing the stress in ex vivo culture, growth potentials can be regained. Recent concepts about cell senescence are similar to a stress-responsive, adaptive phenotype that develops through multiple stages during the development of degenerative diseases, which can spread from cell to cell and occur at any point in life. ${ }^{62}$ In other words, senescence could be an alternative cell 
fate that develops in response to injury or metabolic dysfunction and might occur in nondividing as well as dividing cells. ${ }^{63}$ Below is a brief review of the cell number limitations and loss of phenotype during ex vivo expansion, donor-site morbidity, and age-related decline in chondrogenic capacities; all these elements lead to cell senescence during cartilage tissue engineering. Critical obstacles for researchers and clinical therapists will also be presented (Figure 1.4).

\subsubsection{Ex vivo expansion}

Chondrocyte senescence developing during ex vivo expansion is commonly characterized by accumulation of reactive oxygen species (ROS) and advanced glycation end products, increased expression of senescence-associated $\beta$-galactosidase (SA- $\beta$-gal), nuclear and mitochondrial DNA damage, and decreased mitochondrial function. Average articular chondrocyte telomere erosion rate in vivo is about $30 \mathrm{bp}$ per year. ${ }^{64}$ During an $8-10$-fold cellular ex vivo expansion, telomere length is impaired as long as $900 \mathrm{bp}$ due to loss of the telomerase activity of chondrocytes. ${ }^{65}$

Similar to chondrocytes, MSC senescence results in cell proliferation arrest, characterized by flat shape, circumscribed nuclei, increased lysosome compartment, shortened telomere, and endogenous SA- $\beta$-gal activity. ${ }^{66 ; 67}$ All the characteristics just mentioned develop during MSC long-term ex vivo culture. ${ }^{67}$ Bone marrow-derived stem cells (BMSCs) isolated from fresh bone marrow aspirates underwent senescence with a change in morphology and shape after 38 population doublings and largely lost their ex vivo differentiation capacities at or around the sixth passage ${ }^{68 ; 69}$ but there is also evidence of adverse changes as early as the first or second passage. ${ }^{70 ; 71}$ Surprisingly, the osteogenic differentiation potential, including alkaline phosphatase $(A L P)$ expression and bone nodule formation ex vivo, appeared to be retained despite replicative senescence. $^{72}$ Banfi et al. observed loss of osteogenic differentiation along with proliferation capacities in BMSCs passaged at around 22 cell doublings. ${ }^{70}$ Consistent results were obtained from Muraglia et al., who investigated differentiation in a BMSC population derived from a single cell. ${ }^{73}$ What the cases just mentioned have in common is the initial loss of adipogenic differentiation capacity. Overall, ex vivo expansion leads to a progressive decrease of proliferative abilities and differentiation potentials. Similarly, Li et al. found that human placenta-derived MSCs underwent aging and spontaneous osteogenic differentiation during regular culture expansion, with down-regulation of human telomerase reverse transcriptase and up-regulation of the osteogenic gene runt-related transcription factor 2 (RUNX2) and ALP expression. Stem cell selfrenewal associated genes octamer-binding transcription factor 4 (OCT4) and SRY (sex determining region $\mathrm{Y}$ )-box 2 (SOX2) expression declined progressively. ${ }^{63}$

In addition, researchers have investigated the effect of seeding density during MSC ex vivo 
expansion. Despite sporadic evidence suggesting that plating density is not critical for maintaining a multipotent MSC population, time in culture does affect MSC characteristics in general; loss of adipogenic and chondrogenic differentiation abilities was observed in the higher density group. ${ }^{74}$ More studies have shown that high-density plating produced a higher percentage of flattened human BMSCs with characteristics of cellular senescence and the loss of ability to differentiate, while low-density plating resulted in a higher proliferation rate as well as more multi-potent cells. ${ }^{75-77}$ The evidence just provided suggests that seeding density could be an influential factor for developing senescence; low-density seeding could be useful when selecting the homogenous subpopulations of MSCs with higher proliferation and differentiation potentials. ${ }^{78 ; 79}$

\subsubsection{Donor age}

Another parameter that should be considered is aging, as decreased proliferation and the propensity toward senescence were observed in aged donors. Chondrocytes obtained from aged individuals (older than 40 years) have a much lower ability to repair cartilage damage than those obtained from younger patients. ${ }^{80}$ Pestka et al. recently revealed the difference in chondrocyte quality during ex vivo expansion in cells collected from $252 \mathrm{ACl}$ patients. ${ }^{21}$ Results suggested that no specific parameters other than age could be identified as influencing the quality of cells. ${ }^{21} \mathrm{~A}$ more dramatic change in chondrogenic potentials of human chondrocytes from juveniles $(<13$ years old) and adults (13 years and older) is also documented by Adkisson et al.. ${ }^{81}$

More attention has been paid to multi-potent cells in cartilage tissue engineering. Differences in MSCs from aged donors have been found in proliferation, cell attachment, and senescence in both animal and human cells. ${ }^{82-87}$ However, there have been conflicting reports about changes in MSC differentiation potentials attributed to donor age. Several previous studies have shown no difference attributable to donor age in human BMSC differentiation potential. ${ }^{88-91}$ In recent years, Kretlow et al. observed different chondrogenic capacities of murine BMSCs from animals of different ages. ${ }^{92}$ Zheng et al. demonstrated the impaired chondrogenic differentiation in aged rat BMSCs. ${ }^{93}$ Microarray analysis indicated significant age-related differences in the expression of genes that influence cartilage ECM formation. ${ }^{93}$ Age-related mechanical properties and collagen content changes were also noted in bovine BMSCs. ${ }^{94}$ Inconsistent results were obtained from human BMSCs as well. Scharstuhl et al. isolated BMSCs from the femoral shafts of 98 patients and investigated the relationship between chondrogenic differentiation capacities and age or OA. ${ }^{91}$ Surprisingly, no correlation from either factor was observed. However, Payne et al. found an age-related decline in chondrogenic differentiation in BMSCs even with transforming growth factor $\beta 1$ (TGF- $\beta 1$ ) stimulation, though only in men. ${ }^{95}$ Since 1999 , donor age has been identified as an important factor in periosteum-derived stem cell (PDSC) ex vivo chondrogenic differentiation. ${ }^{96}$ Later, De Bari et al. demonstrated that adult PDSCs could undergo 
chondrogenesis regardless of donor age..$^{97}$

\subsubsection{Trauma and degenerative diseases}

Trauma such as joint injuries is most commonly caused by mechanical factors, which promote human articular chondrocyte senescence by increasing oxidative stress, as characterized by cellcycle arrest, senescent morphology, and increased SA- $\beta$-gal activity, possibly through accelerating telomere shortening. ${ }^{98}$ Challenging human MSCs with oxidative stress results in similar characteristics, but manifests an increased tolerance regarding proliferation. ${ }^{99}$ Intracellular ROS were found to correlate with articular chondroctye senescence through activation of p38 kinase, which further promotes ROS generation, forming a positive feedback loop. Hong et al. found that ionizing radiation induced chondrocyte senescence by negative post-transcriptional regulation of SIRT via ROS-dependent p38 kinase activation. ${ }^{100}$ Sirtuin 1, a mammalian Sir2 ortholog and nicotine adenine dinucleotide-dependent deacetylase, has reportedly been involved in cell aging pathways. ${ }^{101}$

$\mathrm{OA}$ is characterized by degeneration of articular cartilage, limited intraarticular inflammation with synovitis, and changes in peri-articular and subchondral bone. Murphy et al. observed reduced chondrogenic differentiation capacities of BMSCs from patients with advanced OA. ${ }^{102}$ Han et al. observed decreased proliferative and chondrogenic potentials of SDSCs collected from OA patients during ex vivo expansion; microarray analysis suggested late-passage cells overexpressed cell-cycle prolongation and cell aging-associated genes, while repressing expression of cell growth-related genes. ${ }^{103}$ Additionally, aging changes in the joint tissue contribute to the development of $\mathrm{OA}$, as cellular senescence results in the development of a senescent secretory phenotype, and aging changes the matrix with increased formation of advanced glycation end products that affect the mechanical properties of joint tissues.

\subsection{Potential contribution of Decellularized Extracellular Matrix for Cartilage Regeneration}

The stem cell niche is a specific site in adult tissues where stem cells reside and undergo selfrenewal and differentiation. It is formed by the supporting cells and ECM that provide a microenvironment for stem cells and the cytokines and physical signals emanating from the supporting cells. ${ }^{104-106}$ In vivo, the cells are surrounded by an ECM that is responsible for the multidimensional and long-range ordering of highly organized tissues. The ECM is primarily composed of various collagens, laminins, and glycoproteins serving as substrates for a myriad of adhesion molecules including integrins, cadherins, and discoidin domain receptors. ${ }^{107}$ Cell-matrix interaction-induced signaling constitutes a critical determinant of cell behavior, making the ECM composition a key factor in the stem cell niche. It functions as a reservoir for growth factors and provides natural and intrinsic cues that direct the remodeling process during cell differentiation. ${ }^{108-}$ 
Due to the highly conserved nature of ECM components between species, decellularized matrix is applicable in tissue engineering through tissue-processing methods. Recently, decellularized tissue matrix derived from different tissues or organs such as heart, lung, brain, liver, bladder, and adipose have been engineered through simple biochemical methods that function as a natural scaffold to support proliferation and differentiation of the recellularized cells as summarized in a recent review. ${ }^{112}$ Demineralized bone matrix was able to induce ectopic bone formation due to the existence of the active osteoinductive ingredient BMP. ${ }^{113}$ Cartilage-derived matrix can also induce chondrogenesis of BMSCs and can support neocartilage formation from chondrocytes without exogenous growth factors. ${ }^{114 ; 115}$ Cartilage-derived matrix is advantageous in serving as a scaffold for cell-based cartilage repair. Chondrocytes can be used to deposit matrix, which can be decellularized later to from DECM.

Similarly, stem cells, especially tissue-specific stem cells can be applied to deposit the decellularized stem cell matrix (DSCM). DSCM deposited by porcine SDSCs provides a tissuespecific microenvironment favoring expanded cell chondrogenesis. ${ }^{116}$ A rejuvenated effect was also observed in porcine chondrocytes and NPC after expansion on SDSC derived DSCM. ${ }^{117 ; 18}$ Human BMSCs derived DSCM provides a tissue-specific microenvironment favoring expanded BMSC endochondral bone formation. ${ }^{119}$ The combination of a tissue-specific stem cell and DSCM would help provide large-quantity and high-quality cells to improve cartilage regeneration and benefit cartilage repair, which will greatly advance the development of the next generation $\mathrm{ACl}$ in the near future.

\subsection{Future Directions of Cartilage Engineering}

The need for cartilage defect repair is demanding as the aging population grows. The benefits of a cell based technique such as $\mathrm{ACl}$ that results in hyaline repair tissue with good integration at the defect is attractive and companies have been investing to support research. ${ }^{120}$ However, modest results from clinical trials show that limitations of $\mathrm{ACl}$, such as poor cell persistence, viability, post-translation, and cell relocation to non-target sites, still exist. ${ }^{121}$ Long-term evaluation and more in vivo studies are needed. Current development of $\mathrm{ACl}$ and the next generation of cartilage repair largely depend on progress in the cartilage tissue engineering field. One focus in the next generation of cell-based cartilage tissue engineering and repair is stem cells, especially

tissue-specific stem cells. ${ }^{122 ; 123}$ Finding tissue-specific stem cells for cartilage tissue engineering is not accomplished yet though SDSCs have been proposed as a good candidate. ${ }^{54}$ Biomaterials, which can be applied directly or used as stem cell delivery vehicles, should help elicit and 
enhance beneficial stem cell responses. Other than these, cell senescence also presents a big challenge in cartilage engineering due to the unmet demand of large quantity of high quality cells from donor of elder age, degenerative disease or extensive ex vivo expansion. Current efforts in applying growth factors, antioxidants, and modulating nutrients and oxygen factors have significantly improved proliferative abilities in both chondrocytes and MSCs. The promoted chondrogenic differentiation also alleviated progression to cell senescence to a lesser extent. However, efficiency and concerns about immune rejection as well as transformation of cells could be worrisome. Fortunately, the creation of the ex vivo microenvironment using DECM, especially DSCM, has given us hope. Through incubating cells in a more youthful and natural ex vivo niche, cell senescence could be slowed. Ideally, a tissue-specific DSCM could be reconstructed to rejuvenate and/or reprogram autologous chondrocytes and stem cells in proliferation and chondrogenic potential, which may be a future direction for the next generation of cartilage engineering. 


\section{REFERENCES}

1. Naumann A, Dennis JE, Awadallah A et al. Immunochemical and mechanical characterization of cartilage subtypes in rabbit. $J$ Histochem Cytochem. 2002;50:1049-58.

2. Aigner T, McKenna L. Molecular pathology and pathobiology of osteoarthritic cartilage. Cell Mol Life Sci. 2002;59:5-18.

3. Hunziker EB, Michel M, Studer D. Ultrastructure of adult human articular cartilage matrix after cryotechnical processing. Microsc Res Tech. 1997;37:271-84.

4. Newman AP. Articular cartilage repair. Am J Sports Med 1998;26:309-24.

5. Olsen BR, Reginato AM, Wang W. Bone development. Annu Rev Cell Dev Biol 2000;16:191220.

6. DeLise AM, Fischer L, Tuan RS. Cellular interactions and signaling in cartilage development. Osteoarthr Cartilage. 2000;8:309-34.

7. Redman SN, Oldfield SF, Archer CW. Current strategies for articular cartilage repair. Eur Cell Mater. 2005;9:23-32.

8. Heinegård D, Saxne T. The role of the cartilage matrix in osteoarthritis. Nat Rev Rheumatol 2011;7:50-6.

9. Goldring MB, Goldring SR. Osteoarthritis. J Cell Physiol 2007;213:626-34.

10. Pitsillides AA, Beier F. Cartilage biology in osteoarthritis--lessons from developmental biology. Nat Rev Rheumatol 2011;7:654-63.

11. van der Kraan PM, Buma P, van Kuppevelt $T$ et al. Interaction of chondrocytes, extracellular matrix and growth factors: relevance for articular cartilage tissue engineering. Osteoarthritis Cartilage 2002;10:631-7.

12. Urban JPG. The effect of physical factors on disc cell metabolism. In. Buckwalter JA, Goldberg VM, Woo SL-Y, eds. Musculoskeletal Soft Tissue Aging: Impact on Mobility. Rosemont, IL. American Academy of Orthopaedic Surgeons, 1993;391-412.

13. Iatridis JC, MacLean JJ, O'Brien M et al. Measurements of proteoglycan and water content distribution in human lumbar intervertebral discs. Spine (Phila Pa 1976) 2007;32:1493-97.

14. Shoukry M, Li J, Pei M. Reconstruction of an in vitro niche for the transition from intervertebral disc development to nucleus pulposus regeneration. Stem Cells Dev. 2013;22:1162-76.

15. Koelling S, Miosge N. Stem cell therapy for cartilage regeneration in osteoarthritis. Expert Opin Biol Ther 2009;9:1399-405.

16. Mobasheri A, Csaki C, Clutterbuck AL et al. Mesenchymal stem cells in connective tissue engineering and regenerative medicine: applications in cartilage repair and osteoarthritis therapy. Histol Histopathol 2009;24:347-66.

17. An HS, Anderson PA, Haughton VM et al. Introduction: disc degeneration: summary. Spine (Phila Pa 1976) 2004;29:2677-8. 
18. Pestka JM, Schmal H, Salzmann G et al. In vitro cell quality of articular chondrocytes assigned for autologous implantation in dependence of specific patient characteristics. Arch Orthop Trauma Surg 2011;131:779-89.

19. Buckwalter JA. Aging and degeneration of the human intervertebral disc. Spine 1995;20:1307-14.

20. Aigner T, Rose J, Martin J et al. Aging theories of primary osteoarthritis: from epidemiology to molecular biology. Rejuvenation Res 2004;7:134-45.

21. Madry H, Grün UW, Knutsen G. Cartilage repair and joint preservation: medical and surgical treatment options. Dtsch. Arztebl. Int. 2011;40:669-77.

22. Hjelle K, Solheim E, Strand T et al. Articular cartilage defects in 1,000 knee arthroscopies. Arthroscopy. 2002;18:730-4.

23. Hart LG, Deyo RA, Cherkin DC. Physician office visits for low back pain. Frequency, clinical evaluation, and treatment patterns from a U.S. national survey. Spine 1995;20:11-9.

24. The burden of musculoskeletal diseases in the United States chapter 2: Spine: low back and neck pain [homepage on the Internet]. Available at: http://www.boneandjointburden.org. Accessed January 18, 2013.

25. Katz JN. Lumbar disc disorders and low-back pain: socioeconomic factors and consequences. J Bone Joint Surg Am 2006;88:21-4.

26. Boos $\mathrm{N}$, Weissbach $\mathrm{S}$, Rohrbach $\mathrm{H}$ et al. Classification of agerelated changes in lumbar intervertebral discs: 2002 Volvo Award in basic science. Spine 2002;27:2631-44.

27. Miller JA, Schmatz C, Schultz AB. Lumbar disc degeneration: correlation with age, sex, and spine level in 600 autopsy specimens. Spine 1988;13:173-8.

28. Phelip X. Why the back of the child? Eur Spine $J$ 1999;8:426-8.

29. Roberts S, Evans $\mathrm{H}$, Trivedi $\mathrm{J}$ et al. Histology and pathology of the human intervertebral disc. J Bone Joint Surg Am 2006;88:10-4.

30. Berlemann U, Gries NC, Moore RJ. The relationship between height, shape and histological changes in early degeneration of the lower lumbar discs. Eur Spine J 1998;7:212-7.

31. Choi KS, Cohn MJ, Harfe BD. Identification of nucleus pulposus precursor cells and notochordal remnants in the mouse: implications for disc degeneration and chondroma formation. Dev Dyn 2008;237:3953-8.

32. Cappello R, Bird JL, Pfeiffer D et al. Notochordal cells produce and assemble extracel- lular matrix in a distinct manner, which may be responsible for the maintenance of healthy nucleus pulposus. Spine (Phila Pa 1976) 2006;31:873-82.

33. Erwin WM, Inman RD. Notochord cells regulate intervertebral disc chondrocyte proteoglycan production and cell proliferation. Spine (Phila Pa 1976) 2006;31:1094-9. 
34. Hunter CJ, Matyas JR, Duncan NA. The three-dimensional architecture of the notochordal nucleus pulposus: novel observations on cell structures in the canine intervertebral disc. $J$ Anat 2003;202:279-91.

35. Butler WF. Comparative anatomy and development of the mammalian disc. In: The Biology of the Intervertebral Disc. Gosh P, ed. CRC Press, Boca Raton, FL, 1989;84-108.

36. Kim KW, Lim TH, Kim JG et al. The origin of chondrocytes in the nucleus pulposus and histologic findings associated with the transition of a notochordal nucleus pulposus to a fibrocartilaginous nucleus pulposus in intact rabbit intervertebral discs. Spine (Phila Pa 1976) 2003;28:982-90.

37. Urban JP. Disc biochemistry in relation to function. In: The Lumbar Spine. Wiesel SW, JN Weinstein, HN Herkowitz, J Dvorak and GR Bell, eds. W.B. Saunders Company, Philadelphia, PA, 1996;271-81.

38. Brittberg M, Lindahl A, Nilsson A et al. Treatment of deep cartilage defects in the knee with autologous chondrocyte transplantation. N. Engl. J. Med. 1994;331:889-95.

39. Brittberg M. Cell Carriers as the Next Generation of Cell Therapy for Cartilage Repair: a review of the matrix-induced autologous chondrocyte implantation procedure. Am. J. Sports Med. 2010;6:1259-71.

40. Harris JD, Siston RA, Brophy RH et al. Failures, re-operations, and complications after autologous chondrocyte implantation--a systematic review. Osteoarthritis Cartilage. 2011;19:77991.

41. Lewis G. Nucleus pulposus replacement and regeneration/repair technologies: present status and future prospects. J Biomed Mater Res B Appl Biomater 2012;100:1702-20.

42. Moseley JB Jr, Anderson AF, Browne JE et al. Long-term durability of autologous chondrocyte implantation: a multi- center, observational study in US patients. Am J Sports Med 2010;38:238-46.

43. Ganey T, Libera J, Moos $\vee$ et al. Disc chondrocyte trans- plantation in a canine model: a treatment for degenerated or damaged intervertebral disc. Spine (Phila Pa 1976) 2003;28:260920.

44. Meisel HJ, Siodla V, Ganey T et al. Clinical experience in cell-based therapeutics: disc chondrocyte transplantation: a treatment for degenerated or damaged intervertebral disc. Biomol Eng 2007;24:5-21.

45. Gruber HE, Hanley EN Jr. Analysis of aging and degeneration of the human intervertebral disc: comparison of surgical speciments with normal controls. Spine (Phila Pa 1976) 1998;23:751-7.

46. Wang $F$, Wu XT, Zhuang SY et al. Ex vivo observation of human nucleus pulposus chondrocytes isolated from degenerated intervertebral discs. Asian Spine J 2011;5:73-81. 
47. Hegewald AA, Endres M, Abbushi A et al. Adequacy of herniated disc tissue as a cell source for nucleus pulposus regeneration. J Neurosurg Spine 2011;14:273-80.

48. Hu MH, Hung LW, Yang SH et al. Lovostatin promotes redifferentiation of human nucleus pulposus cells during expansion in monolayer culture. Artif Organs 2011;35:411-6.

49. Wang JY, Baer AE, Kraus VB et al. Intervertebral cells exhibit differences in gene expression in alginate and monolayer culture. Spine (Phila Pa 1976) 2001;26:1747-51.

50. Cristofalo VJ, Lorenzini A, Allen RG et al. Replicative senescence: a critical review. Mech Ageing Dev 2004;125:827-48.

51. Kim KW, Chung HN, Ha KY et al. Senescence mechanisms of nucleus pulposus chondrocytes in human intervertebral discs. Spine $J$ 2009;9:658-66.

52. Li JT, Pei M. Cell senescence: a challenge in cartilage engineering and regeneration. Tissue Eng Part B 2012;18:270-87.

53. Roberts S, Evans EH, Kletsas D et al. Senescence in human intervertebral discs. Eur Spine J 2006;15:S312-6.

54. Jones B, Pei M. Synovium-derived stem cells: a tissue-specific stem cell for cartilage tissue engineering and regeneration. Tissue Eng Part B Rev. 2012;18:301-11.

55. Takahashi K, Yamanaka S. Induction of pluripotent stem cells from mouse embryonic and adult fibroblast cultures by defined factors. Cell. 2006;126:663-76.

56. Kimura T, Yasui $N$, Ohsawa $S$ et al. Chondrocytes embedded in collagen gels maintain cartilage phenotype during long-term cultures. Clin. Orthop. Relat. Res. 1984;186:231-9.

57. Zheng $\mathrm{MH}$, Willers $\mathrm{C}$, Kirilak $\mathrm{L}$ et al. Matrix-induced autologous chondrocyte implantation (MACl): Biological and histological assessment. Tissue Eng. 2007;13:737-46.

58. Grigolo B, Lisignoli G, Piacentini A et al. Evidence for redifferentiation of human chondrocytes grown on a hyaluronan-based biomaterial (HYAff 11): Molecular, immunohistochemical and ultrastructural analysis. Biomaterials. 2002;23:1187-95.

59. Danisovic L, Varga I, Zamborsky R et al. The tissue engineering of articular cartilage: cells, scaffolds and stimulating factors. Exp. Biol. Med. (Maywood). 2012;237:10-7.

60. Hayflick, L. The limited in vitro Lifetime of human diploid cell strains. Exp Cell Res. 1965;37: 614-36.

61. Martin JA, Buckwalter JA. The role of chondrocyte senescence in the pathogenesis of osteoarthritis and in limiting cartilage repair. J Bone Joint Surg Am. 2003;85-A Suppl 2:106-10.

62. Tchkonia T, Morbeck DE, Von Zglinicki T et al. Fat tissue, aging, and cellular senescence. Aging Cell 2010;9:667-84.

63. Li Z, Liu C, Xie Z et al. Epigenetic dysregulation in mesenchymal stem cell aging and spontaneous differentiation. PLoS One 2011;6:e20526.

64. Martin JA, Buckwalter JA. Telomere erosion and senescence in human articular cartilage chondrocytes. J Gerontol A Biol Sci Med Sci 2001;56:B172-9. 
65. Parsch D, Brummendorf TH, Richter $\mathrm{W}$ et al. Replicative aging of human articular chondrocytes during ex vivo expansion. Arthritis Rheum 2002;46:2911-6.

66. Parsch D, Fellenberg J, Brummendorf TH et al. Telomere length and telomerase activity during expansion and differentiation of human mesenchymal stem cells and chondrocytes. $J \mathrm{Mol}$ Med (Berl) 2004;82:49-55.

67. Wagner W, Horn P, Castoldi M et al. Replicative senescence of mesenchymal stem cells: a continuous and organized process. PLoS One 2008;3:e2213.

68. Bonab MM, Alimoghaddam K, Talebian $\mathrm{F}$ et al. Aging of mesenchymal stem cell in vitro. BMC Cell Biol 2006;7:14.

69. Vacanti V, Kong E, Suzuki G et al. Phenotypic changes of adult porcine mesenchymal stem cells induced by prolonged passaging in culture. J Cell Physiol 2005;205:194-201.

70. Banfi A, Muraglia A, Dozin B et al. Proliferation kinetics and differentiation potential of ex vivo expanded human bone marrow stromal cells: implications for their use in cell therapy. Exp Hematol 2000;28:707-15.

71. Chen J, Sotome S, Wang J et al. Correlation of in vivo bone formation capability and in vitro differentiation of human bone marrow stromal cells. J Med Dent Sci 2005;52:27-34.

72. Bruder SP, Jaiswal N, Haynesworth SE. Growth kinetics, self-renewal, and the osteogenic potential of purified human mesenchymal stem cells during extensive subcultivation and following cryopreservation. J Cell Biochem 1997;64:278-94.

73. Muraglia A, Cancedda R, Quarto R. Clonal mesenchymal progenitors from human bone marrow differentiate in vitro according to a hierarchical model. J Cell Sci 2000;113:1161-6.

74. Neuhuber B, Swanger SA, Howard $L$ et al. Effects of plating density and culture time on bone marrow stromal cell characteristics. Exp Hematol 2008;36:1176-85.

75. Digirolamo CM, Stokes D, Colter D et al. Propagation and senescence of human marrow stromal cells in culture: a simple colony-forming assay identifies samples with the greatest potential to propagate and differentiate. Br J Haematol 1999;107:275-81.

76. Colter DC, Class R, DiGirolamo CM et al. Rapid expansion of recycling stem cells in cultures of plastic-adherent cells from human bone marrow. Proc Natl Acad Sci USA 2000;97:3213-8.

77. Sekiya I, Larson BL, Smith JR et al. Expansion of human adult stem cells from bone marrow stroma: conditions that maximize the yields of early progenitors and evaluate their quality. Stem Cells 2002;20:530-41.

78. Jiang $\mathrm{Y}$, Jahagirdar BN, Reinhardt RL et al. Pluripotency of mesenchymal stem cells derived from adult marrow. Nature 2002;418:41-9.

79. Reyes M, Verfaillie CM. Characterization of multi-potent adult progenitor cells, a subpopulation of mesen- chymal stem cells. Ann N Y Acad Sci 2001;938:231-3. 
80. Barbero A, Grogan S, Schafer D et al. Age related changes in human articular chondrocyte yield, proliferation and post-expansion chondrogenic capacity. Osteoarthritis Cartilage 2004;12:476-84.

81. Adkisson HD 4th, Martin JA, Amendola RL et al. The potential of human allogeneic juvenile chondrocytes for restoration of articular cartilage. Am J Sports Med 2010;38:1324-33.

82. Bergman RJ, Gazit D, Kahn AJ et al. Age-related changes in osteogenic stem cells in mice. $J$ Bone Miner Res 1996;11:568-77.

83. Bellows CG, Pei W, Jia $Y$ et al. Proliferation, differentiation and self-renewal of osteoprogenitors in vertebral cell populations from aged and young female rats. Mech Ageing Dev 2003;124:747-57.

84. Tokalov SV, Gruener S, Schindler S et al. A number of bone marrow mesenchymal stem cells but neither phenotype nor differentiation capacities changes with age of rats. Mol Cells 2007;24:255-60.

85. Tokalov SV, Gruner S, Schindler $S$ et al. Age-related changes in the frequency of mesenchymal stem cells in the bone marrow of rats. Stem Cells Dev 2007;16:439-46.

86. Stenderup K, Justesen J, Clausen $\mathrm{C}$ et al. Aging is associated with decreased maximal life span and accelerated senescence of bone marrow stromal cells. Bone 2003;33:919-26.

87. Mareschi K, Ferrero I, Rustichelli D et al. Expansion of mesenchymal stem cells isolated from pediatric and adult donor bone marrow. J Cell Biochem 2006;97:744-54.

88. Justesen J, Stenderup K, Eriksen EF et al. Maintenance of osteoblastic and adipocytic differentiation potential with age and osteoporosis in human marrow stromal cell cultures. Calcif Tissue Int 2002;71:36-44.

89. Leskela HV, Risteli J, Niskanen S et al. Osteoblast recruitment from stem cells does not decrease by age at late adulthood. Biochem Biophys Res Commun 2003;311:1008-13.

90. Stenderup K, Justesen J, Eriksen EF et al. Number and proliferative capacity of osteogenic stem cells are maintained during aging and in patients with osteoporosis. J Bone Miner Res 2001;16:1120-9.

91. Scharstuhl A, Schewe B, Benz K et al. Chondrogenic potential of human adult mesenchymal stem cells is independent of age or osteoarthritis etiology. Stem Cells 2007;25:3244-51.

92. Kretlow JD, Jin YQ, Liu W et al. Donor age and cell passage affects differentiation potential of murine bone marrow-derived stem cells. BMC Cell Biol 2008;9:60.

93. Zheng $\mathrm{H}$, Martin JA, Duwayri $\mathrm{Y}$ et al. Impact of aging on rat bone marrow-derived stem cell chondrogenesis. J Gerontol A Biol Sci Med Sci 2007;62:136-48.

94. Erickson IE, van Veen SC, Sengupta $S$ et al. Cartilage matrix formation by bovine mesenchymal stem cells in three-dimensional culture is age-dependent. Clin Orthop Relat Res 2011;469:2744-53. 
95. Payne KA, Didiano DM, Chu CR. Donor sex and age influence the chondrogenic potential of human femoral bone marrow stem cells. Osteoarthritis Cartilage 2010;18:705-13.

96. O'Driscoll SW. Articular cartilage regeneration using periosteum. Clin Orthop Relat Res 1999;(367 Suppl):S186-203.

97. De Bari C, Dell'Accio F, Luyten FP. Human periosteum-derived cells maintain phenotypic stability and chondrogenic potential throughout expansion regardless of donor age. Arthritis Rheum 2001;44:85-95.

98. Martin JA, Brown TD, Heiner $A D$ et al. Chondrocyte senescence, joint loading and osteoarthritis. Clin Orthop Relat Res 2004;(427 Suppl):S96-103.

99. Brandl $A$, Meyer $M$, Bechmann $V$ et al. Oxidative stress induces senescence in human mesenchymal stem cells. Exp Cell Res 2011;317:1541-7.

100. Hong EH, Lee SJ, Kim JS et al. Ionizing radiation induces cellular senescence of articular chondrocytes via negative regulation of SIRT1 by p38 kinase. J Biol Chem 2010;285:1283-95.

101. Hekimi S, Guarente L. Genetics and the specificity of the aging process. Science 2003;299:1351-4.

102. Murphy JM, Dixon K, Beck $S$ et al. Reduced chondrogenic and adipogenic activity of mesenchymal stem cells from patients with advanced osteoarthritis. Arthritis Rheum 2002;46: 704-13.

103. Han HS, Lee S, Kim JH et al. Changes in chondrogenic phenotype and gene expression profiles associated with the in vitro expansion of human synovium-derived cells. $J$ Orthop Res 2010;28:1283-91.

104. Li L, Xie T. Stem cell niche: Structure and function. Annu Rev Cell Dev Biol 2005;21:605-31. 105. Lin H. The stem-cell niche theory: Lessons from flies. Nat Rev Genet 2002;3:931-40.

106. Spradling A, Drummond-Barbosa D, Kai T. Stem cells fi nd their niche. Nature 2001;414:98104.

107. Griffith LG, Swartz MA. Capturing complex 3D tissue physiology in vitro. Nature Reviews 2006;7:211-24.

108. Badylak SF, Kochupura PV, Cohen IS et al. The use of extracellular matrix as an inductive scaffold for the partial replacement of functional myocardium. Cell Transplant 2006;15 suppl 1:s29-40.

109. Badylak SF, Vorp DA, Spievack AR et al. Esophageal reconstruction with ECM and muscle tissue in a dog model. J Surg Res 2005;128:87-97.

110. Bhrany AD, Beckstead BL, Lang TC et al. Development of an esophagus acellular matrix tissue scaffold. Tissue Eng 2006;12:319-30.

111. Brown $B$, Lindberg $\mathrm{K}$, Reing $\mathrm{J}$ et al. The basement membrane component of biologic scaffolds derived from extracellular matrix. Tissue Eng 2006;12:519-26. 
112. Hoshiba $\mathrm{T}$, Lu H, Kawazoe $\mathrm{N}$ et al. Decellularized matrices for tissue engineering. Expert Opin. Biol. Ther. 2010;10:1717-28.

113. Urist MR. The classic: a morphogenetic matrix for differentiation of bone tissue. Clin Orthop Relat Res 2009;467:3068-70.

114. Diekman BO, Rowland CR, Lennon DP et al. Chondrogenesis of adult stem cells from adipose tissue and bone marrow: induction by growth factors and cartilage-derived matrix. Tissue Eng Part A 2010;16:523-33.

115. Yang Q, Peng J, Guo Q et al. A cartilage ECM-derived 3-D porous acellular matrix scaffold for in vivo cartilage tissue engineering with $\mathrm{PKH} 26$-labeled chondrogenic bone marrow-derived mesenchymal stem cells. Biomaterials 2008;29:2378-87.

116. He F, Chen X, Pei M. Reconstruction of an in vitro tissue-specific microenvironment to rejuvenate synovium-derived stem cells for cartilage tissue engineering. Tissue Eng Part $A$ 2009;15:3809-21.

117. He F, Pei M. Rejuvenation of nucleus pulposus cells using extracellular matrix deposited by synovium-derived stem cells. Spine 2012;37:459-69.

118. Pei M, He F. Extracellular matrix deposited by synovium-derived stem cells delays chondrocyte dedifferentiation and enhances redifferentiation. J Cell Physiol 2012;227:2163-74.

119. Pei M, He F, Kish VL. Expansion on extracellular matrix deposited by human bone marrow stromal cells facilitates stem cell proliferation and tissue-specific lineage potential. Tissue Eng Part A. 2011;17:3067-76.

120. Jaklenec A, Stamp A, Deweerd E et al. Progress in the tissue engineering and stem cell industry "are we there yet?". Tissue Eng Part B Rev 2012;18:155-66.

121. Vasiliadis HS, Wasiak J, Salanti G. Autologous chondrocyte implantation for the treatment of cartilage lesions of the knee: a systematic review of randomized studies. Knee Surg Sports Traumatol Arthrosc 2010;18:1645-55.

122. Danisovic L, Varga I, Zamborsky R et al. The tissue engineering of articular cartilage: cells, scaffolds and stimulating factors. Exp Biol Med (Maywood) 2012;237:10-7.

123. Dhinsa BS, Adesida AB. Current clinical therapies for cartilage repair, their limitation and the role of stem cells. Curr Stem Cell Res Ther 2012;7:143-8. 
Figure 1.1

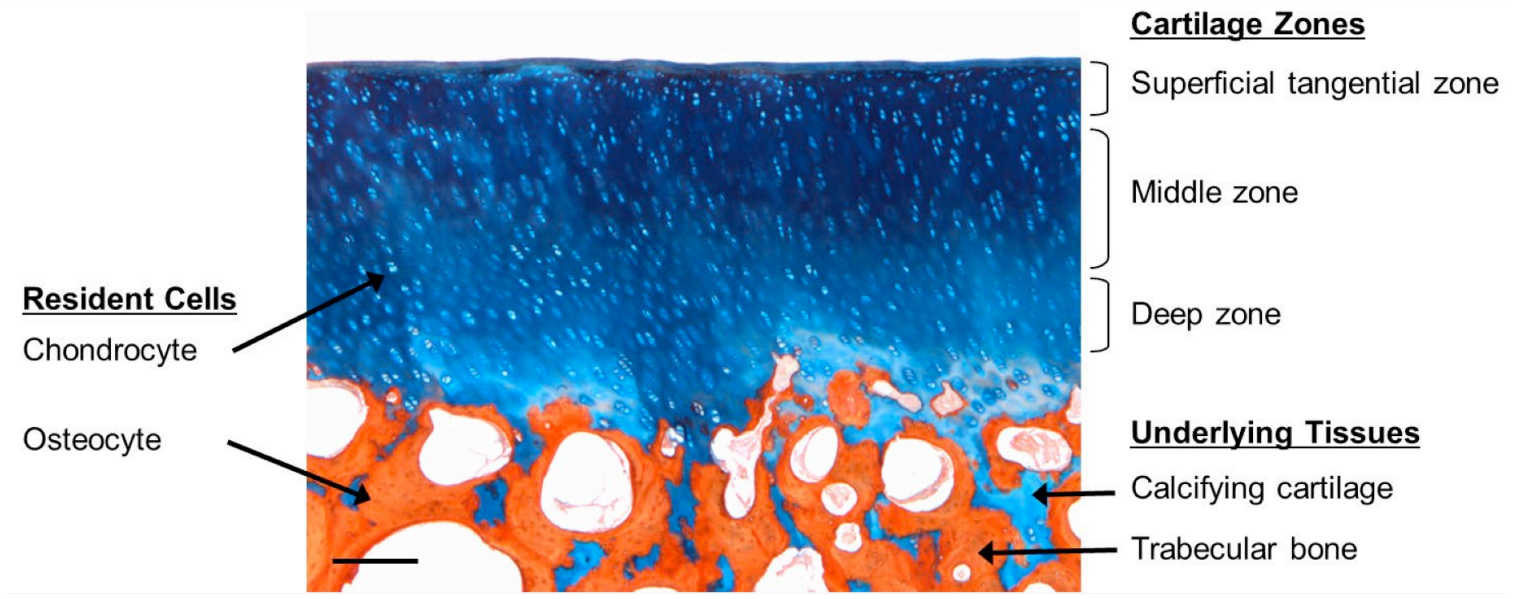

Figure 1.1 Section of cartilage detailing the various zones from the upper superficial zone down to the underlying bone. Differences in cell phenotype can be detected between the superficial, middle and deep zones. These differences can still be observed during in vitro culture, demonstrating functional differences between the cells of each zone. Figures are from Johnstone $B$, Alini M, Cucchiarini $M$ et al. Tissue engineering for articular cartilage repair--the state of the art. Eur Cell Mater 2013;25:248-67. 
Figure 1.2
B. Differentiation
D. Hypertrophy

A. Condensation \& Proliferation

C.ECM synthesis

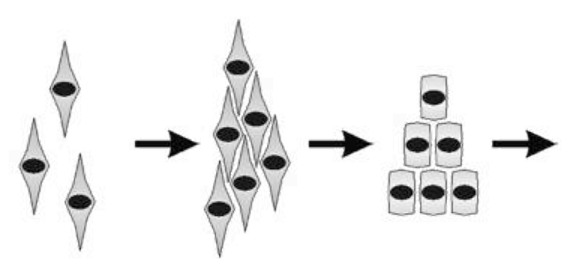

Mesenchymal cells
Chondrocytes

Chondroblasts

Hypertrophic chondrocytes

E. Endochondral ossification

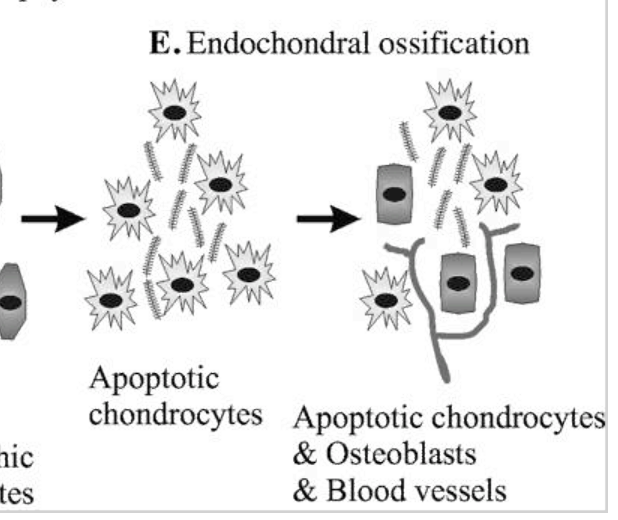

Figure 1.2 Schematic representation of the chondrogenesis and endochondral ossification. A. First mesenchymal cells condense to form a dense cell mass. B. Mesenchymal cells proliferate and differentiate into chondroblasts. C. These cells start secreting cartilage ECM and become mature chondrocytes. D. Eventually, chondrocytes grow to become hypertrophic, and if the tissue undergoes endochondral ossification. E. Cartilage is vascularized, ECM is degraded, hypertrophic chondrocytes become apoptotic, and osteoblasts invade the free space within the tissue. Figures are from Quintana L, zur Nieden NI, Semino CE. Morphogenetic and regulatory mechanisms during developmental chondrogenesis: new paradigms for cartilage tissue engineering. Tissue Eng Part B Rev. 2009;1:29-41. 
Figure 1.3

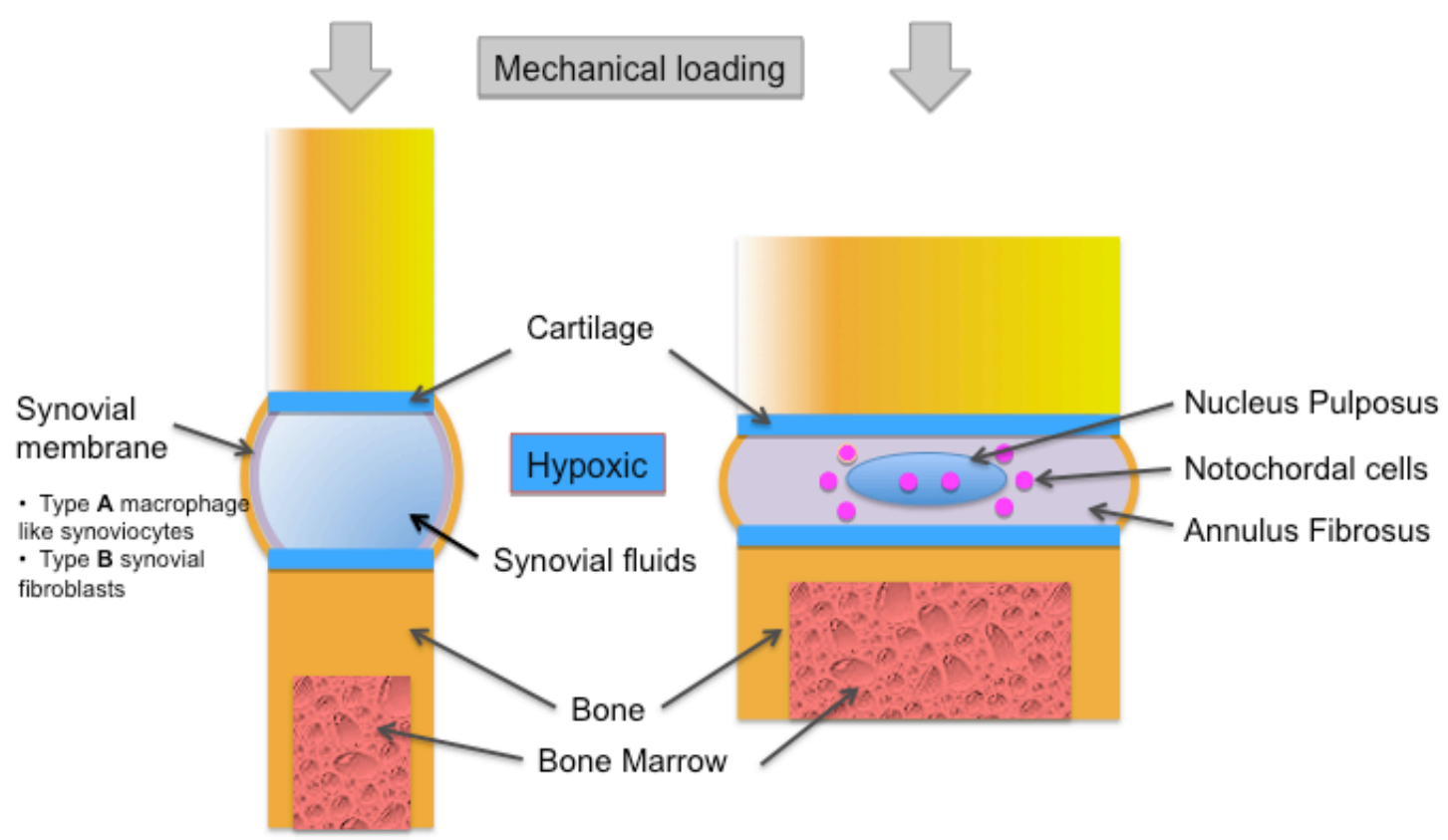

Figure 1.3 Resemblance between synovial joint and intervertebral disc. Figures are from Shoukry M, Li J, Pei M. Reconstruction of an in vitro niche for the transition from intervertebral disc development to nucleus pulposus regeneration. Stem Cells Dev. 2013;8:1162-76. 
Figure 1.4

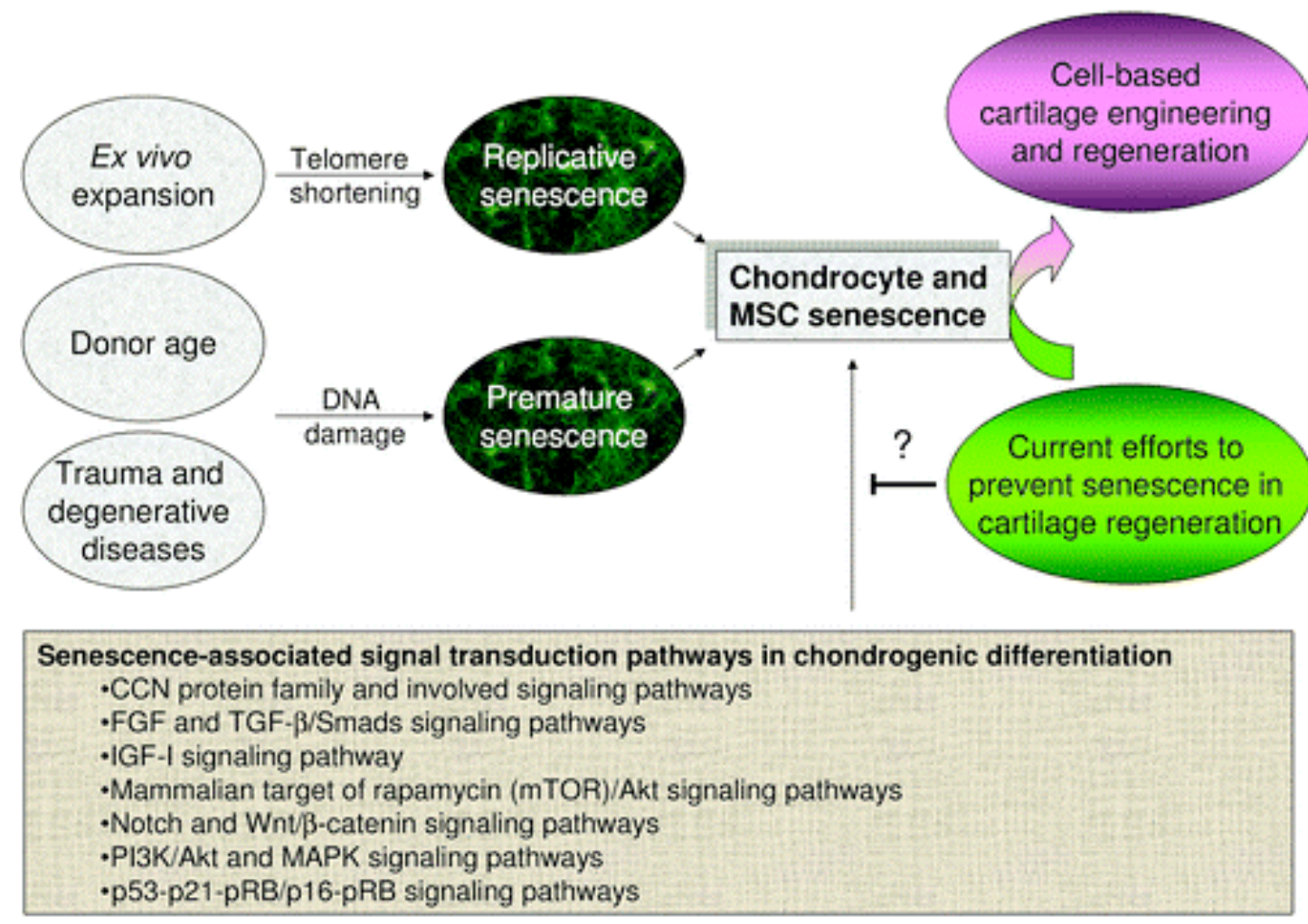

Figure 1.4 Senescence-associated signal transduction pathways in chondrogenic differentiation.

Figures are from $\mathrm{Li} \mathrm{J}, \mathrm{Pei} \mathrm{M}$. Cell senescence: a challenge in cartilage engineering and regeneration. Tissue Eng Part B. 2012;4:270-87. 

\begin{tabular}{lccccc} 
CHAPTER & 2:L OW-DENSITY & EXPANSION & PROTECTS \\
\hline HUMAN & SYNOVIUM-DERIVED & STEM & CELLS & FROM \\
\hline
\end{tabular} REPLICATIVE SENESCENCE: A PRELIMINEARY STUDY

As published in Drug Deliv. And Transl. Res. 2012; 2:363-374.

Jingting Li, M.S., Brendan Jones, B.S., Ying Zhang, M.S., Tatiana Vinardell, Ph.D., and Ming Pei, M.D., Ph.D.

Tissue Engineering Laboratory, Department of Orthopaedics, and Division of Exercise Physiology, West Virginia University, Morgantown, WV 26506

Key words: Seeding density, proliferation, multi-differentiation, synovium derived stem cells, cell senescence 


\begin{abstract}
Our hypothesis in this study is that low seeding density expansion could retain human synoviumderived stem cell (hSDSC) "stemness", defined as higher proliferation and multi-differentiation capacity; retention of "stemness" probably occurs through the mitogen-activated protein kinase (MAPK) signaling pathway. hSDSCs were expanded in conventional plastic flasks for two consecutive passages at either low or high density (30 or 3,000 cells $/ \mathrm{cm}^{2}$ ). Expanded cells were assessed for the effect of seeding density on their morphology, proliferation, apoptosis, stem cell surface markers, and multi-lineage differentiation capacity (chondrogenic, adipogenic, and osteogenic differentiation) using flow cytometry, biochemical analysis, histology, immunostaining, and real-time polymerase chain reaction. The MAPK signaling pathway (Erk1/2, p38, and JNK) and senescence-associated markers (p21 and caveolin) were also evaluated for their role in cell density-based monolayer expansion using western blot. Our data suggested that low seeding density expansion yielded hSDSCs with enhanced proliferation and multi-differentiation capacity compared to those grown at high seeding density, despite the fact that the cells expanded at both high and low density had lower osteogenic capacity. Low seeding density also down-regulated Erk1/2 and JNK expression and up-regulated p38 expression, which might be responsible for the retained "stemness" in the cells expanded at low density. Low seeding density expansion could retain hSDSC proliferation and multi-differentiation capacity and protect cells from replicative senescence.
\end{abstract}




\section{INTRODUCTION}

Autologous chondrocyte implantation is a biological solution for the treatment of focal cartilage defects [1]. Due to the limited sources of chondrocytes available from patients themselves and lack of an effective ex vivo expansion system, researchers turned to mesenchymal stem cells (MSCs), which reside in adult tissues and possess multi- lineage differentiation potentials. MSCs have been isolated from various human tissues, such as bone marrow, adipose, periosteum, and synovium [2,3]. Further application in clinical treatment is based on efficient ex vivo expansion to produce large-scale and high-quality human MSCs.

Since MSCs have proliferation potential, optimization of cell seeding density during monolayer expansion represents a simple and effective method to yield a sufficient number of cells for clinical use. This approach has been investigated in bone marrow stromal cells (BMSCs) and adipose stem cells (ASCs). Recent data indicate that altering the monolayer expansion conditions affects ASCs in their self-renewal rate, multipotency, and lineage-specific differentiation potential. Estes et al. found that monolayer culture conditions (such as growth factor supplementation, cell seeding density, etc.) may "prime" cells or predispose them toward a specific phenotype and thus underscore the importance of early culture conditions in determining the growth and differentiation potential of ASCs [4]. Time in culture affects BMSC stem cell characteristics [5]. More interestingly, seeding BMSCs at low densities allows for the detection of a distinct population of rapidly self-renewing cells that have a higher capacity for multi-lineage differentiation $[6,7]$.

Recently, synovium-derived stem cells (SDSCs), tissue-specific stem cells for chondrogenic differentiation [8, 9], have attracted much attention in cartilage engineering and regeneration [1014]. Since there is no study on whether seeding density during ex vivo cell expansion favors SDSC proliferation and differentiation capacity, this study seeks to determine the effects of cell seeding density on human SDSC (hSDSC) ex vivo expansion and subsequent multi- lineage differentiation potentials. Considering the roles of the three major mitogen-activated protein kinase (MAPK) signaling pathways [the extracellular signal-regulated kinase 1/2 (Erk1/2), p38, and c-jun N-terminal kinase (JNK) pathways] in controlling embryogenesis, cell differentiation, cell proliferation, and cell death [15], we wondered whether the MAPK signaling pathway and replicative senescence were involved in the potential mechanisms underlying seeding densitybased cell expansion. In this study, we hypothesized that low seeding density expansion could retain hSDSC "stemness", defined as higher proliferation and multi-differentiation capacity; retention of stemness likely occurs through the MAPK signaling pathway. 


\section{MATERIALS AND METHODS}

\section{Expansion of hSDSCs at low and high density}

Adult human synovium fibroblasts, referred to as hSDSCs [16], were pooled from two donors (one Hispanic female, 43 years old; one Caucasian male, 60 years old; both had no known joint disease). These cells were obtained at passage 1 from Asterand (North America Laboratories, Detroit, MI, USA). Passage 2 hSDSCs were expanded for two consecutive passages at either low density $\left(30\right.$ cells $\left./ \mathrm{cm}^{2}\right)$ or high density $\left(3,000 \mathrm{cells} / \mathrm{cm}^{2}\right)$ in conventional plastic flasks in complete medium [ a -minimum essential medium (Invitrogen, Carlsbad, CA, USA) containing $10 \%$ fetal bovine serum (FBS, Atlanta Biologicals, Lawrenceville, GA, USA), $100 \mathrm{U} / \mathrm{mL}$ penicillin, $100 \mathrm{~g} / \mathrm{mL}$ streptomycin, and $0.25 \mathrm{~g} / \mathrm{mL}$ Fungizone (Invitrogen)] at $37^{\circ} \mathrm{C}$ in a humidified $5 \% \mathrm{CO}_{2}$ and $21 \%$ $\mathrm{O}_{2}$ incubator. Culture medium was changed every 3 days. Cell number was counted using a hemocytometer and cell morphology was photographed by phase contrast microscope.

\section{Cell surface area measurement}

At day 4 during cell expansion, images were taken from 10 fields in culture flasks from both lowand high-density groups. Cell surface areas were measured quantitatively using Image $\mathrm{J}$ software (NIH Image, National Institutes of Health, Bethesda, MD, USA). Fifty cells were randomly selected from either low- or high-density groups. Values were presented as vertical scatter plot.

\section{Cell proliferation and apoptosis assay}

Cell number fold change was calculated by expanded cell number \{cell number per flask [total cell number/ number of flasks $(n)]$ in high-density group $(n=6)$ and low-density group $(n=26)\}$ divided by seeded cell number (seeding density $\times$ surface area). Human SDSCs were pre-labeled with CellVue $^{\circledR}$ Claret (Sigma, St. Louis, MO, USA) at $2 \times 10^{-6} \mathrm{M}$ for $5 \mathrm{~min}$ according to the manufacturer's protocol. After a 9-day expansion, cells from both low- and high-density groups were collected and analyzed using BD dual laser FACS Calibur (BD Biosciences, San Jose, CA, USA). For each sample, 20,000 events were collected using CellQuest Pro software (BD Biosciences) and cell proliferation index was analyzed by ModFit LT ${ }^{\mathrm{TM}}$ version 3.1 (Verity Software House, Topsham, ME, USA).

After cell expansion, Annexin V-FITC Apoptosis Detection Kit (Biovision, Mountain View, CA, USA) was used to detect apoptosis. Briefly, $2 \times 10^{5}$ cells from both low- and high-density groups ( $n=3$ each) were labeled with FITC annexin $\mathrm{V}$ and propidium iodide for $15 \mathrm{~min}$ at room temperature. For each sample, 10,000 events were collected; samples were analyzed using FACS Calibur (BD Biosciences). FCS Express 3 software package (De Novo Software, Los Angeles, CA, USA) was used to generate histograms. 
Surface marker analysis using flow cytometry

After cell expansion, $2 \times 10^{5}$ hSDSCs from each group were incubated on ice for 30 min in PBS containing $0.1 \%$ ChromPure Human Immunoglobulin (IgG) whole molecule (Jackson Immuno Research, West Grove, PA, USA) and $1 \% \mathrm{NaN}_{3}$ (Sigma), and then incubated on ice for $30 \mathrm{~min}$ with mouse anti-human monoclonal FITC-conjugated antibodies to the stage-specific embryonic antigen-4 (SSEA-4) (Biolegend, San Diego, CA, USA) and isotype-matched IgG3 (Beckman Coulter, Fullerton, CA, USA). After washing with cold PBS, hSDSCs were fixed in $300 \mu \mathrm{L}$ of 0.4 $\%$ paraformaldehyde. Cells were analyzed on a BD dual laser FACS Calibur (BD Biosciences) using the FCS Express 3 software package (De Novo Software).

\section{Chondrogenic induction of expanded hSDSCs}

After cell expansion, $3 \times 10^{5}$ of passage 4 hSDSCs from each group were centrifuged at $500 \times \mathrm{g}$ for $5 \mathrm{~min}$ in a 15- $\mathrm{mL}$ polypropylene tube to form a pellet. After overnight incubation, the pellets were transferred to a serum-free chondrogenic medium consisting of high-glucose Dulbecco's Modified Eagle's Medium, $40 \mathrm{\mu} \mathrm{g} / \mathrm{mL}$ proline, $10^{-7} \mathrm{M}$ dexamethasone, $100 \mathrm{U} / \mathrm{mL}$ penicillin, $100 \mu$ $\mathrm{g} / \mathrm{mL}$ streptomycin, $0.1 \mathrm{mM}$ ascorbic acid-2-phosphate, and $1 \times \mathrm{ITS}^{\mathrm{TM}}$ Premix $(6.25 \mu \mathrm{g} / \mathrm{mL}$ insulin, $6.25 \mu \mathrm{g} / \mathrm{mL}$ transferrin, $6.25 \mu \mathrm{g} / \mathrm{mL}$ selenous acid, $5.35 \mu \mathrm{g} / \mathrm{mL}$ linoleic acid, and $1.25 \mu \mathrm{g} / \mathrm{mL}$ bovine serum albumin, from BD Biosciences) with the supplementation of $10 \mathrm{ng} / \mathrm{mL}$ transforming growth factor-beta3 (TGF- $\beta 3$; PeproTech Inc., Rocky Hill, NJ, USA) in a $37^{\circ} \mathrm{C}, 5 \% \mathrm{O}_{2}$ incubator for up to 27 days. At days 0,9 , and 27 , pellets from each group were collected for evaluation of chondrogenic differentiation using histochemistry, immunohistochemistry, biochemistry, and quantitative real-time polymerase chain reaction (PCR).

\section{Histochemistry and immunohistochemistry}

The pellets $(n=2)$ were fixed in $4 \%$ paraformaldehyde at $4{ }^{\circ} \mathrm{C}$ overnight, followed by dehydrating in a gradient ethanol series, clearing with xylene, and embedding in paraffin blocks. Fivemicrometer sections were histochemically stained with Alcian blue (Sigma, counterstained with fast red) and Safranin $O$ (Sigma, counterstained with hematoxylin) for sulfated glycosaminoglycans (GAG). For immunostaining, the sections were immunolabeled with primary antibodies against collagen I (Abcam, Cambridge, MA, USA), collagen II (II-II6B3; Developmental Studies Hybridoma Bank, lowa City, IA, USA), and collagen X (Sigma), followed by the secondary antibody of biotinylated horse anti-mouse IgG (Vector, Burlingame, CA, USA) or IgM (Vector). Immunoactivity was detected using Vectastain ABC reagent (Vector) with 3,3'-diaminobenzidine as a substrate.

Biochemical analysis for DNA and GAG content 
The pellets (n04) were digested at $60{ }^{\circ} \mathrm{C}$ for $6 \mathrm{~h}$ with $125 \mu \mathrm{g} / \mathrm{mL}$ papain in PBE buffer $(100 \mathrm{mM}$ phosphate, $10 \mathrm{mM}$ EDTA, pH 6.5) containing $10 \mathrm{mM}$ cysteine. To quantify cell density, the amount of DNA in the papain digestion was measured using the QuantiT ${ }^{\mathrm{TM}}$ PicoGreen $^{\circledR}$ dsDNA Assay kit (Invitrogen) with a CytoFluor ${ }^{\circledR}$ Series 4000 (Applied Biosystems, Foster City, CA, USA). GAG was measured using dimethylmethylene blue dye and a Spectronic ${ }^{\mathrm{TM}}$ BioMate $^{\mathrm{TM}} 3$ Spectrophotometer (Thermo Scientific, Milford, MA, USA) with bovine chondroitin sulfate (Sigma) as a standard.

\section{TaqMan quantitative $P C R$}

Total RNA was extracted from the pellets $(n=4)$ using an RNase-free pestle in TRIzol ${ }^{\circledR}$ (Invitrogen). Two micrograms of mRNA was used for reverse transcriptase with High- Capacity cDNA Archive Kit (Applied Biosystems) at $37{ }^{\circ} \mathrm{C}$ for $120 \mathrm{~min}$. Chondrogenic marker genes [collagen I (assay ID Hs00164004_m1), collagen II (assay ID Hs00156568_m1), collagen X (assay ID Hs00166657_m1), aggrecan (assay ID AIQJAP5), and SRY (sex determining region Y)-box 9 (Sox9) (assay ID Hs00165814_m1)] were customized by Applied Biosystems as part of the Custom TaqMan ${ }^{\circledR}$ Gene Expression Assays. Eukaryotic 18S rRNA (assay ID HS99999901-s1 $A B I)$ was carried out as the endogenous control gene. Real-time PCR was performed with iCycler $\mathrm{iQ}^{\mathrm{TM} M u l t i-C o l o r}$ Real-Time PCR Detection System and the data were calculated by computer software (Perkin-EImer, Wellesley, MA, USA). Relative transcript levels were calculated as $x=2^{-\Delta}$ ${ }^{\Delta \mathrm{Ct}}$, in which $\Delta \Delta \mathrm{Ct}=\Delta \mathrm{E}-\Delta \mathrm{C}, \Delta \mathrm{E}=C t_{\exp }-C t_{18 s}$, and $\Delta \mathrm{C}=C t_{c t 1}-C t_{18 s}$.

\section{Adipogeneic induction and analysis of expanded $h S D S C s$}

Expanded hSDSCs $(n=3)$ were replated at $10,000 \mathrm{cells} / \mathrm{cm}^{2}$. Once cells reached confluence, the culture medium was switched to adipogenic induction medium consisting of complete medium supplemented with $1 \mu \mathrm{M}$ dexamethasone, $0.5 \mathrm{mM}$ isobutyl-1-methyxanthine, $200 \mu \mathrm{M}$

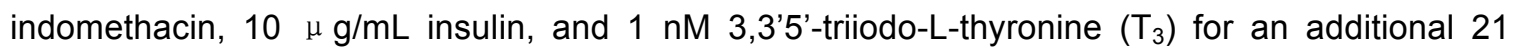
days. Oil Red O (ORO) staining and quantitative assay were conducted as described in our previous study [17]. Briefly, cells were fixed in $4 \%$ paraformaldehyde for 60 min and stained with $0.3 \%$ ORO solution (Sigma) for $30 \mathrm{~min}$. After rinsing in distilled water, cells were photographed using AMSCOPE MP1900 digital camera (Amscope, iScope Corporation, USA). ORO was extracted from cells using $100 \%$ isopropanol and the absorbance at $510 \mathrm{~nm}$ was determined. For a blank control, we used $100 \%$ isopropanol. ORO optical density (OD) value was normalized by total DNA content.

\section{Osteogenic induction of expanded hSDSCs}

Expanded hSDSCs were replated at $8,000 \mathrm{cells} / \mathrm{cm}^{2}$. Once cells reached $90 \%$ confluence, the culture medium was switched to osteogenic induction medium consisting of complete medium 
supplemented with $0.01 \mu \mathrm{M}$ dexamethasone, $10 \mathrm{mM} \beta$-glycerolphosphate, $50 \mu \mathrm{M}$ ascorbate-2phosphate, and $0.01 \mu \mathrm{M}$ 1,25-dihydroxyvitamin D3 for an additional 21 days. Osteogenic differentiation was assessed using alkaline phosphatase (ALP) and Alizarin Red S (ARS) staining as described before [17]. ALP activity and accumulated calcium quantitative assay were conducted using a spectrophotometric method.

\section{ALP staining and activity assay}

After a 21-day incubation in osteogenic medium, hSDSCs were stained using the Leukocyte Alkaline Phosphatase Kit (Sigma). Expanded hSDSCs $(n=3)$ were also collected for ALP activity assay by measuring the formation of $p$-nitrophenol ( $p-N P$ ) from p-nitrophenyl phosphate. Briefly, cell cultures were lysed in a buffer containing $1.5 \mathrm{M}$ Tris- $\mathrm{HCl}, 1 \mathrm{mM} \mathrm{ZnCl}_{2}$, and $1 \mathrm{mM} \mathrm{MgCl}, \mathrm{pH}$ 9.0 , containing $2 \%$ Triton $\mathrm{X}-100$, and reacted with phosphatase substrate reagent $(2 \mathrm{mg} / \mathrm{mL})$ in a microplate. p-NP was quantified based on the spectrophotometric absorbance at $405 \mathrm{~nm}$ and enzymatic activity was expressed as millimoles of p-NP per microgram of protein.

\section{ARS staining and extracellular calcium quantitative assay}

Expanded hSDSCs ( $n=3$ ) cultured for 21 days in osteogenic medium were fixed with $70 \%$ icecold ethanol for $1 \mathrm{~h}$, and then incubated in $40 \mathrm{mM}$ ARS at $\mathrm{pH} 4.2$ for $20 \mathrm{~min}$ at room temperature with agitation on an orbital shaker $(60 \mathrm{rpm})$. After two rinses with deionized water, matrix mineralbound staining was photographed under a Nikon TE300 phase-contrast microscope (Nikon, Japan). Accumulated calcium was extracted using $0.5 \mathrm{~mL}$ of $0.5 \mathrm{~N} \mathrm{HCl}$ and quantified according to the manufacturer's instructions in Quanti-Chrom Calcium Assay Kit (BioAssay Systems, Hayward, CA, USA). Total calcium was calculated from standard solutions prepared in parallel and normalized to the total protein content. The values of blank controls were subtracted from the corresponding samples.

\section{Western blot}

To investigate whether the MAPK signaling pathway was involved in seeding density-based cell expansion, the expanded cells from each group were homogenized and dissolved in the lysis buffer (Cell Signaling, Danvers, MA, USA) with protease inhibitors. Total proteins were quantified using $\mathrm{BCA}^{\mathrm{TM}}$ Protein Assay Kit (Thermo Fisher Scientific, Rockford, IL, USA). Thirty micrograms of protein from each sample was denatured and separated using NuPAGE ${ }^{\circledR}$ Novex $^{\circledR}$ Bis-Tris Mini Gels (Invitrogen) in the XCell Sure-Lock ${ }^{\mathrm{TM}}$ Mini-Cell (Invitrogen) at $120 \mathrm{~V}$ at $4{ }^{\circ} \mathrm{C}$ for $3 \mathrm{~h}$. Bands were transferred onto a nitrocellulose membrane (Invitrogen) using an XCell II ${ }^{\mathrm{TM}}$ Blot module (Invitrogen) at $15 \mathrm{~V}$ at $4{ }^{\circ} \mathrm{C}$ overnight. The membrane was incubated with primary mono-clonal antibodies in $5 \%$ bovine serum albumin (BSA) in TBST buffer (10 mM Tris- $\mathrm{HCl}, \mathrm{pH} 7.5,150 \mathrm{mM}$ $\mathrm{NaCl}$, and $0.05 \%$ Tween-20) at room temperature for $1 \mathrm{~h} \mathrm{(} \beta$-actin served as an internal control), 
followed by the secondary antibody of horseradish peroxidase-conjugated goat anti-mouse (Thermo Fisher Scientific) at room temperature for $1 \mathrm{~h}$. SuperSignal West Femto Maximum Sensitivity Substrate (Thermo Fisher Scientific) and CL-XPosure Film (Thermo Fisher Scientific) were used for exposure. The primary antibodies used in immunoblotting included MAPK family antibody sampler kit [p44/42 MAPK (Erk1/2), MAPK/JNK, and p38 MAPK] and phosphor-MAPK family antibody sampler kit, p21, and caveolin-1; all were from Cell Signaling.

\section{Statistical methods}

Numerical data are presented as the mean and the standard error of the mean. Mann-Whitney $U$ test was used for pair-wise comparison in biochemistry, ALP activity, calcium assay, ORO assay, and real-time PCR data analysis. All statistical analyses were performed with SPSS 13.0 statistical software (SPSS Inc., Chicago, IL, USA). P values less than 0.05 were considered statistically significant. 


\section{RESULTS}

Low-density expansion enhanced hSDSC proliferation capacity

Expanded hSDSCs at low and high density exhibited differences in cell morphology, cell number, and cell size. Compared to cells grown at high density, low-density expanded cells remained spindle shaped and smaller in size, and formed colony-forming units (Fig. 2.1a). When cells plated at high density became confluent, cell number change was compared between the highdensity group from six $175-\mathrm{cm}^{2}$ flasks and the low-density group from twenty-six $175 \mathrm{~cm}^{2}$ flasks. We found that 9-day expansion of passage 2 hSDSCs yielded a 5.1 -fold increase in cell number $\left(15,200\right.$ cells $\left./ \mathrm{cm}^{2}\right)$ when seeded at high density compared to an 84.4-fold increase $(2,533$ cells $/ \mathrm{cm}^{2}$ ) when plated at low density. Passage $3 \mathrm{hSDSCs}$ continued to expand at the same density for another passage. Compared to the previous passage (passage 2), 9-day expansion at high density yielded a lower cell number increase $\left(11,429 \mathrm{cells} / \mathrm{cm}^{2}, 3.8\right.$-fold) while low-density expansion yielded a higher cell number increase $\left(2,725 \mathrm{cells} / \mathrm{cm}^{2}, 90.8\right.$-fold) (Fig. 2.1b). Cell seeding density-based changes were also reflected in cell size. Low-density expansion cell size $(3,065.2 \pm 2,540.1$ pixels $)$ was significantly smaller $(p=0.0000)$ than those grown at high density $(8,407.9 \pm 4,240.6$ pixels) (Fig. 2.1c).

Our flow cytometry data showed that cell changes were also reflected in the stem-cell-related marker, proliferation index, and apoptosis in expanded cells at low and high density (Fig. 2.2). We found that low-density expansion yielded cells with higher levels of SSEA-4 expression not only in percentage (51.9 \% vs. $47.5 \%$ ) but also in median fluorescence intensity (58.8 vs. 50.0) compared to those seeded at high density. SSEA-4 data also corroborated proliferation index data showing that low-density expansion yielded cells with a higher proliferation index (89.6 vs. 5.7) compared to those grown at high density. Intriguingly, there was a similar apoptotic cell rate $(4.1 \%$ vs. $3.0 \%)$ in the cells expanded at low and high density.

\section{Low-density expansion enhanced hSDSC multi-differentiation potentials}

To determine whether seeding density affected cell multi-differentiation potential, expanded cells at either low or high density were evaluated for their chondrogenic, adipogenic, and osteogenic differentiation capacity.

After a 27-day incubation in chondrogenic induction medium, low-density expanded cells yielded pellets with intensified staining of sulfated GAG and collagens I, II, and X compared to those expanded at high density (Fig. 2.3a). The pellet size from cells expanded at high density was slightly larger than those from low-density expanded cells (Fig. 2.3a), which might be explained by the higher cell viability in day 27 pellets from cells expanded at high density (Fig. 2.3b). Our 
biochemical analysis data showed that, compared to the cells plated at high density, low-density expanded cells yielded pellets with a significantly higher ratio of GAG to DNA (chondrogenic index) (Fig. 2.3b). Consistent with the above data, our real-time PCR data also showed that lowdensity expansion yielded day 27 pellets with higher mRNA levels of Sox9 $(p=0.0000)$, aggrecan $(p=0.0002)$, collagen I $(p=0.0015)$, collagen II $(p=0.0002)$, and collagen $X(p=0.0007)$ than those from high-density groups (Fig. 2.4).

After a 21-day incubation in osteogenic induction medium, low-density expanded cells exhibited intensified staining of ALP while high-density expanded cells had much weaker ALP staining; this finding is corroborated by quantitative data that ALP activity was higher $(p=0.0030)$ in cells expanded at low density than those grown at high density (Fig. 2.5a). Surprisingly, both groups showed weak staining for calcium deposition using alizarin red $S$ staining without a significant difference ( $p=0.6492$ ) between the groups (Fig. 2.5b). Similar to osteogenic potential, after a 21day incubation in adipogenic induction medium, low-density expanded cells exhibited intensified staining of lipid droplets detected using Oil Red O staining compared to those from high-density expanded cells; this finding was supported by quantitative data ( $p=0.0002)$ (Fig. 2.5c).

\section{Potential mechanisms underlying low seeding density-mediated cell rejuvenation}

To further determine potential mechanisms underlying low seeding density-mediated cell rejuvenation, western blot was used to investigate the expression of the MAPK signaling pathway (Erk1/2, p38, and JNK) and senescence-associated markers ( $p 21$ and caveolin-1) in hSDSCs after expansion at low and high density. Image $\mathrm{J}$ analysis showed that Erk1/2 expression was about one fifth the level in the cells expanded at low density than at high density; JNK expression followed that same trend. In contrast, p38 MAPK had a 2.3-fold increase in the cells expanded at low density than at high density (Fig. 2.6a). As expected, senescence-associated markers, p21 and caveolin-1, decreased to some extent in the cells expanded at low density compared to high density (Fig. 2.6b). 


\section{DISCUSSION}

Stem cell ex vivo expansion is an approach to overcome the shortage in cell number in cartilage engineering and regeneration. However, replicative senescence is a concomitant consequence during monolayer expansion; expanded cells lose their proliferation and multi-differentiation capacity [18]. Though challenging, strategies to expand stem cells in vitro with intact self-renewal and differentiation potentials have focused on identifying molecules and signaling pathways involved. A variety of methods have been investigated to fulfill this need especially in long-term ex vivo culture $[19,20]$. Optimization of cell seeding density is a promising solution to protect stem cells from undergoing replicative senescence. Our study, for the first time, demonstrated that low seeding density not only benefited hSDSC proliferation but also enhanced expanded cell multidifferentiation capacity. We also found that the MAPK signaling pathway was involved in seeding density-based cell expansion and low seeding density tended to retard hSDSC replicative senescence.

Generally, low seeding density expansion results in dense colony formation while high seeding density expanded cells are more evenly distributed across the culture plate. Relatively sparse distribution of high seeding density expanded cells does not benefit colony formation [21] and may not provide the necessary stimuli for growth due to loss of cell-cell contact [7]. Single-cellderived colonies in low seeding density were directly related to expanded cell adipogenic potential [21], which may explain why the cells expanded at low density had higher adipogenic capacity in our study. Cell morphology changes, such as cell shape in the low- seeding-density group, have been reported to favor DNA synthesis [22], which might be responsible for higher cell proliferation potential. Cell shape has also been reported to regulate the switch in lineage commitment by modulating endogenous RhoA activity [23]. Rho kinases (ROCKs), the major downstream effector of RhoA GTPase, regulate renewal and neuronal differentiation of embryonic stem cells in a cell-seeding-density-dependent manner [24]. RhoA was also reported to regulate BMSCs undergoing adipogenic and osteogenic differentiation through ROCKs [23]. Smaller size hSDSCs from low-density expansion benefited generation of single-cell-derived colonies and therefore apparently retained their multi-potentiality for differentiation, which was consistent with previous reports from other groups [4, 6, 21].

Consistent with other reports [5, 21], we found that low seeding density promoted hSDSC proliferation and produced a higher percentage of smaller sized cells; in expanded hSDSCs, low seeding density enhanced proliferation index and SSEA-4 expression but not apoptosis, indicating that low- seeding-density expansion can retain hSDSC "stemness". The retention of "stemness" was also demonstrated by low-seeding-density-expanded hSDSCs' multi- 
differentiation capacity, despite low osteogenic differentiation in the cells expanded at both low and high density. This effect is probably because hSDSCs are a tissue-specific stem cell for chondrogenesis $[8,11]$. In contrast, expansion at high seeding density resulted in decreased cell proliferation, increased cell senescence, and loss of multi-differentiation capacity, which is consistent with a previous report [25].

Three MAPK conduits, Erk1/2, p38, and JNK, rank among the most extensively examined signal transduction networks, and their contribution in MSC chondrogenesis has been thoroughly reviewed recently [26]. For the first time, our study found that low seeding density expansion yielded hSDSCs with down-regulation of the Erk1/2 and JNK levels and up-regulation of the p38 level, which might be responsible for enhancing expanded cell "stemness" in terms of proliferation and multi-differentiation capacity. Consistent with our findings, other investigators found that Erk1/2 was remarkably up-regulated in senescent cells [27] and Erk1/2 and p38 exerted an opposite role in the regulation of chondrogenesis of mesenchymes [28]. The progression of spontaneous chondrogenesis in micromass cultures of embryonic chick limb bud MSCs is accompanied by a gradual increase in endogenous p38 phosphorylation [28]. Treatments with p38 inhibitors have been shown to decrease cartilage matrix formation in embryonic chick or mouse limb MSCs $[28,29]$ and to inhibit chondrogenic marker genes (Sox9, Col2a1, and aggrecan) as well [30]. The transfection of prechondrogenic limb mesenchymes with constitutively active MKK6, which activates p38, was shown to significantly increase Sox9 expression [29]. To sum up, the p38 signaling pathway is a positive regulator of the differentiation of prechondrogenic limb mesenchyme cells into hyaline chondrocytes. The loss of Erk1/2 and JNK expression in the low seeding density group could possibly be related to increased adipogenic differentiation [31-33].

Expression of caveolin-1 and p21 is down-regulated in the cells expanded at low density. Caveolins are major structural components of caveolae, the lipid rafts on cell membranes. Caveolin functions as a scaffolding protein that interacts with signaling molecules and growth factor receptors. Caveolin-1 expression is up-regulated in senescent human diploid fibroblasts and MSCs [34, 35]. Decreased expression of caveolin-1 in hSDSCs expanded at low seeding density might also be responsible for the enhanced adipogenic differentiation potential [34]. Caveolin-1 is reported to be able to induce expression of p21 and further cellular senescence [36]. Expression of p21, the inhibitor of cyclin-dependent kinase, was found to be increased in late-passage MSCs. Knockdown of p21 promoted proliferation and enhanced osteogenic potentials of human MSCs, possibly through increasing telomere length and telomerase activity without chromosomal abnormalities [37, 38]. Despite no difference in calcium deposition between low- and high-density groups, our data suggested that the slight down-regulation of p21 was 
possibly responsible for the increase of ALP level in the cells expanded at low density after osteogenic induction.

In summary, our study demonstrates that low seeding density can protect expanded cells from replicative senescence and enhance hSDSC proliferation and multi-differentiation capacity, especially for expanded cell chondrogenic potential. Similar to our previous study in expanding SDSCs using basic fibroblast growth factor (FGF-2) [39], chondrogenically differentiated SDSCs exhibited an increased amount of collagen I and collagen $X$ compared with the high-density group, indicating that low seeding density may favor multi- differentiation capacity instead of a specific tissue lineage, such as chondrogenesis. This study was done using pooled cells from two donors. One donor was male and one was female; one was middle-aged and one was elderly. Even with this range of donors, donor-to-donor variability cannot be determined, which is a limitation of the study. Our finding also suggests that the MAPK signaling pathway is involved in cell-seeding-density-based cell expansion. Despite the fact that the underlying mechanism is still under investigation, low seeding density provides a feasible and promising approach to yield a sufficient number of cells for hSDSC-based cartilage engineering and regeneration. 


\section{ACKNOWLEDGEMENTS}

We thank Suzanne Smith for editing the manuscript. This study was supported by a faculty startup fund from West Virginia University. 


\section{REFERENCES}

1. Harris JD, Siston RA, Pan X, Flanigan DC. Autologous chondrocyte implantation: a systematic review. J Bone Joint Surg Am. 2010;92(12):2220-33.

2. Csaki C, Schneider PR, Shakibaei M. Mesenchymal stem cells as a potential pool for cartilage tissue engineering. Ann Anat. 2008;190 (5):395-412.

3. De Bari C, Dell'Accio F, Tylzanowski P, Luyten FP. Multipotent mesenchymal stem cells from adult human synovial membrane. Arthritis Rheum. 2001;44(8):1928-42.

4. Estes BT, Diekman BO, Guilak F. Monolayer cell expansion conditions affect the chondrogenic potential of adipose-derived stem cells. Biotechnol Bioeng. 2008;99(4):986-95.

5. Neuhuber B, Swanger SA, Howard L, Mackay A, Fischer I. Effects of plating density and culture time on bone marrow stromal cell characteristics. Exp Hematol. 2008;36(9):1176-85.

6. Colter DC, Class R, DiGirolamo CM, Prockop DJ. Rapid expansion of recycling stem cells in cultures of plastic-adherent cells from human bone marrow. Proc Natl Acad Sci USA. 2000;97 (7):3213-8.

7. Colter DC, Sekiya I, Prockop DJ. Identification of a subpopulation of rapidly self-renewing and multipotential adult stem cells in colonies of human marrow stromal cells. Proc Natl Acad Sci USA. 2001;98(14):7841-5.

8. Jones B, Pei M. Synovium-derived stem cells: a tissue-specific stem cell for cartilage tissue engineering and regeneration. Tissue Eng Part B Rev. 2012;18(4):301-11.

9. Kurth TB, Dell'accio F, Crouch V, Augello A, Sharpe PT, De Bari C. Functional mesenchymal stem cell niches in the adult knee joint synovium in vivo. Arthritis Rheum. 2011;63(5):1289-300.

10. Pei M, He F, Boyce BM, Kish VL. Repair of full-thickness femoral condyle cartilage defects using allogeneic synovial cell-engineered tissue constructs. Osteoarthritis Cartilage. 2009;17(6):714-22.

11. Pei M, He F, Vunjak-Novakovic G. Synovium-derived stem cell-based chondrogenesis. Differentiation. 2008;76(10):1044-56.

12. Pei M, He F, Kish V, Vunjak-Novakovic G. Engineering of functional cartilage tissue using stem cells from synovial lining: a preliminary study. Clin Orthop Relat Res. 2008;466(8):1880-9.

13. Sakaguchi Y, Sekiya I, Yagishita K, Muneta T. Comparison of human stem cells derived from various mesenchymal tissues: superiority of synovium as a cell source. Arthritis Rheum. 2005;52(8):2521-9.

14. Segawa Y, Muneta T, Makino H, Nimura A, Mochizuki T, Ju YJ, et al. Mesenchymal stem cells derived from synovium, meniscus, anterior cruciate ligament, and articular chondrocytes share similar gene expression profiles. J Orthop Res. 2009;27(4):435-41. 
15. Pearson G, Robinson F, Beers Gibson T, Xu BE, Karandikar M, Berman K, Cobb MH. Mitogen-activated protein (MAP) kinase pathways: regulation and physiological functions. Endocr Rev. 2001;22(2):153-83.

16. Li J, He F, Pei M. Creation of an in vitro microenvironment to enhance human fetal synoviumderived stem cell chondrogenesis. Cell Tissue Res. 2011;345(3):357-65.

17. Pei M, He F, Kish VL. Expansion on extracellular matrix deposited by human bone marrow stromal cells facilitates stem cell proliferation and tissue-specific lineage potential. Tissue Eng Part A. 2011;17(23-24):3067-76.

18. Li JT, Pei M. Cell senescence: a challenge in cartilage engineering and regeneration. Tissue Eng Part B. 2012;18(4):270-87.

19. Csaszar E, Kirouac DC, Yu M, Wang W, Qiao W, Cooke MP, et al. Rapid expansion of human hematopoietic stem cells by automated control of inhibitory feedback signaling. Cell Stem Cell. 2012;10 (2):218-29.

20. Pei M, Li JT, Shoukry M, Zhang Y. A review of decellularized stem cell matrix: a novel cell expansion system for cartilage tissue engineering. Eur Cell Mater. 2011;22:333-43.

21. Sekiya I, Larson BL, Smith JR, Pochampally R, Cui JG, Prockop DJ. Expansion of human adult stem cells from bone marrow stroma: conditions that maximize the yields of early progenitors and evaluate their quality. Stem Cells. 2002;20 (6):530-41.

22. Ben-Ze'ev A, Farmer SR, Penman S. Protein synthesis requires cell-surface contact while nuclear events respond to cell shape in anchorage-dependent fibroblasts. Cell. 1980;21(2):36572.

23. McBeath R, Pirone DM, Nelson CM, Bhadriraju K, Chen CS. Cell shape, cytoskeletal tension, and RhoA regulate stem cell lineage commitment. Dev Cell. 2004;6(4):483-95.

24. Chang TC, Chen YC, Yang MH, Chen CH, Hsing EW, Ko BS, et al. Rho kinases regulate the renewal and neural differentiation of embryonic stem cells in a cell plating density-dependent manner. PLoS One. 2010;5(2):e9187.

25. Digirolamo CM, Stokes D, Colter D, Phinney DG, Class R, Prockop DJ. Propagation and senescence of human marrow stromal cells in culture: a simple colony-forming assay identifies samples with the greatest potential to propagate and differentiate. $\mathrm{Br} J$ Haematol. 1999;107(2):275-81.

26. Bobick BE, Kulyk WM. Regulation of cartilage formation and maturation by mitogen-activated protein kinase signaling. Birth Defects Res C Embryo Today. 2008;84(2):131-54.

27. Lim IK, Won Hong K, Kwak IH, Yoon G, Park SC. Cytoplasmic retention of p-Erk1/2 and nuclear accumulation of actin proteins during cellular senescence in human diploid fibroblasts. Mech Ageing Dev. 2000;119(3):113-30. 
28. Oh CD, Chang SH, Yoon YM, Lee SJ, Lee YS, Kang SS, et al. Opposing role of mitogenactivated protein kinase subtypes, erk-1/ 2 and p38, in the regulation of chondrogenesis of mesenchymes. J Biol Chem. 2000;275(8):5613-9.

29. Weston AD, Chandraratna RA, Torchia J, Underhill TM. Requirement for RAR-mediated gene repression in skeletal progenitor differentiation. J Cell Biol. 2002;158(1):39-51.

30. Bobick BE, Kulyk WM. MEK-ERK signaling plays diverse roles in the regulation of facial chondrogenesis. Exp Cell Res. 2006;312 (7):1079-92.

31. Fu L, Tang T, Miao Y, Zhang S, Qu Z, Dai K. Stimulation of osteogenic differentiation and inhibition of adipogenic differentiation in bone marrow stromal cells by alendronate via ERK and JNK activation. Bone. 2008;43(1):40-7.

32. Jaiswal RK, Jaiswal N, Bruder SP, Mbalaviele G, Marshak DR, Pittenger MF. Adult human mesenchymal stem cell differentiation to the osteogenic or adipogenic lineage is regulated by mitogen-activated protein kinase. J Biol Chem. 2000;275(13):9645-52.

33. Chiu LH, Yeh TS, Huang HM, Lu SJ, Yang CB, Tsai YH. Diverse effects of type II collagen on osteogenic and adipogenic differentiation of mesenchymal stem cells. J Cell Physiol. 2011;227(6):2412-20.

34. Park JS, Kim HY, Kim HW, Chae GN, Oh HT, Park JY, et al. Increased caveolin-1, a cause for the declined adipogenic potential of senescent human mesenchymal stem cells. Mech Ageing Dev. 2005;126(5):551-9.

35. Park WY, Park JS, Cho KA, Kim DI, Ko YG, Seo JS, et al. Up-regulation of caveolin attenuates epidermal growth factor signaling in senescent cells. J Biol Chem. 2000;275(27):20847-52.

36. Galbiati F, Volonte D, Liu J, Capozza F, Frank PG, Zhu L, et al. Caveolin-1 expression negatively regulates cell cycle progression by inducing $G(0) / G(1)$ arrest via a p53/p21(WAF1/Cip1)-dependent mechanism. Mol Biol Cell. 2001;12(8):2229-44.

37. Yew TL, Chiu FY, Tsai CC, Chen HL, Lee WP, Chen YJ, et al. Knockdown of p21(Cip1/Waf1) enhances proliferation, the expression of stemness markers, and osteogenic potential in human mesenchymal stem cells. Aging Cell. 2011;10(2):349-61.

38. Plasilova M, Schonmeyr B, Fernandez J, Clavin N, Soares M, Mehrara BJ. Accelerating stem cell proliferation by down-regulation of cell cycle regulator p21. Plast Reconstr Surg. 2009;123(2 Suppl):149S-57.

39. Li JT, Pei M. Optimization of an in vitro three-dimensional microenvironment to reprogram synovium-derived stem cells for cartilage tissue engineering. Tissue Eng Part A. 2011;17:703-12. 


\section{FIGURE LEGENDS}

Figure 2.1 Cell seeding density affected expanded cell morphology, cell number, and cell size. a Human SDSCs were expanded at high and low density on conventional plastic flasks for 9 days. Scale bar is $200 \mu \mathrm{m}$. b Cell number was presented as a fold increase by initially seeded cell amount during two consecutive passages. c Cell size was measured in pixels using Image $\mathrm{J}$ software from 50 cells chosen randomly in 10 fields.

Figure 2.2 Cell seeding density affected expanded cell stem cell marker expression, proliferation index, and apoptosis. a Flow cytometry was used to evaluate SSEA-4 expression in the cells expanded at either high or low density. b Passage 3 expanded cells were measured for proliferation index using CellVue ${ }^{\circledR}$ Claret flow cytometry kit. c Flow cytometry was used to evaluate apoptosis in the cells expanded at either high or low density.

Figure 2.3 Cell seeding density affected expanded cell chondrogenic potential at the protein level. a After a 27-day incubation in chondrogenic induction medium, representative pellets were photographed for the final size. Safranin $O(S O)$ and Alcian blue (AB) were used to stain sulfated GAG. Immunostaining was used to detect collagens I, II, and X. b Biochemical analysis was used to measure DNA and GAG amounts. DNA ratio, DNA amount adjusted by that at day 0 , indicates cell viability in a serum-free pellet culture system; ratio of GAG to DNA indicates chondrogenic index. Significant differences were indicated as follows: ${ }^{* *} p<0.01$ and ${ }^{* * *} p<0.001$. Data were shown as average $\pm S D$ for $n=4$.

Figure 2.4 Cell seeding density affects expanded cell chondrogenic potential at the mRNA level. Chondrogenic markers Sox9, aggrecan (AG), collagen I (Col I), collagen II (Col II), and collagen X (Col X) were measured at the mRNA level in pellets from the cells expanded at either high or low density. Significant differences were indicated as follows: ${ }^{* *} p<0.01$ and ${ }^{* * *} p<0.001$. Data were shown as average $\pm S D$ for $n=4$.

Figure 2.5 Cell seeding density affects expanded cell osteogenic and adipogenic potential. After a 21-day incubation in osteogenic medium, osteogenesis was evaluated using alkaline phosphatase (ALP) staining and quantitative activity assay (a) and Alizarin Red S (ARS) staining and quantitative extracellular calcium assay (b). After a 21-day incubation in adipogenic medium, adipogenesis was evaluated using Oil Red O (ORO) staining and quantitative lipid assay (c). Significant differences were indicated as follows: ${ }^{* *} p<0.01$ and ${ }^{* * *} p<0.001$. Data were shown as average $\pm S D$ for $n=4$. 
Figure 2.6 Western blot was used to measure the expression of Erk1/2, JNK, and p38 in the MAPK signaling pathway (a) and the expression of p21 and caveolin-1 (senescence-associated markers) (b) in the cells expanded at either high or low density. A band (with an asterisk) between Jnk bands (46 and $54 \mathrm{kDa}$ ) was a contamination from a previous binding with another antibody but could not be stripped from 1.2 the membrane. Image $\mathrm{J}$ software was used to measure immunoblotting bands. The activation of Erk1/2, JNK, or p38 was represented by phosphorylated protein adjusted by total protein; the activation of p21 or caveolin-1 was represented by expressed protein adjusted by $\beta$-actin. The value of interest was set up as 1 in the high-density group. 
Figure 2.1

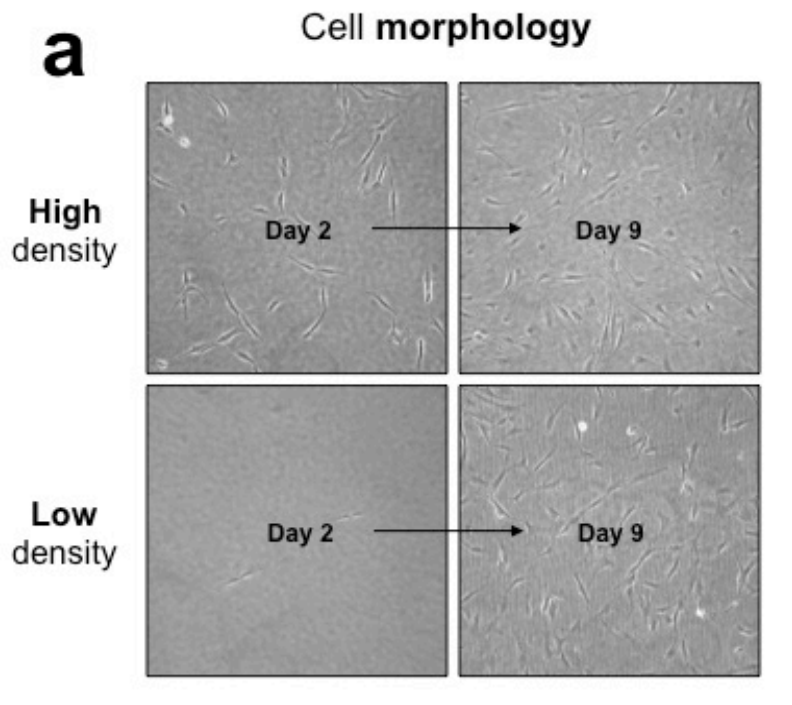
b

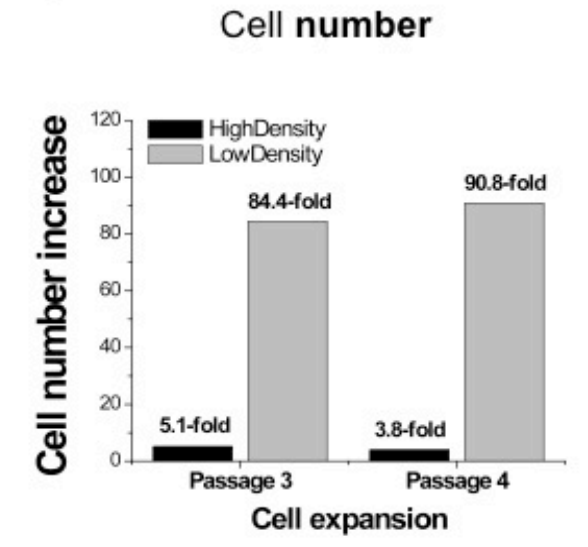

C

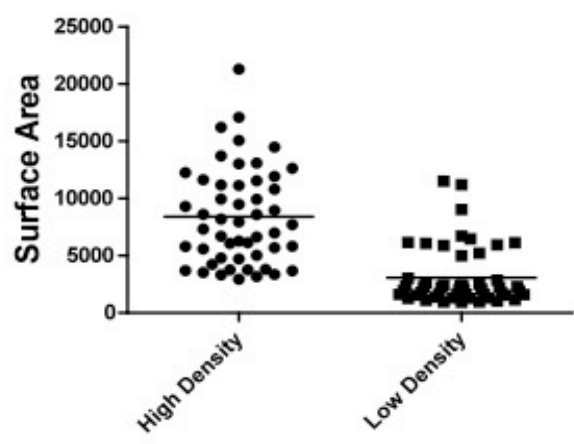

Cell size

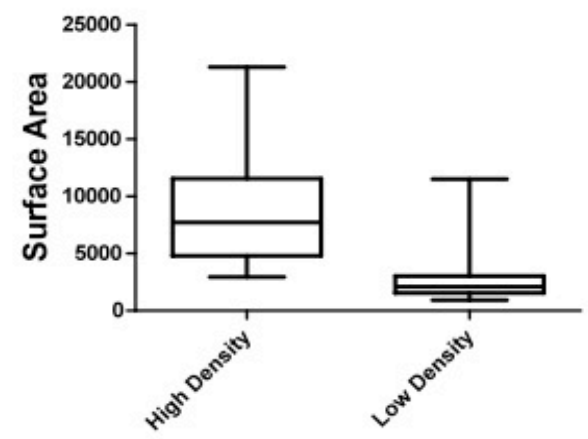


Figure 2.2

High density

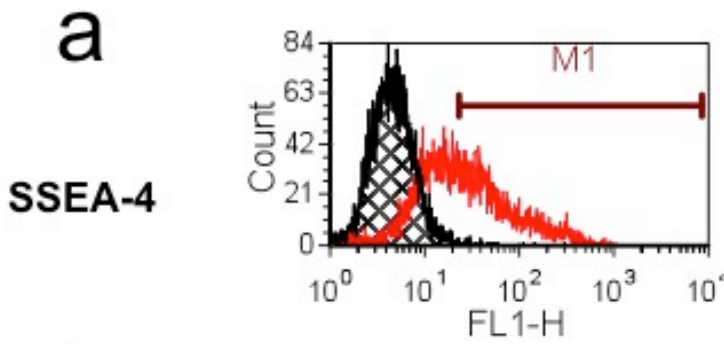

Proliferation Index

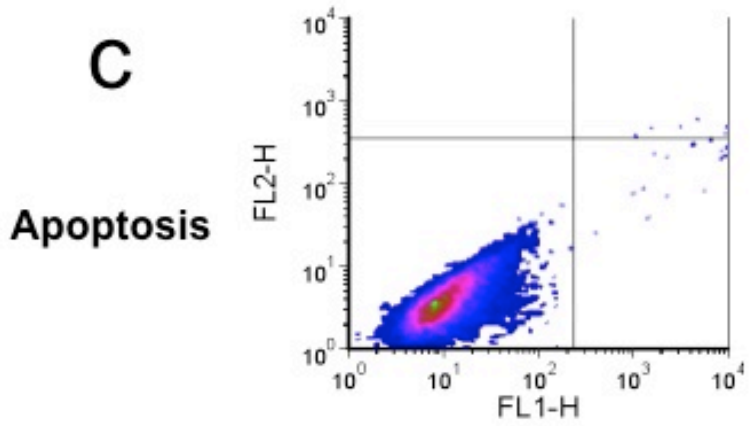

Low density
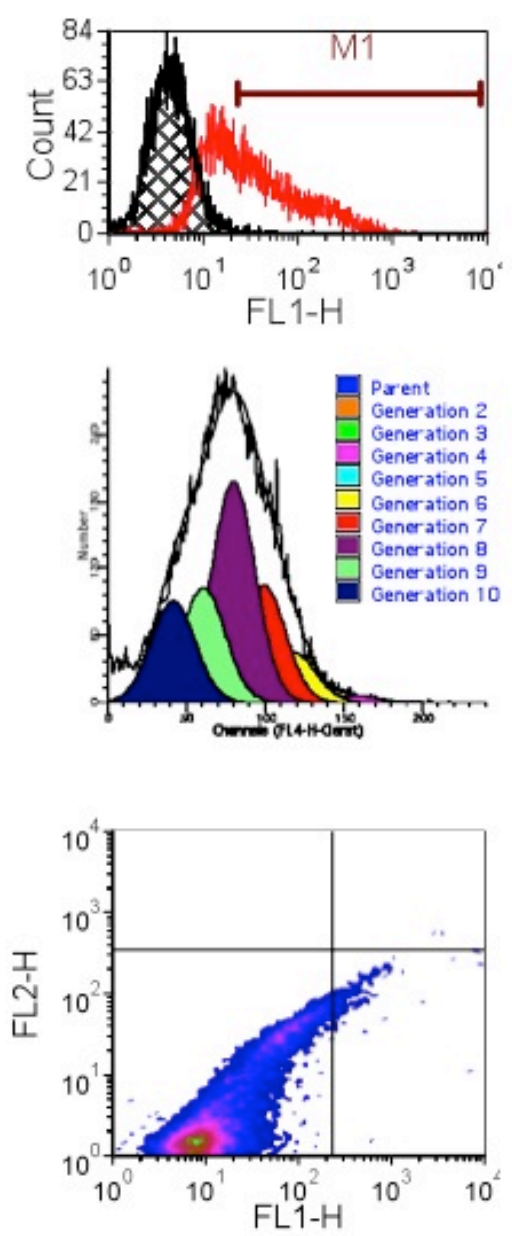
Figure 2.3
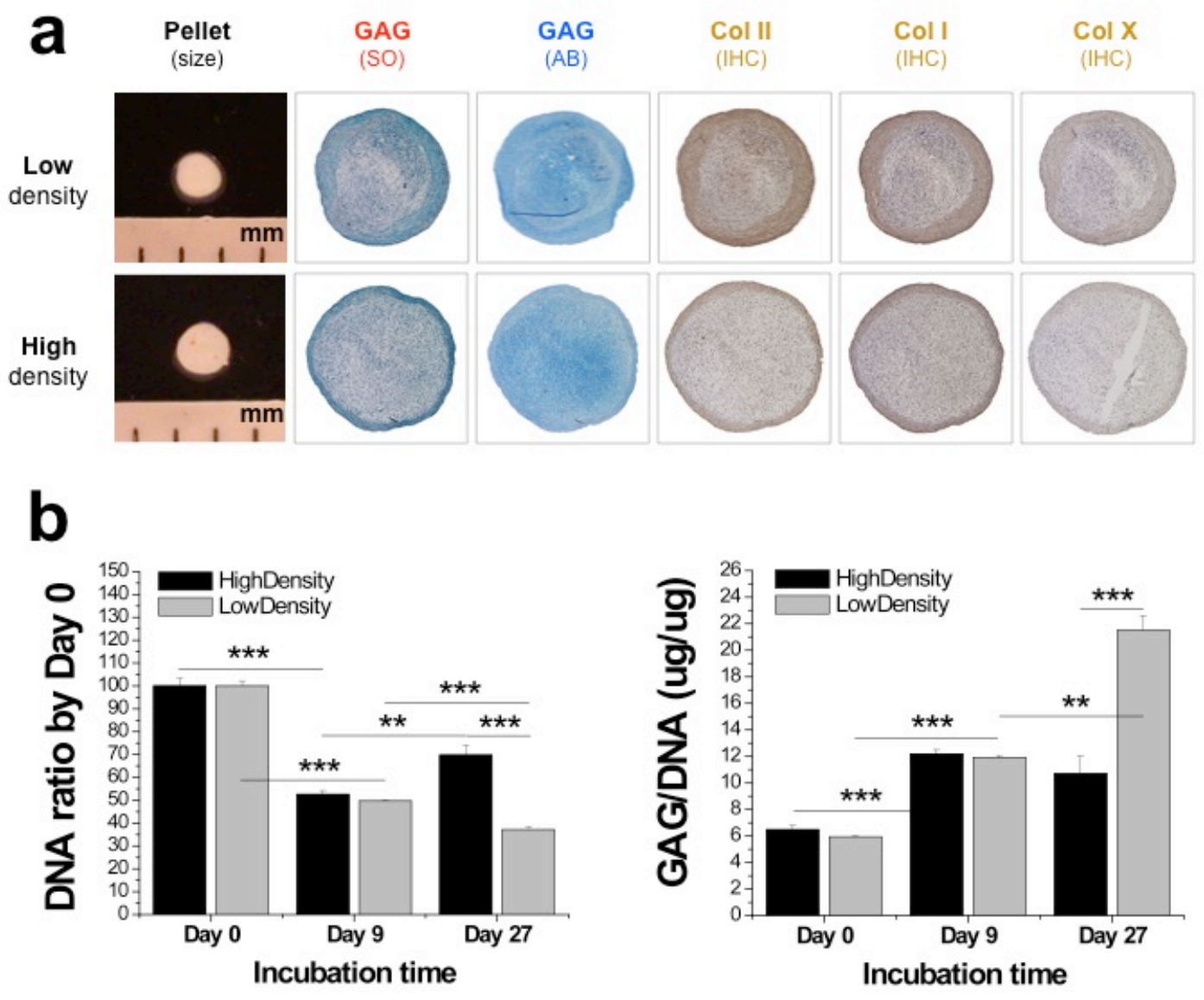
Figure 2.4
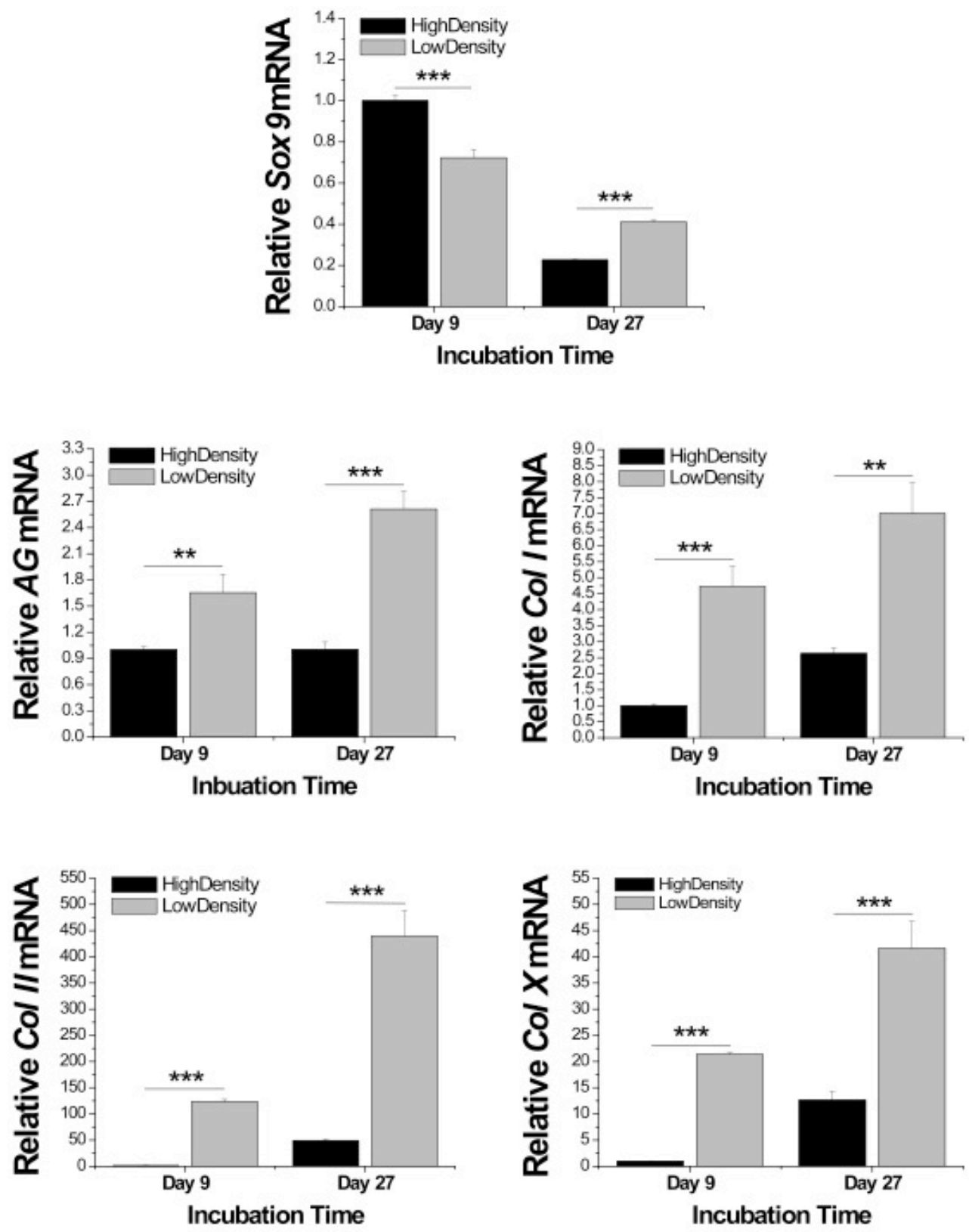
Figure 2.5

\section{osteogenesis}
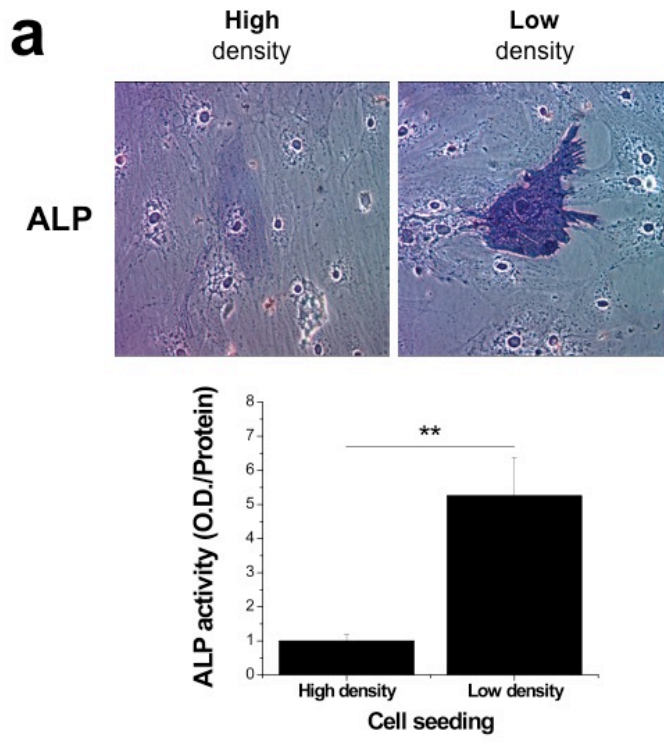

b
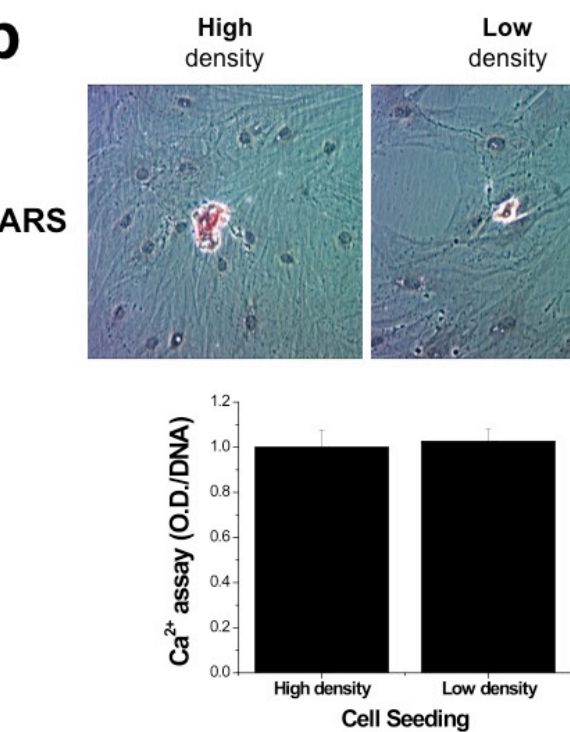

adipogenesis
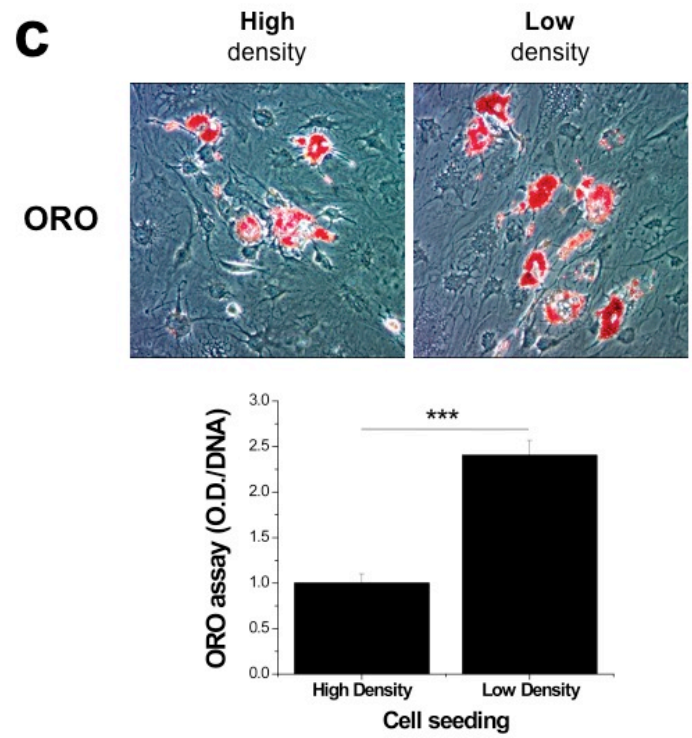
Figure 2.6

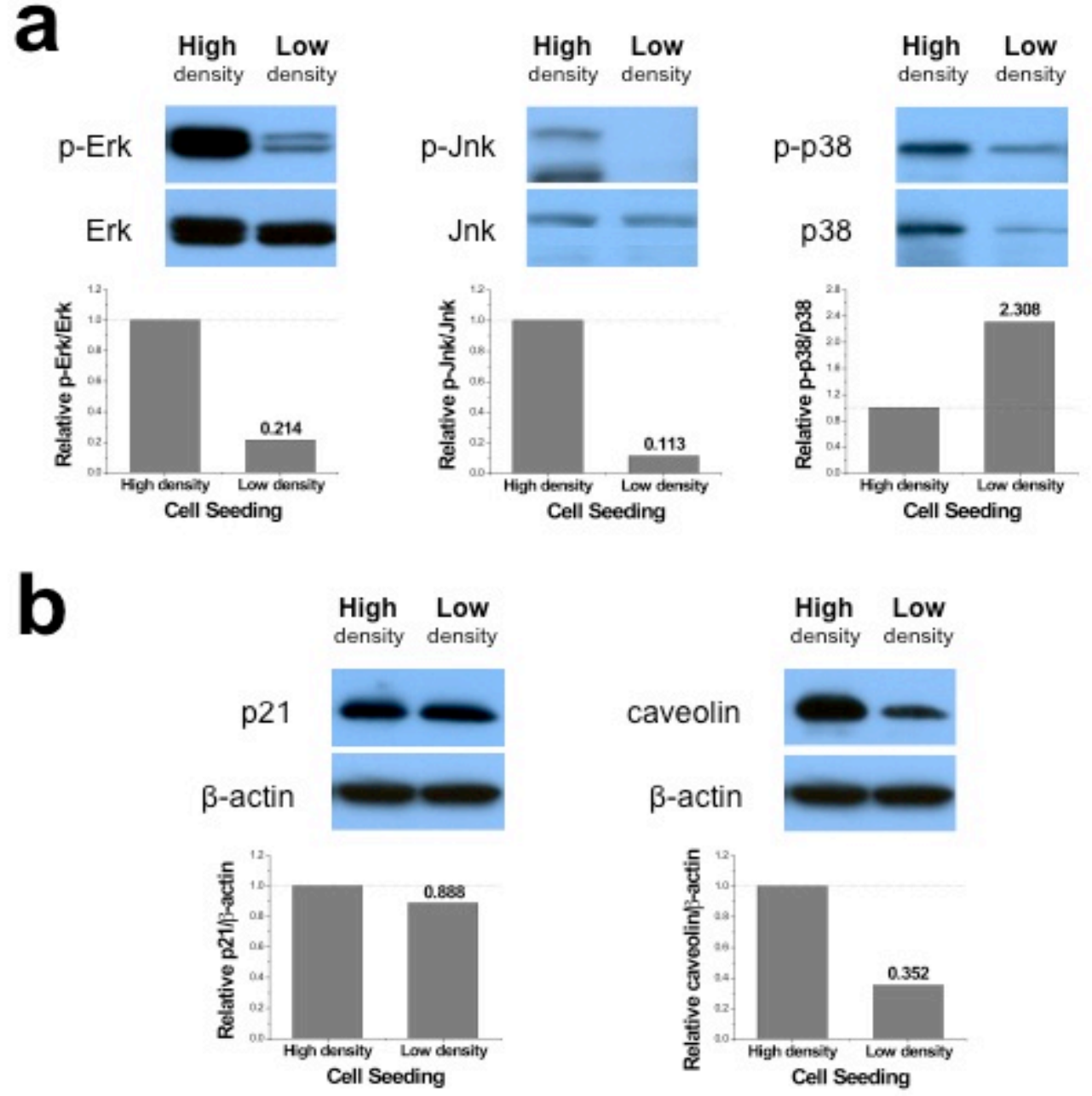


CHAPTER 3:OPTIMIZATION OF AN IN VITRO THREEDIMENSIONAL MICROENVIRONMENT TO REPROGRAM SYNOVIUM-DERIVED STEM CELLS FOR CARTILAGE TISSUE ENGINEERING

As published in Tissue Eng Part A 2011;17:703-12.

Jingting Li, M.S., and Ming Pei, Ph.D.

Tissue Engineering Laboratory, Department of Orthopaedics, and Division of Exercise Physiology, West Virginia University, Morgantown, WV 26506

Key words: Cartilage regeneration, synovium derived stem cells, extracellular matrix

Running head of the title: ENGINNERING A MICROENVIRONMENT FOR STEM CELL EXPANSION 


\begin{abstract}
Adult stem cells gradually lose their stemness when plated in monolayer culture after isolation from their in vivo niche. In this study, we hypothesized that the in vitro microenvironment can be optimized by modulating oxygen tension andmitotic signal in a tissue-specific extracellularmatrix (ECM) deposited by synovium-derived stem cells (SDSCs) to rejuvenate expanded SDSC proliferation and chondrogenic potential. Passage 3 SDSCs were plated on either SDSC-derived ECM or plastic flask and incubated in either hypoxia $\left(5 \% \mathrm{O}_{2}\right)$ or normoxia $\left(21 \% \mathrm{O}_{2}\right)$ with or without the supplementation of $10 \mathrm{ng} / \mathrm{mL}$ of basic fibroblast growth factor-2 (FGF-2) for 7 days, followed by pellet culture in a serum-free chondrogenic medium for 14 days. Our data showed that, compared with the mitotic effect of FGF-2 on SDSCs, ECM expansion greatly enhanced SDSC proliferation while retaining SDSC stem cell characteristics. More importantly, ECM pretreatment yielded SDSC pellets with a comparable chondrogenic index to FGF-2 pretreatment, both of which were much higher than SDSC expansion on plastic flask alone. FGF-2 pretreatment led to the highest glycosaminoglycans and DNA content; intriguingly, it also contributed to the highest expression level of hypertrophic marker genes. Surprisingly, the hypertrophic marker genes could be downregulated if the pretreatment was combined with hypoxia or ECM. The combination of hypoxia, FGF-2, and SDSC-derived ECM contributed to the highest cell number in SDSC expansion. Our study indicates that the three-dimensional microenvironment for ex vivo expansion can be optimized to provide high-quality stem cells for stem cell-based cartilage defect repair.
\end{abstract}




\section{INTRODUCTION}

Damage to the articular cartilage caused by osteoarthritis is becoming a significant clinical problem due to the limited ability of cartilage to regenerate and the increase in the elderly population. Autologous cartilage transplantation is a solution but is limited by donor-site availability. ${ }^{1}$ Recently, significant advances and tremendous progress have been made in exploring the potential of adult stem cells in cartilage repair. Adult stem cells have proliferation and multi-lineage differentiation capacity; however, once isolated from the body and expanded in monolayer, they lose their proliferation and multi-lineage differentiation ability (stemness) during passaging. Reconstructing a three-dimensional (3D) microenvironment by imitating an in vivo stem cell niche for ex vivo expansion becomes an important priority for stem cell-based therapy of cartilage defects.

Recent studies suggest that growth factors can enhance proliferation and differentiation potential of adult stem cells. Of them, basic fibroblast growth factor-2 (FGF-2) is unique because mesenchymal stem cells (MSCs) expanded in FGF- supplemented medium were smaller and grew more rapidly than those in non-FGF-supplemented medium. Eighty percent of differentially expressed extracellular matrix (ECM)-related genes were downregulated; moreover,MSC expansion in the presence of FGF-2 enhanced their chondrogenic potential. ${ }^{2}$ Another important parameter, low oxygen, also contributes to the establishment of an undifferentiated niche microenvironment. Early embryonic development takes place in a hypoxic microenvironment and hypoxia seems to prevent cellular differentiation and to maintain pluripotency of stem/ progenitor cells. ${ }^{3}$ When exposed to hypoxia, MSCs increased expression of a subset of genes normally found in embryonic cells, such as OCT-4 and Rex-1, ${ }^{4,5}$ as well as SSEA-4. ${ }^{4}$ Hypoxiapreconditioned MSCs acquired higher colony forming units and increased differentiation potential. $^{5-7}$

It is well established that stem cells reside, proliferate, and differentiate inside the body within a complex 3D microenvironment, indicating that a tissue-specific stem cell canbeusedto prepare its own in vitro microenvironment for stem cell proliferation while maintaining and enhancing its lineage-specific stemness. As a new member in MSC families, synovium-derived stem cells (SDSCs) are reported as a tissue-specific stem cell for chondrogenesis. ${ }^{8-11}$ Our previous studies suggested that SDSCs could be negatively isolated from the synovial membrane ${ }^{12}$ for in vitro cartilage tissue engineering ${ }^{13}$ and in vivo cartilage regeneration. ${ }^{14}$ Our most recent study indicated that SDSC-derived extracellular matrix (S-ECM) can serve as an in vitro 3D microenvironment, greatly enhancing SDSC propagation and allowing restoration of stem cell stemness toward chondrogenesis. ${ }^{15}$ Considering that articular chondrocytes reside in a hypoxic 
condition $^{16}$ and mitogens such as FGF- 2 are involved in MSC chondrogenesis, ${ }^{2}$ three important microenvironmental factors-oxygen tension and mitogens as well as 3D ECM-are assumed to contribute to the regulation of the seeded SDSCs for chondrogenesis. In this study, we hypothesized that the in vitro microenvironment can be optimized by modulating oxygen tension and mitotic signal in ECM deposited by SDSCs to rejuvenate expanded SDSCs' proliferation and chondrogenic differentiation capacity. The ability to reconstitute an in vitro 3D microenvironment will greatly benefit SDSC-based therapy for cartilage defects. 


\section{MATERIALS AND METHODS}

\section{Isolation and culture of SDSCs}

Two 3-month-old pigs were collected from a local slaughterhouse and synovial tissue was harvested from both knees. After finely mincing, synovial tissue was digested in $0.1 \%$ trypsin (Roche, Indianapolis, IN) at $37^{\circ} \mathrm{C}$ for $30 \mathrm{~min}$ and then in $0.1 \%$ collagenase $\mathrm{P}$ (Roche) for $2 \mathrm{~h}$. The released synovial cells were collected from the filtrate and plated in a complete medium (aminimum essential medium containing $10 \%$ fetal bovine serum, $100 \mathrm{U} / \mathrm{mL}$ penicillin, $100 \mathrm{mg} / \mathrm{mL}$ streptomycin, and $0.25 \mathrm{mg} / \mathrm{mL}$ fungizone [Invitrogen, Carlsbad, CA]). Nonadherent cells were removed during the medium change every 2 days. For negative isolation of synovial fibroblasts from primary cultures, the synovial cell suspension $\left(10^{7}\right.$ cells $\left./ \mathrm{mL}\right)$ was incubated with $5 \times 10^{7} / \mathrm{mL}$ Dynabeads ${ }^{\circledR}$ M-450 CD14 containing a monoclonal antibody specific for macrophages (Dynal Biotech, Oslo, Norway) at $4^{\circ} \mathrm{C}$ for $1 \mathrm{~h}$. The conjugatedcells andthe unboundDynabeads were collected using the Dynal Magnetic Particle Concentrator ${ }^{\circledR}$ (Dynal Biotech), and the depleted supernatant with synovial fibroblasts (characterized as SDSCs in our previous study ${ }^{12}$ ) was saved for further passaging.

\section{Preparation of SDSC-derived ECM}

The preparation method of SDSC-derived ECM was described in our previous study.15 Briefly, plastic flasks (P-Flask) were precoated with $0.2 \%$ gelatin (Sigma, St. Louis, MO) at $37^{\circ} \mathrm{C}$ for $1 \mathrm{~h}$ and seeded with passage 3 SDSCs. After cells reached $90 \%$ confluence, 50mM L-ascorbic acid phosphate (Wako Chemicals USA Inc., Richmond, VA) was added for 8 days. The deposited ECM was incubated with $0.5 \%$ Triton $X-100$ containing $20 \mathrm{mM}$ ammonium hydroxide at $37^{\circ} \mathrm{C}$ for $5 \mathrm{~min}$ and stored at $4^{\circ} \mathrm{C}$ in phosphate-buffered saline containing $100 \mathrm{U} / \mathrm{mL}$ penicillin, $100 \mathrm{mg} / \mathrm{mL}$ streptomycin, and $0.25 \mathrm{mg} / \mathrm{mL}$ fungizone.

\section{SDSC expansion under different microenvironmental conditions}

Passage 3 SDSCs were plated at 3,000 cells/cm2 in P-Flask ("P") or ECM-coated flasks (SECM, "E") and incubated in hypoxia $\left(5 \% \mathrm{O}_{2}\right.$, "5") or normoxia $\left(21 \% \mathrm{O}_{2}\right.$, "21") in the complete medium with or without treatment of $10 \mathrm{ng} / \mathrm{mL}$ FGF-2 ("F") for one passage. There were eight pretreatments in SDSC expansion: "P-Flask+21\% $\mathrm{O}_{2}$ " (P21), "P-Flask+5\% $\mathrm{O}_{2}$ " (P5), "PFlask+FGF-2+21\% O $\mathrm{O}_{2}$ " (PF21), "P-Flask+FGF-2+5\% O $\mathrm{O}_{2}$ " (PF5), "S-ECM+21\% O ${ }_{2}$ " (E21), "SECM 5\% $\mathrm{O}_{2}$ " (E5), "S-ECM+FGF-2+21\% $\mathrm{O}_{2}$ " (EF21), and "SECM+FGF-2+5\% $\mathrm{O}_{2}$ " (EF5). During SDSC expansion, cell number was counted and morphology was photographed.

\section{Chondrogenic differentiation of SDSCs}


After in vitro expansion, $0.3 \times 10^{6}$ of SDSCs from each pretreatment were centrifuged at $500 \mathrm{~g}$ for $5 \mathrm{~min}$ in a $15-\mathrm{mL}$ polypropylene tube to form a pellet. After overnight incubation, the pellets were cultured in a serum-free chondrogenic medium consisting of high-glucose Dulbecco's modified Eagle's medium, $40 \mathrm{mg} / \mathrm{mL}$ proline, $100 \mathrm{nM}$ dexamethasone, $100 \mathrm{U} / \mathrm{mL}$ penicillin, $100 \mathrm{mg} / \mathrm{mL}$ streptomycin, $0.1 \mathrm{mM}$ ascorbic acid-2-phosphate, and $1 \mathrm{XITS}^{\mathrm{TM}}$ Premix $(6.25 \mathrm{mg} / \mathrm{mL}$ insulin, 6.25 $\mathrm{mg} / \mathrm{mL}$ transferrin, $6.25 \mathrm{mg} / \mathrm{mL}$ selenous acid, $5.35 \mathrm{mg} / \mathrm{mL}$ linoleic acid, and $1.25 \mathrm{mg} / \mathrm{mL}$ bovine serum albumin, from BD Biosciences, Bedford, MA) with the supplementation of $10 \mathrm{ng} / \mathrm{mL}$ transforming growth factor beta 3 (PeproTech Inc., Rocky Hill, NJ) for 14 days. At days 0,7 , and 14 , the pellets were collected for chondrogenic evaluation.

\section{Histochemistry and immunohistochemistry}

The pellets $(n=2)$ were fixed in $4 \%$ paraformaldehyde at $4^{\circ} \mathrm{C}$ overnight, followed by dehydrating in a gradient ethanol series, clearing with xylene, and embedding in paraffin blocks. About 5-mm sections were histochemically stained with Alcian blue (Sigma; counterstained with fast red) and Safranin O (Sigma; counterstained with hematoxylin) for sulfated glycosaminoglycans (GAG). For immunohistochemical analysis, the sections were immunolabeled with primary antibodies against collagen II (II-II6B3; DSHB, lowa City, IA), collagen I (Abcam, Cambridge, MA), and collagen X (Sigma), followed by the secondary antibody of biotinylated horse anti-mouse IgG (Vector, Burlingame, CA). Immunoactivity was detected using Vectastain $A B C$ reagent (Vector) with 3,30diaminobenzidine (DAB) as a substrate.

\section{Biochemical analysis for DNA and GAG content}

The pellets $(n=4)$ were digested for $4 \mathrm{~h}$ at $608 \mathrm{C}$ with $125 \mathrm{mg} / \mathrm{mL}$ papain in PBE buffer $(100 \mathrm{mM}$ phosphate and 10mM EDTA, pH 6.5) containing $10 \mathrm{mM}$ cysteine, by using $200 \mathrm{~mL}$ enzyme per sample. To quantify cell density, the amount of DNA in the papain digestion was measured using the QuantiT ${ }^{\mathrm{TM}}$ PicoGreen ${ }^{\circledR}$ dsDNA assay kit (Invitrogen) with a CytoFluor ${ }^{\circledR}$ Series 4000 (Applied Biosystems, Foster City, CA). GAG was measured using dimethylmethylene blue dye and a Spectronic $^{\mathrm{TM}}$ BioMate $^{\mathrm{TM}} 3$ Spectrophotometer (Thermo Scientific, Milford, MA) with bovine chondroitin sulfate (Sigma) as a standard.

\section{Real-time polymerase chain reaction}

Total RNA was extracted from samples $(n=4)$ using an RNase-free pestle in TRIzol ${ }^{\circledR}$ (Invitrogen). About $1 \mathrm{mgof}$ mRNA was used for reverse transcriptase with High-Capacity cDNA Archive Kit (Applied Biosystems) at $37^{\circ} \mathrm{C}$ for $120 \mathrm{~min}$. Chondrogenic marker genes [collagen II, aggrecan, and SRY (sex determining region Y)-box 9 (Sox9)] and hypertrophic marker genes (collagen $X$, alkaline phosphatase [ALP], and matrix metalloproteinase 13 [MMP13]) were customized by Applied Biosystems as part of the Custom TaqMan ${ }^{\circledR}$ Gene Expression Assays 
(Table 3.1). Eukaryotic 18S rRNA (Assay ID HS99999901_s1 ABI) was carried out as the endogenous control gene. Real-time polymerase chain reaction (PCR) was performed with the iCycler $\mathrm{iQ}^{\mathrm{TM}}$ Multi Color reverse transcriptase-PCR Detection and calculated by computer software (Perkin-Elmer, Wellesley, MA). Relative transcript levels were calculated as $\chi^{-{ }^{-C t}}$, in which $\Delta \Delta \mathrm{Ct}=\Delta \mathrm{E}-\Delta \mathrm{C}, \Delta \mathrm{E}=\mathrm{Ct}_{\mathrm{exp}}-\mathrm{Ct}_{18 \mathrm{~s}}$, and $\Delta \mathrm{C}=\mathrm{Ct}_{\mathrm{ct} 1}-\mathrm{Ct}_{18 \mathrm{~s}}$.

\section{Statistics}

The Mann-Whitney U-test was used for pairwise comparison in biochemistry analysis and realtime PCR data. All statistical analyses were performed with SPSS 13.0 statistical software (SPSS Inc., Chicago, IL). $\rho$-Values $<0.05$ were considered statistically significant. 


\section{RESULTS}

In vitro microenvironment to rejuvenate SDSC proliferation

After SDSCs reached confluence, ascorbic acid supplementation stimulated SDSCs to produce ECM in a 3D format. Three key components (S-ECM, hypoxia, and FGF-2) of the stem cell niche were evaluated for their roles in enhancing stem cell proliferation and maintaining stem cell unique morphology. Compared with flattened and irregular shapes (characteristic of aged cells) in the "P21" and "P5" groups, the expanded SDSCs had shorter and glistening shapes in the "PF21" and "PF5" groups, and longer and glistening fibroblast-like shapes in all ECM groups ("E21," "EF21," "E5," and "EF5"). Compared with the random arrangement of cells plated on PFlask, S-ECM-expanded cells were aligned with matrix fibers (Fig. 3.1).

To assess proliferation efficiency in various microenvironments, after a 6-day expansion, the cell number increased 2.39-fold in the "P5" group, 2.61-fold in the "P21" group, 6.90- fold in the "PF21" group, 12.50-fold in the "PF5" group, 34.52- fold in the "E21" group, 54.52-fold in the "EF21" group, 77.38-fold in the "E5" group, and 93.45-fold in the "EF5" group (Fig. 3.2A). Compared with SDSC expansion on P-Flask in normoxia, a hypoxic culture did not improve SDSC proliferation until combined with FGF-2 and/or S-ECM. In contrast, FGF-2 improved SDSC proliferation not only when combined with hypoxia and/or S-ECM but alsowhen applied alone in P-Flask culture. SDSC expansion on S-ECM acquired a higher cell number than the pretreatments with hypoxia and/or FGF-2. Intriguingly, the highest cell number was in the pretreated groups with S-ECM, hypoxia, and FGF-2. Despite the fact that the same cell number $\left(0.3 \times 10^{6}\right)$ was used to form a pellet followed by incubation in a serum-free chondrogenic medium, SDSC pellets from S-ECM pretreatments were initially smaller in size (not shown here) but became much bigger after a 14-day incubation compared with those from hypoxia or normoxia in P-Flask culture (Fig. 3.2B).

In vitro microenvironment to rejuvenate SDSCs for chondrogenic differentiation

To characterize the effects of various pretreatments on SDSC chondrogenesis, pellets from P4 SDSCs expanded on P-Flask or S-ECM under normxia or hypoxia with or without FGF-2 were induced in a serum-free chondrogenic medium for 14 days. Our histology data (Fig. 3.3) showed that P-Flask expansion yielded SDSC pellets with comparable sulfated GAGs, collagen I, and collagen II staining under normoxia (P21) and hypoxia (P5), mainly located in the peripheral regions of pellets. In contrast, other pretreatments with FGF-2 and/or S-ECM dramatically increased pellet size, sulfated GAGs, and collagen II intensity with homogenous distribution throughout the pellets under either normoxia (PF21) or hypoxia (PF5); on the contrary, collagen I was only detected at the edge of the pellets. Our data suggested that pretreatments with FGF-2 
and S-ECM were key components in the in vitro microenvironment for SDSC chondrogenic potential. Our data also suggested that pretreatment with low oxygen alone in P-Flask culture did not make a significant difference in SDSC chondrogenic potential.

Compared with a decrease in cell number (about 60\%) in the groups pretreated with P-Flask (P21 and P5), our DNA data (Fig. 3.4) showed that pretreatment with ECMs (E21, E5, EF21, and EF5) yielded SDSC pellets with a cell number around $86 \%$ at day 14 , which was comparable to those pretreated with FGF-2 under hypoxic condition (PF5), despite the fact that FGF-2 pretreatment (PF21) yielded pellets with increased cell number up to $124 \%$ after 14-day incubation with chondrogenic medium.

For the pretreated effect of oxygen tension on SDSC chondrogenic potential, our biochemical data (Fig. 3.4) showed that when SDSCs were plated on ECM, pretreatment with hypoxia (E5) yielded SDSC pellets with a higher chondrogenic index (GAG/DNA) than those from pretreatment with normoxia (E21). However, there was no significant difference in chondrogenic index from either pretreatment with hypoxia (P5) and normoxia (P21) when SDSCs were plated on P-Flask, or pretreatment with and without FGF-2 presence, regardless of culture on ECM (EF21 vs. EF5) or P-Flask (P21 vs. P5).

For the pretreated effect of FGF-2 on SDSC chondrogenic potential, our biochemical data (Fig. 3.4) showed that when SDSCs were plated on P-Flask, pretreatment with FGF-2 yielded SDSC pellets with a higher chondrogenic index than those cultured in basal medium alone, at either normoxic (PF21 vs. P21, p<0.001) or hypoxic conditions (PF5 vs. P5, p<0.001). When SDSCs were seeded on ECM, however, supplementation with FGF-2 yielded SDSC pellets with no significant difference in chondrogenic index from those cultured in the basal medium alone, regardless of normoxia (EF21 vs. E21) or hypoxia (EF5 vs. E5).

For the pretreated effect of ECM on SDSC chondrogenic potential, our biochemical data (Fig. 3.4) showed that ECM-treated SDSCs yielded pellets with much higher chondrogenic index than those from P-Flask-expanded SDSCs $(p<0.001)$ no matter if they were incubated in a normoxic or hypoxic incubator. Intriguingly, with supplementation of FGF-2, the chondrogenic index in ECMtreated SDSCs was not statistically different from that of P-Flask-expanded SDSCs, in either the normoxic (EF21 vs. PF21) or hypoxic condition (EF5 vs. PF5).

Our real-time PCR data (Fig. 3.5) were consistent with our biochemical data. There was no significant difference in chondrogenic marker gene levels (collagen II, aggrecan, and Sox9) between hypoxia and normoxia when the SDSCs were pretreated on either P-Flask (P5 vs. P21) 
or ECM (E5 vs. E21 or EF5 vs. EF21). With the supplementation of FGF-2 in P-Flasks, however, hypoxic pretreatment (PF5) yielded SDSC pellets with comparable aggrecan and Sox9 marker genes to all ECM groups. In contrast, normoxic pretreatment (PF21) yielded SDSC pellets with the highest aggrecan and Sox9 marker genes than the other groups as well as comparable collagen II marker level to the hypoxic group (PF5).

To identify if a higher chondrogenic index was associated with chondrocyte hypertrophy, real-time PCR (Fig. 3.6) was used to evaluate three hypertrophic marker genes (collagen X, ALP, and MMP13). Our finding was that pretreatment with ECM and FGF-2 yielded pellets with higher expression of collagen $X$ at day 0 ; these results were much closer after a 14- day incubation in a serum-free chondrogenic medium despite the highest expression level in FGF-2-expanded SDSCs. Pretreatment with FGF-2 yielded pellets with the highest ALP and MMP13 mRNA levels than the other pretreated groups, indicating that the supplementation of FGF-2 was associated with chondrogenic hypertrophy of expanded cells. Surprisingly, hypoxic pretreatment could decrease the hypertrophic marker gene level of FGF-2-expanded SDSCs (PF5 vs. PF21). 


\section{DISCUSSION}

The goal for stem cell research is to eventually provide differentiated products for regenerative medicine; thus, the promotion of stem cell self-renewal at the expense of differentiation is not an option. Considering the signals that govern the transition between self-renewal and differentiation programs being of utmost importance when designing defined stem cell culture and derivation formats, our study, for the first time, investigated three key components for the in vitro $3 \mathrm{D}$ microenvironment reconstruction: ECM (supporting 3D structure), hypoxia (environmental factor), and FGF-2 (growth modulating factor). We demonstrated that the in vitro microenvironment can be optimized by modulating oxygen tension and mitotic signal in a 3D ECM deposited by SDSCs to rejuvenate SDSC expansion and chondrogenic differentiation capacity. Our data indicated that, compared with the mitotic effect of FGF-2 on SDSCs, ECM expansion greatly enhanced SDSC proliferation while retaining SDSC stem cell morphology. More importantly, ECM pretreatment yielded SDSC pellets with a comparable chondrogenic index to FGF-2 pretreatment, both of which were closer to that from cartilage pellets $(50.43 \pm 1.22$, data not shown) and much higher than that in SDSCs expanded on P-Flask alone. FGF-2 pretreatment led to the highest GAG and DNA content; intriguingly, it also contributed to the highest expression level of hypertrophic marker genes. Surprisingly, the hypertrophic marker genes could be down-regulated if pretreatment was combined with hypoxia or ECM. The combination of hypoxia, FGF-2, and SECM contributed to the highest cell number in SDSC expansion.

Strategies for influencing MSC proliferation and differentiation are not yet well defined. ${ }^{17,18}$ Microenvironmental factors, such as FGF-2, ECM, and oxygen tension, largely contribute to the regulation of these MSCs. FGF-2 could maintain MSCs in an immature state during in vitro expansion and enhance MSC proliferation and differentiation potential ${ }^{2,19-22}$ through the regulation of mitogen-activated protein kinase (MAPK) and the canonical Wingless-type MMTV integration site family (Wnt) signaling. ${ }^{2}$ There is an increasing body of evidence demonstrating a role for the MAPK signaling cascade in the regulation of chondrogenic differentiation that requires exquisite temporal regulation of P38 and extracellular signal-regulated kinases (ERK1/2) phosphorylation. ${ }^{23-25}$ Wnts are a family of secreted proteins that play important roles in development, including chondrogenesis. Wnt pathways have been linked to the MAPK pathway in the regulation of chondrogenesis. ${ }^{26,27}$ Recently, Solchaga et al. found that eighty percent of the differentially expressed ECM-related genes were downregulated on MSCs expanded in the presence of FGF-2, suggesting the maintenance of the undifferentiated status of the cells by FGF-2 through the downregulation of genes that encode the specialized ECM components of differentiated tissues. ${ }^{2}$ Similarly, Ito et al. found that the overall insulin-like growth factor $I$ and transforming growth factor beta (differentiationrelated) signaling pathways were inactivated by 
FGF-2, suggesting that FGF-2 suppresses MSC senescence. ${ }^{28}$ FGF-2 was also found to promote MSC chondrogenic potential. ${ }^{29}$ However, the enhanced chondrogenic differentiation was accompanied by increased expression of hypertrophic marker genes, indicating that MSCs expanded in the presence of FGF-2 also acquired osteogenic differentiation capacity. ${ }^{29}$ Our findings corroborated the above studies. Although FGF-2 pretreatment greatly enhanced SDSC chondrogenic differentiation potential, the expanded SDSCs also exhibited the highest level of hypertrophic marker genes when incubated in a serum-free chondrogenic medium.

As an in vitro 3D structure, ECM was deposited by SDSCs, which appears to approximate native tissue more closely and presents a unique opportunity for in vitro studies of cell behavior under in vivo-like conditions. ${ }^{30,31}$ In 3D cultures, the steady-state level of ERK1/2 activity was enhanced when compared with that by $2 \mathrm{D}$ signaling. 30 This steady-state level may be responsible for ECMexpanded SDSCs acquiring a higher proliferation capacity with comparable chondrogenic potential because in the same way signaling through ERK1/2 pathway is required to shift embryonic stem cells from a program of self-renewal to one allowing for differentiation and lineage commitment. ${ }^{32}$ Our study also suggested that SDSC expansion in the presence of ECM combined with FGF-2 yielded more stem cells without compromised chondrogenic potential. This increase in cell proliferation may reflect the reciprocal interaction of ECM and FGF-2 in the body. In vivo, numerous growth factors and morphogens are immobilized by binding to the ECM through specific heparin-binding domains or by direct binding to ECM molecules such as collagen, or direct anchoring to cell membranes. ${ }^{33}$ Immobilization of growth factors in this manner can serve to increase local concentration of the protein by hindering diffusion and receptormediated endocytosis. Heparin sulfate-proteoglycans are required for functional FGF-FGF receptor binding and also act as reservoirs for local ligand availability, regulating diffusion, gradient formation, and degradation of FGFs as well as other morphogenetic proteins that have important roles to play in the development of musculoskeletal tissues. ${ }^{34-36}$ Surprisingly, the combined application of ECM decreased osteogenic potential of FGF-2-pretreated SDSCs though the underlying mechanism remains to be elucidated.

Hypoxia alters fundamental and physiologically important intracellular pathways and has long been recognized as a critical stimulus for chondrocyte development. ${ }^{37}$ Because MSCs are adapted to low oxygen in vivo, standard in vitro culture may be inherently stressful to these MSCs and appears to induce an oxidative stress response in these cells. However, MSCs expanded in low oxygen appeared to be adapted to the physiological environment, in which low oxygen selected a population of cells with faster proliferation potentials. ${ }^{5}$ Moreover, gene analysis revealed that a low oxygen condition affects specific regulatory pathways in MSCs, leading to the activation of several molecular and cellular events that favor the production of chondrogenic- 
specific ECM components. ${ }^{38}$ Induction of collagen II in hypoxia-expanded cells is attributed to enhanced chondrogenic ability. ${ }^{39}$ These data suggest that low oxygen tension is a key regulatory factor of proliferation, differentiation, and activity of chondrogenic cells. In our study, pretreatment with low oxygen alone did not show a role in SDSC expansion and subsequent chondrogenic differentiation; however, hypoxia pretreatment increased SDSC proliferation when combined with ECM and acquired the highest cell number when combined with ECM and FGF-2. More importantly, hypoxia decreased osteogenic potential of FGF-2-preteated SDSCs without compromising chondrogenic capacity, which is consistent with previous investigations. ${ }^{40-42}$ It was reported that expanded MSCs under low oxygen showed attenuated osteogenic responsiveness in vitro. ${ }^{40}$ Similarly, hypoxia has also recently been suggested to inhibit expression of type $X$ collagen, which is the major marker of chondrocyte hypertrophy, during the chondrogenesis of epiphyseal chondrocytes ${ }^{41}$ and of adipose-derived $\mathrm{MSCs},{ }^{42}$ thereby preventing the potential calcification of engineered cartilage. This result strongly suggested that hypoxia is a useful tool for cartilage tissue engineering.

The stress of in vitro culture could induce cell senescence. ${ }^{43}$ The causative role of oxidative stress in cell senescence has been confirmed by studies in which cells cultured under hyperoxia displayed accelerated onset of telomere-driven replicative senescence, ${ }^{44}$ whereas these treated with oxidants senesced prematurely in a telomere-independent manner. ${ }^{45}$ In contrast to fibroblasts and other somatic cells, the role of reactive oxygen species (ROS) in MSC growth and senescence remains elusive. Some indirect evidence showing the involvement of ROS in MSC proliferation is derived from studies on bone marrow and adipose tissue-derived cells, whose growth rate and replicative lifespan were markedly improved upon treatment with antioxidants. ${ }^{46,47}$ Other studies have shown that significant MSC growth prolongation may also be achieved in cells cultured under reduced oxygen pressure, ${ }^{48}$ which may be attributed to overexpression of genes favoring MSC proliferation. ${ }^{49}$ Recently, MSCs cultured on this ECM showed remarkable promotion of proliferation and retention of stem cell population with a lower level of ROS and higher level of telomerase activity when compared with those cultured on uncoated PFlask. ${ }^{50}$ However, a high level of ROS was reported to be associated with a loss of stem cell characteristics and increased differentiation and apoptosis. ${ }^{51}$ Therefore, the ability of hypoxia and ECM to suppress ROS may contribute to the retention of stem cell characteristics.

Taken together, FGF-2, low oxygen, and ECM may play a key role in reconstituting an in vitro tissue-specific microenvironment. To provide large-scale and high-quality stemcells for cartilage tissue engineering and regeneration, the potential mechanisms underlying the $3 D$ microenvironment for expansion and reprogramming of SDSCs toward chondrogenic differentiation need to be elucidated. The functionality of tissue constructs engineered using 
microenvironment-expanded stem cells needs to be further evaluated for mechanical properties. Inaddition, bonemarrowstromal cells also deserve to be compared with SDSCs for the difference in tissue-specific induction after expansion in such a 3D microenvironment. 


\section{ACKNOWLEDGMENTS}

We thank Suzanne Smith for editing the article and Fan He for conducting real-time PCR. 


\section{REFERENCES}

1. Lee, C.R., Grodzinsky, A.J., Hsu, H.P., Martin, S.D., and Spector, M. Effects of harvest and selected cartilage repair procedures on the physical and biochemical properties of articular cartilage in the canine knee. J Orthop Res 18, 790, 2000.

2. Solchaga, L.A., Penick, K., Porter, J.D., Goldberg, V.M., Caplan, A.I., and Welter, J.F. FGF-2 enhances the mitotic and chondrogenic potentials of human adult bone marrow-derived mesenchymal stem cells. J Cell Physiol 203, 398, 2005.

3. Lin, Q., Kim, Y., Alarcon, R.M., and Yun, Z. Oxygen and cell fate decisions. Gene Regul Syst Biol 2, 43, 2008.

4. D'Ippolito, G., Diabira, S., Howard, G.A., Roos, B.A., and Schiller, P.C. Low oxygen tension inhibits osteogenic differentiation and enhances stemness of human MIAMI cells. Bone 39, 513, 2006.

5. Grayson, W.L., Zhao, F., Izadpanah, R., Bunnell, B., and Ma, T. Effects of hypoxia on human mesenchymal stem cell expansion and plasticity in 3D constructs. J Cell Physiol 207, 331, 2006.

6. Grayson, W.L., Zhao, F., Bunnell, B., and Ma, T. Hypoxia enhances proliferation and tissue formation of human mesenchymal stem cells. Biochem Biophys Res Commun 358, 948, 2007.

7. Martin-Rendon, E., Hale, S.J., Ryan, D., Baban, D., Forde, S.P., Roubelakis, M., Sweeney, D., Moukayed, M., Harris, A.L., Davies, K., and Watt, S.M. Transcriptional profiling of human cord blood CD133p and cultured bone marrow mesenchymal stem cells in response to hypoxia. Stem cells 25, 1003, 2007.

8. Dickhut, A., Pelttari, K., Janicki, P., Wagner, W., Eckstein, V., Egermann, M., and Richter, W. Calcification or dedifferentiation: requirement to lock mesenchymal stem cells in a desired differentiation stage. J Cell Physiol 219, 219, 2009.

9. Mochizuki, T., Muneta, T., Sakaguchi, Y., Nimura, A., Yokoyama, A., Koga, H., and Sekiya, I. Higher chondrogenic potential of fibrous synovium- and adipose synovium-derived cells compared with subcutaneous fat-derived cells: distinguishing properties of mesenchymal stem cells in humans. Arthritis Rheum 54, 843, 2006.

10. Sakaguchi, Y., Sekiya, I., Yagishita, K., and Muneta, T. Comparison of human stem cells derived from various mesenchymal tissues: superiority of synovium as a cell source. Arthritis Rheum 52, 2521, 2005.

11. Segawa, Y., Muneta, T., Makino, H., Nimura, A., Mochizuki, T., Ju, Y.J., Ezura, Y., Umezawa, A., and Sekiya, I. Mesenchymal stem cells derived from synovium, meniscus, anterior cruciate ligament, and articular chondrocytes share similar gene expression profiles. J Orthop Res 27, 435, 2009.

12. Pei, M., He, F., and Vunjak-Novakovic, G. Synovium-derived stem cell-based chondrogenesis. Differentiation 76, 1044, 2008. 
13. Pei, M., He, F., Kish, V.L., and Vunjak-Novakovic, G. Engineering of functional cartilage tissue using stem cells from synovial lining: a preliminary study. Clin Orthop Relat Res 466, 1880, 2008.

14. Pei, M., He, F., Boyce, B.M., and Kish, V.L. Repair of full-thickness femoral condyle cartilage defects using allogeneic synovial cell-engineered tissue constructs. Osteoarthritis Cartilage 17, 714, 2009.

15. He, F., Chen, X., and Pei, M. Reconstruction of an in vitro tissue-specific microenvironment to rejuvenate synovium-derived stem cells for cartilage tissue engineering. Tissue Eng Part A 15, 3809, 2009.

16. Schipani, E., Ryan, H.E., Didrickson, S., Kobayashi, T., Knight, M., and Johnson, R.S. Hypoxia in cartilage: HIF- 1alpha is essential for chondrocyte growth arrest and survival. Genes Dev 15, 2865, 2001.

17. Barry, F.P., and Murphy, J.M. Mesenchymal stem cells: clinical applications and biological characterization. Int J Biochem Cell Biol 36, 568, 2004.

18. Caplan, A.I. Review: mesenchymal stem cells: cell-based reconstructive therapy in orthopedics. Tissue Eng 11, 1198, 2005.

19. Martin, I., Muraglia, A., Campanile, G., Cancedda, R., and Quarto, R. Fibroblast growth factor-2 supports ex vivo expansion and maintenance of osteogenic precursors from human bone marrow. Endocrinology 138, 4456, 1997.

20. Mastrogiacomo, M., Cancedda, R., and Quarto, R. Effect of different growth factors on the chondrogenic potential of human bone marrow stromal cells. Osteoarthritis Cartilage 9 Suppl A, S36, 2001.

21. Tsutsumi, S., Shimazu, A., Miyazaki, K., Pan, H., Koike, C., Yoshida, E., Takagishi, K., and Kato, Y. Retention of multi- lineage differentiation potential of mesenchymal cells during proliferation in response to FGF. Biochem Biophys Res Commun 288, 413, 2001.

22. Bianchi, G., Banfi, A., Mastrogiacomo, M., Notaro, R., Luzzatto, L., Cancedda, R., and Quarto, R. Ex vivo enrichment of mesenchymal cell progenitors by fibroblast growth factor 2. Exp Cell Res 287, 98, 2003.

23. Hoffman, L.M., Weston, A.D., and Underhill, T.M. Molecular mechanisms regulating chondroblast differentiation. J Bone Joint Surg 85, 124, 2003.

24. Seghatoleslami, M.R., Roman-Blas, J.A., Rainville, A.M., Modaressi, R., Danielson, K.G., and Tuan, R.S. Progression of chondrogenesis in $\mathrm{C} 3 \mathrm{H} 10 \mathrm{~T} 1 / 2$ cells is associated with prolonged and tight regulation of ERK1/2. J Cell Biochem 88, 1129, 2003.

25. Stanton, L.A., Underhill, T.M., and Beier, F. MAP kinases in chondrocyte differentiation. Dev Biol 263, 165, 2003. 
26. Tufan, A.C., Daumer, K.M., and Tuan, R.S. Frizzled-7 and limb mesenchymal chondrogenesis: effect of misexpression and involvement of N-cadherin. Dev Dyn 223, 241, 2002.

27. Tuli, R., Tuli, S., Nandi, S., Huang, X., Manner, P.A., Hozack, W.J., Danielson, K.G., Hall, D.J., and Tuan, R.S. Transforming growth factor-beta-mediated chondrogenesis of human mesenchymal progenitor cells involves $\mathrm{N}$-cadherin and mitogen-activated protein kinase and Wnt signaling crosstalk. J Biol Chem 278, 41227, 2003.

28. Ito, T., Sawada, R., Fujiwara, Y., Seyama, Y., and Tsuchiya, T. FGF-2 suppresses cellular senescence of human mesenchymal stem cells by down-regulation of TGF-beta2. Biochem Biophys Res Commun 359, 108, 2007.

29. Ito, T., Sawada, R., Fujiwara, Y., and Tsuchiya, T. FGF-2 increases osteogenic and chondrogenic differentiation potentials of human mesenchymal stem cells by inactivation of TGFbeta signaling. Cytotechnology 56, 1, 2008.

30. Cukierman, E., Pankov, R., Stevens, D.R., and Yamada, K.M. Taking cell-matrix adhesions to the third dimension. Science 294, 1708, 2001.

31. Ahlfors, J.E., and Billiar, K.L. Biomechanical and biochemical characteristics of a human fibroblast-produced and remodeled matrix. Biomaterials 28, 2183, 2007.

32. Kunath, T., Saba-El-Leil, M.K., Almousailleakh, M., Wray, J., Meloche, S., and Smith, A. FGF stimulation of the Erk1/2 signalling cascade triggers transition of pluripotent embryonic stem cells from self-renewal to lineage commitment. Development 134, 2895, 2007.

33. Rider, C.C. Heparin/heparan sulphate binding in the TGF- beta cytokine superfamily. Biochem Soc Trans 34, 458, 2006.

34. Couchman,J.R. Syndecans:proteoglycan regulators of cell-surface microdomains? Nat Rev Mol Cell Biol 4, 926, 2003.

35. Bernfield, M., Gotte, M., Park, P.W., Reizes, O., Fitzgerald, M.L., Lincecum, J., and Zako, M. Functions of cell surface heparan sulfate proteoglycans. Annu Rev Biochem 68, 729, 1999.

36. Farach-Carson, M.C., Hecht, J.T., and Carson, D.D. Heparan sulfate proteoglycans: key players in cartilage biology. Crit Rev Eukaryot Gene Expr 15, 29, 2005.

37. Danet, G.H., Pan, Y., Luongo, J.L., Bonnet, D.A., and Simon, M.C. Expansion of human SCID-repopulating cells under hypoxic conditions. J Clin Invest 112, 126, 2003.

38. Wang, D.W., Fermor, B., Gimble, J.M., Awad, H.A., and Guilak, F. Influence of oxygen on the proliferation and metabolism of adipose derived adult stem cells. J Cell Physiol 204, 184, 2005.

39. Estes, B.T., Wu, A.W., and Guilak, F. Potent induction of chondrocytic differentiation of human adipose-derived adult stem cells by bone morphogenetic protein 6 . Arthritis Rheum 54 , 1222, 2006. 
40. Xu, Y., Malladi, P., Chiou, M., Bekerman, E., Giaccia, A.J., and Longaker, M.T. In vitro expansion of adipose-derived adult stromal cells in hypoxia enhances early chondrogenesis. Tissue Eng 13, 2981, 2007.

41. Chen, X.C., Wang, R., Zhao, X., Wei, Y.Q., Hu, M., Wang, Y.S., Zhang, X.W., Zhang, R., Zhang, L., Yao, B., Wang, L., Jia, Y.Q., Zeng, T.T., Yang, J.L., Tian, L., Kan, B., Lin, X.J., Lei, S., Deng, H.X., Wen, Y.J., Mao, Y.Q., and Li, J. Prophylaxis against carcinogenesis in three kinds of unestablished tumor models via IL12-gene-engineered MSCs. Carcinogenesis 27, 2434, 2006.

42. Betre, H., Ong, S.R., Guilak, F., Chilkoti, A., Fermor, B., and Setton, L.A. Chondrocytic differentiation of human adiposederived adult stem cells in elastin-like polypeptide. Biomaterials 27, 91, 2006.

43. Ito, K., Hirao, A., Arai, F., Matsuoka, S., Takubo, K., Hamaguchi, I., Nomiyama, K., Hosokawa, K., Sakurada, K., Nakagata, N., Ikeda, Y., Mak, T.W., and Suda, T. Regulation of oxidative stress by ATM is required for self-renewal of haematopoietic stem cells. Nature 431, 997, 2004.

44. von Zglinicki, T., Saretzki, G., Docke, W., and Lotze, C. Mild hyperoxia shortens telomeres and inhibits proliferation of fibroblasts: a model for senescence? Exp Cell Res 220, 186, 1995.

45. Chen, Q.M., Prowse, K.R., Tu, V.C., Purdom, S., and Linskens, M.H. Uncoupling the senescent phenotype from telomere shortening in hydrogen peroxide-treated fibroblasts. Exp Cell Res 265, 294, 2001.

46. Choi, K.M., Seo, Y.K., Yoon, H.H., Song, K.Y., Kwon, S.Y., Lee, H.S., and Park, J.K. Effect of ascorbic acid on bone marrow-derived mesenchymal stem cell proliferation and differentiation. $J$ Biosci Bioeng 105, 586, 2008.

47. Lin, T.M., Tsai, J.L., Lin, S.D., Lai, C.S., and Chang, C.C. Accelerated growth and prolonged lifespan of adipose tissue-derived human mesenchymal stem cells in a medium using reduced calcium and antioxidants. Stem Cells Dev 14, 92, 2005.

48. Li, H.S., Chen, J.W., and Zhu, L.L. Continuous hypoxia improves the proliferation of human bone marrow-derived mesenchymal stem cells in vitro. BasicMed Sci Clin 25, 268, 2005.

49. Ohnishi, S., Yasuda, T., Kitamura, S., and Nagaya, N. Effect of hypoxia on gene expression of bone marrow-derived mesenchymal stem cells and mononuclear cells. Stem Cells 25, 1166, 2007.

50. Lai, Y., Sun, Y., Skinner, C.M., Son, E.L., Lu, Z., Tuan, R., Jilka, R.L., Ling, J., and Chen, X.D. Reconstitution of marrow-derived extracellular matrix ex vivo: a robust culture system for expanding large-scale highly functional human mesenchymal stem cells. Stem Cells Dev 19, 1095, 2010.

51. Tothova, Z., Kollipara, R., Huntly, B.J., Lee, B.H., Castrillon, D.H., Cullen, D.E., McDowell, E.P., Lazo-Kallanian, S., Williams, I.R., Sears, C., Armstrong, S.A., Passegue, E., DePinho, R.A., 
and Gilliland, D.G. FoxOs are critical mediators of hematopoietic stem cell resistance to physiologic oxidative stress. Cell 128, 325, 2007. 


\section{FIGURE LEGENDS}

Figure 3.1 SDSC morphology in preparation of ECM (before and after the supplementation of ascorbic acid $[\mathrm{AA}]$ ) and after plating on S-ECM ("E") or plastic flasks (P-Flask, "P") and incubated in hypoxia $\left(5 \% \mathrm{O}_{2}\right.$, "5") or normoxia $\left(21 \% \mathrm{O}_{2}\right.$, "21") with or without $10 \mathrm{ng} / \mathrm{mL}$ of fibroblast growth factor-2 for 5 days. SDSC, synovium-derived stem cell; S-ECM, SDSC-derived extracellular matrix.

Figure 3.2 After 6-day plating with initial cell number as $0.53 \times 10^{6}$ in one $175 \mathrm{~cm}^{2}$ flask, the expanded SDSCs under different pretreatments were counted for cell number $(A)$ followed by a 14-day incubation of SDSC pellets in a serum-free chondrogenic medium (B).

Figure 3.3 Histology and immunohistochemistry of SDSC pellets after 7-day and 14-day chondrogenic induction in a serum-free chondrogenic mediu. Safranin-O (SO) and Alcian blue (AB) were used to detect collagen I (Col I) and collagen II (Col II). The scale bar is $800 \mu \mathrm{m}$. GAG, glycosaminoglycans.

Figure 3.4 Biochemical analysis for DNA and GAG contents in SDSC pellets after 14-day chondrogenic induction in a serum-free chondrogenic medium. Cell proliferation was shown as DNA content adjusted by that at day 0 . The ratio of GAG to DNA was used to represent chondrogenic index. Data are shown as average $\pm S D$ for $n=4 . S D$, standard deviation.

Figure 3.5 TaqMan real-time polymerase chain reaction for evaluation of chondrogenic marker genes (Col II, aggrecan, and Sox9) in SDSC pellets after 14-day chondrogenic induction. 18S RNA was used as an internal control. The mRNA level in SDSC pellets at day 0 from P21 was set as 1 . Data are shown as average $\pm S D$ for $n=4$.

Figure 3.6 TaqMan real-time polymerase chain reaction for evaluation of hypertrophic marker genes (Col X, ALP, and MMP-13) in SDSC pellets after 14-day chondrogenic induction. 18S RNA was used as an internal control. The mRNA level in SDSC pellets at day 0 from P21 was set as 1 . Data are shown as average $\pm S D$ for $n=4$. ALP, alkaline phosphatase; MMP, matrix metalloproteinase. 
Table 3.1 TaqMan-customized porcine marker gene primers and probes

\begin{tabular}{|c|c|c|c|}
\hline Name & Primer/probe & Sequence (5'-3') & Gene ID \\
\hline \multicolumn{4}{|c|}{ Chondrogenic markers } \\
\hline \multirow[t]{3}{*}{ Collagen II $\alpha 1$} & Forward & TCCTGGCCTCGTGGGT & 397323 \\
\hline & Reverse & GGGATCCGGGAGAGCCA & \\
\hline & Probe & CTCCCCTGGGAAACC & \\
\hline \multirow[t]{3}{*}{ Aggrecan } & Forward & GCCACTGTTACCGCCACTT & 397255 \\
\hline & Reverse & CACTGGCTCTCTGCATCCA & \\
\hline & Probe & CTGACCGGGCGACCTG & \\
\hline \multirow[t]{3}{*}{ Sox9 } & Forward & TGGCAAGGCTGACCTGAAG & 396840 \\
\hline & Reverse & GCTCAGCTCGCCGATGT & \\
\hline & Probe & CCCCATCGACTTCCGC & \\
\hline \multicolumn{4}{|c|}{ Hypertrophic markers } \\
\hline \multirow[t]{3}{*}{ Collagen $\mathrm{X} \alpha 1$} & Forward & GGCCCGGCAGGTCATC & 448809 \\
\hline & Reverse & TGGGATGCCTTTTGGTCCTT & \\
\hline & Probe & TCAGACCTGGTTCCCC & \\
\hline \multirow[t]{3}{*}{$\overline{A L P}$} & Forward & CCCTTCACTGCCATCCTGTAC & 100170147 \\
\hline & Reverse & CCATGGAGACGTTCTCTCTCTCA & \\
\hline & Probe & ACGGCCCTGGCTACAA & \\
\hline \multirow[t]{3}{*}{ MMP13 } & Forward & AGTTTGGCCATTCCTTAGGTCTTG & 397346 \\
\hline & Reverse & GGCTTTTGCCAGTGTAGGTATAGAT & \\
\hline & Probe & ACCACTCCAAGGACCC & \\
\hline
\end{tabular}


Figure 3.1
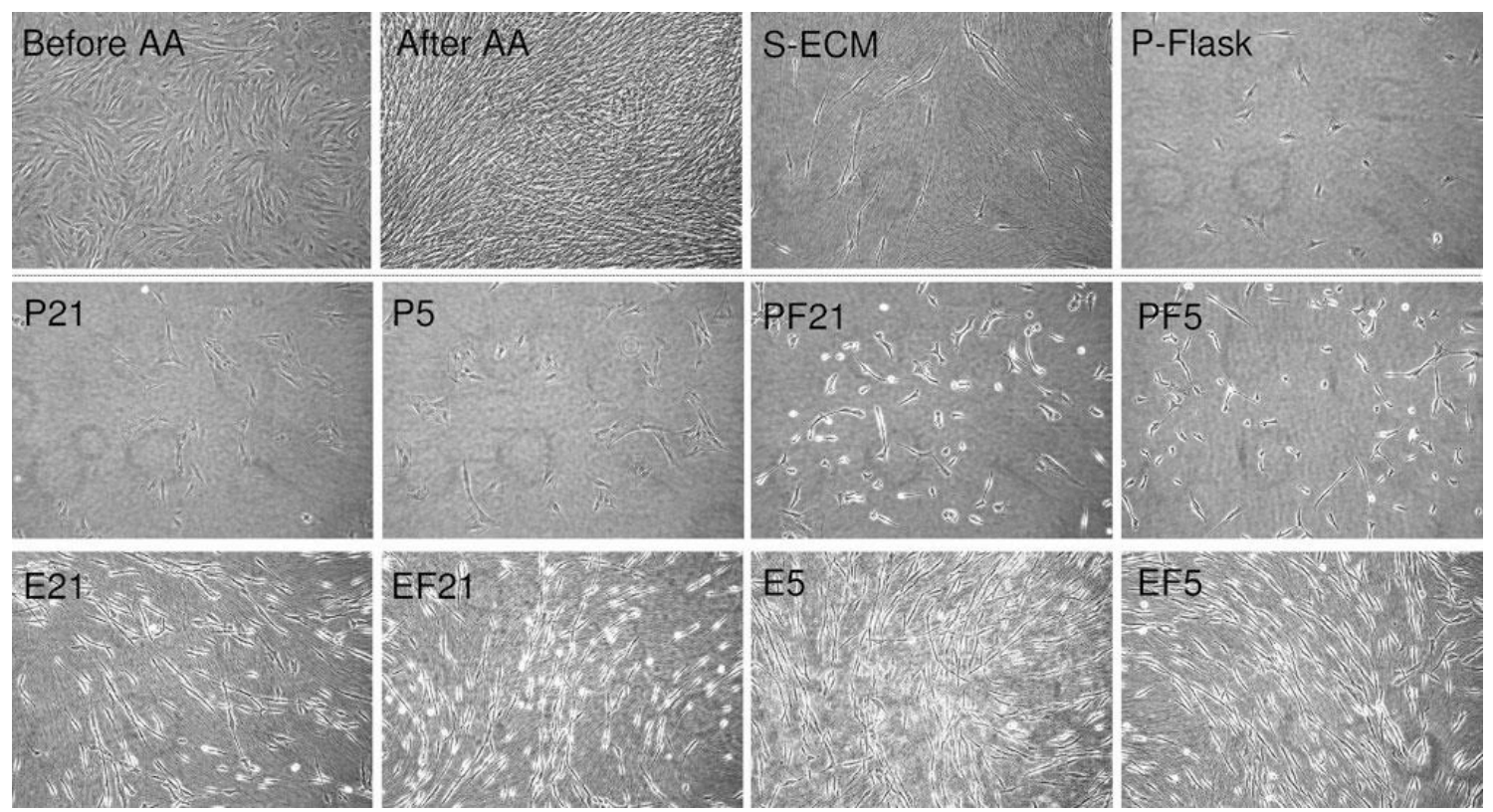
Figure 3.2

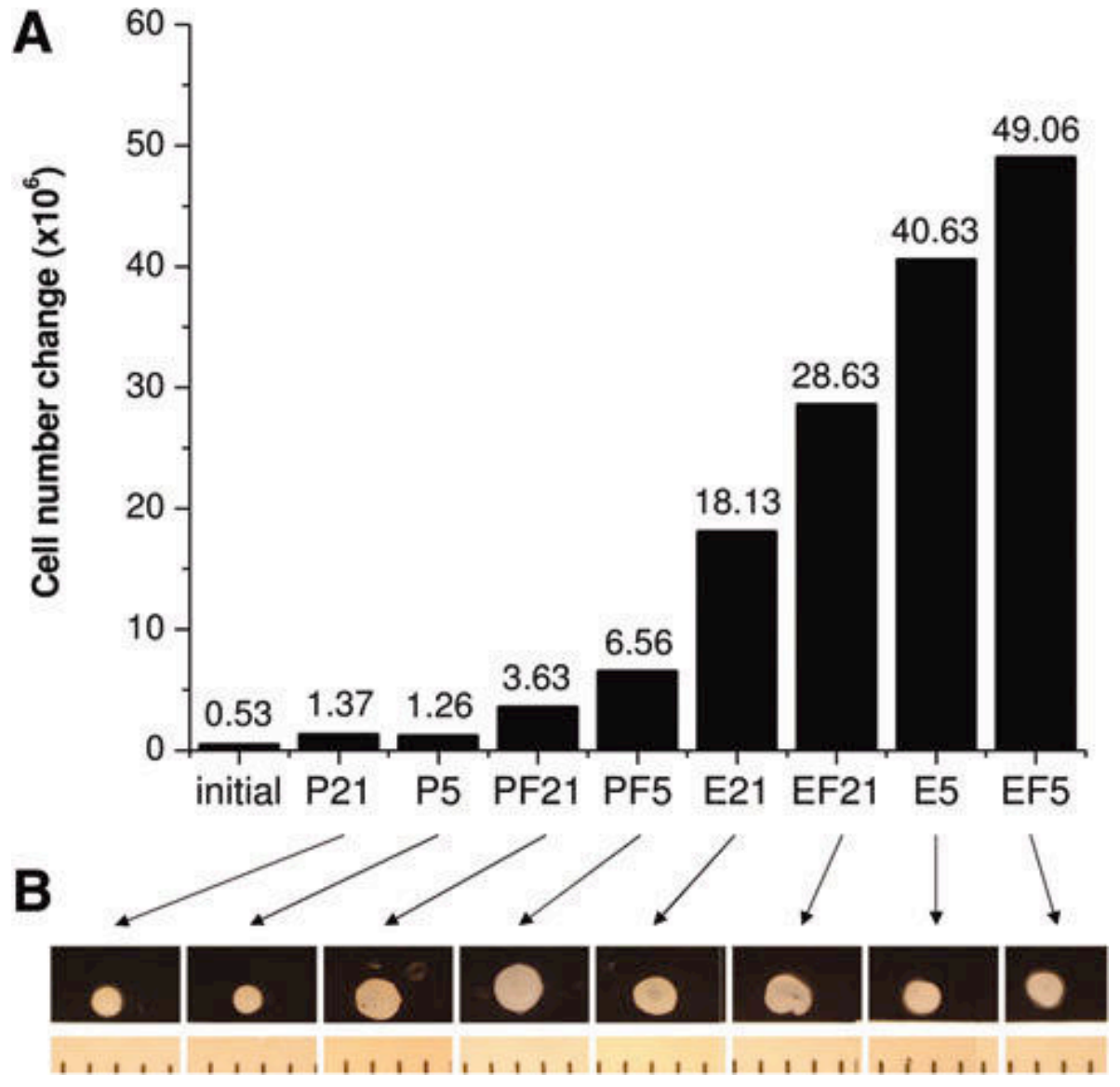


Figure 3.3

P21

P5

PF21

$$
\text { PF5 }
$$

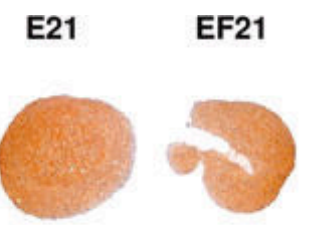

E5

EF5

GAG

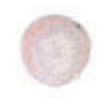

(5)
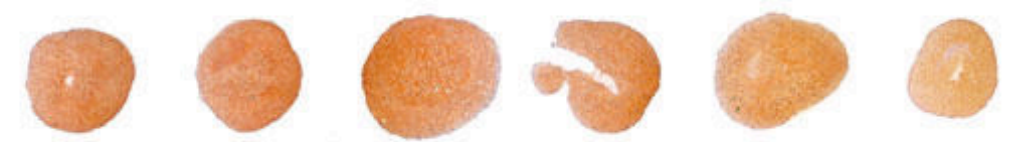

GAG

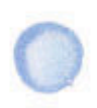

(2)
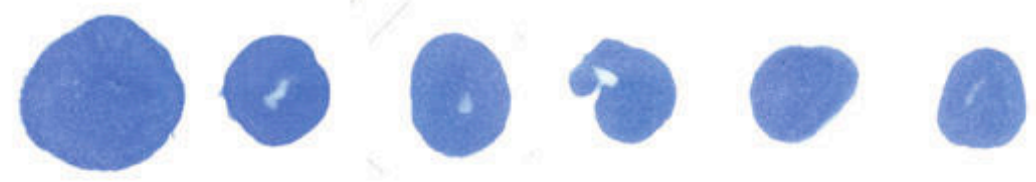

Col II
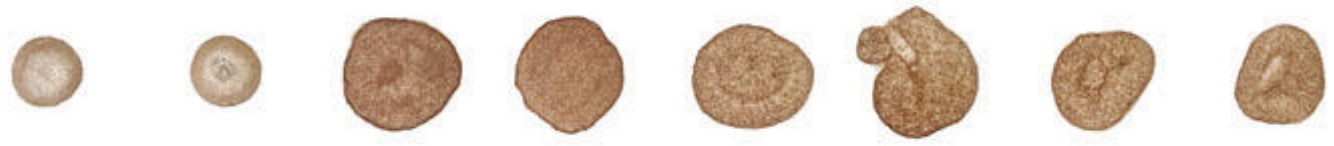

Coll
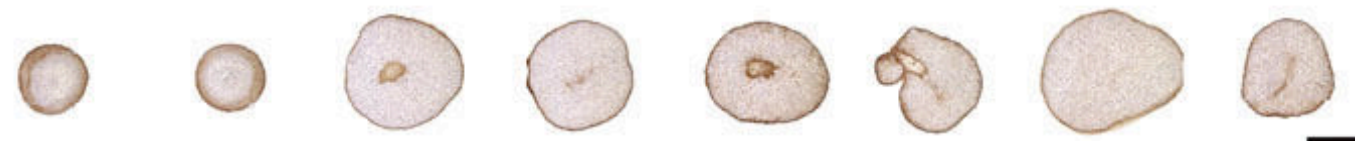
Figure 3.4
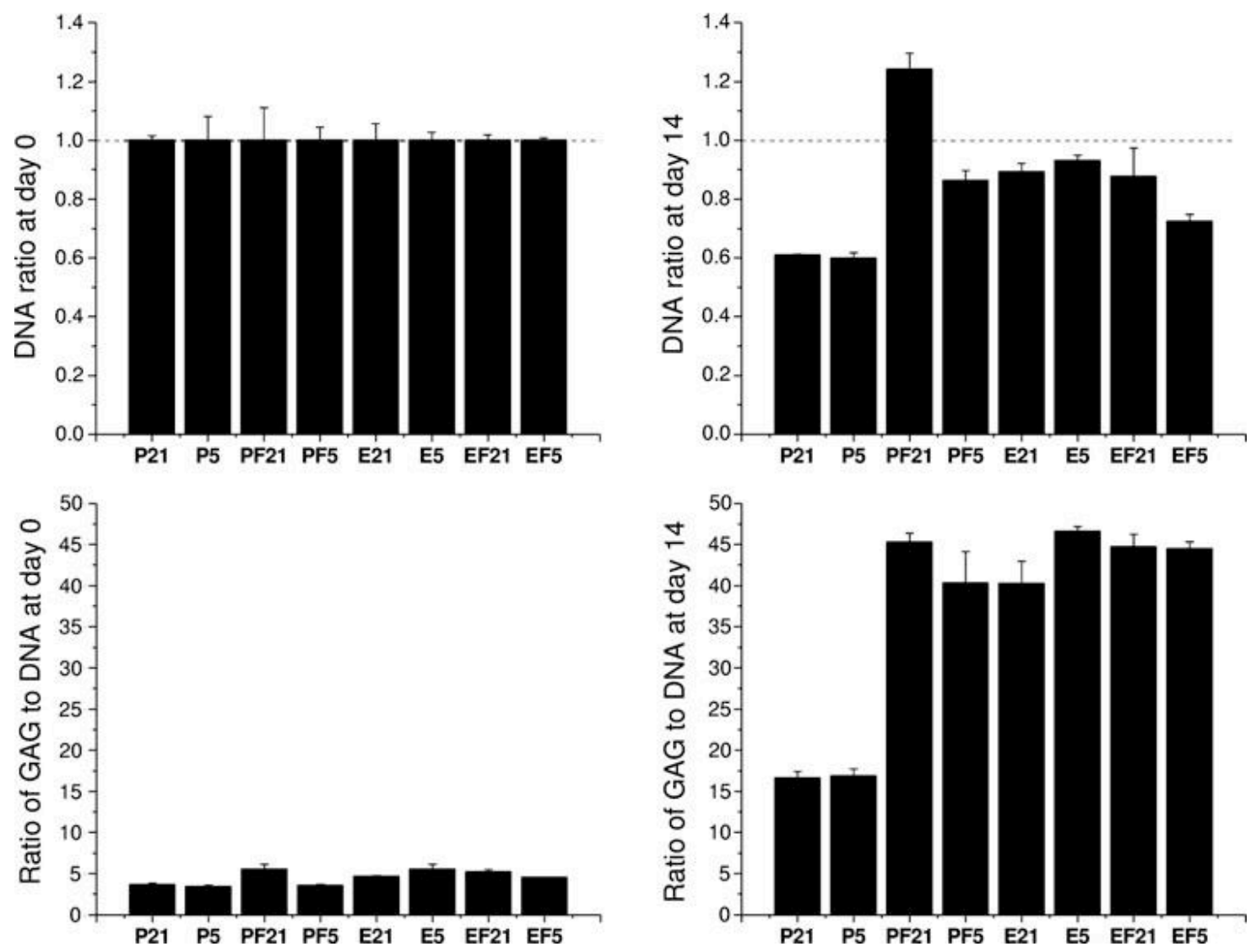
Figure 3.5
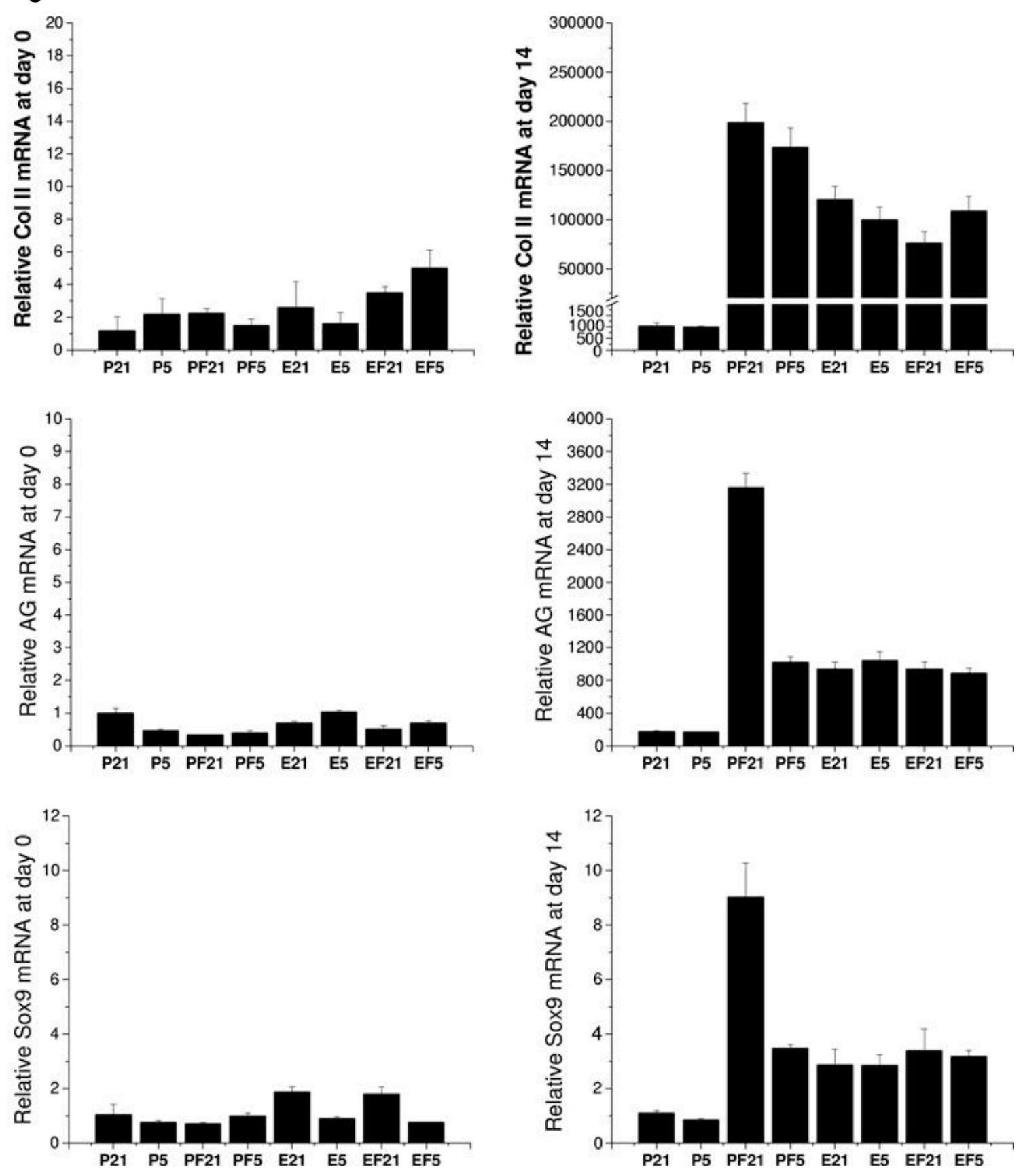
Figure 3.6
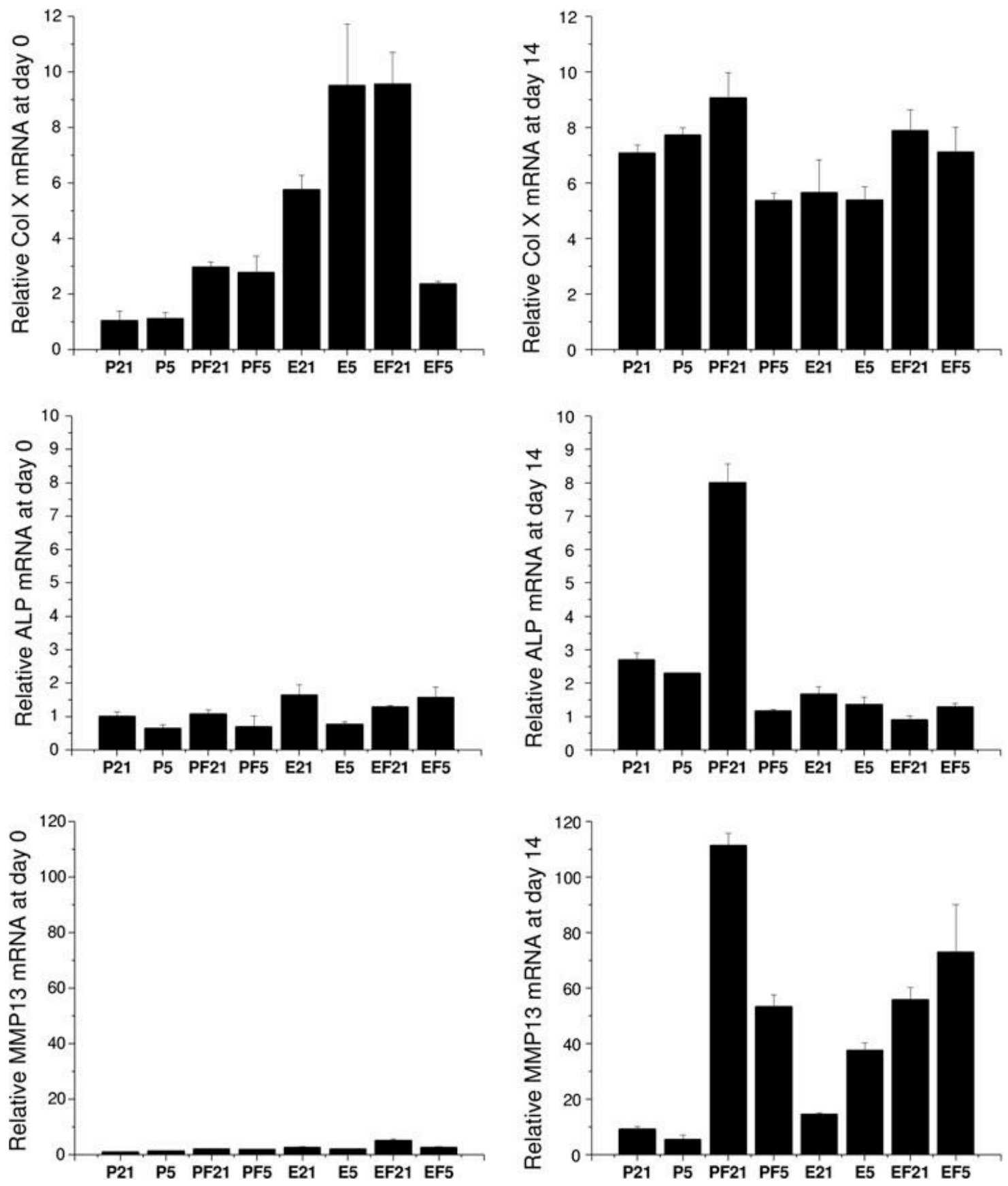
CHAPTER 4: PROBING THE ROLE OF DECELLULARIZED MATRIX FOR ENHANCING HUMAN SYNOVIUM-DERIVED STEM CELL CHONDROGENESIS

Jingting Li, M.S., and Ming Pei, M.D., Ph.D.

Tissue Engineering Laboratory, Department of Orthopaedics, and Division of Exercise Physiology, West Virginia University, Morgantown, WV 26506

Key words: human synovium derived stem cells, decellularized matrix, chondrogenesis, 


\begin{abstract}
Application of cell-based therapy in cartilage defect repair remains challenging due to the shortage of autologous chondrocytes and limited regenerative capacity of cartilage. Alternative cell source such as synovium-derived stem cell (SDSC) has been characterized as tissue-specific stem cell for chondrogenesis. Decellularized extracellular matrix (DECM) deposited by SDSCs served as ex vivo expansion system for maintaining stemness and enhancing chondrogenic potential. However, whether other potential and more accessible cell deposited DECMs could also provide an ex vivo microenvironment as human SDSC-derived DECM (SE) is not known. In this study, we found that human adipose-, urine-derived stem cell and dermal fibroblast deposited DECMs (AE, UE and DE) could also serve as ex vivo expansion system for promoting SDSC proliferation and chondrogenic potential. Compared to the plastic flask $(\mathrm{PL})$ expansion, all DECMexpanded SDSCs yield higher cell number and proliferation index. The highest cell number and proliferation index were obtained in UE, followed by $A E, D E, S E$ and PL. The expansion on $A E$, UE, and DE resulted the SDSCs with an elongated and less spread cell shape than SDSCs on SE and PL analyzed by scanning electron microscopy. The significantly lower elasticity was observed in SDSC expanded on DECMs than SDSCs on PL accordingly, which is consistent with the elasticity measurement of DECMs (DE>SE>AE>UE). Despite a robust and enhanced chondrogenesis was also observed in DECM-expanded SDSCs pellets compared to $\mathrm{PL}$ expanded cells, AE, DE and UE pretreated SDSCs yielded pellets exhibited the larger size, higher DNA content and chondrogenic index (GAG/DNA), and higher level of chondrogenic marker genes expression than SE-expanded pellets. Histological staining and immunostaining for sulfated GAGs, collagens I and II were consistent with the biochemistry and real-time PCR data. However, the higher hypertrophic marker gene expression is also observed in DE-expanded SDSC pellets, which could be explained by the higher stiffness of DE. There was no concomitant enhancement of osteogenic and adipogenic potential of DECM-pretreated SDSCs. In conclusion, the DECM deposited by the adipose, skin and urine-derived cells can serve as ex vivo expansion substrates, enhancing the maintenance of the embedded SDSCs and rejuvenate them with higher chondrogenic potential. Although the mechanisms underlying the greatest chondrogenic potential in SDSCs expanded on $A E, D E$ and UE are under further investigated, the potential application of these easily accessible sources would provide great opportunity for repairing cartilage defects in patients with autologous cells.
\end{abstract}




\section{INTRODUCTION}

Adult articular cartilage exhibits little capacity for intrinsic repair. Injury and joint degeneration resulted minor lesions may lead to progressive damage, causing significant pain and disability. The successful repair of articular cartilage defects is a major clinical challenge. There have been numerous attempts to develop tissue-engineered grafts or patches to repair focal chondral and osteochondral defects. Cell-based therapy remains the most promising for articular cartilage repair. However, with the practical clinical limitations (donor morbidity, shortage of healthy donors) surrounding the use of autologous chondrocytes, the cartilage engineering filed rapidly move towards other progenitor cell sources.

Mesenchymal stem cells (MSCs) were firstly isolated from bone marrow by Johnstone and Pittenger ${ }^{1 ; 2}$ and widely applied in tissue engineering since then. Other than bone marrow, MSCs has also been identified in adipose ${ }^{3}$ skeletal muscle ${ }^{4}$ and other tissues. ${ }^{5}$ In determining the optimal source of cells for cartilage repair, the two primary criteria that are generally considered are the performance of the cells and their ease of access. MSCs from different sources suggested their tissue-specificity. Synovium-derived stem cells (SDSCs) has been suggested as a tissue-specific stem cell for chondrogenesis. ${ }^{6}$ Low yield and high donor morbidity makes bone marrow-derived stem cells (BMSCs) less abundant and accessible than adipose-derived stem cells (ASCs). Recently, urine-derived stem cells (USCs) have been demonstrated to express MSC surface markers and possess multi-lineage differentiation potentials. ${ }^{7}$ Dermal fibroblasts (DFs) from skin was also reported to acquire multi-lineage differentiation potentials. ${ }^{8}$ Thus, the skin, adipose, urine derived MSCs constitutes promising cell source in clinical applications.

Dedifferentiation of chondrocytes due to traditional two-dimensional cell culture and cell senescence due to repeated passaging and elderly donor bring challenge for large-scale ex vivo expansion. ${ }^{9 ; 10}$ Potential genetic modification, biomaterial scaffolds and growth factors have been investigated to improve the efficiency. ${ }^{11}$ Our previous studies indicated that decellularized extracellular matrix (DECM) deposited by SDSCs can serve as an in vitro three-dimensional expansion system, greatly enhancing SDSC propagation and facilitating restoration of stem cell stemness toward chondrogenesis. ${ }^{12 ; 13}$ However, whether MSCs derived from easily accessible sources such as skin, adipose or urine can be used to deposit DECMs and served as microenvironment for maintaining or promoting SDSC stemness is not known.

In this study, we intended to investigate whether DECMs from the more accessible human cell sources, including ASCs, USCs and DFs, can serve as in vitro microenvironment for stem cell expansion while promoting chondrogenic potential. 


\section{MATERIALS AND METHODS}

\section{Preparation of DECMs}

Adult human synovium-derived stem cells (SDSCs), adipose-derived stem cells (ASCs) and dermal fibroblasts (DFs) purchased from ZenBio Inc., Research Triangle Park, NC and human urine-derived stem cells (USCs), a generous gift from Dr. Yuanyuan Zhang, Wake Forest Institute for Regenerative Medicine, were used to prepare DECMs. Methods for preparing these DECMs were described in our previous study. ${ }^{10}$ Briefly, plastic flasks were pre-coated with $0.2 \%$ gelatin (Sigma, St. Louis, MO) at $37^{\circ} \mathrm{C}$ for $1 \mathrm{~h}$ and seeded with passage 4 SDSCs, ASCs, DFs and USCs at 6,000 cells per $\mathrm{cm}^{2}$. After cells reached $90 \%$ confluence, $250 \mu \mathrm{M}$ L-ascorbic acid phosphate (Wako Chemicals USA Inc., Richmond, VA) was added for another 10 days. The deposited ECM flasks were incubated with $0.5 \%$ Triton X-100 containing $20 \mathrm{mM}$ ammonium hydroxide at $37^{\circ} \mathrm{C}$ for $5 \mathrm{~min}$ to remove the cells and stored at $4^{\circ} \mathrm{C}$ in PBS containing $100 \mathrm{U} / \mathrm{mL}$ penicillin, $100 \mu \mathrm{g} / \mathrm{mL}$ streptomycin and $0.25 \mu \mathrm{g} / \mathrm{mL}$ fungizone until use.

\section{SDSCs expansion on plastic flasks or different DECMs}

Passage 3 SDSCs $\left(3,000\right.$ cells per $\left.\mathrm{cm}^{2}\right)$ were plated on either DECM-coated flasks (SE, AE, DE, $\mathrm{UE}$ ) or conventional uncoated plastic flasks (PL) for one passage. The growth medium was changed every three days. Cell number was counted by hemacytometer (Hausser Scientific, Horsham, PA) and morphology was photographed by phase contrast microscopy during cell expansion.

\section{Proliferation index assay}

Before passage 3 SDSCs were seeded on plastic flasks or DECMs, cells from each group were labeled with CellVue ${ }^{\circledR}$ Claret (Sigma) at $2 \times 10^{-6} \mathrm{M}$ for 5 minutes according to the manufacture protocol. After 6-day expansion, cells were collected and measured by a BD dual laser FACS Calibur (BD Biosciences). 20,000 events of each sample were collected using CellQuest Pro software (BD Biosciences) and cell proliferation index was analyzed by ModFit LTTM version 3.1 (Verity Software House).

\section{Fluorescence-activated cell sorting analysis}

The following primary antibodies were used to detect expanded SDSC surface immunophenotype profiles: CD29 (Abcam, Cambridge, MA), CD90 (BD Pharmingen, San Jose, CA), CD105 (BioLegend, San Diego, CA), stage-specific embryonic antigen 4 (SSEA4) (BioLegend) and isotype- matched IgGs (Beckman Coulter, Fullerton, CA). The secondary antibody was goat antimouse IgG $(H+L)$ R-phycoerythrin conjugated (Life Technologies). Samples $(n=3)$ of each $2 \times$ $10^{5}$ expanded cells were incubated on ice in cold PBS containing $0.1 \%$ Chrom-Pure Human IgG 
whole molecule (Jackson ImmunoR- esearch Laboratories, West Grove, PA) and $1 \% \mathrm{NaN}_{3}$ (Sigma) for $30 \mathrm{~min}$. The cells were then sequentially incubated in the dark in the primary and secondary antibodies for $30 \mathrm{~min}$. Fluorescence was analyzed by a FACS Calibur (BD Biosciences) using FCS Express software package (De Novo Software, Los Angeles, CA).

\section{Chondrogenic differentiation of SDSCs}

Expanded SDSCs $\left(0.3 \times 10^{6}\right)$ from each pretreatment group were centrifuged at $500 \times \mathrm{g}$ for $5 \mathrm{~min}$ in a $15-\mathrm{mL}$ polypropylene tube to form a pellet. After overnight incubation, the pellets were cultured in a serum-free chondrogenic medium consisting of high-glucose DMEM, $40 \mu \mathrm{g} / \mathrm{mL}$ proline, $100 \mathrm{nM}$ dexamethasone, $100 \mathrm{U} / \mathrm{mL}$ penicillin, $100 \mu \mathrm{g} / \mathrm{mL}$ streptomycin, $0.1 \mathrm{mM}$ ascorbic acid-2-phosphate, and $1 \times$ ITS TM Premix $(6.25 \mu \mathrm{g} / \mathrm{mL}$ insulin, $6.25 \mu \mathrm{g} / \mathrm{mL}$ transferrin, $6.25 \mu \mathrm{g} / \mathrm{mL}$ selenous acid, $5.35 \mu \mathrm{g} / \mathrm{mL}$ linoleic acid and $1.25 \mu \mathrm{g} / \mathrm{mL}$ bovine serum albumin, from BD Biosciences, Bedford, MA) with the supplementation of $10 \mathrm{ng} / \mathrm{mL}$ transforming growth factor beta3 (TGF- $\beta 3$, PeproTech Inc., Rocky Hill, NJ) in $5 \% \mathrm{O}_{2}$ incubator as long as 35 days. At days 0,14 , and 35 , pellets from each group were collected for evaluation of chondrogenesis.

\section{Immunofluorescent staining of DECMs}

Decellularized ECMs were fixed with $4 \%$ paraformaldehyde for 30 min. After blocking in 10\% normal goat serum for $1 \mathrm{~h}$, ECMs were incubated with monoclonal antibody for type I collagen (Sigma), fibronectin (Santa Cruz Biotechnology, Dallas, TX), or laminin (Santa Cruz Biotechnology) overnight followed by Alexa Fluor 488 goat anti-mouse IgG (Life Technologies) for $30 \mathrm{~min}$. DECMs were visualized with a Zeiss LSM 510 confocal on an Axiolmager Z1 microscope using a $63 \times$ objective lens (Carl Zeiss, Jena, Germany).

\section{Adipogeneic differentiation and detection of SDSCs}

Expanded cells were cultured for 21 days in adipogenic medium (growth medium supplemented with $1 \mathrm{mM}$ dexamethasone, $0.5 \mathrm{mM}$ isobutyl-1-methyxanthine, $200 \mathrm{mM}$ indomethacin, and $10 \mathrm{mM}$ insulin). The cultures $(n=3)$ were fixed in $4 \%$ paraformaldehyde and stained with a $0.6 \%(w / v)$ Oil Red O (ORO) solution (60\% isopropanol, 40\% water) for $15 \mathrm{~min}$. Intracellular lipid-filled droplet-bound staining was photographed under a Nikon TE300 phase-contrast microscope (Nikon, Tokyo, Japan).

\section{Osteogenic differentiation and detection of SDSCs}

Expanded cells $(n=3)$ cultured for 21 days in osteogenic medium (growth medium supplemented with $0.1 \mathrm{mM}$ dexamethasone, $10 \mathrm{mM} \beta$-glycerol phosphate, $50 \mathrm{mM}$ ascorbate-2-phosphate, and $0.01 \mathrm{mM} \mathrm{1,25-dihydroxyvitamin} D_{3}$ ) were collected for alkaline phosphatase (ALP) activity assay with a reagent kit (Sigma) by measuring the formation of $p$-nitrophenol ( $p-N P$ ) from $p$-nitro-phenyl 
phosphate following the manufacturer's instructions. p-NP was quantified based on the spectrophotometric absorbance at $405 \mathrm{~nm}$, and enzymatic activity was expressed as millimoles of $\mathrm{p}-\mathrm{NP} / \mathrm{min} / \mathrm{mg}$ DNA. For evaluation of calcium deposition, induced cells $(n=3)$ were fixed with $70 \%$ ice-cold ethanol for $1 \mathrm{~h}$, and then incubated in $40 \mathrm{mM}$ Alizarin Red S (ARS) at pH 4.2 for 20 min with agitation. After rinsing, matrix mineral-bound staining was photographed. Quantification of staining was performed by incubating cells with a solution of $10 \%$ acetic acid and $20 \%$ methanol for $15 \mathrm{~min}$ to extract the calcium-chelated ARS stain. Samples were analyzed for absorption at $450 \mathrm{~nm}$, which was normalized to total DNA amount for standardization.

\section{Histochemistry and immunostaining}

Representitive pellets $(n=2)$ were fixed in $4 \%$ paraformaldehyde at $4^{\circ} \mathrm{C}$ overnight, followed by dehydrating in a gradient ethanol series, clearing with xylene, and embedding in paraffin blocks. $5-\mu \mathrm{m}$ sections were histochemically stained with Alcian blue (Sigma, counterstained with fast red) and Safranin O (Sigma, counterstained with hematoxylin) for sulfated glycosaminoglycans (GAG). For immunostaining, the sections were immunolabeled with primary antibodies against collagen II (II-II6B3, DSHB, lowa City, IA), collagen I (Abcam, Cambridge, MA., USA), and collagen X (Sigma), followed by the secondary antibody of biotinylated horse anti-mouse IgG or IgM (Vector, Burlingame, CA., USA). Immunoactivity was detected using Vectastain ABC reagent (Vector) with 3, 3'-diaminobenzidine as a substrate.

\section{Biochemical analysis for DNA and GAG content}

The pellets $(n=4)$ were digested for $4 \mathrm{~h}$ at $60^{\circ} \mathrm{C}$ with $125 \mu \mathrm{g} / \mathrm{mL}$ papain in PBE buffer $(100 \mathrm{mM}$ phosphate, $10 \mathrm{mM}$ EDTA, pH 6.5) containing $10 \mathrm{mM}$ cysteine. To quantify cell density, the amount of DNA in the papain digestion was measured using the QuantiT ${ }^{\mathrm{TM}}$ PicoGreen ${ }^{\circledR}$ dsDNA assay kit (Invitrogen) with a CytoFluor® Series 4000 (Applied Biosystems, Foster City, CA). GAG was measured using dimethylmethylene blue dye and a Spectronic $^{\mathrm{TM}}$ BioMate $^{\mathrm{TM}} 3$ Spectrophotometer (Thermo Scientific, Milford, MA) with bovine chondroitin sulfate (Sigma) as a standard.

\section{Real-time polymerase chain reaction (PCR)}

Total RNA was extracted from samples $(n=4)$ using an RNase-free pestle in TRIzol $($ Invitrogen). $2 \mu \mathrm{g}$ of mRNA was used for reverse transcriptase (RT) with High-Capacity cDNA Archive Kit (Applied Biosystems) at $37^{\circ} \mathrm{C}$ for $120 \mathrm{~min}$. Chondrogenic marker genes [collagens II (Assay ID Hs00156568_m1), SRY (sex determining region Y)-box 9 (SOX9) (Assay ID Hs00165814_m1), and aggrecan(ACAN) (Assay ID AIQJAP5) and hypertrophic marker genes (collagen X) (Assay ID Hs00166657_m1)] were customized by Applied Biosystems as part of the Custom Taqman® Gene Expression Assays. Eukaryotic 18S rRNA (Assay ID HS99999901_s1 ABI) was carried out 
as the endogenous control gene. Real-time PCR was performed with the iCycler $\mathrm{IQ}^{\mathrm{TM}}$ Multi Color RT-PCR Detection and calculated by computer software (Perkin-Elmer, Wellesley, MA). Relative transcript levels were calculated as $\mathrm{X}=2^{-\Delta \Delta \mathrm{Ct}}$, in which $\Delta \Delta \mathrm{Ct}=\Delta \mathrm{E}-\Delta \mathrm{C}, \Delta \mathrm{E}=\mathrm{Ct}_{\mathrm{exp}}-\mathrm{Ct}_{18 \mathrm{~s}}$, and $\Delta \mathrm{C}=\mathrm{Ct}_{\mathrm{ct} 1^{-}}$ $\mathrm{Ct}_{18 \mathrm{~s}}$.

Atomic force microscopy (AFM)

Elasticity of decellularized ECMs and expanded cells was investigated using an MFP-3D-BIO AFM (Asylum Research, TE2000- U, Santa Barbara, CA) integrated with an inverted fluorescence microscope (Nikon Eclipse, TieU, Nikon Instruments Inc., Melville, NY) and Olympus TR400-PB cantilevers with spring constant of $0.09 \mathrm{~N} / \mathrm{m}$. The samples were imaged in Petri dishes filled with aMEM containing $10 \%$ FBS. The location of the cantilever on the sample was confirmed using a 10 microscopy objective; each sample was mapped in five randomly selected $50 \mathrm{~mm}$ by $50 \mathrm{~mm}$ areas for a total of $\mathbf{2 0 0 0}$ data points/sample. For the quantitative nanomechanical analysis, a Sneddon's modification of the Hertz model developed for a four-sided pyramid was employed. The ECM and cell elasticity (Young's modulus, E) were corrected with the indentation of the tip, $d$, through the following equation: $E=\pi / 2 \cdot\left(1-v^{2} F\right) / \tan a \delta^{2}$, where $E$ is the Elastic modulus, $v$ is Poisson's ratio with a value of 0.5 for ECM and cells, $F$ is the force given by the cantilever deflection multiplied with the cantilever spring constant $(0.09 \mathrm{~N} / \mathrm{m})$, a is the open angle used in this study which had a value of $36^{\circ}$, and lastly $\delta$ is the indentation depth. ${ }^{14}$

\section{Scanning electron microscope (SEM)}

Representative samples $(\mathrm{n}=2$ ) were primarily fixed in $2.5 \%$ glutaraldehyde (Sigma) for $2 \mathrm{~h}$, followed by secondary fixation in $2 \%$ osmium tetroxide (Sigma) for another $2 \mathrm{~h}$. The samples were then dehydrated in a gradient ethanol series, in hexamethyldisila- zane (HMDS, Sigma) at a ratio of 1:1 with ethanol twice for $1 \mathrm{~h}$ each time, in HMDS at a ratio of 1:2 with ethanol overnight, and in HMDS three times for $4 \mathrm{~h}$ each time. The samples were air-dried for $24 \mathrm{~h}$ and gold sputter was added. The images were recorded by an SEM (Hitachi, Model S 2400).

\section{Statistics}

Kruskal-Wallis test was used to determine significant differences among all groups and the MannWhitney $U$ test was used to determine differences when there were only two groups in biochemistry analysis and real-time PCR data. All statistical analyses were performed with SPSS 13.0 statistical software (SPSS Inc., Chicago, IL). $P$ values less than 0.05 were considered statistically significant. 


\section{RESULTS}

Evaluation of proliferative capacity and MSC surface marker expression on DECMs expanded SDSCS

To evaluate the proliferative effect exerted by DECMs, human SDSCs were seeded on five different substrates. After one passage expansion on plastic flasks or DECMs, the embedded cells exhibited a flattened and irregular shape with enlarged size (characteristic of aged cells) in Plastic groups $(P L)$ and a glistening spindle shape in all DECM groups (SE, AE, DE and UE). Compared to the random distribution of cells plated on Plastic, DECM-expanded cells were more organized (Figure 4.1A). Compared to that in the PL group, after 8-day-expansion cell number increased 1.08-fold in the SE group, 5-fold in the DE, 6-fold in the AE and 11-fold in the UE group (Figure 4.1a). Proliferation index results also suggested the same trend (Figure 4.1B and 4.1b). Median fluorescence intensity (MFI) of MSCs surface marker including CD29, CD90 and CD105 were significantly decreased especially in $D E, U E$ and $A E$, despite the percentages of positive staining was the same. SSEA-4 expression was also higher in all four DECMs expanded SDSC groups than SDSC from PL group (Figure 4.1C and 4.1c).

Evaluation of DECMs and expanded SDSC ultra-morphology, elasticity and composition on different culture substrates

Scanning electron microscopy was employed to observe the fine cell and matrix morphology during expansion on different substrates. SDSC expanded on PL exhibited enlarged, well spread and flatten shape; in contrast, SDSCs expanded on DECMs groups (especially DE, UE and AE) were less spread and embedded in the matrix, with an elongated and spindle fibroblast like shape (Figure 4.2A). Compared to a fiber-like surface appearance in DE, AE and SE, UE exhibited a smoother appearance, indicative of fine matrix fibers.

To characterize DECMs physically, we analyzed the elasticity properties of DECMs alone and elasticity of SDSCs expanded on these DECMs. The elasticity of plastic flasks is considered infinite. Compared to SE, AE $[25.65 \pm 9.38$ versus $61.82 \pm 35.86(\mathrm{kPa})]$ and UE $[21.41 \pm 11.3$ versus $61.82 \pm 35.86(\mathrm{kPa})$ ] have lower elasticity; accordingly SDSCs seeded on these DECMs also have lower elasticity than SDSCs on SE [3.29 \pm 1.42 versus $3.58 \pm 1.94]$ [1.9 \pm 1.15 versus $3.58 \pm 1.94]$. However, DE has highest elasticity among all DECMs $(88.29 \pm 49.9 \mathrm{kPa})$ and SDSCs expanded on DE also have higher elasticity than SDSCs on SE $[4.87 \pm 2.16$ versus 3.58 $\pm 1.94]$ though lower than PL $[4.87 \pm 2.16$ versus $9.07 \pm 4.56]$ (Figure $4.2 \mathrm{~B}$ ). 
Three main common components of ECM were immunostained to probe the composition of DECM-derived from different cell sources (Figure 4.2C). Both fibronectin and collagen I but not laminin were detected (data not shown).

\section{Evaluation of DECM-mediated SDSC chondrogenic capacity}

To determine the rejuvenating effects of DECMs on SDSC chondrogenic potential, expanded SDSC were chondrogenically induced for up to 35 days. The evaluation of chondrogenesis consisted of biochemical, histological and real-time PCR for chondrogenic markers.

As shown in Figure 4.3A, chondrogenic index (ratio of GAG to DNA) of PL expanded pellet is the highest among all groups. After 14-day differentiation, all four DECM-treated SDSCs yielded pellets with higher GAG content than PL expanded SDSCs; however, only pellets from the DE had the highest chondrogenic index among all groups (Figure 4.3B). At day 35, all pellets from DECM groups had a higher DNA content suggesting higher cell viability, and higher chondrogenic index than pellets in the PL group, especially for pellets from the UE and AE groups, which had the highest chondrogenic index, followed by DE and SE (Figure 4.3C). Consistent with biochemistry data, day 35 pellets from all DECM groups had bigger size compared to the $\mathrm{PL}$ group, especially pellets from the AE, DE and UE groups were larger than the SE group. Among the four DECM groups, pellets from the UE group had the biggest size. Sulfated GAGs stained by alcian blue and safarnin $\mathrm{O}$ and immunostaining for collagens II also suggested the strongest staining in pellets from SDSCs expanded in the UE groups, followed by DE, AE and SE (Figure 4.4). Chondrogenic marker genes ( $S O X 9, A C A N, C O L 2 A 1)$ expression was highest in UE at day 14 and highest in DE, followed by $A E$, UE and SE at day 35 (Figure $4.5 \mathrm{~A}$ ). Interestingly, the hypertrophic marker COL1A1 and COL10A1 were also highly expressed in DE (Figure 4.5B).

\section{Evaluation of DECM-expanded SDSC adipogenic and osteogenic potentials}

To determine the rejuvenation effect of DECM expansion on SDSC, expanded SDSC were induced in adipogenic or osteogenic medium for 21 days. Our adipogenic induction data showed that all DECM expanded SDSC exhibited comparable level of positive staining for ORO. The AE expanded SDSC showed the highest adipogenesis among all groups though no significant difference was observed (Figure 4.6A). Osteogenic induction data showed that expanded SDSC from all substrates stained positive and comparable level for ALP except UE groups being the highest. However, the ARS staining for calcium deposition as later stage osteogenic marker and quantitative assessment showed low level of positive staining and calcium but not significant in DE and AE expanded SDSCs (Figure 4.6B). 


\section{DISCUSSION}

Large quantity and high quality of cells is urgently needed for successful cartilage regeneration. Our previous studies have indicated that decellularized extracellular matrix (DECM) deposited by stem cells especially the tissue-specific synovium-derived stem cells (SDSCs) for chondrogenesis could serve as expansion substrates for promoting proliferative and chondrogenic potentials. Recently, adipose, urine-derived mesenchymal stem cells (MSCs) and dermal fibroblasts and their deposited matrixes have been intensively studied in regenerative medicine due to their availability. However, whether these more accessible autologous stem cells deposited matrix could exhibit same or even better effect than SDSC-derived DECM in terms of enhancing SDSC stemness is not known. In this study, we successfully deposited DECMs using MSCs from synovium, adipose and urine and dermal fibroblasts. We demonstrated that DECMs derived from these sources could significantly enhance not only proliferative but also chondrogenic potentials without concomitant adipogenic and osteogenic potentials of the recellularized SDSCs. The evaluation of microstructure and elasticity of the DECMs and cells suggested that the optimized DECMs could maintain stem cell function and rejuvenate the SDSC stemness.

Currently, the decellularization of tissue or organ has been widely shown to be an attractive scaffold for tissue engineering. However, the potential risks of pathogen transmission and the provocation of undesirable inflammatory and immunological reactions could rise during the application of xenogenic or allogenic decellularized matrix and lead to negative outcomes for the regenerated tissues and organs. Autologous subcutaneous adipose tissue depots a potential source of adult or somatic stem cells. Within the increase incidence of obesity in the United States and abroad, subcutaneous adipose tissue is abundant and readily accessible. ${ }^{15}$ Approximately 400,000 liposuction surgeries are performed in the United States each year. ${ }^{16}$ These procedures yield anywhere from $100 \mathrm{~mL}$ to $>3 \mathrm{~L}$ of lipoaspirate tissue, which is routinely discarded. ${ }^{16}$ Within these tissue, up to 300 -fold more stem cells can be obtained from $100 \mathrm{~g}$ of adipose tissue compared to $100 \mathrm{~mL}$ of bone marrow aspirate. ${ }^{17 ; 18}$ Application of human adiposederived stem cells (ASCs) and decellularized adipose tissue have been intensively investigated in recent years. The mutlipotent ASCs were investigated for their potentials to become adipocyte, cardiomyocyte, chondrocyte, endothelial cell, myocyte, neuronal-like cell, osteoblasts etc. as recently reviewed. ${ }^{19 ; 20}$ Flynn et al. showed that decellularized adipose tissue can enhance adipogenesis in human ASCs. ${ }^{21}$ However, the enormous potential of ASC-deposited DECM is not fully uncovered yet. Cerqueira et al. suggested that human ASC-derived cell sheet-based constructs could potentially treat full-thickness excisional skin wounds. ${ }^{22}$ Infrapatellar fat pad tissue derived ASC-deposited matrix expansion could also enhance chondrogenic potential in porcine ASCs. ${ }^{23}$ 
Similarly, human voided urine and urine obtained from the upper urinary tract could be used to isolate and expand stem/progenitor cells. ${ }^{24 ; 25}$ The urine-derived stem cells (USCs) isolated from one single urine specimen can generate up to 100 million cells at early passage. Our recent work showed that these nonchondrogenic USCs deposited DECM can strengthen the chondrogenic capacity of repeated passaged bone marrow-derived stem cells. ${ }^{26}$ Dermal fibroblasts (DFs) can be extracted from biopsies. It is useful for obtaining cells from smaller specimens. It can synthesize and deposit ECM components and has been widely applied in tissue engineering, such as tendon/ligament. ${ }^{27}$ All the above evidences suggest that sufficient numbers of these autologous cells could be obtained from simple procedure and few specimens and used for cellbased therapy. In this study, ASC, USC and DF-deposited DECMs exhibited proliferative and chondrogenic potential enhancing effect on the tissue-specific SDSC. This provides great opportunity for repairing cartilage defect with patient's own stem cells. These easily accessible cells deposited DECM expansion system could serve as expansion system for providing enough tissue specific cells for cell based transplantation or therapy.

The exploration of DECMs deposited by different cells is from the concept of mimicking the "stem cell niche" in vivo. Stem cells reside within instructive and tissue-specific niches in the body, which is a complex and controlled biochemical mixtures of soluble and insoluble factors. ${ }^{28 ; 29}$ It is widely accepted that stem cells display high sensitivity to the ECM composed of complex and well-defined nanostructures of protein fibers such as fibrillar collagens and elastins with feature sizes (diameter and spacing). Only if we find the best microenvironment, we can bring out the best potentials of the stem cells. It is well known that physical properties of the substrates can influence the MSC spreading and differentiation potentials. When cultured on stiff substrate, MSC are well spread, with high cytoskeletal tension, and express high levels of bone cell markers. ${ }^{30}$ In contrast, cells on soft substrate are less spread, have low cytoskeletal tension, and become quiescent. ${ }^{31}$ Our study also showed similar finding. The expansion of SDSCs on the lower elastic DECMs exhibiting a less spread morphology compared to the well spread shape SDSCs on plastic flasks. The maintained or enhanced stemness were demonstrated by higher proliferation and chondrogenesis after induction for 35 days in SDSCs expansion on DECM groups. The higher expression of COL1OA1 as a hypertrophic marker in DE also corroborated the higher elasticity of DE.

Other than substrate elasticity, cell shape has also been known to regulate human MSCs lineage commitment. ${ }^{32} \mathrm{Kim}$ et al. fabricated the nanogrooves with different widths and spacing to study the adhesion, migration and differentiation response of human MSCs. Interestingly, the proliferation is not influenced but the osteogenic and neurogenic potentials were enhanced at the 
1:3 spacing ratio rather than $1: 1$ or 1:5 spacing ratio, suggesting an existence of potentially optimized nanotographical density for stem cell function. ${ }^{33}$ The interplay between matrix elasticity and cell shape has been revealed by a recent study. It indicated that cells cultured on $1000 \mu \mathrm{m}^{2}$ circles, squares, and rectangles tend to commit to primarily adipogenic and osteogenic lineage regardless of matrix elasticity, while cell cultured on 2500 and $5000 \mu \mathrm{m}^{2}$ shapes more heavily depend on shape and elasticity for lineage specification. ${ }^{34}$ Similarly, we also observed that SDSC expanded on $\mathrm{DE}, \mathrm{AE}$ and $\mathrm{UE}$ exhibiting a more spindle and enlongated shape compared to enlarged shape of SDSC expanded on SE and PL. Correspondently, we also observed higher proliferative and chondrogenic potentials in the DE, AE and UE expanded SDSCs than SE and PL groups. Since there has been no studies correlated the specific cell shape, matrix elasticity with chondrogenic potential, the further investigation is on the way.

The future direction of this study is that the fully characterization of DECMs with biochemical methods. Although our immunofluorescence data suggested that all these DECMs contained collagen I and fibronectin (two of the most common components in the ECMs), we cannot exclude that differences among these DECMs existed since they are deposited by different cells. Consistently, Lu et al. investigated the ECM scaffolds prepared by autologous chondrocytes, MSC and dermal fibroblasts also showed differences among them. ${ }^{35}$ However, not only the composition but also the quantification of these components within the ECMs matters since a subtle difference might provide important cues for proliferation and differentiation of cells in vivo and in vitro. 


\section{REFERENCES}

1. Johnstone B, Hering TM, Caplan Al et al. In vitro chondrogenesis of bone marrow- derived mesenchymal progenitor cells. Exp Cell Res 1998;238:265-72.

2. Pittenger MF, Mackay AM, Beck SC et al. Multilineage potential of adult human mesenchymal stem cells. Science 1999;284:143-7.

3. Zuk PA, Zhu M, Mizuno $\mathrm{H}$ et al. Multilineage cells from human adipose tissue: implications for cell-based therapies. Tissue Eng. 2001;7:211-28.

4. Asakura A, Komaki M, Rudnicki M. Muscle satellite cells are multipotential stem cells that exhibit myogenic, osteogenic, and adipogenic differentiation. Differentiation. 2001;68:245-53.

5. Mafi R, Hindocha S, Mafi $P$ et al. Sources of adult mesenchymal stem cells applicable for musculoskeletal applications - a systematic review of the literature. Open Orthop J. 2011;5 Suppl 2:242-8.

6. Jones BA, Pei M. Synovium-derived stem cells: a tissue-specific stem cell for cartilage engineering and regeneration. Tissue Eng Part B Rev. 2012;18:301-11.

7. Zhang $\mathrm{Y}, \mathrm{McNeill} \mathrm{E}$, Tian $\mathrm{H}$ et al. Urine derived cells are a potential source for urological tissue reconstruction. J Urol. 2008;180:2226-33.

8. Lorenz K, Sicker M, Schmelzer E et al. Multilineage differentiation potential of human dermal skin-derived fibroblasts. Experimental Dermatology. 2008;17:925-32.

9. Benya PD, Padilla SR, Nimni ME. Independent regulation of collagen types by chondrocytes during the loss of differentiated function in culture. Cell. 1978;15:1313-21.

10. Li J, Pei M. Cell senescence: a challenge in cartilage engineering and regeneration. Tissue Eng Part B Rev. 2012;18:270-87.

11. Ahmed TA, Hincke MT. Mesenchymal stem cell - based tissue engineering strategies for repair of articular cartilage. Histol Histopathol. 2014 Jan 23.

12. Li J, Hansen KC, Zhang $\mathrm{Y}$ et al. Rejuvenation of chondrogenic potential in a young stem cell microenvironment. Biomaterials. 2014;35:642-53.

13. He F, Chen X, Pei M. Reconstruction of an in vitro tissue-specific microenvironment to rejuvenate synovium-derived stem cells for cartilage tissue engineering. Tissue Eng Part $A$. 2009;15:3809-21.

14. A-Hassan E, Heinz WF, Antonik MD et al. Relative microelastic mapping of living cells by atomic force microscopy. Biophys J 1998;74:1564e78.

15. Bray GA. Medical consequences of obesity. J Clin Endocrinol Metab. 2004; 89:2583-2589

16. Katz AJ, Llull R, Hedrick $\mathrm{MH}$ et al. Emerging approaches to the tissue engineering of fat. Clin Plast Surg. 1999;26:587-603.

17. Pittenger MF, Mackay AM, Beck SC et al. Multilineage potential of adult human mesenchymal stem cells. Science. 1999;284:143-7. 
18. Oedayrajsingh-Varma MJ, van Ham SM, Knippenberg $M$ et al. Adipose tissue-derived mesenchymal stem cell yield and growth characteristics are affected by the tissue-harvesting procedure. Cytotherapy. 2006;8:166-77.

19. Konno M, Hamabe A, Hasegawa $S$ et al. Adipose-derived mesenchymal stem cells and regenerative medicine. Dev Growth Differ. 2013 Apr;55(3:309-18.

20. Gimble JM, Katz AJ, Bunnell BA. Adipose-derived stem cells for regenerative medicine. Circ Res. 2007;100:1249-60.

21. Flynn LE. The use of decellularized adipose tissue to provide an inductive microenvironment for the adipogenic differentiation of human adipose-derived stem cells. Biomaterials. 2010;31:4715-24.

22. Cerqueira MT, Pirraco RP, Santos TC et al. Human adipose stem cells cell sheet constructs impact epidermal morphogenesis in full-thickness excisional wounds. Biomacromolecules. 2013;14:3997-4008.

23. He F, Pei M. Extracellular matrix enhances differentiation of adipose stem cells from infrapatellar fat pad toward chondrogenesis. J Tissue Eng Regen Med. 2013;7:73-84.

24. Zhang $\mathrm{Y}$, McNeill E, Tian $\mathrm{H}$ et al. Urine derived cells are a potential source for urological tissue reconstruction. J Urol 2008;180:2226-33.

25. Bharadwaj S, Liu G, Shi $Y$ et al. Characterization of urine-derived stem cells obtained from upper urinary tract for use in cell-based urological tissue engineering. Tissue Eng Part A 2011;17:2123-32.

26. Pei M, Li JT, Zhang Y et al. Expansion on matrix deposited by nonchondrogenic urine stem cells strengthens repeated passage bone marrow stromal cells' chondrogenic capacity. Cell Tissue Res 2013 (in press)

27. Liu W, Chen B, Deng D et al. Repair of tendon defect with dermal fibroblast engineered tendon in a porcine model. Tissue Eng. 2006;12:775-88.

28. Lutolf M P, Blau HM. Artificial stem cell niches. Adv. Mater. 2009;21:3255-68.

29. Lutolf MP, Gilbert PM, Blau HM. Designing materials to direct stem-cell fate. Nature 2009;462:433-41.

30. Engler AJ, Sen S, Sweeney HL et al. Matrix elasticity directs stem cell lineage specification. Cell, 2006;126:677-89.

31. Winer JP, Janmey PA, McCormick ME et al. Bone marrow-derived human mesenchymal stem cells become quiescent on soft substrates but remain responsive to chemical or mechanical stimuli. Tissue Eng Part A, 2009;15:147-54.

32. McBeath $\mathrm{R}$, Pirone DM, Nelson $\mathrm{CM}$ et al. Cell shape, cytoskeletal tension, and RhoA regulate stem cell lineage commitment. Dev Cell. 2004;6:483-95. 
33. Kim J, Kim HN, Lim KT et al. Designing nanotopographical density of extracellular matrix for controlled morphology and function of human mesenchymal stem cells. Sci Rep. 2013;19;3:3552.

34. Harris GM, Piroli ME, Jabbarzadeh E. Deconstructing the Effects of Matrix Elasticity and Geometry in Mesenchymal Stem Cell Lineage Commitment. Adv. Funct. Mater.. 2013 doi: 10.1002/adfm.201303400

35. Lu H, Hoshiba T, Kawazoe $\mathrm{N}$ et al. Autologous extracellular matrix scaffolds for tissue engineering. Biomaterials. 2011;32:2489-99. 


\section{FIGURE LEGENDS}

Figure 4.1 DECMs expansion enhanced SDSC proliferation. SDSCs were expanded on five different substrates, including plastic flasks (PL), SECM (SE), AECM (AE), DECM (DE) and UECM (UE) for one passage (A). Cell number was counted (a). Proliferation index in expanded SDSCs was analyzed by flow cytometry ( $B$ and $b$ ). Histogram (C) and the quantification of percentage and median fluorescence intensity of positive MSC surface markers including CD90, CD29, CD105 and SSEA-4 were analyze by flow cytometry (c).

Figure 4.2 Cell and DECMs morphology was observed by scanning electron microscopy (A). Elasticity of SDSCs during expansion and matrix alone was analyzed by atomic force microscopy (B). Immunofluorescent staining of collagen I and fibronectin was used to characterize the components of DECMs (C).

Figure 4.3 Biochemical analysis of sulfated GAG and DNA content in expanded SDSC after chondrogenic differentiation for up to 35 days. (A) Chondrogenic index in day 0 pellets. (B and $C$ ) DNA and GAG content was analyzed in day 14 and day 35 pellets from expanded SDSCs. Chondrogenic index was calculated as ratio of GAG to DNA.

Figure 4.4 Histological staining and immunostaining for chondrogenic differentiation markers in day 35 pellets of SDSC after expansion. Alcian blue $(A B)$ and Safranin $O(S O)$ were used to stain sulfated GAGs and immunohistochemistry staining (IHC) was used to stain collagen II, I and X.

Figure 4.5 Real-time PCR was employed to detect the chondrogenic and hypertrophic marker gene expression. Chondrogenic marker genes (SOX9, ACAN, COL II) (A) and hypertrophic marker gene (COL I and $X)(B)$ was detected in both day 14 and 35 pellets.

Figure 4.6 Adipogenic and osteogenic potential was analyzed in expanded SDSCs after induction for 21 days. Oil Red $O$ staining (ORO) was used to evaluate the adipogenesis. Alkaine phosphatase (ALP) staining as well as Alizarin Red staining (ARS) was applied to evaluate the osteogenesis (A). Quantification of ORO, ALP activity and extracellular calcium assay was also evaluated. 
Figure 4.1

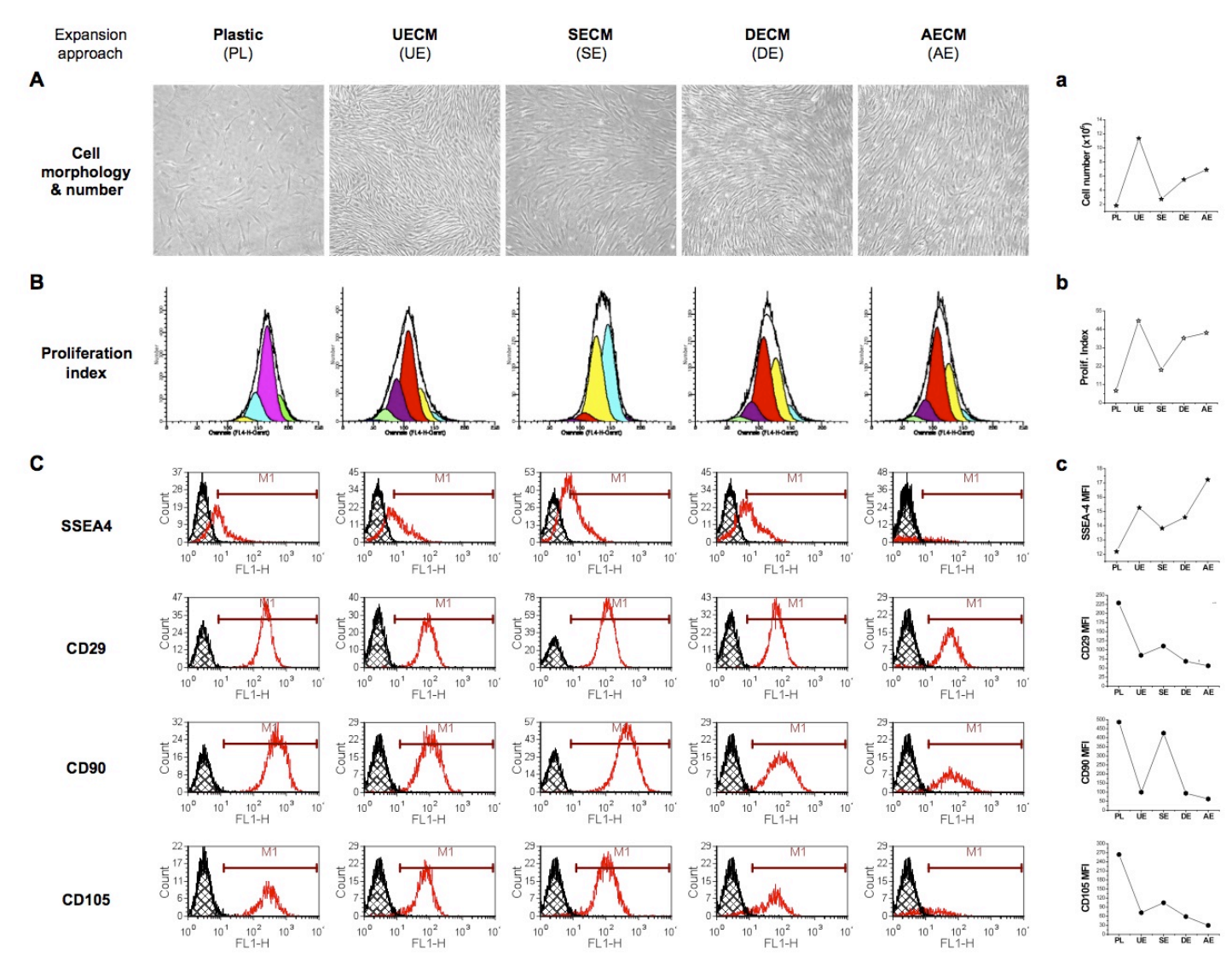


Figure 4.2

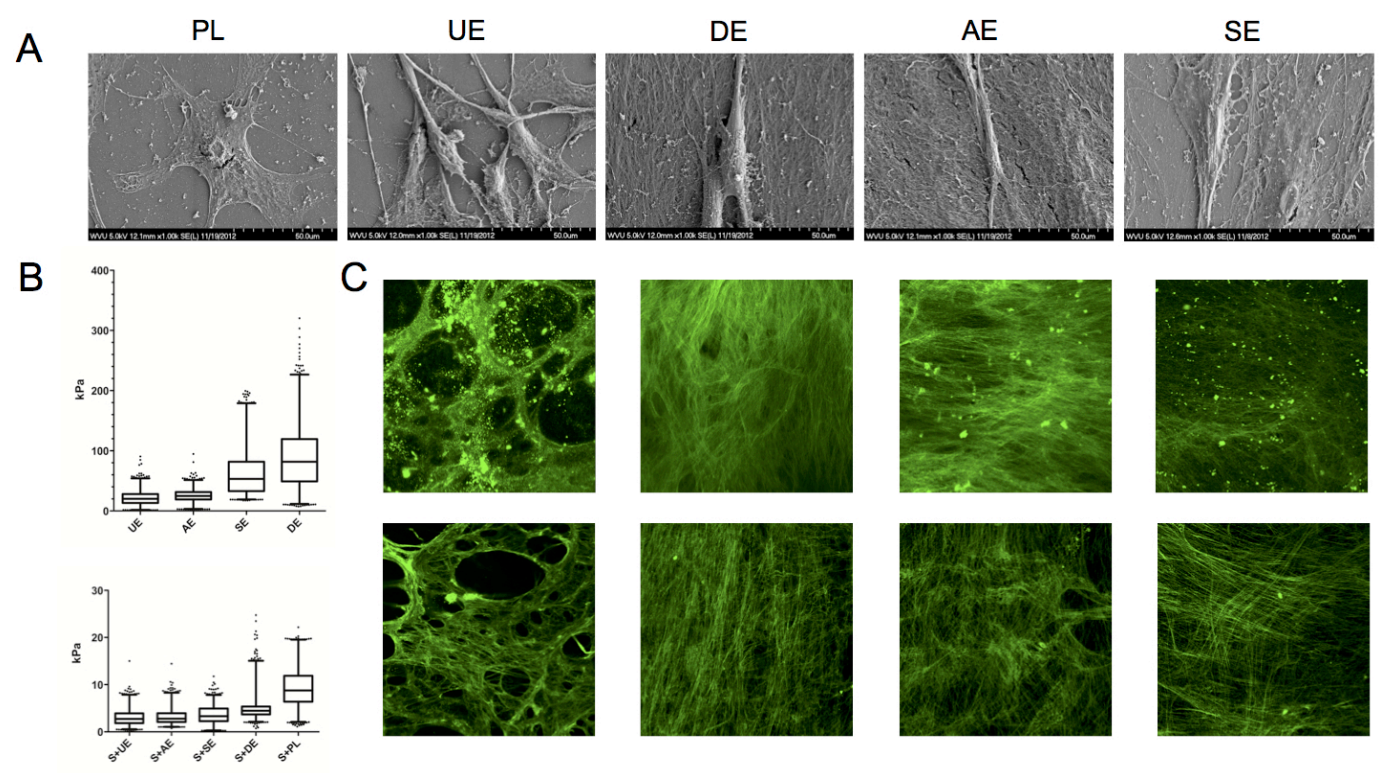


Figure 4.3

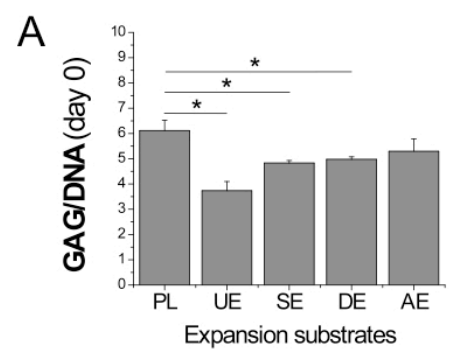

B
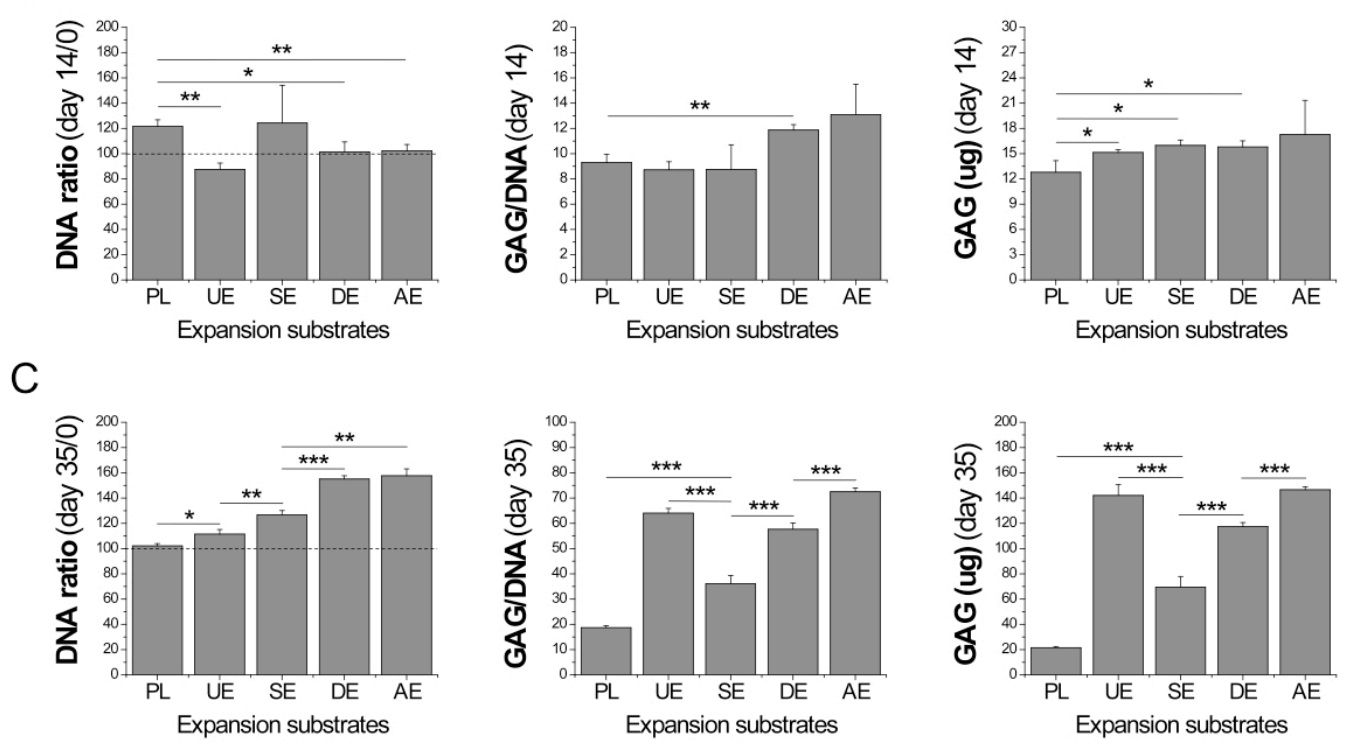
Figure 4.4

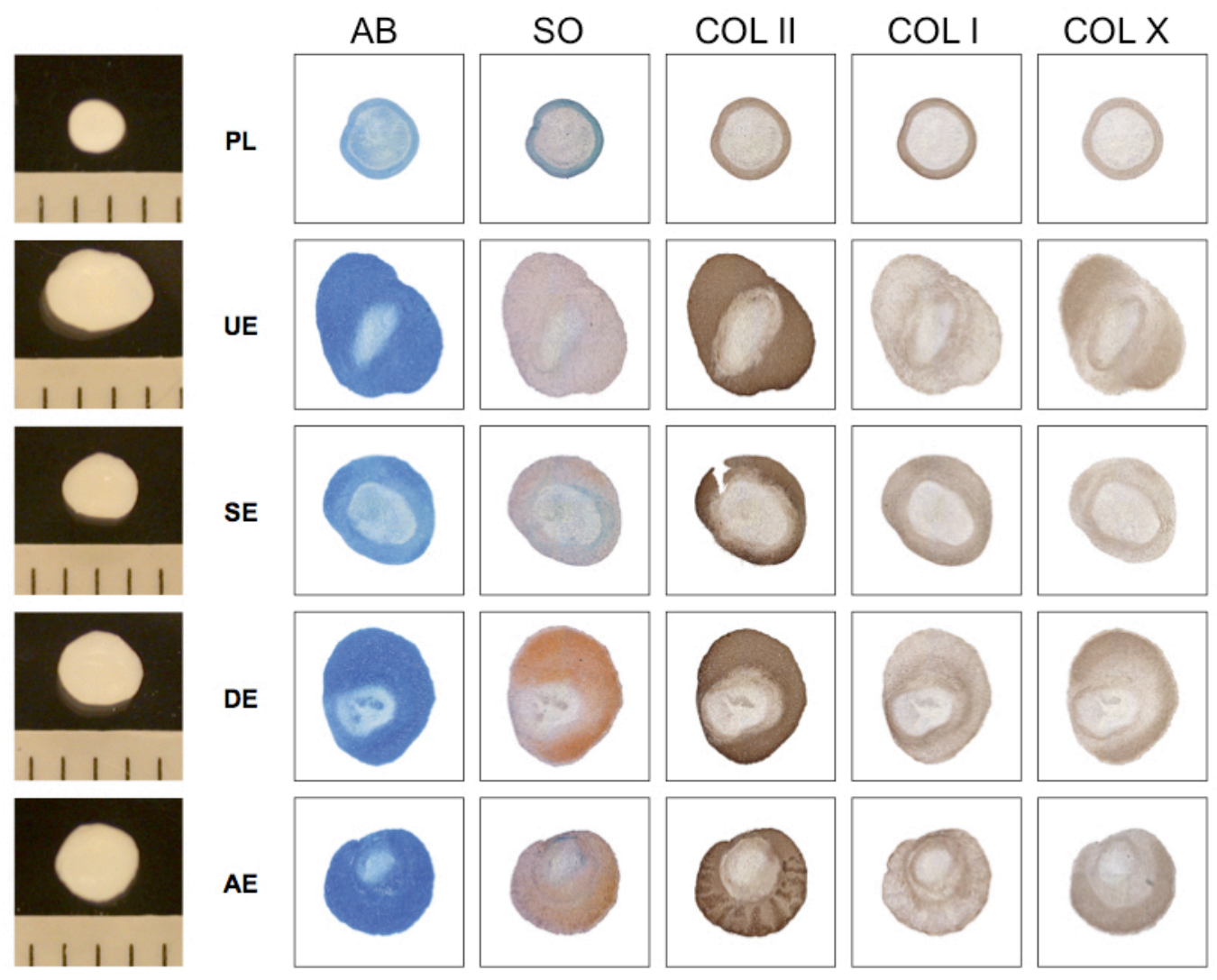


Figure 4.5

A

Sox 9

AGG

Col II
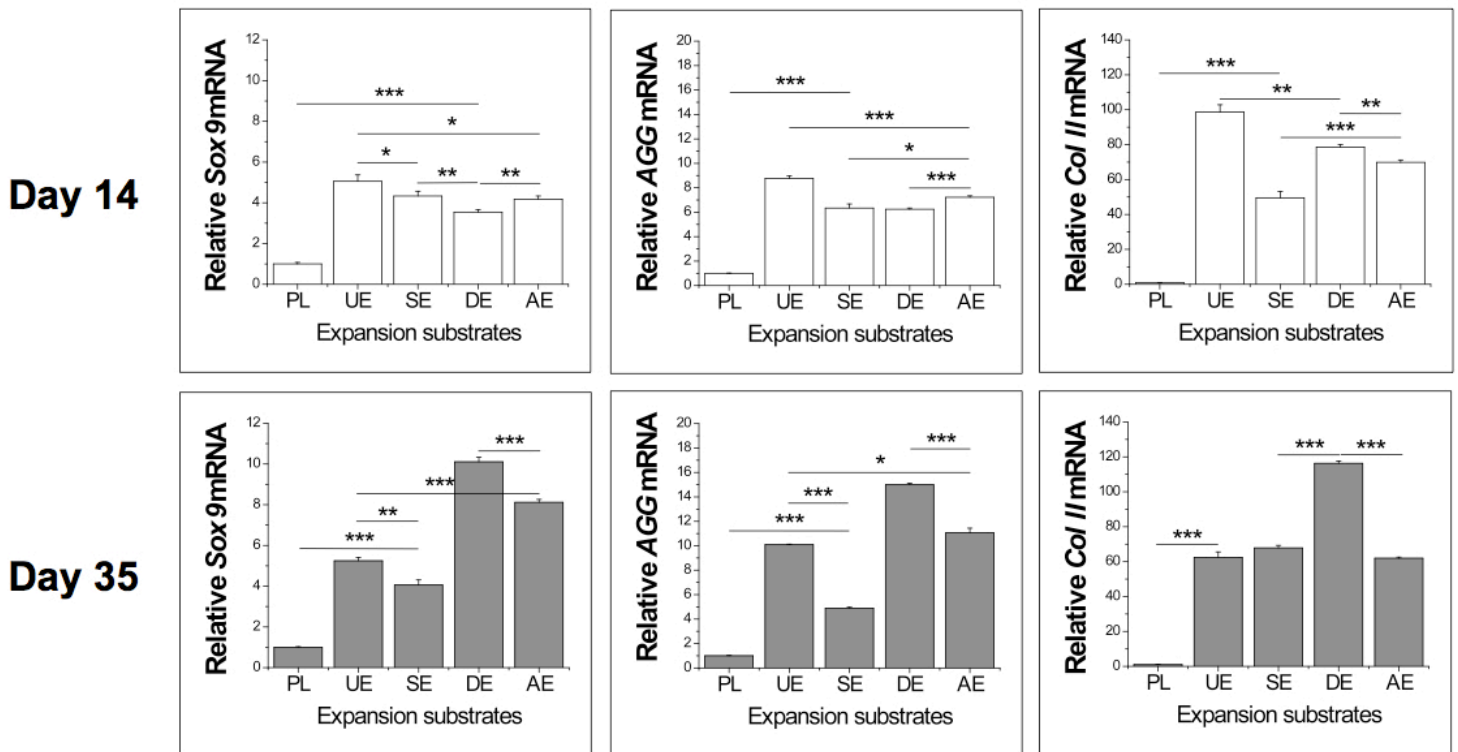

B

Coll

Col X

Day 14
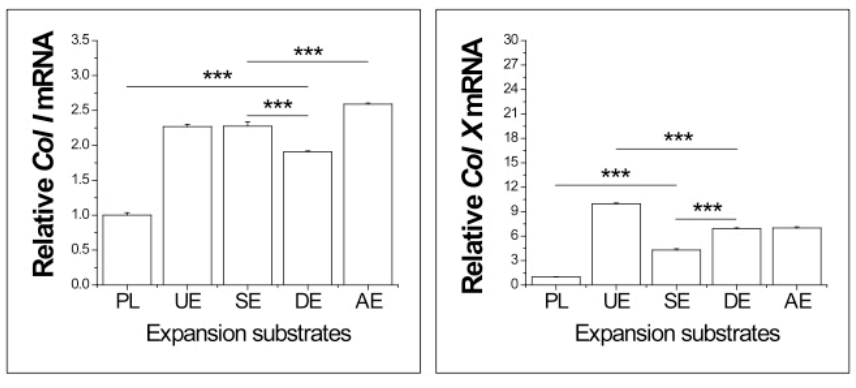

Day 35
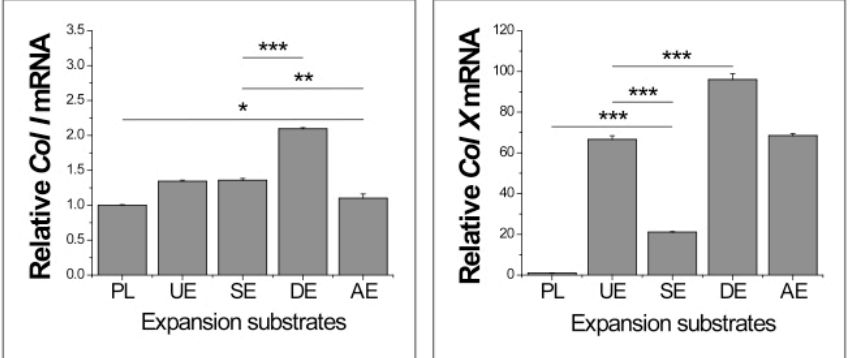
Figure 4.6

A

PL
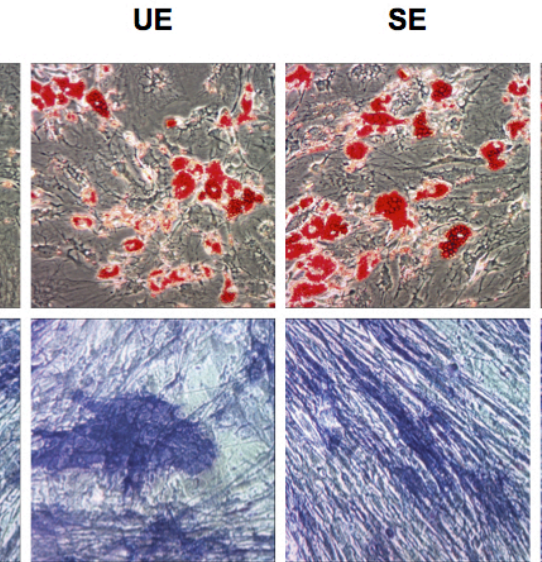

ALP
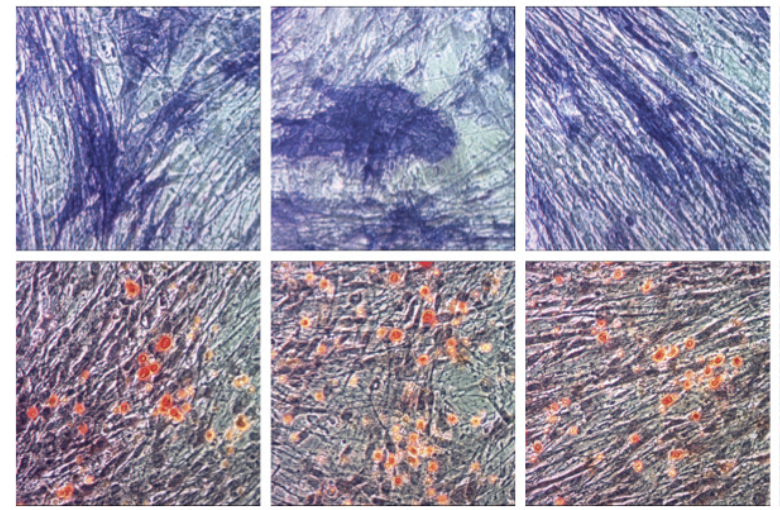

B

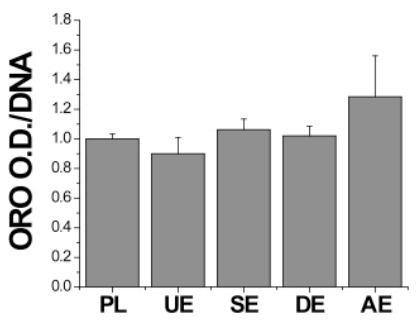

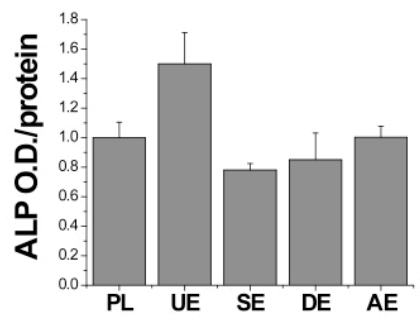

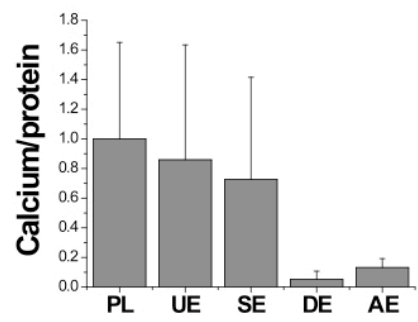


C H A P T E R 5: CREATION $\mathrm{OF}$ A N I $N$ $\begin{array}{llllll}\text { MICROENVIRONMENT TO } & \text { ENHANCE HUMAN } & \text { FETAL }\end{array}$ VITRO SYNOVIUM-DERIVED STEM CELL CHONDROGENESIS

As published in Cell Tissue Research 2011;345:357-65.

Jingting Li, M.S., Fan He, Ph.D. and Ming Pei, M.D., Ph.D.

Tissue Engineering Laboratory, Department of Orthopaedics, and Division of Exercise Physiology, West Virginia University, Morgantown, WV 26506

Key words: synovium derived stem cells, extracellular matrix, hypoxia, chondrogenesis,

Running head of the title: ENGINEERING A MICROENVIRONMENT FOR STEM CELL EXPANSION 


\begin{abstract}
Our aim was to assess the feasibility of the sequential application of extracellular matrix (ECM) and low oxygen to enhance chondrogenesis in human fetal synovium-derived stem cells (hfSDSCs). Human fetal synovial fibroblasts (hfSFs) were characterized and found to include hfSDSCs, as evidenced by their multi-differentiation capacity and the surface phenotype markers typical of mesenchymal stem cells. Passage-7 hfSFs were plated on either conventional plastic flasks $(P)$ or ECM deposited by hfSFs (E) for one passage. Passage-8 hfSFs were then reseeded for an additional passage on either $\mathrm{P}$ or $\mathrm{E}$. The pellets from expanded hfSFs were incubated in a serum-free chondrogenic medium supplemented with $10 \mathrm{ng} / \mathrm{ml}$ transforming growth factor- $\beta 3$ under either normoxia $\left(21 \% \mathrm{O}_{2} ; 21\right)$ or hypoxia $\left(5 \% \mathrm{O}_{2} ; 5\right)$ for 14 days. Pellets were collected for evaluation of the treatments (EE21, EE5, EP21, EP5, PE21, PE5, PP21, and PP5) on expanded hfSF chondrogenesis by using histology, immunostaining, biochemistry, and real-time polymerase chain reaction. Our data suggest that, compared with seeding on conventional plastic flasks, hfSFs expanded on ECM exhibit a lower expression of senescence-associated $\beta$ galactosidase and an enhanced level of stage-specific embryonic antigen-4. ECM-expanded hfSFs also show increased cell numbers and an enhanced chondrogenic potential. Low oxygen $\left(5 \% \mathrm{O}_{2}\right)$ during pellet culture enhances hfSF chondrogenesis. Thus, we demonstrate, for the first time, the presence of stem cells in hfSFs, and that modulation of the in vitro microenvironment can enhance hfSDSC chondrogenesis. hfSDSCs might represent a promising cell source for cartilage tissue engineering and regeneration.
\end{abstract}




\section{INTRODUCTION}

Cartilage defects are a common feature of joint diseases. Despite progress in orthopaedic surgery, the avascular nature of cartilage renders cartilage defect repair challenging ${ }^{1}$. The application of mesenchymal stem cell (MSC)-based tissue engineering has provided a new and exciting opportunity for cartilage repair and regeneration. As a tissue-specific MSC for chondrogenesis $^{2-5}$, synovium-derived stem cells (SDSCs), contained amongst synovial fibroblasts, are a promising source of stem cells for cartilage tissue engineering and regeneration $^{6-9}$. However, adult MSCs have less plasticity and limited proliferation capacity. Adult MSCs cultured in vitro lack telomerase activity ${ }^{10-11}$, resulting in telomere shortening with serial passaging ${ }^{12}$. In contrast, fetal MSCs have longer telomeres and higher telomerase activity than adult $\mathrm{MSCs}^{13}$, indicating that this stem cell source is preferable for tissue engineering and regeneration. Fetal MSCs not only grow more rapidly with more population doublings ${ }^{14-15}$, but also express pluripotency markers, such as Oct-4, Nanog, and stage-specific embryonic antigen-4 $(\text { SSEA-4) })^{13,16}$. Fetal MSCs from umbilical cord blood have demonstrated multilineage potential, including chondrogenic differentiation ${ }^{16-21}$. Therefore, the application of fetal MSCs might meet the tremendous demand of patients suffering from cartilage defects.

Like other MSCs, SDSCs tend to become senescent during ex vivo monolayer expansion. Our recent studies have suggested that extracellular matrix (ECM) deposited by porcine adult SDSCs (paSDSCs) can serve as an in vitro three-dimensional microenvironment, facilitating paSDSC propagation and allowing the restoration of cell-stemness toward chondrogenesis ${ }^{22}$. However, no studies have investigated whether human fetal synovial fibroblasts (hfSFs) contain human fetal SDSCs (hfSDSCs). Whether ECM deposited by hfSFs can enhance hfSF chondrogenic potential remains to be determined. As articular chondrocytes reside in a hypoxic environment ${ }^{23}$, low oxygen tension has been assumed to benefit expanded hfSF chondrogenic differentiation in a pellet culture system. In this study, we have hypothesized that hfSFs include hfSDSCs, and that the sequential application of ECM for cell expansion and low oxygen for expanded cell differentiation can enhance hfSDSC chondrogenesis. Our long-term goal is to promote hfSDSCbased cartilage tissue engineering and regeneration. 


\section{MATERIALS AND METHODS}

\section{Characterization of hfSF multilineage differentiation capacity}

hfSFs were obtained from ScienCell Research Laboratories (catalog number: 4700; Carlsbad, Calif., USA) and characterized for multilineage differentiation capacity. Briefly, hfSFs were plated in growth medium [aMEM containing 10\% fetal bovine serum (FBS), $100 \mathrm{U} / \mathrm{ml}$ penicillin, 100 $\mu \mathrm{g} / \mathrm{ml}$ streptomycin, and $0.25 \mu \mathrm{g} / \mathrm{ml}$ fungizone] until $90 \%$ confluence. For adipogenesis, the medium was switched to adipogenic medium consisting of growth medium supplemented with 1 $\mu \mathrm{M}$ dexamethasone, $0.5 \mathrm{mM}$ isobutyl-1-methyxanthine (IBMX), $200 \mu \mathrm{M}$ indomethacin, and $10 \mu \mathrm{M}$ insulin for an additional 14 days. Adipogenic differentiation was assessed by using Oil Red $\mathrm{O}$ staining for adipocytes ${ }^{22}$. For osteogenesis, the medium was switched to osteogenic medium consisting of growth medium supplemented with $0.1 \mu \mathrm{M}$ dexamethasone, $10 \mathrm{mM} \beta$-glycerol phosphate, $50 \mu \mathrm{M}$ L-ascorbic acid phosphate, and $0.01 \mu \mathrm{M}$ 1,25-dihydroxyvitamin D3 for an additional 14 days. Osteogenic differentiation was assessed by using alkaline phosphatase staining for bioactivity 24 (Kroeze et al. 2011). Cells incubated in growth medium served as a control. For chondrogenesis, hfSFs were incubated in a pellet culture system supplemented with a serum-free chondrogenic medium for 14 days. Chondrogenic differentiation was assessed by using immunostaining for collagen II and Alcian blue staining for sulfated glycosaminoglycans (GAGs); the detailed protocol is described below.

\section{Preparation of hfSF-derived ECM}

hfSFs were used to prepare ECM according to our published method ${ }^{25}$. Briefly, conventional plastic flasks were precoated with $0.2 \%$ gelatin (Sigma, St. Louis, Mo., USA) at $37^{\circ} \mathrm{C}$ for $1 \mathrm{~h}$ and seeded with hfSFs. After cells reached $90 \%$ confluence, $50 \mu \mathrm{M}$ L-ascorbic acid phosphate was added for 8 days. The deposited ECM was incubated with $0.5 \%$ Triton X-100 containing $20 \mathrm{mM}$ ammonium hydroxide at $37^{\circ} \mathrm{C}$ for $5 \mathrm{~min}$ to remove the cells and then stored until use at $4^{\circ} \mathrm{C}$ in phosphate-buffered saline (PBS) containing $100 \mathrm{U} / \mathrm{ml}$ penicillin, $100 \mu \mathrm{g} / \mathrm{ml}$ streptomycin, and 0.25 $\mu \mathrm{g} / \mathrm{ml}$ fungizone.

\section{ECM-mediated hfSF expansion}

Passage 7 hfSFs (3000 cells per $\mathrm{cm}^{2}$ ) were plated in growth medium in either ECM-coated flasks (ECM; E) or conventional plastic flasks (plastic; P) for one passage. Passage $8 \mathrm{hfSFs}$ were then reseeded for an additional passage in either $E$ or $P$. This gave four pretreatment groups in total : $E E, E P, P E$, and PP. The medium was replaced every 3 days.

\section{Flow cytometry assay}


Triple individual samples of $0.3 \times 10^{6}$ cells each were incubated on ice in PBS containing $0.1 \%$ ChromPure Human IgG (Jackson Immuno Research, West Grove, Pa., USA) and $1 \% \mathrm{NaN}_{3}$ for $30 \mathrm{~min}$. Primary monoclonal antibodies (fluorescein-isothiocyanate-conjugated) were applied for 30 min, including CD29 (catalog number: ab21845; Abcam, Cambridge, Mass., USA), CD90 (catalog number: 555595; BD Pharmingen, San Jose, Calif., USA), CD105 (catalog number: 312403; Biolegend, San Diego, Calif., USA), the SSEA-4 (catalog number: 330409; Biolegend), and isotype-matched IgGs (Beckman Coulter, Fullerton, Calif., USA). After being washed with cold PBS, hfSFs were fixed in $300 \mu \mathrm{l} 0.4 \%$ paraformaldehyde. Cells were analyzed on a BD dual laser FACSCalibur (BD Biosciences, San Jose, Calif., USA) by using FCS Express Version 3 (De Novo Software, Los Angeles, Calif., USA) software package.

\section{Senescence $\beta$-galactosidase staining}

The Senescence $\beta$-galactosidase Staining Kit (Cell Signaling Technology, Mississauga, ON, Canada; catalog number: 9860) was used to detect senescence-associated $\beta$-galactosidase activity in expanded hfSFs according to the manufacturer's protocol. Briefly, hfSFs expanded on either ECM or plastic were fixed in $2 \%$ formaldehyde $/ 0.2 \%$ glutaraldehyde. After being rinsed, they were incubated in the staining solution $[5 \mathrm{mM}$ potassium ferrocyanide, $5 \mathrm{mM}$ potassium ferricyanide, $1 \mathrm{mg} \mathrm{X-gal} \mathrm{in} \mathrm{N-N-} \mathrm{dimethylformamide,} 40 \mathrm{mM}$ citric acid/sodium phosphate $(\mathrm{pH} 6)$, $0.15 \mathrm{M} \mathrm{NaCl}$, and $2 \mathrm{mM} \mathrm{MgCl}_{2}$ ] at $37^{\circ} \mathrm{C}$ for $48 \mathrm{~h}$. Development of a cytoplasmic blue color was visualized under a phase-contrast microscope.

\section{Chondrogenic differentiation of expanded hfSFs}

Expanded hfSFs $\left(0.3 \times 10^{6}\right)$ from each pretreatment group were centrifuged at $500 \mathrm{~g}$ for $5 \mathrm{~min}$ in a $15-\mathrm{ml}$ polypropylene tube to form a pellet. After overnight incubation (day 0 ), the pellets were cultured in a serum-free chondrogenic medium consisting of high-glucose DMEM, $40 \mu \mathrm{g} / \mathrm{ml}$ proline, $100 \mathrm{nM}$ dexamethasone, $100 \mathrm{U} / \mathrm{ml}$ penicillin, $100 \mu \mathrm{g} / \mathrm{ml}$ streptomycin, $0.1 \mathrm{mM} \mathrm{L}$-ascorbic acid phosphate, and $1 \times$ ITS Premix $(6.25 \mu \mathrm{g} / \mathrm{ml}$ insulin, $6.25 \mu \mathrm{g} / \mathrm{ml}$ transferrin, $6.25 \mu \mathrm{g} / \mathrm{ml}$ selenous acid, $5.35 \mu \mathrm{g} / \mathrm{ml}$ linoleic acid, and $1.25 \mu \mathrm{g} / \mathrm{ml}$ bovine serum albumin; BD Biosciences, Bedford, Mass., USA) with supplementation of $10 \mathrm{ng} / \mathrm{ml}$ transforming growth factor beta3 (TGFB3; PeproTech, Rocky Hill, N.J., USA) for 14 days. The pellets were incubated under either normoxic $\left(21 \% \mathrm{O}_{2} ; 21\right)$ or hypoxic $\left(5 \% \mathrm{O}_{2} ; 5\right)$ conditions for 14 days. This gave a total of eight treatment groups: EE21, EE5, EP21, EP5, PE21, PE5, PP21, and PP5. The pellets were collected for evaluation of the effect of ECM and/or hypoxia on expanded hfSF chondrogenesis.

\section{Histochemistry and immunohistochemistry}

The protocols for histochemistry and immunochemistry were as given in Pei et al ${ }^{7-9}$. Pellets $(n=2)$ were fixed in $4 \%$ paraformaldehyde at $4^{\circ} \mathrm{C}$ overnight, followed by dehydrating in a gradient 
ethanol series, clearing with xylene, and embedding in paraffin blocks. Sections ( $5 \mu \mathrm{m}$ thick) were histochemically stained with Alcian blue for sulfated GAGs. For immunohistochemical analysis, the sections were immunolabeled with primary antibodies against collagen I (Abcam) and collagen II (II-II6B3; DSHB, lowa City, lowa, USA), followed by the secondary antibody (biotinylated horse anti-mouse IgG; Vector, Burlingame, Calif., USA). Immunoactivity was detected by using Vectastain $A B C$ reagent (Vector) with 3,3'-diaminobenzidine as a substrate.

\section{Biochemical analysis for DNA and GAG content}

Pellets $(n=6)$ were digested for $4 \mathrm{~h}$ at $60^{\circ} \mathrm{C}$ with $125 \mu \mathrm{g} / \mathrm{ml}$ papain in PBE buffer (100 mM phosphate, $10 \mathrm{mM}$ EDTA, pH 6.5) containing $10 \mathrm{mM}$ cysteine, by using $200 \mu \mathrm{l}$ enzyme per sample. The amount of DNA per pellet was measured by using the QuantiT PicoGreen dsDNA assay kit (Invitrogen, Carlsbad, Calif., USA) with a CytoFluor Series 4000 (Applied Biosystems, Foster City, Calif., USA). The amount of GAG per pellet was measured by using dimethylmethylene blue dye and a Spectronic BioMate 3 Spectrophotometer (Thermo Scientific, Milford, Mass., USA) with bovine chondroitin sulfate as a standard.

\section{Real-time polymerase chain reaction}

Total RNA was extracted from pellets $(n=4)$ by using RNase-free pestles in TRIzol (Invitrogen). Samples of $1 \mu \mathrm{g}$ mRNA were used for reverse transcriptase (RT) with the High-Capacity cDNA Archive Kit (Applied Biosystems) at $37^{\circ} \mathrm{C}$ for $120 \mathrm{~min}$. Chondrogenic marker genes [collagen II (Assay ID Hs00156568_m1), aggrecan (Assay ID AIQJAP5), and SRY (sex determining region Y)-box 9 (Sox9; Assay ID Hs00165814_m1)] and a hypertrophic marker gene [collagen X (Assay ID Hs00166657_m1)] were customized by Applied Biosystems as part of their Custom TaqMan Gene Expression Assays. Eukaryotic 18S RNA (Assay ID HS99999901_s1 ABI) was employed as the endogenous control gene. Real-time polymerase chain reaction (PCR) was performed with the iCycler $\mathrm{IQ}^{\mathrm{TM}}$ Multi Color RT-PCR Detection System and calculated by computer software

(Perkin-Elmer, Wellesley, Mass., USA). Relative transcript levels were calculated as $X=2^{-\Delta \Delta C t}$, in which $\Delta \Delta \mathrm{Ct}=\Delta \mathrm{E}-\Delta \mathrm{C}, \Delta \mathrm{E}=\mathrm{Ct}_{\mathrm{exp}}-\mathrm{Ct}_{18 \mathrm{~s}}$, and $\Delta \mathrm{C}=\mathrm{Ct}_{\mathrm{ct} 1}-\mathrm{Ct}_{18 \mathrm{~s}}$.

\section{Statistics}

The Mann-Whitney $U$ test was used to determine differences when there were only two groups for comparison in the biochemistry analysis and real-time PCR data. All statistical analyses were performed with SPSS 13.0 statistical software (SPSS, Chicago, III., USA). P values less than 0.05 were considered to indicate statistical significance. 


\section{RESULTS AND DISCUSSION}

\section{hfSFs exhibited mesenchymal stem cell properties}

To determine whether hfSFs included hSDSCs, hfSFs were characterized for their multilineage differentiation capacity (Fig. 5.1a-f). After incubation in an adipogenic medium, hfSFs were intensively stained with Oil Red $O$ suggesting their adipogenic differentiation. Following incubation in an osteogenic medium, hfSFs were positively stained with alkaline phosphatase indicating their osteogenic potential. After incubation in a serum-free chondrogenic medium, hfSF pellets were intensively stained with sulfated GAGs and collagen II indicative of their chondrogenic differentiation. hfSFs were also characterized for MSC surface phenotype markers by using flow cytometry (Fig. 5.1g-i). A high percentage of expression of CD29 (99.4\%), CD90 (99.6\%), and CD105 (96.5\%) was recorded in hfSFs. For the first time, our data provide evidence supporting the idea that hfSFs include stem cells (referred to as hfSDSCs); we have previously found stem cells in adult synovial fibroblasts ${ }^{8}$.

\section{ECM-expanded hfSFs exhibited "anti-senescence" and enhanced "stemness"}

To identify whether ECM could prevent senescence in expanded hfSFs and enhance their chondrogenic potential, hfSFs were expanded for two passages on PP, PE, EP, or EE. Compared with expansion on $\mathrm{P}$ during the last passage (PP and EP), hfSFs incubated on ECM during the last passage (PE and EE) produced longer, more fibroblast-like cells (Fig. 5.2a-d). After incubation in a serum-free chondrogenic medium for 14 days, intriguingly, the hfSF-pellet sizes in the ECM groups (PE21, PE5, EE21, EE5) were generally larger than those in the P groups (PP21, PP5, EP21, EP5; Fig. 5.2a-d). Our $\beta$-galactosidase data suggested that ECM could effectively decrease expansion-associated senescence compared with that on conventional plastic flasks $(11.70 \pm 1.51 \%$ versus $37.21 \pm 0.75 \%, P=0.0000$; Fig. $5.2 \mathrm{e}-\mathrm{g})$. In contrast, our flow cytometry data showed that ECM could increase expanded hfSF "stemness" by up-regulation of SSEA-4 expression (percentage: $76.2 \%$ versus $46.1 \%$; mean fluorescence intensity: 31.9 versus 24.1, compared with conventional plastic flasks; Fig. 5.2h, i).

\section{ECM-expanded hfSFs exhibited enhanced chodrogenic potential}

In vitro expansion of fetal synovial fibroblasts was different from that of their adult counterpart. When expanded on conventional plastic flasks, adult synovial fibroblasts easily became senescent, as evidenced by their decreased proliferation rate and differentiation potential and their increased $s^{2} e^{22}$. In contrast, hfSFs retained their fibroblast shape and smaller size for many passages (at least nine passages in this study). We collected hfSFs from passages 2, 7, and 9 and then incubated hfSFs in a pellet culture system supplemented with a serum-free chondrogenic medium for 14 days. We found that the chondrogenic index (GAG/DNA) was 
$2.48 \pm 0.24$ in pellets from passage- 2 cells, $3.61 \pm 0.29$ in pellets from passage- 7 cells, and $12.26 \pm 0.45$ for pellets from passage- 9 cells (data not shown), suggesting that hfSFs maintained excellent differentiation capabilities until at least passage 7 . Therefore, hfSFs at passage 7 were chosen for expansion and comparison after a two-passage incubation on ECM and/or plastic. Our biochemical analysis showed that, compared with those from PP21, hfSFs from EE21 $(131.82 \pm 3.43 \%$ versus $115.98 \pm 8.12 \%, \quad P=0.0171)$ and PE21 $(170.31 \pm 17.37 \%$ versus $115.98 \pm 8.12 \%, P=0.0021$ ) yielded pellets with a higher DNA ratio, and compared with those from PP5, hfSFs from PE5 $(190.20 \pm 2.05 \%$ versus $167.73 \pm 10.55 \%, P=0.0102)$ yielded pellets with a higher DNA ratio (Fig. 5.3a). Our chondrogenic index data showed a similar trend. Compared with those from PP21, hfSFs from EE21 (16.47 \pm 0.70 versus $12.26 \pm 0.45, P=0.0001)$ and PE21 (15.07 \pm 0.69 versus $12.26 \pm 0.45, P=0.0012)$ yielded pellets with a higher chondrogenic index, and compared with those from PP5, hfSFs from PE5 (22.92 \pm 1.09 versus $15.82 \pm 1.12, P=0.0004)$ yielded pellets with a higher chondrogenic index; the difference was not statistically significant $(16.49 \pm 0.78$ versus $15.82 \pm 1.12, P=0.4232)$ in pellets from EE5 and PP5 (Fig. 5.3b). Taken together, the pellets from the ECM groups exhibited a higher cell number and greater matrix deposition contributing to their larger size.

Our histology data showed that pellets from cells with a plastic pretreatment and grown under normoxic conditions (PP21) displayed less intensity for sulfated GAGs and collagen II staining, even than those with pretreatment of ECM followed by plastic (EP21). The pellets from the ECM groups (PE21, PE5, EE21, EE5) exhibited an intense distribution of sulfated GAGs (Fig. 5.3c-j) and collagen II (Fig. 5.3c2-j2) throughout the pellets. Real-time PCR data showed that pellets from cells with a plastic pretreatment and grown under normoxic conditions (PP21 and EP21) had lower mRNA levels of aggrecan (Fig. 5.4a), collagen II (Fig. 5.4b), and Sox9 (Fig. 5.4c), whereas pellets from cells with ECM pretreatment and grown under hypoxic conditions (PE5) yielded the highest mRNA levels of aggrecan (Fig. 5.4a) and collagen II (Fig. 5.4b). The pellets from the ECM groups had relatively comparable collagen X mRNA (Fig. 5.4d) expression compared with those from the plastic group. Intriguingly, despite the significant difference between EE21 and EE5 with regard to mRNA levels of aggrecan, collagen II, and Sox9, no significant difference was noted in the chondrogenic index or for the histological staining.

\section{Low oxygen enhanced hfSF chondrogenesis in a pellet culture system}

To identify whether hypoxia enhanced expanded hfSF chondrogenesis, hfSF pellets were incubated in a serum- free chondrogenic medium in a $5 \%$ or $21 \% \mathrm{O}_{2}$ incubator for 14 days. The pellets cultured under low oxygen were larger in size than the corresponding pellets under normal oxygen incubation (Fig. 5.2a-d). Expanded hfSFs on plastic yielded pellets with a higher DNA ratio when incubated under low oxygen compared with normal oxygen (PP5 versus PP21, 
$\mathrm{P}=0.0002$; EP5 versus EP21, $\mathrm{P}=0.0001$ ). Intriguingly, $5 \% \mathrm{O}_{2}$ incubation failed to result in a DNA difference in the pellets from hfSFs expanded on ECM (Fig. 5.3a). In addition, expanded hfSFs yielded pellets with a higher chondrogenic index when incubated under low oxygen compared with normal oxygen (PP5 versus PP21, $\mathrm{P}=0.0010$; EP5 versus $E P 21, \mathrm{P}=0.0000$; PE5 versus $P E 21, P=0.0005$ ), except for the EE group (EE5 versus $E E 21, P=0.9778$; Fig. 5.3b). Our histology data showed that hfSF-pellets incubated in $5 \% \mathrm{O}_{2}$ yielded intense staining of sulfated GAGs (Fig. 5.3c-j) and collagen II (Fig. 5.3c2-j2) compared with those under normoxic conditions, despite similar staining between EE21 and EE5; these results are in accord with our biochemistry data and real-time PCR data, indicating that $5 \% \mathrm{O}_{2}$ incubation enhances hfSF-pellet chondrogenesis. Our real- time PCR data also suggested that plastic-expanded hfSFs yielded pellets with a higher mRNA level of collagen $X$ when incubated under $5 \% \mathrm{O}_{2}$ instead of $21 \% \mathrm{O}_{2}$. However, this phenomenon did not apply to hfSFs expanded on ECM (Fig. 5.4d).

Our study demonstrated that low oxygen $\left(5 \% \mathrm{O}_{2}\right)$ played a key role in hfSF chondrogenesis. Upregulation of Sox9 mRNA (a chondrogenic transcriptional factor) in hfSF pellets treated with low oxygen might be responsible for the enhanced mRNAs of chondrogenic marker genes, such as aggrecan and collagen II. Hypoxia is a critical factor in cartilage development ${ }^{23}$. Hypoxia inducible factors (HIF) $1 \alpha$ and $2 \alpha$ are induced when cells surviving hypoxia exposure are involved in inducing genes related to cell proliferation, apoptosis, and resistance to oxidative stress. Our data might be explained on the basis that hypoxia and HIF-1 $\alpha$ upregulate Sox9 expression ${ }^{26,27}$ and subsequent chondrogenic matrix formation ${ }^{28,29}$ in mesenchymal cells.

\section{Concluding remarks}

To the best of our knowledge, we have demonstrated, for the first time, that (1) hfSFs include hfSDSCs; (2) ECM deposited by hfSFs enhances hfSDSC "anti-senescence" and "stemness" and chondrogenic potential; (3) low oxygen improves hfSDSC chondrogenesis in a pellet culture system. The mechanism underlying the enhancement of the chondrogenic potential of the expanded hfSDSCs by the ECM microenvironment needs to be further investigated. hfSDSCs might provide a robust cell source for cartilage tissue engineering and regeneration. 


\section{ACKNOWLEGEMENTS}

We thank Suzanne Smith for editing the manuscript and Dr. Kathleen Brundage for her help in performing flow cytometry and data analysis. Imaging experiments were performed in the West Virginia University Microscope Imaging Facility. 


\section{REFERENCES}

1. Noel D, Djouad F, Jorgense C (2002) Regenerative medicine through mesenchymal stem cells for bone and cartilage repair. Curr Opin Investig Drugs 3:1000-1004.

2. Dickhut A, Pelttari K, Janicki P, Wagner W, Eckstein V, Egermann M, Richter W (2009) Calcification or dedifferentiation: requirement to lock mesenchymal stem cells in a desired differentiation stage. J Cell Physiol 219:219-226.

3. Mochizuki T, Muneta T, Sakaguchi Y, Nimura A, Yokoyama A, Koga H, Sekiya I (2006) Higher chondrogenic potential of fibrous synovium and adipose synovium-derived cells compared with subcutaneous fat-derived cells: distinguishing properties of mesenchymal stem cells in humans. Arthritis Rheum 54:843-853.

4. Sakaguchi Y, Sekiya I, Yagishita K, Muneta T (2005) Comparison of human stem cells derived from various mesenchymal tissues: superiority of synovium as a cell source. Arthritis Rheum 52:2521-2529.

5. Segawa Y, Muneta T, Makino H, Nimura A, Mochizuki T, Ju YJ, Ezura Y, Umezawa A, Sekiya I (2009) Mesenchymal stem cells derived from synovium, meniscus, anterior cruciate ligament, and articular chondrocytes share similar gene expression profiles. J Orthop Res 27:435-441.

6. Kurth TB, Dell'accio F, Crouch V, Augello A, Sharpe PT, De Bari C (2011) Functional mesenchymal stem cell niches in the adult knee joint synovium in vivo. Arthritis Rheum 63:12891300.

7. Pei M, He F, Kish VL, Vunjak-Novakovic G (2008) Engineering of functional cartilage tissue using stem cells from synovial lining: a preliminary study. Clin Orthop Relat Res 466:1880-1889.

8. Pei M, He F, Vunjak-Novakovic G (2008) Synovium-derived stem cell-based chondrogenesis. Differentiation 76:1044-1056.

9. Pei M, He F, Boyce BM, Kish VL (2009) Repair of full-thickness femoral condyle cartilage defects using allogeneic synovial cell- engineered tissue constructs. Osteoarthritis Cartilage 17:714-722.

10. Banfi A, Bianchi G, Notaro R, Luzzatto L, Cancedda R, Quarto R (2002) Replicative aging and gene expression in long-term cultures of human bone marrow stromal cells. Tissue Eng 8:901-910.

11. Zimmermann S, Voss M, Kaiser S, Kapp U, Waller CF, Martens UM (2003) Lack of telomerase activity in human mesenchymal stem cells. Leukemia 17:1146-1149.

12. Simonsen JL, Rosada C, Serakinci N, Justesen J, Stenderup K, Rattan SI, Jensen TG, Kassem M (2002) Telomerase expression extends the proliferative life-span and maintains the osteogenic potential of human bone marrow stromal cells. Nat Biotechnol 20:592-596.

13. Guillot PV, Gotherstrom C, Chan J, Kurata H, Fisk NM (2007) Human first-trimester fetal MSC express pluripotency markers and grow faster and have longer telomeres than adult MSC. Stem 
Cells 25:646-654.

14. Banfi A, Muraglia A, Dozin B, Mastrogiacomo M, Cancedda R, Quarto R (2000) Proliferation kinetics and differentiation potential of ex vivo expanded human bone marrow stromal cells: implications for their use in cell therapy. Exp Hematol 28:707-715.

15. Campagnoli C, Roberts IA, Kumar S, Bennett PR, Bellantuono I, Fisk NM (2001) Identification of mesenchymal stem/progenitor cells in human first-trimester fetal blood, liver, and bone marrow. Blood 98:2396-2402.

16. Kita K, Gauglitz GG, Phan TT, Herndon DN, Jeschke MG (2010) Isolation and characterization of mesenchymal stem cells from the sub-amniotic human umbilical cord lining membrane. Stem Cells Dev 19:491-502.

17. Baksh D, Yao R, Tuan RS (2007) Comparison of proliferative and multilineage differentiation potential of human mesenchymal stem cells derived from umbilical cord and bone marrow. Stem Cells 25:1384-1392.

18. Bieback K, Kern S, Klüter H, Eichler H (2004) Critical parameters for the isolation of mesenchymal stem cells from umbilical cord blood. Stem Cells 22:625-634.

19. Choi YS, Im MW, Kim CS, Lee MH, Noh SE, Lim SM, Kim SL, Cho CG, Kim DI (2008) Chondrogenic differentiation of human umbilical cord blood-derived multilineage progenitor cells in atelocollagen. Cytotherapy 10:165-173.

20. Reed SA, Johnson SE (2008) Equine umbilical cord blood contains a population of stem cells that express Oct4 and differentiate into mesodermal and endodermal cell types. J Cell Physiol 215:329-336.

21. Rebelatto $C K$, Aguiar AM, Moretão MP, Senegaglia AC, Hansen $P$, Barchiki $F$, Oliveira J, Martins J, Kuligovski C, Mansur F, Christofis A, Amaral VF, Brofman PS, Goldenberg S, Nakao LS, Correa A (2008) Dissimilar differentiation of mesenchymal stem cells from bone marrow, umbilical cord blood, and adipose tissue. Exp Biol Med (Maywood) 233:901-913.

22. He F, Chen X, Pei M (2009) Reconstruction of an in vitro tissue- specific microenvironment to rejuvenate synovium-derived stem cells for cartilage tissue engineering. Tissue Eng Part $A$ 15:3809- 3821.

23. Schipani E, Ryan HE, Didrickson S, Kobayashi T, Knight M, Johnson RS (2001) Hypoxia in cartilage: HIF-1alpha is essential for chondrocyte growth arrest and survival. Genes Dev 15:2865- 2876.

24. Kroeze RJ, Knippenberg M, Helder MN (2011) Osteogenic differentiation strategies for adipose-derived mesenchymal stem cells. Methods Mol Biol 702:233-248.

25. Li J, Pei M (2011) Optimization of an in vitro three-dimensional microenvironment to reprogram synovium-derived stem cells for cartilage tissue engineering. Tissue Eng Part $A$ 17:703-712.

26. Amarilio R, Viukov SV, Sharir A, Eshkar-Oren I, Johnson RS, Zelzer E (2007) HIF1alpha 
regulation of Sox9 is necessary to maintain differentiation of hypoxic prechondrogenic cells during early skeletogenesis. Development 134:3917-3928.

27. Robins JC, Akeno N, Mukherjee A, Dalal RR, Aronow BJ, Koopman P, Clemens TL (2005) Hypoxia induces chondrocyte-specific gene expression in mesenchymal cells in association with transcriptional activation of Sox9. Bone 37:313-322.

28. Myllyharju J, Schipani E (2010) Extracellular matrix genes as hypoxia-inducible targets. Cell Tissue Res 339:19-29.

29. Schipani E (2005) Hypoxia and HIF-1 alpha in chondrogenesis. Semin Cell Dev Biol 16:539546. 


\section{FIGURE LEGENDS}

Figure 5.1 Characterization of multilineage differentiation capacity (a-f) and mesenchymal stem cell properties $(\mathrm{g}-\mathrm{i})$ of human fetal synovial fibroblasts (hfSF). Adipogenic differentiation was assessed by using Oil Red O staining for lipid droplets (a) with cells incubated in growth medium serving as a control (b); osteogenic differentiation was assessed by using alkaline phosphatase (ALP) staining for ALP activity (c) with cells incubated in growth medium serving as a control (d); chondrogenic differentiation was assessed by using Alcian blue staining for sulfated glycosaminoglycans (GAGs; e) and immunostaining for collagen II (f). Bar $800 \mu \mathrm{m}$. Flow cytometry was used to characterize MSC surface phenotype markers, namely, CD29 (g), CD90 (h), and CD105 (i), in hfSFs

Figure 5.2 Effect of extracellular matrix (ECM) on hfSF expansion and anti-senescence. Following substrate pre-treatment, hfSFs were expanded on either plastic $(P)$ or ECM (E) for two passages with either the same substrate (PP, a; EE, b) or a different substrate (PE, c; EP d). Cell morphology was studied 6 days post-expansion by phase-contrast microscopy; expanded cells were centrifuged to form pellets and cultured in a serum-free chondrogenic medium for 14 days under either normoxia $\left(21 \% \mathrm{O}_{2}, 21\right)$ or hypoxia $\left(5 \% \mathrm{O}_{2}, 5\right)$. Cell senescence was evaluated by using $\beta$-galactosidase (Beta-gal) staining (g) after expansion for $48 \mathrm{~h}$ on either plasitc (e) or ECM (f). Data are shown as average $\pm S D$ for $n=4 ;{ }^{* * *} P<0.001$ indicates a statistically significant difference. Flow cytometry was used to determine the stage-specific embryonic antigen-4 level in hfSFs after expansion on either ECM (h) or plastic (i)

Figure 5.3 Assessment of expanded hfSF chondrogenic differentiation at the protein level. Biochemistry analyses were used to measure DNA and GAG contents per pellet. The DNA ratio was used to represent cell proliferation (a) and was calculated from the DNA content at day 14 adjusted by that at day 0 to minimize the initial difference in cell amounts in pellet preparation. The ratio of GAG to DNA at day 14 was used to represent the chondrogenic index in pellets (b). Data are shown as average $\pm S D$ for $n=6 ;{ }^{*} P<0.05,{ }^{* *} P<0.01,{ }^{* *} P<0.001$ indicate a statistically significant difference. Alcian blue staining was conducted for sulfated GAGs (c-j) and immunohistochemical staining was carried out for collagen I (c 1 -j 1 ) and collagen II (c 2 -j 2 ). Treatments as explained in Fig. 2. Bar $800 \mu \mathrm{m}$

Figure 5.4 Assessment of expanded hfSF chondrogenic differentiation at the molecular level. TaqMan real-time polymerase chain reaction was used to assess quantitatively the mRNA levels of aggrecan (AG, a), collagen II (Col II, b), Sox9 (c), and collagen X (Col X, d) in the pellets from expanded hfSFs at day 14. Treatments as explained in Fig. 2. Data are shown as average \pm SD 
for $n=4 ;{ }^{*} P<0.05,{ }^{* *} P<0.01,{ }^{* * *} P<0.001$ indicate a statistically significant difference 
Figure 5.1
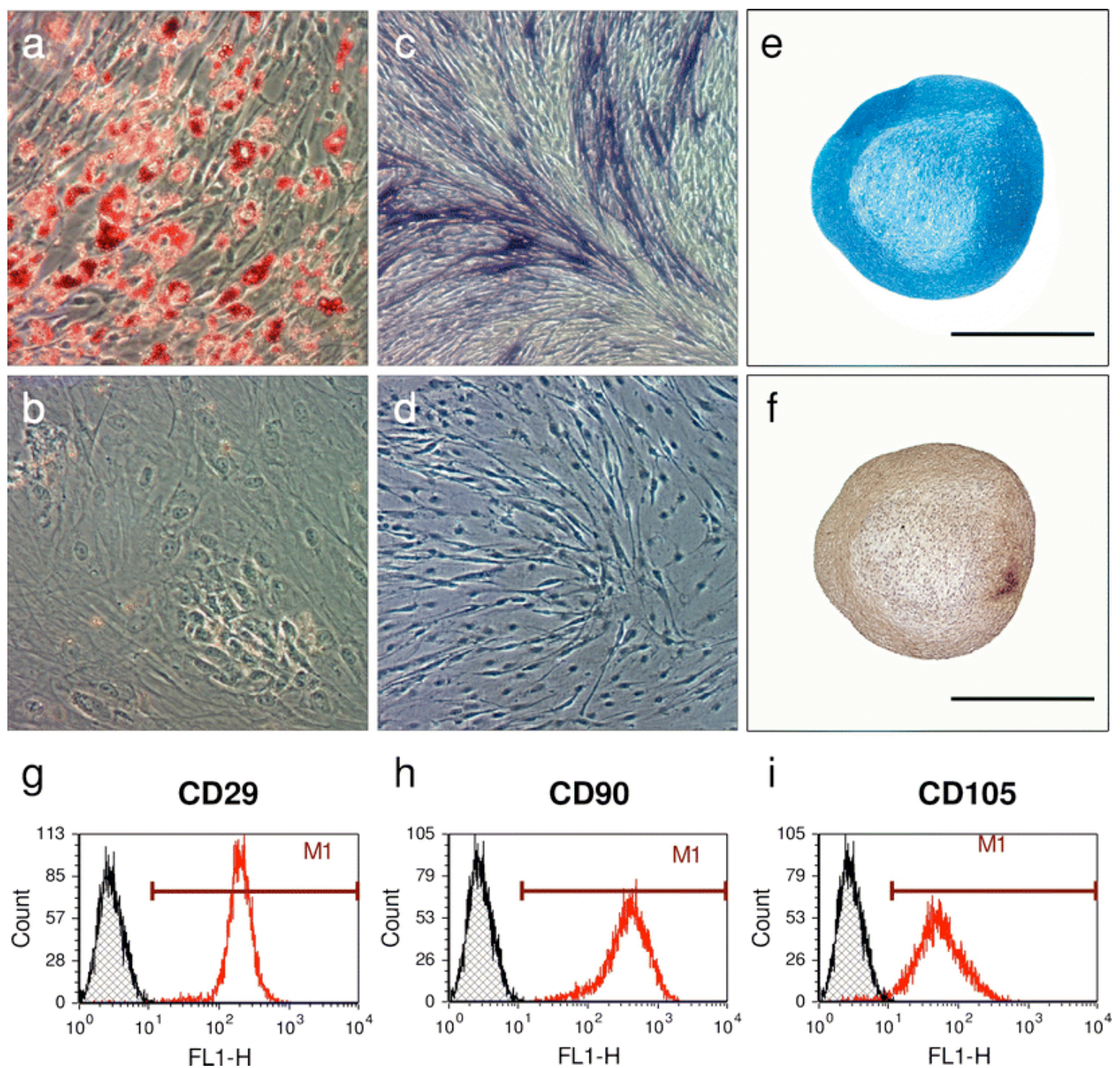
Figure 5.2
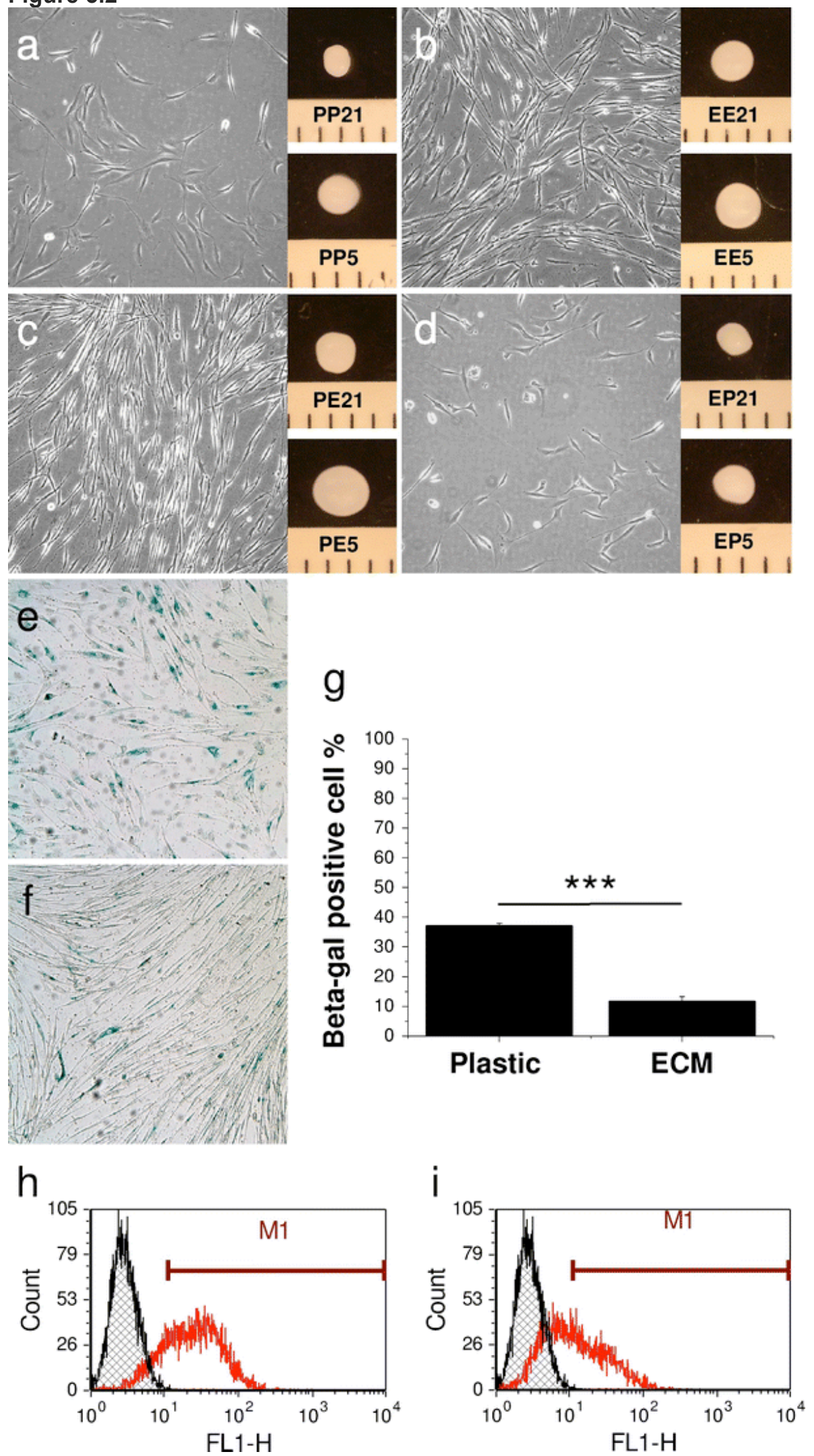
Figure 5.3
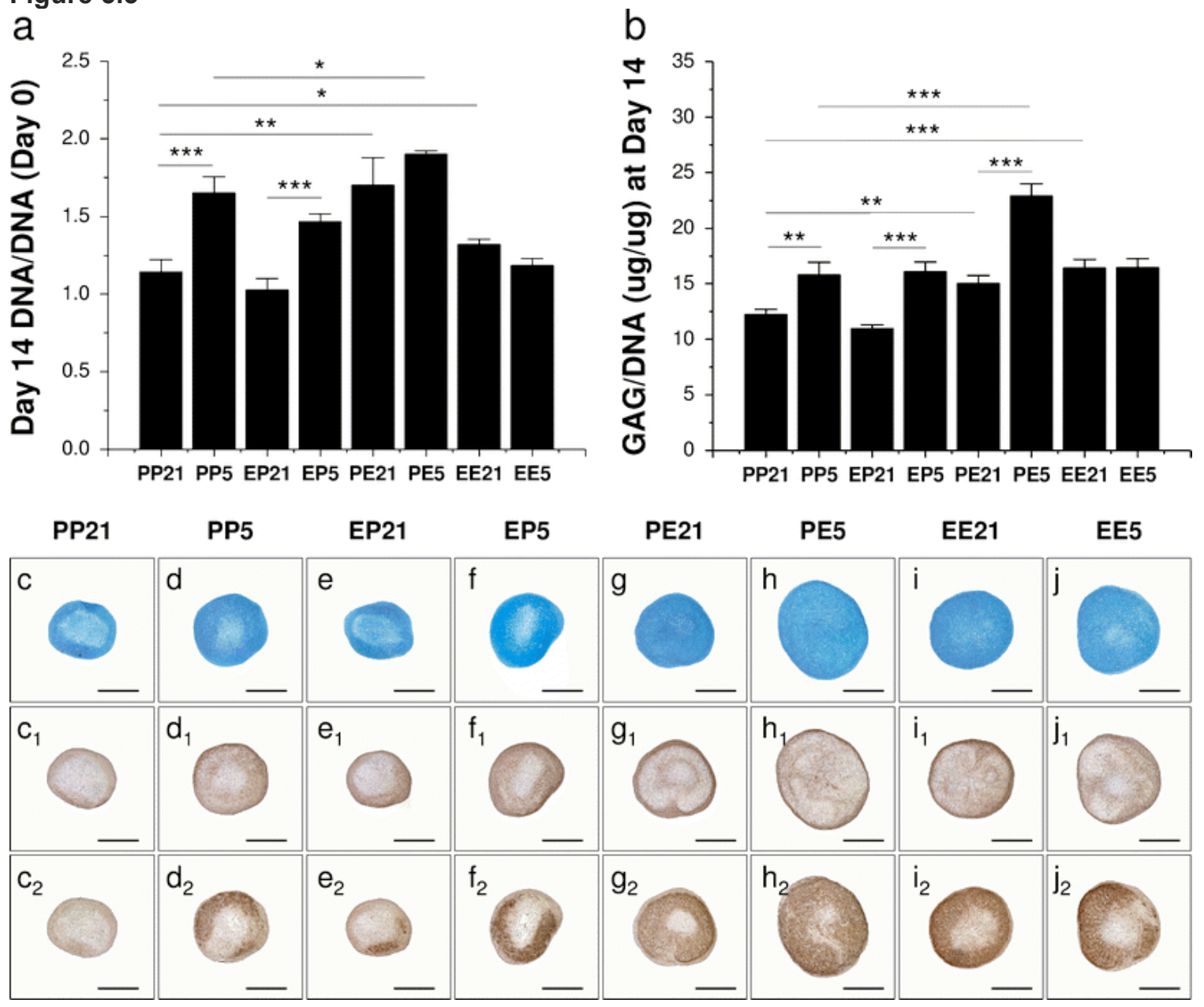
Figure 5.4
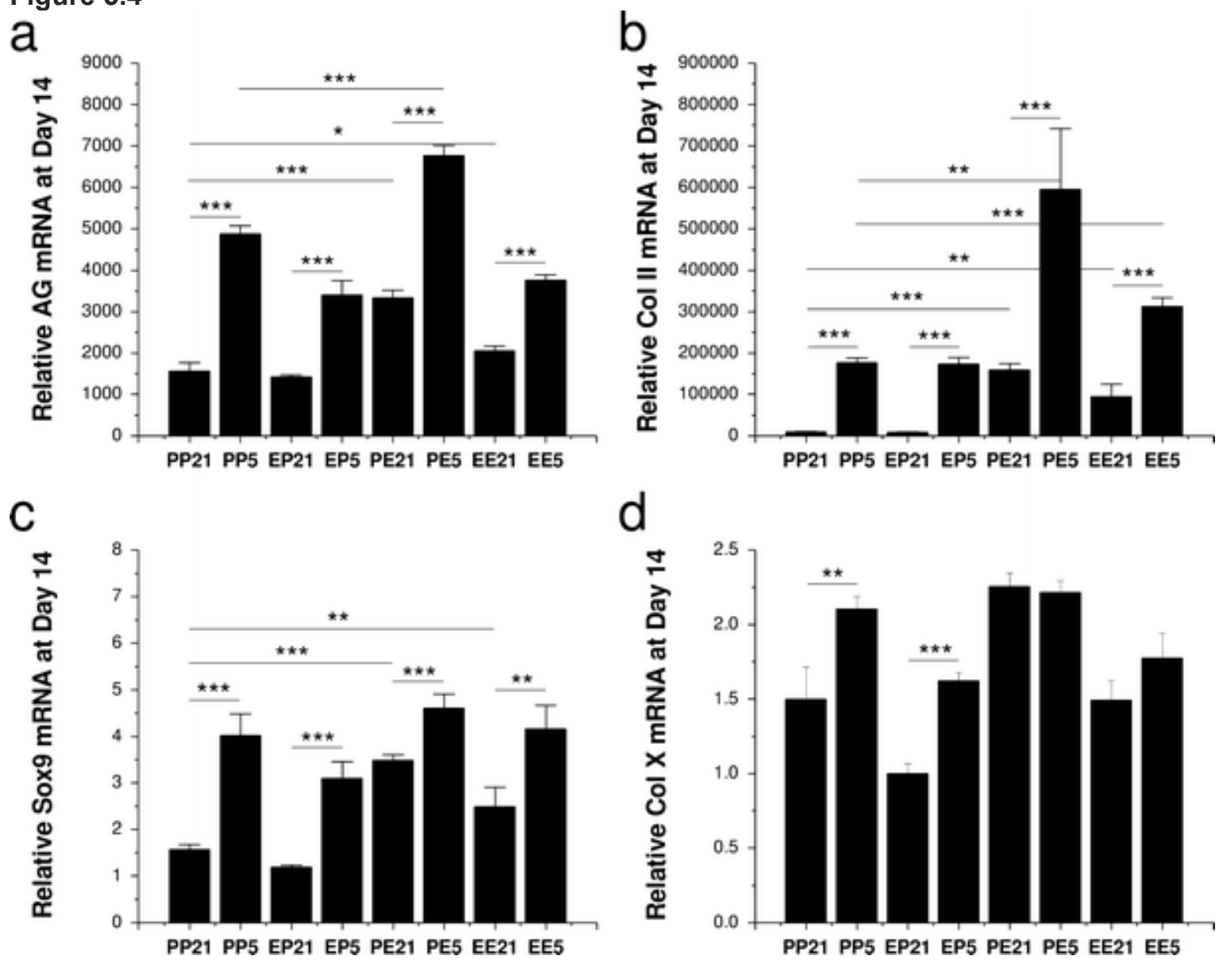
C H A P T E R POTENTIAL MICROENVIRONME

6: RE JUVENATION A $\quad$ YOUNG CHONDROGENIC STEM $\quad$ CELL

As published in Biomaterials 2014 Jan;35(2):642-53.

Jingting Li, M.S., Kirk C. Hansen, Ph.D., Ying Zhang, M.S., Chenbo Dong, M.S., Cerasela Z. Dinu , Ph.D., Monika Dzieciatkowska, Ph.D. and Ming Pei, M.D., Ph.D.

Tissue Engineering Laboratory, Department of Orthopaedics, and Division of Exercise Physiology, West Virginia University, Morgantown, WV 26506

Key words: synovium derived stem cells, young decellularized stem cell matrix, chondrogenesis 


\begin{abstract}
Autologous cells suffer from limited cell number and senescence during ex vivo expansion for cartilage repair. Here we found that expansion on extracellular matrix (ECM) deposited by fetal synovium-derived stem cells (SDSCs) (FE) was superior to ECM deposited by adult SDSCs (AE) in promoting cell proliferation and chondrogenic potential. Unique proteins in FE might be responsible for the rejuvenation effect of $\mathrm{FE}$ while advantageous proteins in $\mathrm{AE}$ might contribute to differentiation more than to proliferation. Compared to $A E$, the lower elasticity of FE yielded expanded adult SDSCs with lower elasticity which could be responsible for the enhancement of chondrogenic and adipogenic differentiation. MAPK and noncanonical Wnt signals were actively involved in ECM-mediated adult SDSC rejuvenation.
\end{abstract}




\section{INTRODUCTION}

Cartilage regeneration is a primary focus in the tissue engineering field due to the limited regenerative abilities of cartilage. Presently, the most effective treatment for repairing cartilage defects is autologous chondrocyte implantation ( $\mathrm{ACl})$. Though this technique has developed through generations and achieved short-term success, it is still mostly restricted by availability of a large quantity of high quality autologous chondrocytes. Despite the fact that bone marrowderived stem cells (BMSCs) and adipose-derived stem cells (ASCs) have been investigated, there are increasing concerns of donor site morbidity due to harvesting, chondrogenic hypertrophy, and unstable chondrogenic phenotype [1,2]. Fortunately, mesenchymal stem cells (MSCs) derived from synovial tissue (SDSC) are currently attractive solutions due to their characteristic as a tissue- specific stem cell for chondrogenesis as well as the ease of harvesting through a small punch biopsy during arthroscopic surgery [3]. However, challenges remain in lengthened culturing time for preparing a sufficient number of such autologous cells, especially when elderly patients are considered [4].

To optimize the application of adult stem cells, an efficient expansion system that can rejuvenate or at least maintain the self- renewal and differentiation potentials of adult SDSCs (ASDSCs) is urgently needed. Recent work from our laboratory suggested that decellularized extracellular matrix (ECM) derived from 3-month- old porcine SDSCs enhanced proliferation and subsequent chondrogenic differentiation of both stem cells [5-11] not only in vitro [12] but also in vivo [13]. Different from the above reports using young porcine cells, in clinics, patients with cartilage defects are usually middle-aged. Adult MSCs lack telomerase activity resulting in telomere shortening after serial passaging in vitro [14]. Studies have shown that decellularized ECM from human adult stem cells, such as SDSCs [15] or BMSCs [16], exhibited a limited capacity to rejuvenate expanded stem cells' chondrogenic potential. Compared to adult MSCs, fetal MSCs maintained longer telomeres and higher telomerase activity [17]. Further, our recent studies demonstrated that human fetal SDSCs (FSDSCs) possessed multi-differentiation capacities, including chondrogenesis, osteogenesis, and adipogenesis [18], suggesting SDSCs from a fetal source could be a cell source for deposition of a decellularized ECM, which provides a young and healthy microenvironment for ASDSC rejuvenation.

In this study, we hypothesized that ECM deposited by FSDSCs provided a better in vitro microenvironment for ASDSC expansion and retention of chondrogenic potential. We explored potential mechanisms underlying ASDSC rejuvenation by using proteomics and immunofluorescent staining for chemical composition of ECM, atomic force microscopy (AFM) for elastic modulus of both ECM and expanded ASDSCs, and Western blot for potential involvement 
of the mitogen-activated protein kinase (MAPK) and Wnt signaling pathways. We also evaluated ECM expanded cells in adipogenic and osteogenic potentials to determine whether this rejuvenation only favored a tissue-specific lineage. 


\section{MATERIALS AND METHODS}

\section{DSCM preparation}

Human fetal source SDSCs (FSDSCs) were obtained from Scien-Cell ${ }^{\mathrm{TM}}$, Research Laboratories (Carlsbad, CA) and adult source SDSCs (ASDSCs) were obtained from Asterand (North America Laboratories, Detroit, MI). Both cell types were used to prepare decellularized ECM, termed FE and $A E$, respectively, as described previously $[15,18]$. Briefly, plastic flasks $(P L)$ were precoated with $0.2 \%$ gelatin (Sigma, St. Louis, MO) at $37{ }^{\circ} \mathrm{C}$ for $1 \mathrm{~h}$ and seeded with passage 3 SDSCs at 6000 cells per $\mathrm{cm} 2$. After cells reached $90 \%$ confluence, $250 \mathrm{mM}$ of L-ascorbic acid phosphate (Wako Chemicals USA Inc., Richmond, VA) was added for 10 days. The deposited ECMs were incubated with $0.5 \%$ Triton $\mathrm{X}-100$ containing $20 \mathrm{mM}$ ammonium hydroxide at $37^{\circ} \mathrm{C}$ for $5 \mathrm{~min}$ to remove the cells; they were stored at $4{ }^{\circ} \mathrm{C}$ in phosphate-buffered saline (PBS) containing 100 $\mathrm{U} / \mathrm{mL}$ penicillin, $100 \mathrm{mg} / \mathrm{mL}$ streptomycin, and $0.25 \mathrm{mg} / \mathrm{mL}$ fungizone until use.

\section{Evaluation of cell proliferation and apoptosis}

Cell counting and morphology

PL expanded passage 3 ASDSCs (PL3) were plated at 3000 cells per $\mathrm{cm} 2$ on $\mathrm{FE}, \mathrm{AE}$, or PL for one passage with growth medium containing alpha-minimum essential medium (aMEM), 10\% fetal bovine serum (FBS), $100 \mathrm{U} / \mathrm{mL}$ penicillin, $100 \mathrm{mg} / \mathrm{mL}$ streptomycin, and $0.25 \mathrm{mg} / \mathrm{mL}$ fungizone. Expanded ASDSCs were termed FE4, AE4, and PL4. Cell number was counted in 175 cm2 flasks ( $n=6)$ using a hemocytometer. To observe cell morphology, FE4, AE4, and PL4 were fixed in $4 \%$ paraformaldehyde; the cell membrane was labeled with Vybrant $\circledast$ Dil Cell-labeling solution (Life Technologies, Grand Island, NY) and mounted with Prolong® Gold antifade reagent with 4',6-diamidino-2-phenylindole (DAPI) (Life Technologies). Both FE and AE were immunostained using monoclonal antibody for type I collagen (Sigma) conjugated with fluorescein isothiocyanate (FITC) and visualized with a Nikon TE2000-S Eclipse inverted microscope (Melville, NY).

Proliferation index

Before cell expansion, passage 3 ASDSCs were labeled with CellVue ${ }^{\circledR}$ Claret (Sigma) at $2 \times 10-$ $6 \mathrm{M}$ for $5 \mathrm{~min}$ according to the manufacturer's protocol. After eight days, expanded cells were collected and measured using a BD FACS Calibur ${ }^{\text {TM }}$ flow cytometer (dual laser) (BD Biosciences, San Jose, CA). Twenty thousand events of each sample were collected using CellQuest Pro software (BD Biosciences) and cell proliferation index was analyzed by ModFit $L T^{\mathrm{TM}}$ version 3.1 (Verity Software House, Topsham, ME).

Flow cytometry analysis 
The following primary antibodies were used to detect expanded SDSC surface immunophenotype profiles: CD29 (Abcam, Cambridge, MA), CD90 (BD Pharmingen, San Jose, CA), CD105 (BioLegend, San Diego, CA), stage-specific embryonic antigen 4 (SSEA4) (BioLegend), integrin b5 (Cell Signaling, Danvers, MA), and isotype-matched IgGs (Beckman Coulter, Fullerton, CA). The secondary antibody was goat anti-mouse $\lg G(H+L)$ R-phycoerythrin conjugated (Life Technologies). Samples ( $n=3$ ) of each $2 \times 105$ expanded cells were incubated on ice in cold PBS containing $0.1 \%$ Chrom-Pure Human IgG whole molecule (Jackson ImmunoResearch Laboratories, West Grove, PA) and 1\% NaN3 (Sigma) for $30 \mathrm{~min}$. The cells were then sequentially incubated in the dark in the primary and secondary antibodies for $30 \mathrm{~min}$. Fluorescence was analyzed by a FACS Calibur (BD Biosciences) using FCS Express software package (De Novo Software, Los Angeles, CA).

\section{Apoptosis assay}

Apoptosis of expanded cells was detected using the Annexin V-FITC Apoptosis Detection Kit (BioVision Inc., Milpitas, CA). Briefly, $2 \times 105$ detached cells from each group $(n=3)$ were labeled with FITC conjugated annexin $\mathrm{V}$ and propidium iodide for $15 \mathrm{~min}$. Samples were measured using FACS Calibur (BD Biosciences) and analyzed using the FCS Express software package (De Novo Software).

Resistance to oxidative stress

Expanded cells were incubated with $1 \mathrm{mM}$ hydrogen peroxide $\left(\mathrm{H}_{2} \mathrm{O}_{2}\right)$ at $37{ }^{\circ} \mathrm{C}$ for $1 \mathrm{~h}$. To measure intracellular reactive oxygen species (ROS), cells were incubated with $1 \mu \mathrm{M}$ 2',7'dichlorodihydrofluorescein diacetate (H2DCFDA) (Life Technologies) for $15 \mathrm{~min}$. The plates were read on a FIUOstar OPTIMA (BMG Labtech Inc., Cary, NC) with an excitation wavelength of 485 $\mathrm{nm}$ and emission of $530 \mathrm{~nm}$. Samples were assayed in triplicate.

\section{Cell and ECM interaction: evidence in morphology, chemistry, and elasticity}

Scanning electron microscope (SEM)

Representative samples $(n=2)$ were primarily fixed in $2.5 \%$ glutaraldehyde (Sigma) for $2 h$, followed by secondary fixation in $2 \%$ osmium tetroxide (Sigma) for another $2 \mathrm{~h}$. The samples were then dehydrated in a gradient ethanol series, in hexamethyldisilazane (HMDS, Sigma) at a ratio of $1: 1$ with ethanol twice for $1 \mathrm{~h}$ each time, in HMDS at a ratio of 1:2 with ethanol overnight, and in HMDS three times for $4 \mathrm{~h}$ each time. The samples were air-dried for $24 \mathrm{~h}$ and gold sputter was added. The images were recorded by an SEM (Hitachi, Model S 2400).

Proteomics analysis of $\mathrm{AE}$ and $\mathrm{FE}$ 
Decellularized ECMs were collected in $25 \mathrm{mM}$ Tris- $\mathrm{HCl}(\mathrm{pH} 7.6) / 150 \mathrm{mM} \mathrm{NaCl} / 0.5 \%$ SDS buffer solution containing protease inhibitors. Samples were precipitated with cold acetone and the pellet was solubilized with ProteaseMax (Promega, Madison, WI) detergent prepared in $50 \mathrm{mM}$ $\mathrm{NH}_{4} \mathrm{HCO}_{3}$ buffer ( $\mathrm{pH}$ 7.9). Protein samples were reduced with dithiothreitol (DTT) at $56{ }^{\circ} \mathrm{C}$ for 45 min and alkylated with $20 \mathrm{mM}$ iodoacetamide in the dark at room temperature for $0.5 \mathrm{~h}$. Trypsin digestion was performed at $37^{\circ} \mathrm{C}$ overnight. Digested peptide mixtures were each separated by high $\mathrm{pH}$ reversed phase chromatography on a $\mathrm{C} 18$ column and 40 fractions (600 mL each) were collected and pooled into eight larger fractions due to the preliminary nature of the experiment. Samples were concentrated under vacuum to approximately $50 \mathrm{~mL}$, and $8 \mathrm{~mL}$ of sample was analyzed on an LTQ-FT Ultra hybrid mass spectrometer (Thermo Fisher Scientific, San Jose, $\mathrm{CA}$ ). In addition, we performed chemical digestion on the remaining pellets using $\mathrm{CNBr}$ for $24 \mathrm{~h}$. The digests were neutralized and peptides were separated by 1D SDS-PAGE; the entire lanes were cut and the bands subjected to trypsin digestion and tandem mass spectrometry analysis as described above. Data analysis was performed as previously reported (reference: http://www.ncbi.nlm.nih.gov/pubmed/ 22897585) with the following exceptions: Spectra were searched against human entries in the Swissprot sequence database (release 04/18/2012; 20,324 sequences), and identifications required a minimum protein confidence of $>99 \%$, two or more unique peptides, and peptide confidence of $>95 \%$.

Immunofluorescent staining of $\mathrm{AE}$ and $\mathrm{FE}$

Decellularized ECMs were fixed with $4 \%$ paraformaldehyde for 30 min. After blocking in $10 \%$ normal goat serum for $1 \mathrm{~h}$, ECMs were incubated with monoclonal antibody for type I collagen (Sigma), fibronectin (Santa Cruz Biotechnology, Dallas, TX), or laminin (Santa Cruz Biotechnology) overnight followed by Alexa Fluor 488 goat anti-mouse IgG (Life Technologies) for 30 min. ECMs were visualized with a Zeiss LSM 510 confocal on an Axiolmager Z1 microscope using a 63 objective lens (Carl Zeiss, Jena, Germany).

Atomic force microscopy (AFM)

Elasticity of decellularized ECMs and expanded cells was investigated using an MFP-3D-BIO AFM (Asylum Research, TE2000U, Santa Barbara, CA) integrated with an inverted fluorescence microscope (Nikon Eclipse, TieU, Nikon Instruments Inc., Melville, NY) and Olympus TR400-PB cantilevers with spring constant of $0.09 \mathrm{~N} / \mathrm{m}$. The samples were imaged in Petri dishes filled with aMEM containing $10 \%$ FBS. The location of the cantilever on the sample was confirmed using a $10 \times$ microscopy objective; each sample was mapped in five randomly selected $50 \mu \mathrm{m}$ by $50 \mu \mathrm{m}$ areas for a total of $\mathbf{2 0 0 0}$ data points/sample. For the quantitative nanomechanical analysis, a Sneddon's modification of the Hertz model developed for a four-sided pyramid was employed. The ECM and cell elasticity (Young's modulus, E) were corrected with the indentation of the tip, $\delta$, 
through the following equation: $E=\pi / 2 \cdot\left(1-v^{2} F\right) / \tan \alpha \delta^{2}$, where $E$ is the Elastic modulus, $v$ is Poisson's ratio with a value of 0.5 for ECM and cells, $F$ is the force given by the cantilever deflection multiplied with the cantilever spring constant $(0.09 \mathrm{~N} / \mathrm{m}), \alpha$ is the open angle used in this study which had a value of $36^{\circ}$, and lastly $\delta$ is the indentation depth [19].

\section{Chondrogenic induction and evaluation}

Chondrogenic induction

Expanded cells $\left(3 \times 10^{5}\right)$ were centrifuged at $500 \mathrm{~g}$ in a $15-\mathrm{mL}$ polypropylene tube to form a pellet. After overnight incubation (day 0 ), the pellets were cultured in a serum-free chondrogenic medium consisting of high-glucose Dulbecco's modified Eagle's medium (DMEM), $40 \mathrm{mg} / \mathrm{mL}$ proline, $100 \mathrm{nM}$ dexamethasone, $100 \mathrm{U} / \mathrm{mL}$ penicillin, $100 \mathrm{mg} / \mathrm{mL}$ streptomycin, $0.1 \mathrm{mM}$ ascorbic

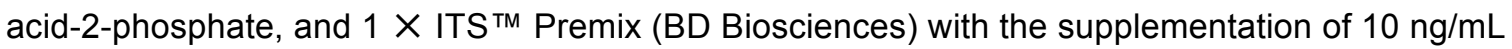
transforming growth factor beta3 (TGF- $\beta 3$, PeproTech Inc., Rocky Hill, NJ) in a $5 \% \mathrm{O}_{2}$ incubator as long as 21 days.

Histology and immunostaining

Representative pellets $(n=2)$ were fixed in $4 \%$ para-formaldehyde at $4{ }^{\circ} \mathrm{C}$ overnight, followed by dehydrating in a gradient ethanol series, clearing with xylene, and embedding in paraffin blocks. Five- $\mu \mathrm{m}$ sections were stained with Alcian blue (counterstained with fast red) and Safranin $O$ (counterstained with hematoxylin) for sulfated glycosaminoglycans (GAGs). For immunohistochemistry, the sections were immunolabeled with primary antibody against type II collagen [II-II6B3, Developmental Studies Hybridoma Bank (DSHB), lowa City, IA], followed by the secondary antibody of biotinylated horse anti-mouse IgG or IgM (Vector, Burlingame, CA). Immunoactivity was detected using Vectastain ABC reagent (Vector) with 3,3'-diaminobenzidine as a substrate.

Biochemical analysis for DNA and GAG content

Representative pellets $(n=4)$ were digested at $60{ }^{\circ} \mathrm{C}$ for $4 \mathrm{~h}$ with $125 \mathrm{mg} / \mathrm{mL}$ papain in PBE buffer (100 mM phosphate, $10 \mathrm{mM}$ ethyl-enediaminetetraacetic acid, $\mathrm{pH}$ 6.5) containing $10 \mathrm{mM}$ cysteine. To quantify cell density, the amount of DNA in the papain digestion was measured using the QuantiT ${ }^{\mathrm{TM}}$ PicoGreen ${ }^{\circledR}$ dsDNA assay kit (Life Technologies) with a CytoFluor ${ }^{\circledR}$ Series 4000 (Applied Bio-systems, Foster City, CA). GAG was measured using dimethyl-methylene blue dye and a Spectronic ${ }^{\mathrm{TM}}$ BioMate $^{\mathrm{TM}} 3$ Spectrophotometer (Thermo Fisher Scientific) with bovine chondroitin sulfate (Sigma) as a standard.

TaqMan® real-time polymerase chain reaction (PCR) 
Total RNA was extracted from pellets ( $n$ 1/4 4) using an RNase-free pestle in TRIzol (Life Technologies). Two mg of mRNA was used for reverse transcriptase with the High-Capacity cDNA Archive Kit (Applied Biosystems) at $37^{\circ} \mathrm{C}$ for $120 \mathrm{~min}$. Chondrogenic marker genes [SRY (sex determining region Y)-box 9 (SOX9) (Assay ID Hs00165814_m1), aggrecan (ACAN) (Assay ID AIQJAP5), and type II collagen (COL2A1) (Assay ID Hs00156568_m1)] were customized by Applied Biosystems as part of their Custom TaqMan ${ }^{\circledR}$ Gene Expression Assays. Eukaryotic $18 \mathrm{~S}$ rRNA (Assay ID HS99999901_s1 ABI) was carried out as the endogenous control gene. Realtime PCR was performed with the iCycler $\mathrm{IQ}^{\mathrm{TM}}$ Multi Color RT-PCR Detection and calculated by computer software (PerkineElmer, Wellesley, MA). Relative transcript levels were calculated as $\mathrm{X}$ $=2^{-\Delta \Delta \mathrm{Ct}}$, in which $\Delta \Delta \mathrm{Ct}=\Delta \mathrm{E}-\Delta \mathrm{C}, \Delta \mathrm{E}=\mathrm{Ct}_{\mathrm{exp}}-\mathrm{Ct}_{18 \mathrm{~s}}$, and $\Delta \mathrm{C}=\mathrm{Ct}_{\mathrm{Ct} 1}-\mathrm{Ct}_{18 \mathrm{~s}}$.

Biomechanical testing

Representative pellets $(n=6)$ were placed into a reservoir filled with PBS and loaded onto the custom miniature stepper motor driven compression device. This device used a $10 \mathrm{~g}$ load cell and a miniature differential variable reluctance transducer (DVRT) for displacement readout. A small preload of $0.0001 \mathrm{~N}$ was applied followed by a $10 \%$ strain at $1 \mathrm{~s}$ duration. From the linear portion of the load displacement curve, the Stiffness and Young's modulus (YMOD) were calculated for the spherical shaped pellet according to Rodriguez et al. [20].

Potential mechanisms underlying ECM-based cell expansion and subsequent chondrogenic differentiation

Western blot

Adult SDSCs from cell expansion and pellets before (day 0 ) and after (day 10) chondrogenic induction were dissolved in the lysis buffer (Cell Signaling) with protease inhibitors. Total proteins were quantified using BCA ${ }^{\mathrm{TM}}$ Protein Assay Kit (Thermo Fisher Scientific). Thirty micrograms of protein from each sample were denatured and separated using NuPAGE $®$ Novex® Bis-Tris Mini Gels in the XCell SureLock ${ }^{\mathrm{TM}}$ Mini-Cell (Life Technologies) at $120 \mathrm{~V}$ at $4^{\circ} \mathrm{C}$ for $3 \mathrm{~h}$. Bands were transferred onto a nitrocellulose membrane using an XCell II ${ }^{\mathrm{TM}}$ Blot module (Life Technologies) at $15 \mathrm{~V}$ at $4^{\circ} \mathrm{C}$ overnight. The membrane was incubated with primary monoclonal antibodies in $5 \%$ bovine serum albumin (BSA) in TBST buffer (10 mM Tris- $\mathrm{HCl}, \mathrm{pH} 7.5,150 \mathrm{mM} \mathrm{NaCl}, 0.05 \%$ Tween-20) for $1 \mathrm{~h}$ ( $\beta$-actin served as an internal control), followed by the secondary antibody of horseradish peroxidase-conjugated goat anti-mouse (Thermo Fisher Scientific) for $1 \mathrm{~h}$. SuperSignal West Femto Maximum Sensitivity Substrate and CL-XPosure Film (Thermo Fisher Scientific) were used for exposure. The primary antibodies used in immunoblotting included the MAPK family antibody sampler kit [extracellular signal-regulated protein kinases 1 and 2 (Erk1/2), Jun N-terminal kinase (Jnk), and p38], phosphorylated ( $p$-) MAPK family antibody sampler kit, 
and Wnt signaling antibody sampler kit (Cell Signaling). Wnt11 polyclonal antibody was obtained from Thermo Fisher Scientific.

\section{Adipogenic and osteogenic induction and evaluation}

Adipogenic differentiation

Expanded cells were cultured for 21 days in adipogenic medium (growth medium supplemented with $1 \mathrm{mM}$ dexamethasone, $0.5 \mathrm{mM}$ isobutyl-1-methyxanthine, $200 \mathrm{mM}$ indomethacin, and $10 \mathrm{mM}$ insulin). The cultures $(n=3)$ were fixed in $4 \%$ paraformaldehyde and stained with a $0.6 \%(w / v)$ Oil Red O (ORO) solution (60\% iso-propanol, $40 \%$ water) for 15 min. Intracellular lipid-filled droplet-bound staining was photographed under a Nikon TE300 phase-contrast microscope (Nikon, Tokyo, Japan). Adipogenic marker genes [lipoprotein lipase (LPL, Assay ID Hs00173425_m1) and peroxisome proliferator-activated receptor gamma (PPARG, Assay ID Hs01115513_m1)] were quantified using TaqMan® real-time PCR.

\section{Osteogenic differentiation}

Expanded cells $(n=3)$ cultured for 21 days in osteogenic medium (growth medium supplemented with $0.1 \mathrm{mM}$ dexamethasone, $10 \mathrm{mM} \beta$-glycerol phosphate, $50 \mathrm{mM}$ ascorbate-2-phosphate, and $0.01 \mathrm{mM} \mathrm{1,25-dihydroxyvitamin} \mathrm{D3)} \mathrm{were} \mathrm{collected} \mathrm{for} \mathrm{alkaline} \mathrm{phosphatase} \mathrm{(ALP)} \mathrm{activity} \mathrm{assay}$ with a reagent kit (Sigma) by measuring the formation of $p$-nitrophenol ( $p$-NP) from $p$-nitrophenyl phosphate following the manufacturer's instructions. p-NP was quantified based on the spectrophotometric absorbance at $405 \mathrm{~nm}$, and enzymatic activity was expressed as millimoles of $\mathrm{p}-\mathrm{NP} / \mathrm{min} / \mathrm{mg}$ DNA. For evaluation of calcium deposition, induced cells $(\mathrm{n}=3)$ were fixed with $70 \%$ ice-cold ethanol for $1 \mathrm{~h}$, and then incubated in $40 \mathrm{mM}$ Alizarin Red S (ARS) at pH 4.2 for 20 min with agitation. After rinsing, matrix mineral-bound staining was photographed. Quantification of staining was performed by incubating cells with a solution of $10 \%$ acetic acid and $20 \%$ methanol for $15 \mathrm{~min}$ to extract the calcium-chelated ARS stain. Samples were analyzed for absorption at $450 \mathrm{~nm}$, which was normalized to total DNA amount for standardization.

\section{Statistical analysis}

ManneWhitney $U$ test was used for pairwise comparison. All statistical analyses were performed with SPSS 13.0 statistical software (SPSS Inc., Chicago, IL). p values less than 0.05 were considered statistically significant. 


\section{RESULTS}

\section{Evaluation of ECM-expanded ASDSC proliferation and viability}

To evaluate the proliferative effect exerted by FE and AE, human ASDSCs were seeded on three substrates: PL, AE, or FE. Cell morphology showed that PL4 exhibited flattened and enlarged morphology (red color); in contrast, ASDSCs grown on ECMs, especially FE4, exhibited a spindle-like shape overlapped with matrix fibers immunostained with type I collagen (initial color was green and merged color was yellow); cell expansion on FE yielded the highest cell number followed by $A E$ with $P L$ having the lowest cell number (Fig. 6.1A). Consistent with the cell counting, AE expansion yielded a 2.1-fold increase and FE expansion yielded a 2.6-fold increase in proliferation index compared with PL expansion (Fig. 6.1B). Our flow cytometry data showed that MSC surface markers, CD29, CD90, and CD105, were down-regulated slightly in percentage but heavily at the median; SSEA4 was up-regulated both in percentage and the median despite an up-regulation only in percentage for integrin $\beta 5$ (Fig. 6.1C). To evaluate cell viability after expansion on these substrates, flow cytometry was used to measure the percentage of apoptotic cells as well as expanded cells' resistance to apoptotic stimuli; the data showed that FE4 exhibited the fewest apoptotic cells (Fig. 6.1D) and both FE4 and AE4 produced about half the ROS compared with PL4 upon treatment with $\mathrm{H}_{2} \mathrm{O}_{2}$ (Fig. 6.1E).

\section{Evaluation of ECM microstructure, composition, and elasticity}

SEM was used to evaluate cell and matrix morphology and help characterize the expansion of ASDSCs on their culture substrates. In accord with cell morphology under confocal microscopy (Fig. 6.1A), SEM data showed that PL4 exhibited an enlarged and flattened cell shape (Fig. 6.2A); in contrast, both $\mathrm{AE} 4$ and FE4, with a fibroblast-like shape, were embedded in the corresponding matrix (Fig. 6.2B and C, respectively). Compared to a rough surface in $\mathrm{AE}$ (Fig. 6.2B), FE exhibited a smoother appearance (Fig. 6.2C), indicative of fine matrix fibers.

From proteomics analyses, we identified peptides that were mapped to approximately 260 proteins or protein families; the most prominent proteins were from the ECM. Collagens were the most abundant as reflected by number of peptides identified, sequence coverage, and ion envelope areas (Fig. 6.2D,E). As shown in Table 6.1, several proteins of interest were identified and the number of spectra assigned to a given protein for both ECMs was listed. Intriguingly, we found that fibrillar collagens shifted into the "insoluble" fraction for AE but not in FE; in contrast, FE contained a fair amount of clusterin but none was detected in AE. Furthermore, we found that some unique matrix proteins existed in FE, such as fibrillin-2, tenascin, and versican core protein, while AE had advantageous matrix proteins, such as elastin, fibulin-6, periostin, thrombospondin1, and TGFB1. Intriguingly, no laminin was measured in either ECM despite plenty of fibronectin 
and type I collagen, which was confirmed by our immunostaining data in both AE (Fig. 6.2F) and FE (Fig. 6.2G).

To determine the effect of mechanical properties of culture substrates on grown cells, AFM was used to measure the elasticity of both substrates and expanded cells. The elasticity of PL could be considered as infinite [21]; AE exhibited a higher elasticity than FE [61.82 \pm 35.86 versus $58.26 \pm 13.37(\mathrm{kPa})(\mathrm{p}=0.000)]($ Fig. $6.2 \mathrm{H})$. Interestingly, the elasticity of expanded ASDSCs was parallel to their substrate; the comparison between PL4 and AE4 was $9.07 \pm 4.56$ versus $3.60 \pm 1.79(\mathrm{kPa})(\mathrm{p}=0.000)$ while the comparison between AE4 and FE4 was $3.60 \pm 1.79$ versus $3.45 \pm 2.29(\mathrm{kPa})(p=0.024)$ (Fig. 6.21).

\section{ECM-mediated ASDSC chondrogenic capacity and potential mechanisms}

To determine the rejuvenation effects of ECM expansion on ASDSC chondrogenic potential, expanded ASDSCs were chondrogenically induced for 21 days. The evaluation consisted of chondrogenic mechanism analysis at the early stage and chondrogenic functionality assessment at the later stage. At the early stage, 10-day pellets were evaluated for chondrogenic differentiation using histology, immunostaining, and real-time PCR. The pellets from PL4 were the smallest in size while those from FE4 were the largest; the pellets from FE4 were also intensely stained with both Alcian blue and Safranin O for sulfated GAGs and immunostained for type II collagen (Fig. 6.3A). All chondrogenic marker genes (SOX9, ACAN, and COL2A1) showed a similar trend, which was that plastic expansion down-regulated while ECM expansion upregulated chondrogenic genes with FE4 being the highest (Fig. 6.3B). To determine potential mechanisms underlying ECM expansion and subsequent chondrogenic differentiation, the MAPK and Wnt signaling pathways were evaluated using Western blot. Our data showed that, compared to up-regulation of p-p38 and p-Jnk, ECM expansion dramatically down-regulated p-Erk; despite the fact that $p$-Erk bounced back in the cell condensation phase, the lowest level was seen in FE4 pellets; different from the change of $p$ - Erk, ECM expansion yielded ASDSC pellets with a relatively lower level of $\mathrm{p}$-Jnk in the cell condensation phase though no significant difference was found among groups after 10-day chondrogenic induction (Fig. 6.4A). Our data also showed that ECM pretreatment down-regulated Wnt3a but up-regulated Wnt5a and Wnt11 in expanded SDSCs; these effects were relayed through cell condensation and chondrogenic differentiation, especially for the Wnt11-mediated non-canonical pathway (Fig. 6.4B).

At the later stage, 21-day pellets were evaluated for chondrogenic differentiation using histology, immunostaining, real-time PCR, biochemistry, and mechanical properties. Similar to the data at day 10, the pellets from PL4 were the smallest in size while those from FE4 were the largest; the pellets from ECM expansion, particularly from FE4, were intensely stained for sulfated GAGs and 
immunostained for type II collagen (Fig. 6.5A). The pellets from FE4 exhibited the highest level of chondrogenic marker genes (SOX9, ACAN, and COL2A1) followed by those from AE4 (ACAN and COL2A1); pellets from the plastic expansion group had the lowest level (Fig. 6.5B). Our biochemistry data showed that AE expansion yielded higher cell viability (DNA\% by day 0 ) during chondrogenic induction; FE expansion yielded the highest GAG amount per pellet and ratio of GAG to DNA (chondrogenic index) followed by those from $A E$ expansion with $P L$ expansion having the least (Fig. 6.5C). Our functionality data showed that ECM expansion yielded ASDSC pellets with significantly enhanced size and comparable Stiffness and Young's modulus (Fig. $6.5 \mathrm{D})$.

\section{Evaluation of ECM-expanded ASDSC adipogenic and osteogenic potentials}

To determine the rejuvenation effect of ECM expansion on ASDSC adipogenic and osteogenic potentials, expanded ASDSCs were incubated in corresponding lineage induction medium for 21 days. Our adipogenic induction data showed that expanded ASDSCs from varied substrates all stained positive for ORO (Fig. 6.6A); FE4 exhibited the highest levels of LPL and PPARG mRNAs followed by AE4 (LPL); PL expansion had the lowest levels (Fig. 6.6B). Our osteogenic induction data showed that expanded SDSCs from varied substrates all stained positive for ARS (Fig. 6.6C) and ALP (Fig. 6.6E); the quantitative assessment for relative ARS density (Fig. 6.6D) and ALP activity (Fig. 6.6F) did not show a significant difference among groups. 


\section{DISCUSSION}

Aging is characterized by reduced tissue and organ functions and regenerative capacities, accompanied by decreases in tissue resident stem cell numbers and loss of potency. Ever since Conboy et al.'s study [22], researchers focused their interest on the influence of ECM on stem cell rejuvenation; however, none have investigated the effect of young ECM on old tissue-specific stem cells' chondrogenic potential. In this study, we found that decellularized ECM, especially from young donors, rejuvenated ASDSCs in expansion, as evidenced by increased cell proliferation and resistance to apoptosis. Chondrogenic differentiation also improved, as evidenced by enhanced pellet size, pellet composition (aggrecan and type II collagen at both mRNA and protein levels), and pellet functionality (Stiffness and Young's Modulus). We found that the MAPK and Wnt signaling pathways were also actively involved in ECM-mediated ASDSC expansion and chondrogenic potential. In the characterization of cell and matrix interaction, we found that unique proteins in FE favored ASDSC rejuvenation; the low elasticity of FE decreased expanded ASDSC elasticity, which might benefit cell chondrogenic and adipogenic potentials.

In previous reports, we discussed the rejuvenation effect and underlying potential mechanisms of decellularized ECM on expanded ASDSCs compared with plastic expansion [5,12]. In this study, we were interested in the comparison between $\mathrm{FE}$ and $\mathrm{AE}$ in composition and their influence on rejuvenation. We found that $\mathrm{FE}$ was better than $\mathrm{AE}$ in promoting cell proliferation and preventing apoptosis, which might be explained by the discrepancy in chemical composition of these two matrices. Our proteomics data showed that FE had more fibrillin-2 (76:2), tenascin C (259:120), and clusterin (5:0) than AE. Fibrillins are produced by fibroblasts physiologically in developing or regenerating tissues; fibrillin-2 binds to other ECM proteins, forming microfibrils, and is mostly expressed during embryogenesis [23]. Tenascin C is a hexameric ECM glycoprotein, which is responsible for various dynamic cellular activities, including adhesion [24], tissue remodeling [25], migration [25], proliferation [26], and growth [24]. Absence of tenascin $C$ alters neural stem cell

number and function in the subventricular zone [27]; tenascin $C$ deletion has also been shown to affect primitive cell populations in the hematopoietic system, raising the possibility that it participates in several stem cell niches as a modulator of growth factor signaling [28]. Despite the fact that both are largely restricted to developing fetal tissues [29], enhanced expression of fibrillin-2 and tenascin $C$ has been observed in adults with fibroproliferative conditions, such as wound healing and sclerosis $[23,25,30]$. Moreover, a fair amount of clusterin was found in FE while none was detected in $A E$, which might be responsible for less apoptosis observed in $F E$ expanded ASDSCs since clusterin could inhibit apoptosis by interacting with activated Bax [31]. 
In contrast, $A E$ had more biglycan (95:37), decorin (95:40), dermatopontin (35:16), elastin (18:2), periostin (400:125), thrombospondin-1 (79:6), and TGFß1 (258:164) than FE. Small leucin-rich proteoglycans (SLRPs) decorin and biglycan were reported to reduce proliferation of preadipocytes, partly by induction of apoptosis [32]. Dermatopontin has been implicated in chondrogenic differentiation [33,34]. Periostin was first identified in osteoblast-like cells [35] and it is thought to play an important role in bone formation and development of periodontal ligaments [36,37]. Notably, periostin and TGF $\beta$ are all involved in osteo-chondrogenesis [38]. Thrombospondin-1 signaling through CD47 inhibits self-renewal by regulating C-Myc and other stem cell transcription factors [39]. Elastin, a structural component of ECM that confers elasticity to tissues, has been used to make biopolymers for MSC differentiation [40]. The low level of elastin measured in FE is because donor cells were contributed by a 6-month-old fetus and elastin expression occurs from midgestation [41]. The above data showed that, compared with the role of $\mathrm{FE}$ during cell expansion, $\mathrm{AE}$ has more matrix components favoring cell differentiation and apoptosis rather than cell proliferation, which is consistent with the observed differences in elasticity and ECM/collagen architecture, i.e. fibrillar collagens were shifted into the "insoluble" fraction in $A E$ but not in FE.

Our previous study using flow cytometry in human BMSCs showed that ECM expansion dramatically increased the level of integrin $\beta 5$ but decreased integrin $\beta 1$ (also termed CD29) at median rather than in percentage [16] and is further confirmed by this report. We also found that FE expansion yielded human ASDSCs with even higher integrin $\beta 5$ but lower integrin $\beta 1$ expression than $A E$, which might be associated with $E C M$ elasticity. Matrix elasticity could have an effect on lineage differentiation potential according to a recent report that ECM elasticity affects integrin activity and trafficking to modulate integrin bone morphogenetic protein (BMP) receptor internalization, thus contributing to stem cell lineage specification [42]. The lower level of elastin in FE may be responsible for lower matrix elasticity compared with $A E$, which is confirmed by the AFM data; lower elasticity in FE might be associated with enhancement of ASDSC chondrogenic and adipogenic potentials, suggesting that matrix elasticity might contribute to lineage-specific differentiation. In contrast to previous reports in which direct differentiation effects assessed matrix elasticity $[43,44]$, in this study, matrix elasticity was investigated for its influence on cell proliferation and differentiation potential.

There have been few studies investigating potential mechanisms underlying the rejuvenating effect of ECM on stem cells. Heterochronic parabiosis by exposure of satellite cells from old mice to young serum restored the activation of Notch signaling as well as the proliferation and regenerative capacity of aged satellite cells [22]. Young matrix derived from human diploid fibroblasts restored senescent fibroblasts evidenced by resumption of proliferative potential, 
growth factor responsiveness, reduction of intracellular ROS levels, recovery of mitochondrial membrane potential, and increased telomere length [45]. Besides the mechanisms mentioned above, in this study, we investigated ECM expansion related changes of the MAPK and Wnt signals, two key pathways involved in cell proliferation and chondrogenic differentiation. ECM pretreatment down-regulated p-Erk level in expanded ASDSCs, indicative of a decline in cell senescence [46]; p- Erk was then up-regulated during cell condensation and down- regulated after 10-day chondrogenic induction, in particular for those expanded on FE, in accord with previous reports that $p$-Erk signals could promote stem cell chondrogenesis in the early stage but inhibit chondrogenic differentiation in the later stage [47]. The functional switch of p-Erk during chondrogenesis supported the claim that expansion on ECM, especially from a young donor, favored ASDSC proliferation and chondrogenic potential.

Our data also showed that Wnt3a, a typical canonical signal, was down-regulated in ECM expanded ASDSCs and then maintained a comparable level with plastic expanded cells during chondrogenic differentiation; in contrast, Wnt5a and Wnt11, two typical noncanonical signals, were dramatically up-regulated in ECM expanded cells, especially those cells grown on FE, and subsequent chondrogenic differentiation. This finding is surprising because Wnt3a was previously considered a stimulator of MSC proliferation [48] while Wnt5a and Wnt11 function by inhibiting $\beta$ catenin signaling and favoring cell migration and differentiation $[49,50]$, despite the fact that both Wnt5a and Wnt11 were also involved in cell proliferation. Wnt5a controlled the proliferation of undifferentiated limb mesenchymal cells in vivo [51] and Wnt11 regulated transcriptional factors octamer-binding transcription factor 4 (OCT4) and NANOG associated with the pluripotent state and affected lineage specification genes toward mesodermal development [52]. Our immunoblotting data showed that Wnt5a and p38 shared a similar trend in cell expansion and condensation, which is in agreement with a previous report that the stimulatory roles of Wnt5a on chondrogenesis in micromass cultures are dependent on the activation of both p38 and protein kinase C (PKC) signaling [53]; PKC is required for MSC chondrogenesis [54]. After a 10-day chondrogenic induction, FE expanded ASDSCs exhibited a down- regulation of p-p38 but an upregulation of Wnt5a which corresponds to the highest chondrogenic differentiation because the inhibition of p38 can cause early stage hypertrophic chondrocytes to revert back to a prehypertrophic phenotype [55] while Wnt5a conversely blocks chondrocyte hypertrophy [56]. The up-regulation of p-Jnk in ASDSCs after expansion on ECM might contribute to an increase of Wnt11. Wnt11 was found to have expression sites restricted within the prehypertrophic chondrocytes of the cartilage elements; it enhanced chondrogenesis without promoting terminal differentiation [57]. Despite the fact that Wnt3a might be transiently up-regulated in the early stage of ECM expansion, our data indicated that noncanonical Wnt signals dominated ECM expanded ASDSCs and subsequent chondrogenic differentiation. 
Our study demonstrated that decellularized ECM deposited by fetal SDSCs can provide a rejuvenating effect and a tissue-specific stem cell microenvironment to enhance adult SDSC expansion and chondrogenic potential, possibly through the MAPK and Wnt signaling pathways. The detailed mechanisms underlying ECM enhanced cell proliferation and chondrogenic potential need further investigation. Decellularized ECM from fetal SDSCs, which demonstrates a "Fountain of Youth" effect for adult SDSC rejuvenation, provides hope for solving the challenge of cell senescence in cartilage engineering and regeneration. 


\section{ACKNOWLEDGMENTS}

The authors thank Suzanne Danley for her help in editing the manuscript and Vincent L. Kish for biomechanical testing and Dr. Sudjit Luanpitpong for technical support. This project was partially supported by Research Grants from the West Virginia University Senate Research Grant Award (R-12-010), the AO Foundation (S-12- 19P), and the National Institutes of Health (NIH) (1 R03 AR062763- 01A1 and 5 R03 DE021433-02) to Ming Pei; from NIH/NCATS Colorado CTSI Grant (UL1 TR000154) and $\mathrm{NIH} / \mathrm{NCl}$ Innovative Molecular Analysis Technologies Program (R21CA132741) to Kirk C. Hansen; and from the NanoSAFE and National Science Foundation grant (EPS-1003907) to Cerasela Z. Dinu. 


\section{REFERENCES}

[1] Boeuf S, Richter W. Chondrogenesis of mesenchymal stem cells: role of tissue source and inducing factors. Stem Cell Res Ther 2010;1:31.

[2] Hellingman CA, Koevoet W, van Osch GJ. Can one generate stable hyaline cartilage from adult mesenchymal stem cells? A developmental approach. J Tissue Eng Regen Med 2012;6:e1e11.

[3] Jones BA, Pei M. Synovium-derived stem cells: a tissue-specific stem cell for cartilage engineering and regeneration. Tissue Eng Part B Rev 2012;18:301e11.

[4] Li J, Pei M. Cell senescence: a challenge in cartilage engineering and regeneration. Tissue Eng Part B Rev 2012;18:270e87.

[5] He F, Chen X, Pei M. Reconstruction of an in vitro tissue-specific microenvironment to rejuvenate synovium-derived stem cells for cartilage tissue engineering. Tissue Eng Part $A$ 2009;15:3809e21.

[6] HeF,Pei M. Extracellular matrix enhances differentiation of adipose stem cells from infrapatellar fat pad toward chondrogenesis. J Tissue Eng Regen Med 2013;7:73e84.

[7] Li J, Pei M. Optimization of an in vitro three-dimensional microenvironment to reprogram synovium-derived stem cells for cartilage tissue engineering. Tissue Eng Part A 2011;17:703e12.

[8] Pei M, He F, Wei L. Three dimensional cell expansion substrate for cartilage tissue engineering and regeneration: a comparison in decellularized matrix deposited by synoviumderived stem cells and chondrocytes. J Tissue Sci Eng 2011;2:104.

[9] He F, Pei M. Rejuvenation of nucleus pulposus cells using extracellular matrix deposited by synovium-derived stem cells. Spine 2012;37:459e69.

[10] Pei M, He F. Extracellular matrix deposited by synovium-derived stem cells delays chondrocyte dedifferentiation and enhances redifferentiation. J Cell Physiol 2012;227:2163e74.

[11] Pei M, Shoukry M, Li JT, Daffner S, France J, Emery SE. Modulation of in vitro microenvironment facilitates synovium-derived stem cell-based nucleus pulposus tissue regeneration. Spine 2012;37:1538e47.

[12] Pei M, Li JT, Shoukry M, Zhang Y. A review of decellularized stem cell matrix: a novel cell expansion system for cartilage tissue engineering. Eur Cell Mater 2011;22:333e43.

[13] Pei M, He F, Li JT, Tidwell J, Jones A, McDonough EB. Repair of large animal partialthickness cartilage defects using matrix rejuvenated synovium- derived stem cells. Tissue Eng Part A 2013;19:1144e54.

[14] Simonsen JL, Rosada C, Serakinci N, Justesen J, Stenderup K, Rattan SI, et al. Telomerase expression extends the proliferative life-span and maintains the osteogenic potential of human bone marrow stromal cells. Nat Biotechnol 2002;20:592e6. 
[15] Pei M, Zhang Y, Li JT, Chen DQ. Antioxidation of decellularized stem cell matrix promotes human synovium-derived stem cell-based chondrogenesis. Stem Cells Dev 2013;22:889e900.

[16] Pei M, He F, Kish VL. Expansion on extracellular matrix deposited by human bone marrow stromal cells facilitates stem cell proliferation and tissue- specific lineage potential. Tissue Eng Part A 2011;17:3067e76.

[17] Guillot PV, Gotherstrom C, Chan J, Kurata H, Fisk NM. Human first-trimester fetal MSC express pluripotency markers and grow faster and have longer telomeres than adult MSC. Stem Cells 2007;25:646e54.

[18] Li J, He F, Pei M. Creation of an in vitro microenvironment to enhance human fetal synoviumderived stem cell chondrogenesis. Cell Tissue Res 2011;345: 357e65.

[19] A-Hassan E, Heinz WF, Antonik MD, D'Costa NP, Nageswaran S, Schoenenberger CA, et al. Relative microelastic mapping of living cells by atomic force microscopy. Biophys $J$ 1998;74:1564e78.

[20] Rodriguez F, Patel SK, Cohen C. Measuring the modulus of a sphere by squeezing between parallel plates. J Appl Polym Sci 1990;40:285e95.

[21] Bhana B, Iyer RK, Chen WL, Zhao R, Sider KL, Likhitpanichkul M, et al. Influence of substrate stiffness on the phenotype of heart cells. Biotechnol Bioeng 2010;105:1148e60.

[22] Conboy IM, Conboy MJ, Wagers AJ, Girma ER, Weissman IL, Rando TA. Rejuvenation of aged progenitor cells by exposure to a young systemic environment. Nature 2005;433:760e4.

[23] Olivieri J, Smaldone S, Ramirez F. Fibrillin assemblies: extracellular determinants of tissue formation and fibrosis. Fibrogenesis Tissue Repair 2010;3:24.

[24] Chiquet-Ehrismann R, Chiquet M. Tenascins: regulation and putative functions during pathological stress. J Pathol 2003;200:488e99.

[25] Udalova IA, Ruhmann M, Thomson SJ, Midwood KS. Expression and immune function of tenascin-C. Crit Rev Immunol 2011;31:115e45.

[26] Huang W, Chiquet-Ehrismann R, Moyano JV, Garcia-Pardo A, Orend G. Interference of tenascin- $C$ with syndecan-4 binding to fibronectin blocks cell adhesion and stimulates tumor cell proliferation. Cancer Res 2001;61:8586e94.

[27] Garcion E, Halilagic A, Faissner A, ffrench-Constant C. Generation of an environmental niche for neural stem cell development by the extracellular matrix molecule tenascin C. Development 2004;131:3423e32.

[28] Ohta M, Sakai T, Saga Y, Aizawa S, Saito M. Suppression of hematopoietic activity in tenascin-C-deficient mice. Blood 1998;91:4074e83.

[29] Szalai E, Felszeghy S, Hegyi Z, Módis Jr L, Berta A, Kaarniranta K. Fibrillin-2, tenascin-C, matrilin-2, and matrilin-4 are strongly expressed in the epithelium of human granular and lattice type I corneal dystrophies. Mol Vis 2012;18:1927e36. 
[30] Brinckmann J, Hunzelmann N, Kahle B, Rohwedel J, Kramer J, Gibson MA, et al. Enhanced fibrillin-2 expression is a general feature of wound healing and sclerosis: potential alteration of cell attachment and storage of TGF-beta. Lab Invest 2010;90:739e52.

[31] Zhang H, Kim JK, Edwards CA, Xu Z, Taichman R, Wang CY. Clusterin inhibits apoptosis by interacting with activated Bax. Nat Cell Biol 2005;7:909e15.

[32] WardM,AjuwonKM.Regulationofpre-adipocyteproliferationandapoptosis by the small leucinerich proteoglycans, biglycan and decorin. Cell Prolif 2011;44:343e51.

[33] Derfoul A, Perkins GL, Hall DJ, Tuan RS. Glucocorticoids promote chondrogenic differentiation of adult human mesenchymal stem cells by enhancing expression of cartilage extracellular matrix genes. Stem Cells 2006;24:1487e95.

[34] Tallheden T, Karlsson C, Brunner A, Van Der Lee J, Hagg R, Tommasini R, et al. Gene expression during redifferentiation of human articular chondrocytes. Osteoarthr Cartil 2004;12:525e35.

[35] Takeshita S, Kikuno R, Tezuka K, Amann E. Osteoblast-specific factor 2: cloning of a putative bone adhesion protein with homology with the insect protein fasciclin I. Biochem $\mathrm{J}$ 1993;294:271e8.

[36] Kashima TG, Nishiyama T, Shimazu K, Shimazaki M, Kii I, Grigoriadis AE, et al. Periostin, a novel marker of intramembranous ossification, is expressed in fibrous dysplasia and in c-Fos overexpressing bone lesions. Hum Pathol 2009;40:226e37.

[37] Rios H, Koushik SV, Wang H, Wang J, Zhou HM, Lindsley A, et al. Periostin null mice exhibit dwarfism, incisor enamel defects, and an early-onset periodontal disease-like phenotype. Mol Cell Biol 2005;25:11131e44.

[38] Serra R, Chang C. TGF-beta signaling in human skeletal and patterning disorders. Birth Defects Res C Embryo Today 2003;69:333e51.

[39] Kaur S, Soto-Pantoja DR, Stein EV, Liu C, Elkahloun AG, Pendrak ML, et al. Thrombospondin-1 signaling through CD47 inhibits self-renewal by regulating C-Myc and other stem cell transcription factors. Sci Rep 2013;3:1673.

[40] Çelebi B, Cloutier M, Rabelo RB, Mantovani D, Bandiera A. Human elastinbased recombinant biopolymers improve mesenchymal stem cell differentiation. Macromol Biosci 2012;12:1546e54.

[41] Sephel GC, Buckley A, Davidson JM. Developmental initiation of elastin gene expression by human fetal skin fibroblasts. J Invest Dermatol 1987;88:732e5. [42] Du J, Chen X, Liang X, Zhang $\mathrm{G}, \mathrm{Xu} \mathrm{J}, \mathrm{He} \mathrm{L}$, et al. Integrin activation and internalization on soft ECM as a mechanism of induction of stem cell differ-

entiation by ECM elasticity. Proc Natl Acad Sci U S A 2011;108:9466e71. [43] Engler AJ, Sen S, Sweeney HL, Discher DE. Matrix elasticity directs stem cell lineage specification. Cell 2006;126:677e89. 
[44] Park JS, Chu JS, Tsou AD, Diop R, Tang Z, Wang A, et al. The effect of matrix stiffness on the differentiation of mesenchymal stem cells in response to TGF- b. Biomaterials 2011;32:3921e30.

[45] Choi HR, Cho KA, Kang HT, Lee JB, Kaeberlein M, Suh Y, et al. Restoration of senescent human diploid fibroblasts by modulation of the extracellular matrix. Aging Cell 2011;10:148e57.

[46] Park JS, Kim HY, Kim HW, Chae GN, Oh HT, Park JY, et al. Increased caveolin-1, a cause for the declined adipogenic potential of senescent human mesenchymal stem cells. Mech Ageing Dev 2005;126:551e9.

[47] Oh CD, Chang SH, Yoon YM, Lee SJ, Lee YS, Kang SS, et al. Opposing role of mitogenactivated protein kinase Subtypes, Erk-1/2 and p38, in the regulation of chondrogenesis of mesenchymes. J Biol Chem 2010;275:5613e9.

[48] Boland GM, Perkins G, Hall DJ, Tuan RS. Wnt 3a promotes proliferation and suppresses osteogenic differentiation of adult human mesenchymal stem cells. J Cell Biochem 2004;93:1210e30.

[49] Liu JX, Hu B, Wang Y, Gui JF, Xiao W. Zebrafish eaf1 and eaf2/u19 mediate effective convergence and extension movements through the maintenance of wnt11 and wnt5 expression. J Biol Chem 2009;284:16679e92.

[50] Ryu JH, Chun JS. Opposing roles of WNT-5A and WNT-11 in interleukin-1beta regulation of type II collagen expression in articular chondrocytes. J Biol Chem 2006;281:22039e47.

[51] Yamaguchi TP, Bradley A, McMahon AP, Jones S. A Wnt5a pathway underlies outgrowth of multiple structures in the vertebrate embryo. Development1999;126:1211e23.

[52] Vijayaragavan K, Szabo E, Bossé M, Ramos-Mejia V, Moon RT, Bhatia M. Noncanonical Wnt signaling orchestrates early developmental events toward hematopoietic cell fate from human embryonic stem cells. Cell Stem Cell 2009;4:248e62.

[53] Jin EJ, Park JH, Lee SY, Chun JS, Bang OS, Kang SS. Wnt-5a is involved in TGF- beta3stimulated chondrogenic differentiation of chick wing bud mesenchymal cells. Int J Biochem Cell Biol 2006;38:183e95.

[54] Chang SH, Oh CD, Yang MS, Kang SS, Lee YS, Sonn JK, et al. Protein kinase C regulates chondrogenesis of mesenchymes via mitogen-activated protein kinase signaling. J Biol Chem 1998;273:19213e9.

[55] Zhen X, Wei L, Wu Q, Zhang Y, Chen Q. Mitogen-activated protein kinase p38 mediates regulation of chondrocyte differentiation by parathyroid hormone. J Biol Chem 2001;276:4879e85. [56] Hartmann C, Tabin CJ. Dual roles of Wnt signaling during chondrogenesis in the chicken limb. Development 2000;127:3141e59.

[57] Church V, Nohno T, Linker C, Marcelle C, Francis-West P. Wnt regulation of chondrocyte differentiation. J Cell Sci 2002;115:4809e18. 


\section{FIGURE LEGENDS}

Figure 6.1 ECM expanded ASDSCs exhibited an enhanced proliferative and anti-apoptotic capacity, especially for cell expansion on FE. (A) ASDSCs were expanded on three substrates ( $\mathrm{PL}, \mathrm{AE}$, and $\mathrm{FE}$ ) for one passage; the cell membrane was labeled with Vybrant Dil Cell labeling solution (red) and the nuclei were stained using DAPI (blue), the ECM fibers were immunostained with type I collagen (green); cell number was counted in $175 \mathrm{~cm}^{2}$ flasks $(n=6)$ using a hemocytometer. (B) Flow cytometry was used to measure the proliferation index of expanded ASDSCs. (C) Flow cytometry was used to measure both percentage and median of MSC surface markers (CD29, CD90, and CD105), SSEA4, and integrin $\beta 5$ of expanded ASDSCs. (D) Flow cytometry was used to measure percentage of apoptotic cells after expansion on the three substrates. (E) Generation of ROS followed by hydrogen peroxide incubation was evaluated. Relative fluorescence emitted by fluorescent dye 2'7'-dichlorofluorescein diacetate was measured and presented as means \pm standard deviation (SD) of the mean for $n=3 .{ }^{*} p<0.05$ indicated a statistically significant difference.

Figure 6.2 Contribution of ECM structure and composition to ASDSC rejuvenation. SEM was used to observe ASDSC morphology during expansion on PL (A), AE (B), or FE (C). Scale bar: $50 \mu \mathrm{m}$. Surface topography and morphology of AE (B) and FE (C) were also observed. Scale bar: $5 \mu \mathrm{m}$. Proteomics was used to measure chemical composition of $A E(D)$ and FE (E). Image figures of both $A E$ and $F E$ showed phase-contrast microscope (PCM) for cell morphology and structure before making ECM and immunostaining for type I collagen, fibronectin, and laminin. AFM was used to measure elasticity of both expanded substrates $(H)$ and expanded ASDSCs $(\mathrm{I})$.

Figure 6.3 FE promoted expanded ASDSCs' early chondrogenic differentiation. PL expanded passage 3 ASDSCs (PL3) were grown on either PL, AE, or FE for one passage; the expanded cells were PL4, AE4, and FE4. The above four cells were chondrogenically induced in a pellet culture system for 10 days. (A) Before histological staining, pellet size was measured with a scale bar as $\mathrm{mm}$; Alcian blue $(A B)$ and Safranin $O(S O)$ were used to stain sulfated GAGs and immunohistochemistry staining (IHC) was used to detect type II collagen (Col II). (B) Real-time polymerase chain reaction (PCR) was used to evaluate chondrogenic marker gene expression (SOX9, ACAN, and COL2A1) in day-10 pellets. Data are shown as average \pm standard deviation $(\mathrm{SD})$ for $n=4 .{ }^{*} p<0.05$ indicated a statistically significant difference.

Figure 6.4 Potential mechanisms underlying ECM-mediated ASDSC proliferation and chondrogenic potential. Western blot was used to detect the MAPK signals (Erk, p38, and Jnk) at both phosphorylation and total protein levels and Wnt signals (Wnt3a, Wnt5a, and Wnt11). $\beta$ - 
actin was also measured as an internal control. ImageJ software was used to quantify immunoblotting bands.

Figure 6.5 FE promoted expanded ASDSCs' later chondrogenic differentiation. PL expanded passage 3 ASDSCs (PL3) were expanded on either PL, AE, or FE for one passage; the expanded cells were PL4, AE4, and FE4. The above four cells were chondrogenically induced in a pellet culture system for 21 days. (A) Before histological staining, pellet size was measured with a scale bar as mm; Alcian blue $(A B)$ and Safranin $O(S O)$ were used to stain sulfated GAGs and immunohistochemistry staining (IHC) was used to detect type II collagen (Col II). (B) Real-time polymerase chain reaction (PCR) was used to evaluate chondrogenic marker gene expression (SOX9, ACAN, and COL2A1). (C) Biochemical analysis was used for DNA and GAG contents of pellets; cell viability in chondrogenic medium was evaluated using DNA ratio (DNA content at day 21 adjusted by that at day 0); a ratio of GAG to DNA indicated chondrogenic index. (D) Functionality of chondrogenically differentiated pellets was evaluated using pellet size, Stiffness, and Young's modulus. Data are shown as average \pm standard deviation (SD) for $n=4$. ${ }^{*} p<0.05$ indicated a statistically significant difference.

Figure 6.6 ECM pretreatment promoted expanded ASDSC adipogenesis rather than osteogenesis. After expansion on $\mathrm{PL}, \mathrm{AE}$, or FE, ASDSCs were replated in either adipogenic or osteogenic induction medium. After a 21-day incubation in adipogenic medium, adipogenesis was evaluated using Oil Red O (ORO) staining (A) and quantitative adipogenic marker genes (LPL and PPARG). After a 21-day incubation in osteogenic medium, osteogenesis was evaluated using Alizarin Red S (ARS) staining and quantitative extracellular calcium assay as well as alkaline phosphatase (ALP) staining and quantitative activity assay. Data were shown as average $\pm S D$ for $n=4 .{ }^{*} p<0.05$ indicated a statistically significant difference. 
Table 6.1 Select ECM and ECM interacting proteins identified in fetal and adult ECMs

\begin{tabular}{|c|c|c|c|c|c|}
\hline \multicolumn{2}{|c|}{ Swiss-Port accession } & \multicolumn{2}{|c|}{ Assigned spectra } & \multicolumn{2}{|c|}{$\begin{array}{l}\% \text { of protein in the } \\
\text { insoluble pellet }\end{array}$} \\
\hline & & $\mathrm{FE}$ & $\mathrm{AE}$ & $\mathrm{FE}$ & $\mathrm{AE}$ \\
\hline & Selected ECM proteins & & & & \\
\hline P98160 & Perlecan & 91 & 95 & $22 \%$ & $51 \%$ \\
\hline P21810 & Biglycan & 37 & 95 & $14 \%$ & $53 \%$ \\
\hline P07585 & Decorin & 40 & 95 & $65 \%$ & $54 \%$ \\
\hline Q07507 & Dermatopontin & 16 & 35 & $100 \%$ & $66 \%$ \\
\hline P15502 & Elastin & 2 & 18 & $100 \%$ & $89 \%$ \\
\hline Q9Y6C2 & EMILIN-1 & 131 & 113 & $1 \%$ & $25 \%$ \\
\hline Q9BXX0 & EMILIN-2 & 35 & 46 & $46 \%$ & $43 \%$ \\
\hline P35555 & Fibrillin-1 & 394 & 529 & $39 \%$ & $53 \%$ \\
\hline P35556 & Fibrillin-2 & 76 & 2 & $0 \%$ & $0 \%$ \\
\hline P02751 & Fibronectin & 767 & 873 & $29 \%$ & $43 \%$ \\
\hline P23142 & Fibulin-1 & 5 & 4 & $0 \%$ & $50 \%$ \\
\hline P98095 & Fibulin-2 & 149 & 150 & $68 \%$ & $63 \%$ \\
\hline Q96RW7 & Fibulin-6 (hemicentin-1) & 1 & 12 & $0 \%$ & $0 \%$ \\
\hline P09382 & Galectin-1 & 22 & 12 & $0 \%$ & $0 \%$ \\
\hline P55001 & Microfibrillar-assoc. prot. 2 & 39 & 47 & $85 \%$ & $81 \%$ \\
\hline Q13361 & Microfibrillar-assoc. prot. 5 & 28 & 37 & $86 \%$ & $68 \%$ \\
\hline P20774 & Mimecan & 16 & 6 & $0 \%$ & $17 \%$ \\
\hline Q14112 & Nidogen-2 & 7 & 6 & $0 \%$ & $0 \%$ \\
\hline Q15063 & Periostin & 125 & 400 & $15 \%$ & $57 \%$ \\
\hline P24821 & Tenascin & 259 & 120 & $3 \%$ & $36 \%$ \\
\hline P22105 & Tenascin-X & 59 & 49 & $10 \%$ & $0 \%$ \\
\hline P07996 & Thrombospondin-1 & 6 & 79 & $33 \%$ & $68 \%$ \\
\hline Q15582 & TGFBI & 164 & 258 & $45 \%$ & $44 \%$ \\
\hline $\mathrm{P} 13611$ & Versican core protein & 58 & 22 & $74 \%$ & $50 \%$ \\
\hline P02452 & Collagen alpha-1(I) chain & 250 & 494 & $11 \%$ & $86 \%$ \\
\hline P08123 & Collagen alpha-2(I) chain & 206 & 339 & $6 \%$ & $59 \%$ \\
\hline P02461 & Collagen alpha-1(III) chain & 41 & 31 & $0 \%$ & $81 \%$ \\
\hline
\end{tabular}




\begin{tabular}{|l|l|l|l|l|l|}
\hline P20908 & Collagen alpha-1(V) chain & 18 & 36 & $28 \%$ & $47 \%$ \\
\hline P05997 & Collagen alpha-2(V) chain & 7 & 12 & $0 \%$ & $75 \%$ \\
\hline P12109 & Collagen alpha-1(VI) chain & 602 & 799 & $79 \%$ & $68 \%$ \\
\hline P12110 & Collagen alpha-3(VI) chain & 3019 & 3542 & $67 \%$ & $56 \%$ \\
\hline Q99715 & Collagen alpha-1(XII) chain & 798 & 1563 & $30 \%$ & $64 \%$ \\
\hline Q05707 & Collagen alpha-1(XIV) chain & 163 & 47 & $17 \%$ & $34 \%$ \\
\hline & Additional proteins & \multicolumn{5}{|l|}{} \\
\hline Q6UY14 & ADAMTS-like protein 4 & 8 & 18 & $0 \%$ & $0 \%$ \\
\hline P10909 & Clusterin & 5 & 0 & $0 \%$ & \\
\hline Q08397 & Lysyl oxidase homolog 1 & 22 & 23 & $36 \%$ & $35 \%$ \\
\hline P21980 & Transglutaminase 2 & 18 & 44 & $28 \%$ & $30 \%$ \\
\hline
\end{tabular}


Figure 6.1
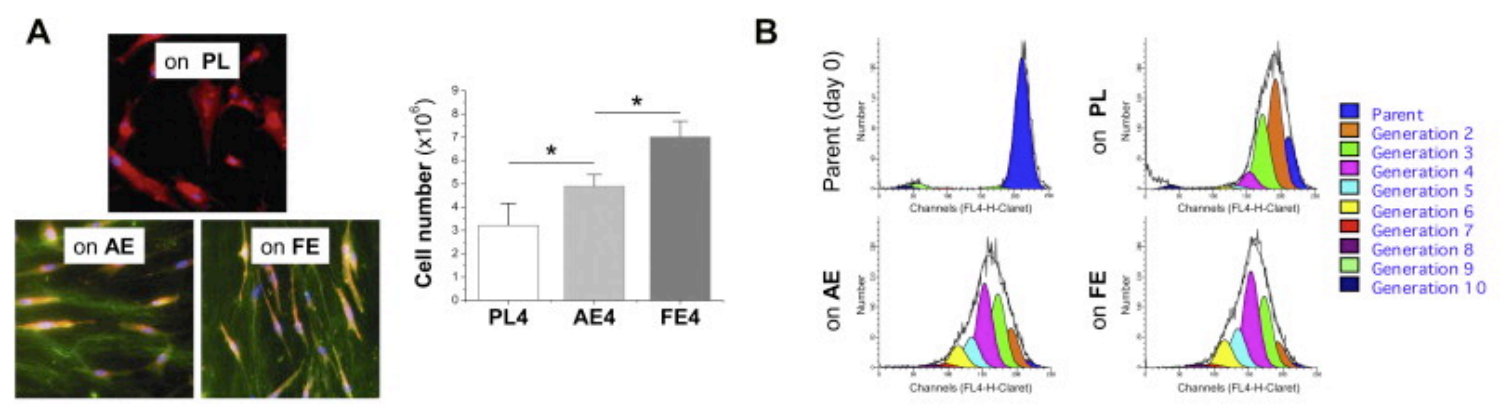

\section{C}
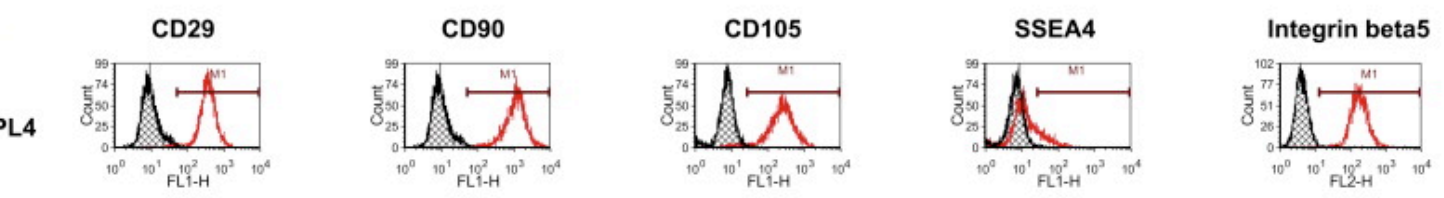

AE4
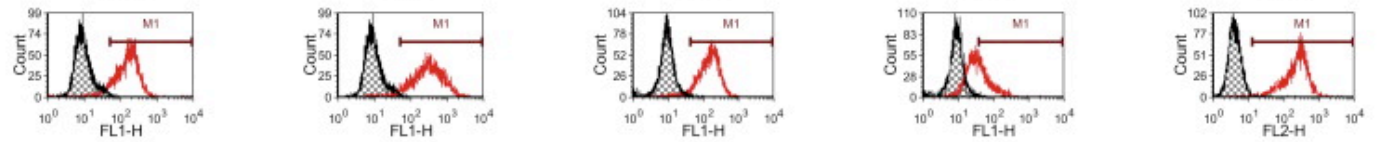

FE4
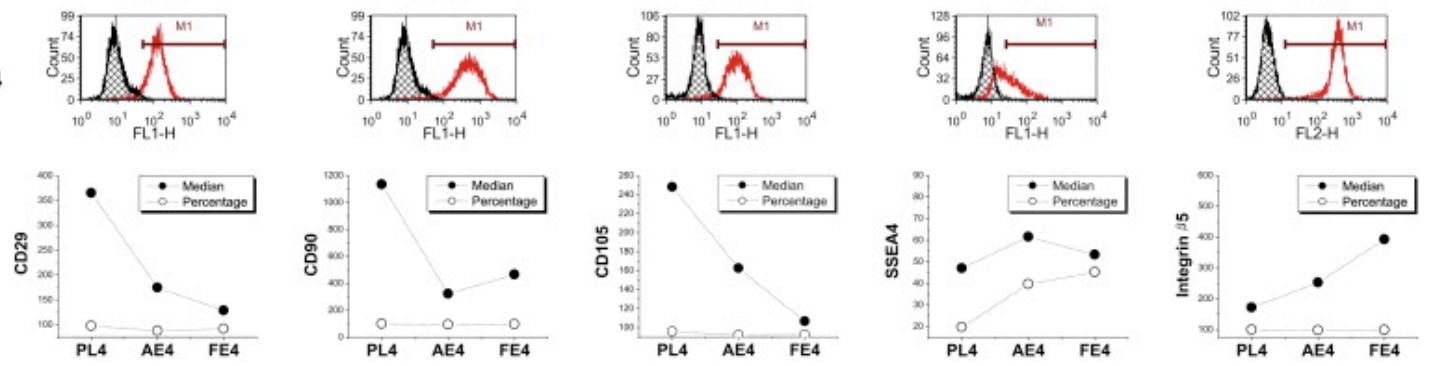

D
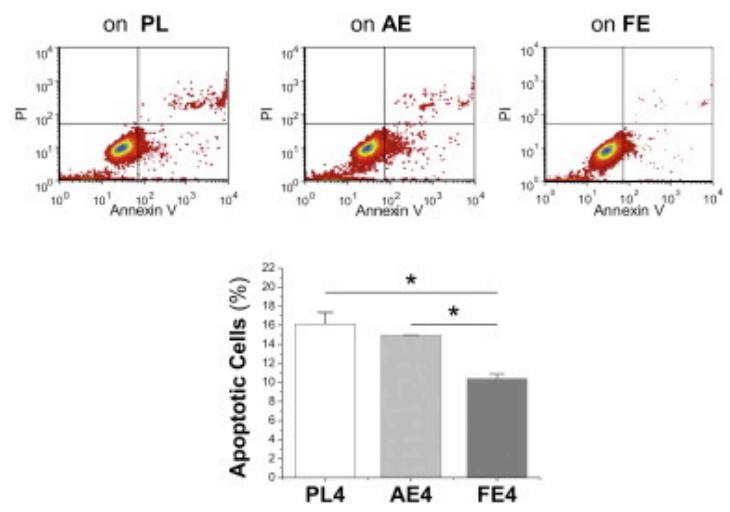

E

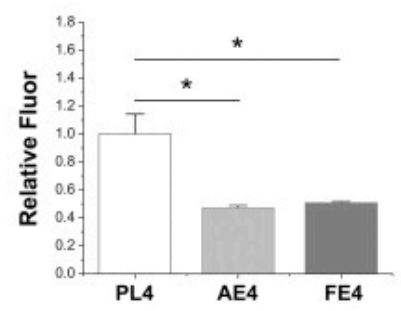


Figure 6.2

A

PL

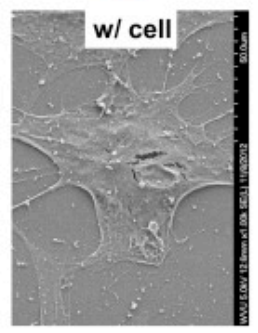

B

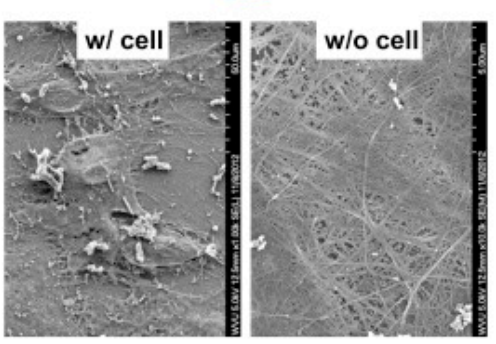

D

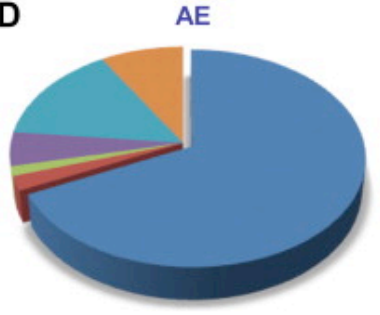

F

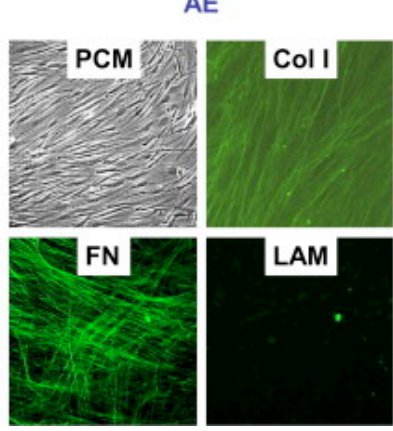

E

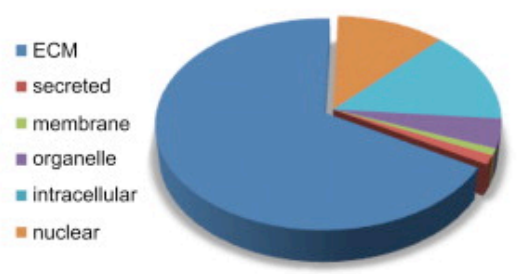

G

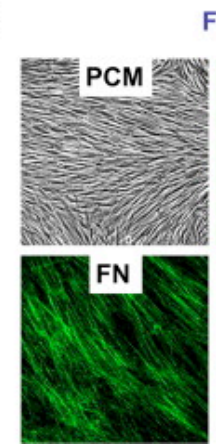

FE

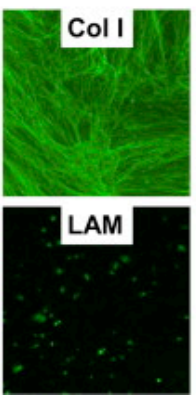

C

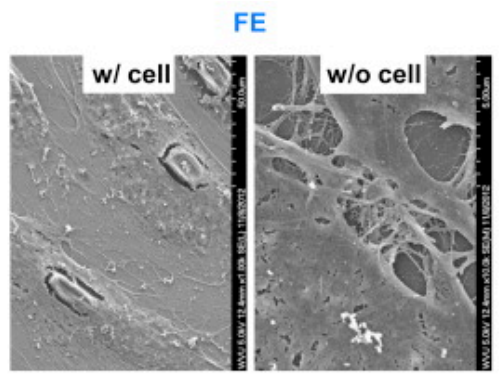

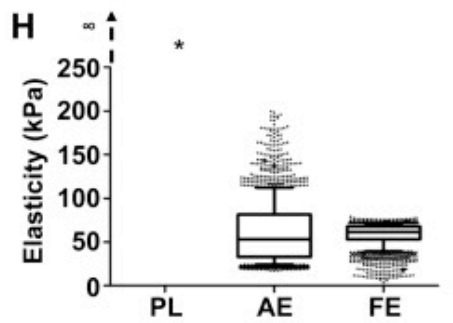

Expanded substrates

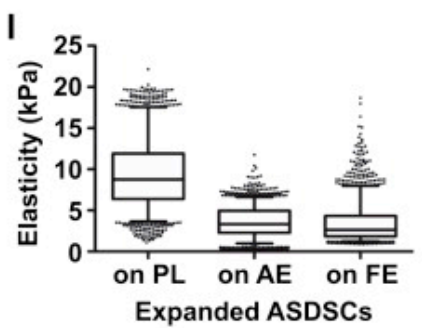


Figure 6.3

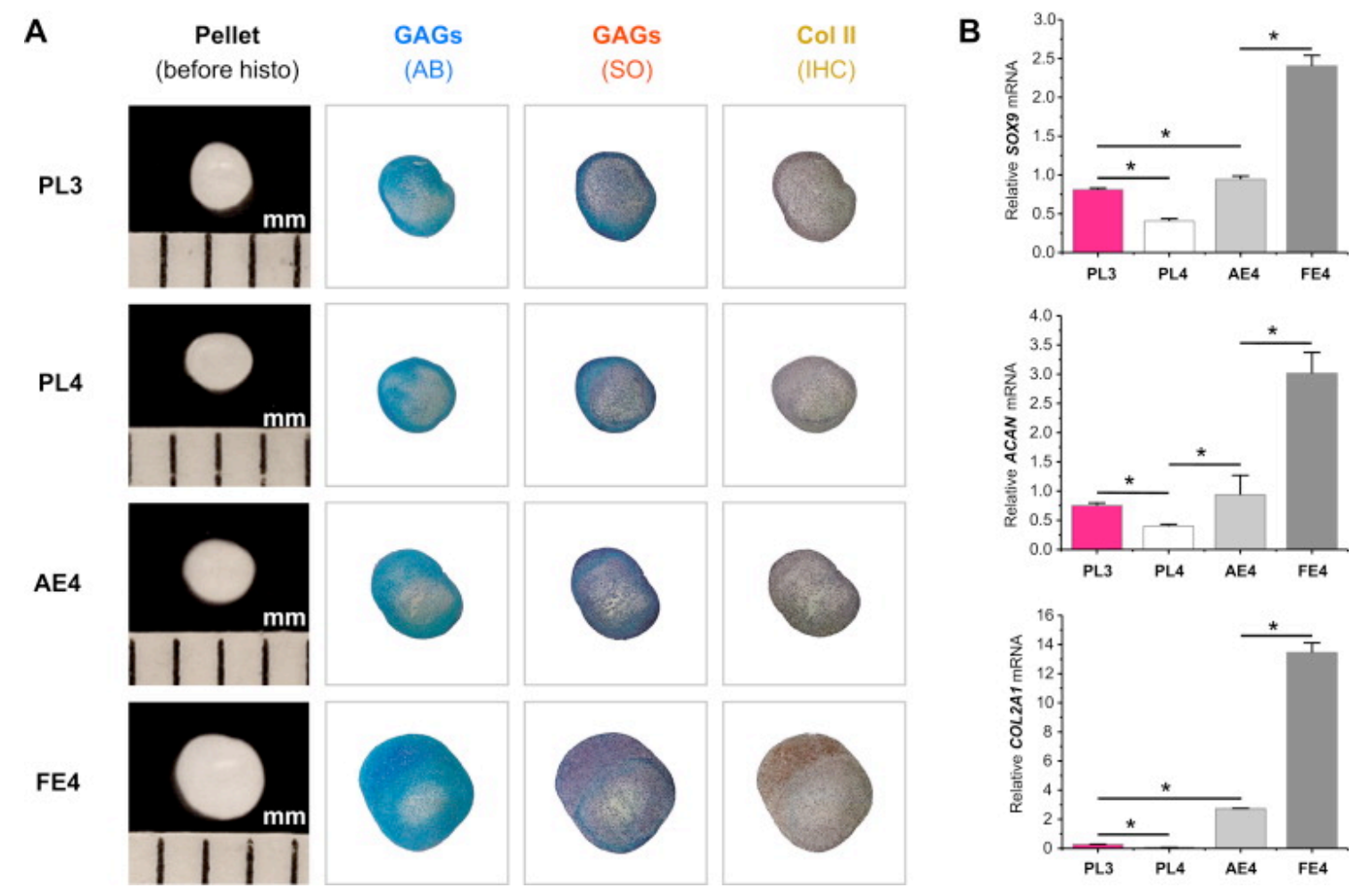


Figure 6.4

A
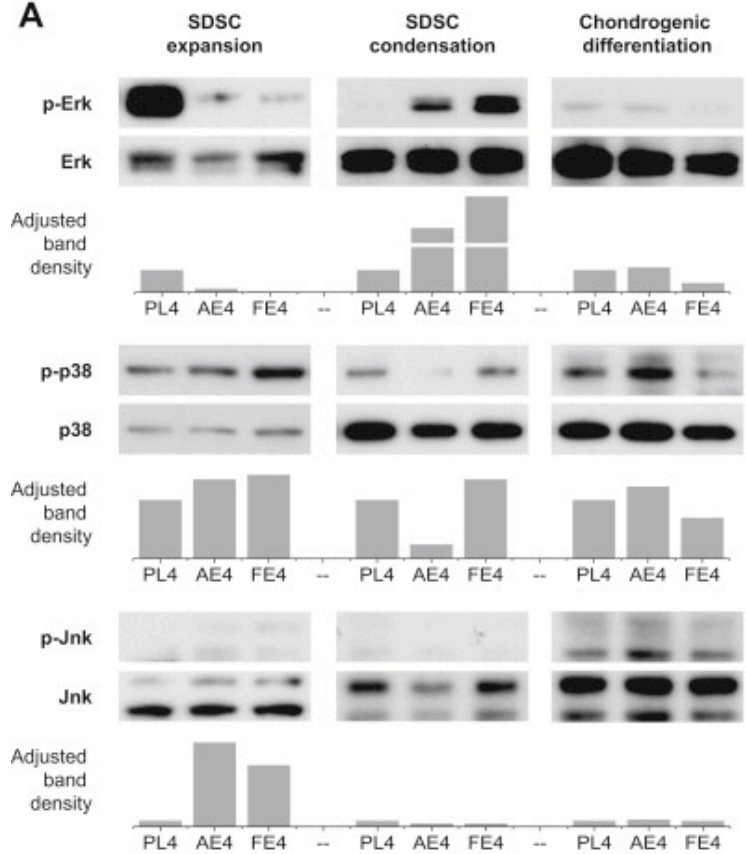

B

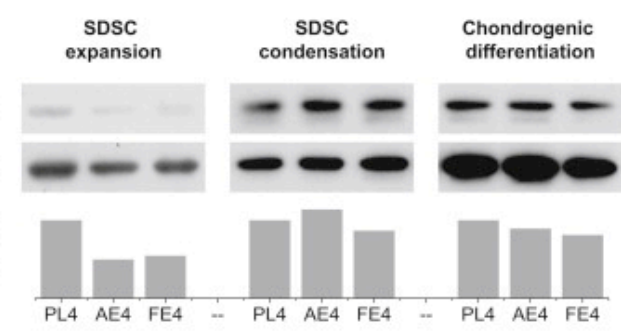

Wnt5a

$\beta$-actin

Adjusted
band

density
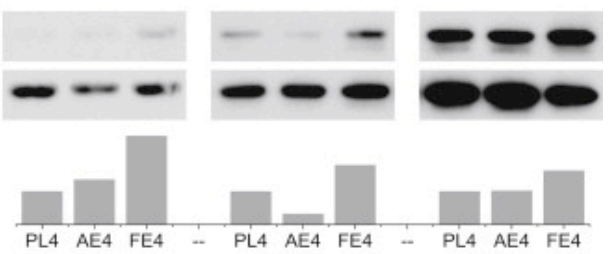

Wnt11

$\beta$-actin

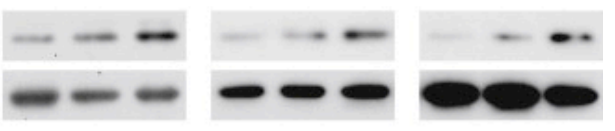

Adjusted

density

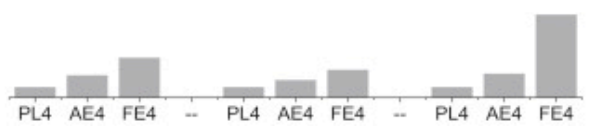


Figure 6.5
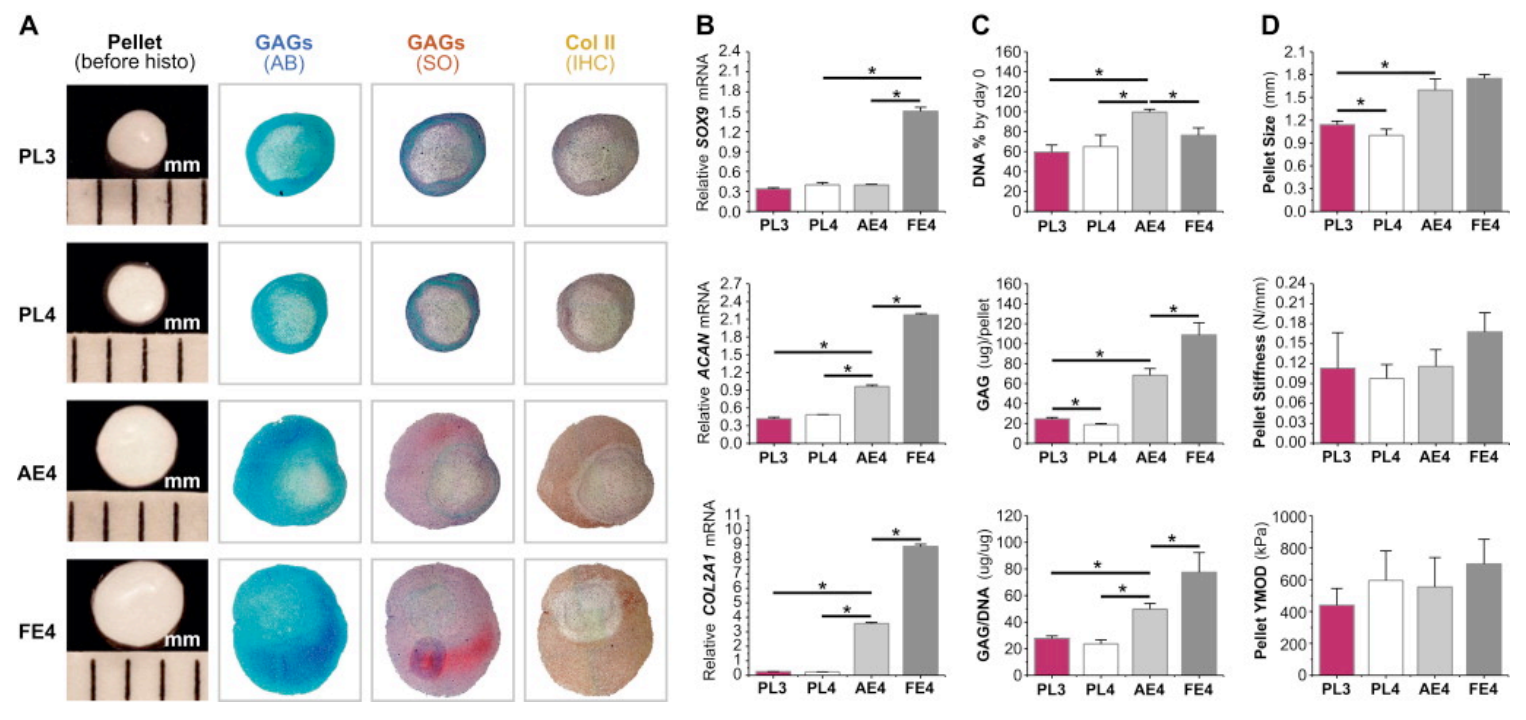
Figure 6.6
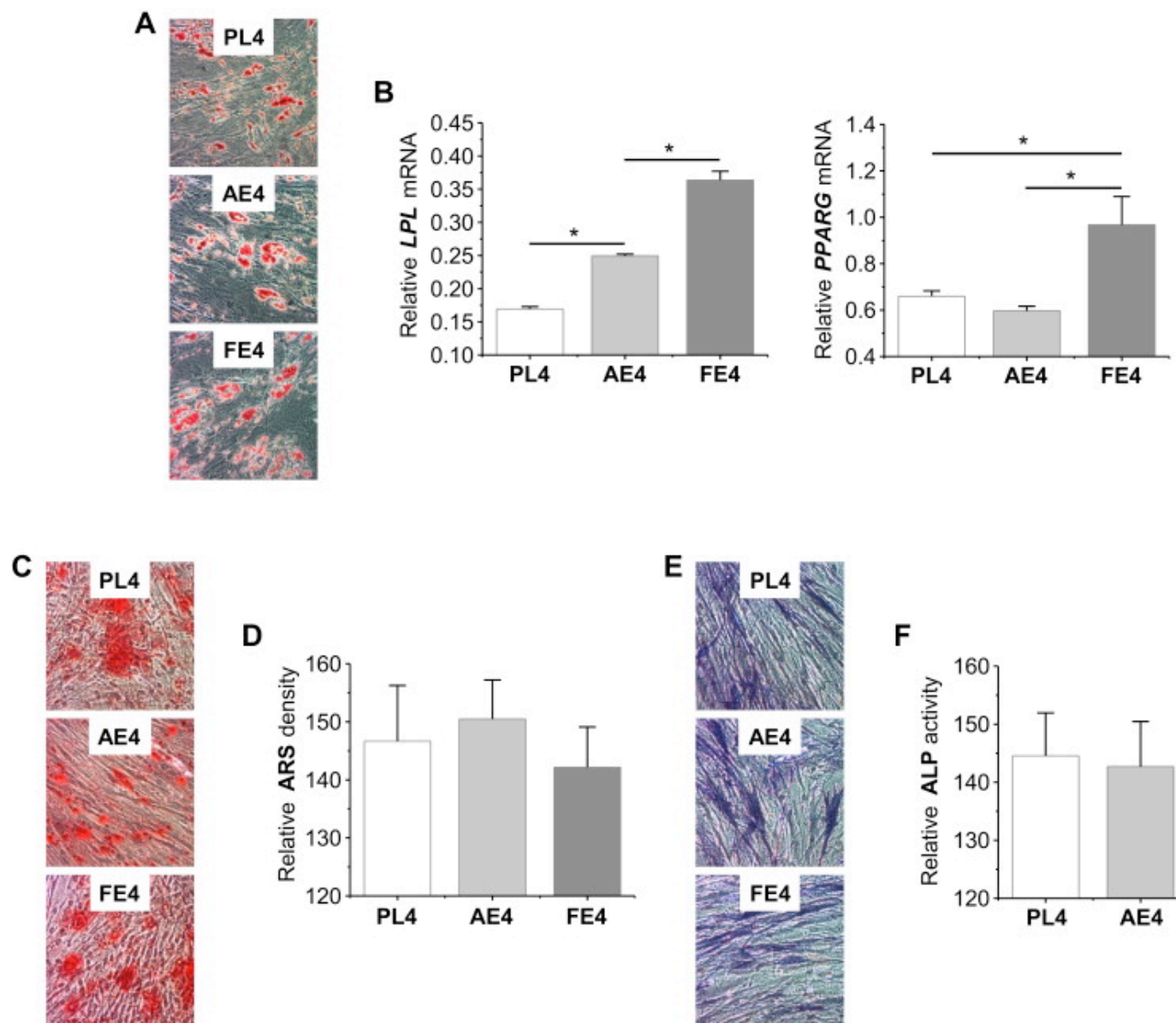

D
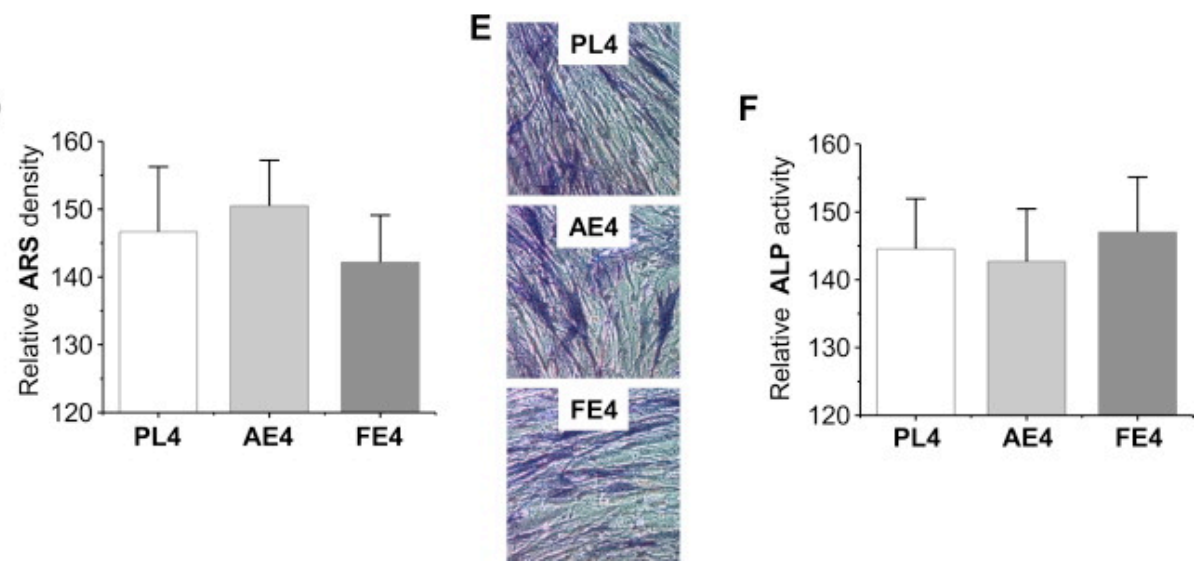
\begin{tabular}{lllllllll} 
CHAPTER 7: A COMPARISON IN RE JUVENATION OF \\
\hline
\end{tabular} \begin{tabular}{lllllll}
\hline HUMAN NUCLEUS PULPOUS CELLS FROM HERNIATED \\
\hline
\end{tabular} \begin{tabular}{lllllll}
\hline DIS C & B Y & SYNOVIUM-DERIVED & STEM & CELLS & $A N D$ \\
\hline
\end{tabular} \begin{tabular}{lllll}
\hline$N U C L E U S$ & $P U L P O S U S$ & $C E L L S$ & $D E P O S I T E D$ & $T I S S U E-$ \\
\hline
\end{tabular} SPECIFIC DECELLULARIZED MATRIXES

Jingting Li, M.S., and Ming Pei, M.D., Ph.D.

Tissue Engineering Laboratory, Department of Orthopaedics, and Division of Exercise Physiology, West Virginia University, Morgantown, WV 26506

Key words: synovium derived stem cells, nucleus pulposus cells, decellularized matrix, redifferentiation 


\begin{abstract}
Low back pain is often related to intervertebral disc (IVD) degeneration and herniation that results from a progressive loss of proteoglycans and water content in the nucleus pulposus. Autologous disc cell-based therapy is a promising approach for IVD regeneration. Unfortunately, the quantity and quality of the autologous herniated nucleus pulposus cells (NPCs) is limited and compromised. The current in vitro expansion of NPCs in monolayer results in dedifferentiation of these cells. Our previous studies indicated that decellularized extracellular matrix (DECM) deposited by stem cell could serve as an in vitro expansion system for enhancing proliferative and chondrogenic differentiation potential in the recellularized cells. Moreover, such an in vitro three-dimensional microenvironment benefits porcine NPCs by allowing them to expand more efficiently while maintaining their differentiation phenotypes. Our most recent study also suggested the young DECM was superior to old DECM in rejuvenating cells with higher proliferation and chondrogenic capacities. However, there has been no study investigated if the DECM deposited by human NPCs (NECM) has the same or better effect than DECM deposited by human SDSCs (SECM) and whether cells derived from fetal donors can serve as a better tissue-specific high-quality microenvironment than adult donors for ex vivo expansion of human NPCs from middle-aged patients while promoting re-differentiation potential. In this study, for the first time, we evaluated the rejuvenating effect of DECMs deposited by human NPCs and SDSCs and compared the effect of fetal and adult donors' NPCs and SDSCs deposited DECMs. First, both fetal and adult SDSC and NPCs were used to prepare young and old SECMs and NECMs. Cell proliferation after expansion evaluated by cell number and proliferation index showed significantly enhanced proliferation in both SECMs and NECMs compared to plastic flasks group as a control. Surface markers for mesenchymal stem cells were analyzed by flow cytometry after expansion on different substrates. Redifferentiation potential to chondrogenesis evaluated by biochemistry, histochemistry and immunohistochemistry, real-time PCR was consistently enhanced in both NECMs expanded NPCs but not in both young and old SECMs expanded cells. In conclusion, both human SDSC and NPC deposited DECMs can rejuvenate NPCs from herniated IVD with higher proliferative potential. But redifferentiation potential of NPCs can only be enhanced by NPC-derived NECMs. The development of an autologous disc cell-based minimally invasive therapeutic approach is beneficial toward physiological reconstruction of a biologically functional disc in a clinical setting.
\end{abstract}




\section{INTRODUCTION}

Approximately $80 \%$ of the adult population is affected by low back pain; this condition has a massive economic impact due to both health care costs and loss of productivity. ${ }^{1}$ Although the causes of low back pain are complicated and not fully understood, an important underlying cause is commonly believed to be degeneration of the intervertebral disc (IVD). ${ }^{2 ; 3}$ The IVD consists of two components: the gelatinous nucleus pulposus (NP) at the center of the disc surrounded by the annulus fibrosus, a more highly organized ring composed mainly of type-l collagen. ${ }^{4}$ The extracellular matrix (ECM) of the NP is up to $80 \%$ hydrated as a result of large amounts of the aggregating proteoglycan aggrecan. ${ }^{5}$ This proteoglycan is enmeshed in a randomly oriented network of type-II collagen fibers. ${ }^{6}$ IVD degeneration is reported to begin in the NP with a progressive decrease in proteoglycan content, leading to loss of hydrogel properties of the NP. ${ }^{7}$ Clinical treatments of IVD disease include various noninvasive and invasive therapies, but are limited to symptomatic relief.

Cell transplantation is a suitable and promising approach for IVD regeneration. Although human NP cells (NPCs) share matrix-producing properties with chondrocytes, recent studies have shown that there are indeed phenotypic differences. ${ }^{8}$ Stem cells seem to be another candidate for cell transplantation; however, the lack of a definitive cell marker to distinguish NPCs from other cells has made clinical application more difficult and less realistic. Animal studies ${ }^{9-11}$ and an early clinical trial (Euro Disc Randomized Trial) ${ }^{11}$ have indicated that autologous disc cell transplantation (ADCT) is technically feasible and biologically relevant to repairing disc damage and retarding disc degeneration. However, one concern of critics of ADCT is that cells isolated from degenerative discs may lack the potential of healthy counterparts. ${ }^{12}$ In addition, the preparation of NPCs for reimplantation is problematic because autologous transplantation requires more cells than can be harvested from a small biopsy. During in vitro expansion, however, like articular chondrocytes, NPCs undergo a characteristic process of dedifferentiation, marked by a loss of type-II collagen expression and the induction of type-I collagen expression. ${ }^{13 ; 14}$ With low cellular yields and low proliferative activity of NPCs in monolayer culture, further enhancement of the biologic and metabolic viability of NPCs is desirable.

In order to make clinical application a reality, in vitro expansion cultures are expected to yield large amounts of high-quality cells in a short period of time. Moreover, these expanded NPCs should preferably express or at least be able to reexpress their NPC phenotype (redifferentiation capacity) in order to produce a functional ECM. Thus, expanded cell amount and redifferentiation capacity are two important parameters in disc regeneration. Our recent finding has shown that decellularized extracellular matrix (DECM) deposited by porcine synovium-derived stem cells 
(SDSCs) can serve as a three-dimensional cell expansion system for SDSC proliferation while enhancing chondrogenic potential. ${ }^{15}$ Such an in vitro three dimensional microenvironment benefits porcine NPCs by allowing them to expand more efficiently while maintaining their differentiation phenotypes. ${ }^{16 ; 17}$ Our recent study also suggests that human fetal SDSC-derived DECM can rejuvenate adult SDSC by decreasing replicative senescence, evidenced by enhancing adult SDSC expansion and chondrogenic differentiation capacity. ${ }^{18}$

Despite the fact that we demonstrated that DECM expansion could overcome porcine NPC replicative senescence, there has been no study investigating whether DECM deposited by human SDSCs or NPCs can rejuvenate NPCs from middle-aged patients' herniated IVD and whether SDSCs or NPCs from young donor is superior to adult donor for depositing the matrix. This is an important issue to be addressed because most NPCs that need expansion are from middle-aged patients, at which herniated discs often occur. In this study, we aim to investigate whether DECM deposited by human SDSC or NPCs from fetal donors can serve as a tissuespecific high-quality microenvironment for ex vivo expansion of human NPCs from middle-aged patients while maintaining NPC differentiation phenotype and re-differentiation potential. The development of an autologous disc cell-based minimally invasive therapeutic approach would greatly benefit physiological reconstruction of a biologically functional disc in a clinical setting. 


\section{MATERIALS AND METHODS}

\section{DECM preparation}

Human fetal source nucleus pulposus cells (NPCs) and synovium-derived stem cells (SDSCs) were obtained from Scien-Cell ${ }^{\mathrm{TM}}$, Research Laboratories (Carlsbad, CA) and adult SDSCs (ASDSC) were obtained from Asterand (North America Laboratories, Detroit, MI). Adult NPC from herniated discs were collected from lumbar spine (L1-L5) of patients (age $30-50$ years old) following Institutional Review Board approval and donor consent. Both cell types were used to prepare DECMs, termed SECM and NECM, respectively, as described previously. ${ }^{18}$ Both DECMs from fetal and adult donors were termed FE and $A E$. Briefly, plastic flasks (PL) were precoated with $0.2 \%$ gelatin (Sigma, St. Louis, MO) at $37{ }^{\circ} \mathrm{C}$ for $1 \mathrm{~h}$ and seeded with passage 3 NPCs at 6000 cells per $\mathrm{cm}^{2}$. After cells reached $90 \%$ confluence, $250 \mathrm{mM}$ of L-ascorbic acid phosphate (Wako Chemicals USA Inc., Richmond, VA) was added for 10 days. The deposited ECMs were incubated with $0.5 \%$ Triton X-100 containing $20 \mathrm{mM}$ ammonium hydroxide at $37^{\circ} \mathrm{C}$ for $5 \mathrm{~min}$ to remove the cells; they were stored at $4{ }^{\circ} \mathrm{C}$ in phosphate-buffered saline (PBS) containing 100 $\mathrm{U} / \mathrm{mL}$ penicillin, $100 \mathrm{mg} / \mathrm{mL}$ streptomycin, and $0.25 \mathrm{mg} / \mathrm{mL}$ fungizone until use.

\section{Cell counting and morphology}

PL expanded passage 2 NPCs were plated at 3000 cells per $\mathrm{cm}^{2}$ on both $\mathrm{FE}, \mathrm{AE}$, or PL for two passages with growth medium containing alpha-minimum essential medium (aMEM), $10 \%$ fetal bovine serum (FBS), $100 \mathrm{U} / \mathrm{mL}$ penicillin, $100 \mu \mathrm{g} / \mathrm{mL}$ streptomycin, and $0.25 \mu \mathrm{g} / \mathrm{mL}$ fungizone. Cell number was counted in $175 \mathrm{~cm}^{2}$ flasks $(n=6)$ using a hemocytometer for both passages and cell morphology was photographed.

\section{Proliferation index}

Before cell expansion, passage 2 NPCs were labeled with CellVue ${ }^{\circledR}$ Claret (Sigma) at $2 \times 10^{-6} \mathrm{M}$ for $5 \mathrm{~min}$ according to the manufacturer's protocol. After eight days, expanded cells were collected and measured using a BD FACS Calibur ${ }^{\mathrm{TM}}$ flow cytometer (dual laser) (BD Biosciences, San Jose, CA). Twenty thousand events of each sample were collected using CellQuest Pro software (BD Biosciences) and cell proliferation index was analyzed by ModFit $L T^{\mathrm{TM}}$ version 3.1 (Verity Software House, Topsham, ME).

\section{Histological analysis}

The pellets $(n=3)$ will be fixed in $4 \%$ paraformaldehyde, dehydrated in a gradient ethanol series, cleared with xylene, and embedded in paraffin blocks. $5-\mu \mathrm{m}$ sections will be histochemically stained with Alcian blue (Sigma, St. Louis, MO). For immunohistochemical analysis, the sections will be immunolabeled with primary antibodies against collagen I (Sigma), collagen II [II-II6B3, 
Developmental Studies Hybridoma Bank (DSHB), lowa City, IA], and collagen X (Sigma), respectively. A secondary antibody of biotinylated horse anti-mouse IgG (Vector, Burlingame, CA) will be incubated on the sections for $30 \mathrm{~min}$. Immunoactivity will be detected using Vectastain $A B C$ reagent (Vector) with 3,3'-diaminobenzidine (DAB, 0.05\%) and hydrogen peroxide $\left(\mathrm{H}_{2} \mathrm{O}_{2}\right.$, $0.015 \%$ ) as a substrate. Hematoxylin (Vector) served as a counterstain.

\section{Biochemical analyses}

Representative pellets $(n=6)$ will be digested for $6 \mathrm{~h}$ at $60^{\circ} \mathrm{C}$ with $125 \mu \mathrm{g} / \mathrm{mL}$ papain in PBE buffer (100 mmol/L phosphate, $10 \mathrm{mmol} / \mathrm{L}$ EDTA, pH 6.5) containing $10 \mathrm{mmol} / \mathrm{L}$ cysteine, by using 100 $\mu \mathrm{L}$ enzyme per sample. To quantify cell density, the amount of DNA in the papain digests will be measured using the Quant-iT ${ }^{\mathrm{Tm}}$. PicoGreen ${ }^{\circledR}$ dsDNA Assay kit (Invitrogen) with a CytoFluor ${ }^{\circledR}$ Series 4000 (Applied Biosystems). GAG will be measured using dimethylmethylene blue dye and a Spectronic ${ }^{\mathrm{TM}}$ BioMate $^{\mathrm{TM}} 3$ Spectrophotometer (Thermo Scientific, Milford, MA) with bovine chondroitin sulfate as a standard.

\section{Flow cytometric analysis}

The following antibodies will be used: stage specific embryonic antigen-4 (SSEA-4), CD29 (BioLegend), CD90 (BD Pharmingen), and CD105 (GeneTex Inc., San Antonio, TX). As isotype controls, IgG1 and IgG2a (Beckman Coulter, Fullerton, CA) along with IgG3 (BD Pharmingen) will be used. The secondary antibody will use FITC-conjugated goat anti-mouse Ig (Abcam). $0.2 \times$ $10^{6}$ cells will be incubated on ice in cold PBS containing 5\% FBS and $1 \% \mathrm{NaN}_{3}$ (Sigma) for 30 min. After incubation, primary antibodies will be added and the cells will be incubated for 60 min at room temperature in the dark. After washing with cold PBS, cells will be incubated with the secondary antibody for $30 \mathrm{~min}$ in the dark. Finally, the cells will be fixed in $400 \mu \mathrm{L}$ of PBS with $1 \%$ paraformaldehyde. The cells will be analyzed on a BD dual laser FACSCalibur (BD Biosciences) using the CellQuest Pro (BD Biosciences) software package.

\section{TaqMan real-time PCR}

For studies of quantitative gene expression, the total RNA samples from representative pellets $(n=6)$ and reverse transcript $(R T)$ will be prepared according to RT-PCR protocol. Chondrogenic marker genes [SRY (sex determining region Y)-box 9 (SOX9) (Assay ID Hs00165814_m1), aggrecan (ACAN) (Assay ID AIQJAP5), and type II collagen (COL2A1) (Assay ID Hs00156568_m1)] were customized by Applied Biosystems as part of their Custom TaqMan ${ }^{\circledR}$ Gene Expression Assays. Eukaryotic 18S RNA (Assay ID Hs99999901_s1 ABI) is carried out as the endogenous control gene. Real-time PCR will be performed with iCycler $\mathrm{IQ}^{\mathrm{TM}}$ Multi Color RTPCR Detection System (Bio-Rad Laboratories, Hercules, CA). The cycle parameters are $50^{\circ} \mathrm{C}$ for 2 min, hot start at $95^{\circ} \mathrm{C}$ for 10 min followed by 40 cycles of denaturation at $95^{\circ} \mathrm{C}$ for 15 seconds, 
and annealing and extension at $60^{\circ} \mathrm{C}$ for $1 \mathrm{~min}$. The cycle threshold (Ct) values for 18S RNA and that of samples will be measured and calculated by computer software (Perkin-Elmer, Wellesley, $\mathrm{MA})$. Relative transcript levels will be calculated as $\chi=2^{-{ }^{-C} \mathrm{Ct}}$, in which $\Delta \Delta \mathrm{Ct}=\Delta \mathrm{E}-\Delta \mathrm{C}, \Delta \mathrm{E}=\mathrm{Ct}_{\mathrm{exp}}-$ $\mathrm{Ct}_{18 \mathrm{~s}}$, and $\Delta \mathrm{C}=\mathrm{Ct}_{\mathrm{ct} 1}-\mathrm{Ct}_{18 \mathrm{~s}}$.

\section{Statistical analysis}

ManneWhitney $U$ test was used for pairwise comparison. All statistical analyses were performed with SPSS 13.0 statistical software (SPSS Inc., Chicago, IL). $\rho$ values less than 0.05 were considered statistically significant. 


\section{RESULTS}

\section{Both SDSC and NPC deposited DECMs enhanced NPC proliferation}

Both fetal and adult SDSCs and NPCs were used to deposit DECMs (SECM and NECM). To evaluate proliferative effect exerted by fetal and adult SECMs or NECM, human adult NPCs were respectively seeded on three different substrates: PL, FE or AE (PL, FNPE or ANPE). Cell morphology showed that NPCs expanded on PL was sporadic and randomly clustered; in contrast, NPCs grown on both DECMs exhibited a glistening look and spindle-like shape (Figure 7.1A and 7.2A). For SECM groups, cell expansion on FE yielded the highest cell number followed by $\mathrm{AE}$ with $\mathrm{PL}$ having the lowest cell number (Figure 7.1B). Proliferation index data was also consistent with the cell counting (Figure 7.1C). For NECM groups, highest cell number was observed in ANPE instead of FNPE (Figure 7.2B). ANPE expansion yielded a 1.8-fold increase and FNPE expansion yielded a 1.2-fold increase in proliferation index compared with PL expansion (Figure $7.2 \mathrm{C}$ ).

Our flow cytometry data showed that MSC surface markers, CD29 and CD90, were downregulated slightly in percentage but heavily at the median fluorescence intensity (MFI) in both DECMs expanded NPCs despite an up-regulation in MFI for CD105 in FNPE from NPCs (Figure 7.3A and 7.3B).

NPC redifferentiation capacity enhanced by NPC- but not SDSC-derived DECM

To determine the influence of DECM expansion on NPC redifferentiation potential, expanded NPC were induced for chondrogenic differentiation for up to 21 days. After 10 or 21-day incubation, pellets were evaluated using histology, immunostaining and biochemistry analysis.

As shown in Figure 7.4A, for SECM pretreatment groups, compared to pellets from PL, AE and FE expanded pellets were smaller in size though pellets from FE is slightly larger than pellets from $A E$ at both day 10 and day 21. Biochemistry data and stronger staining for sulfated GAGs and collagen II also showed highest chondrogenesis in PL expanded NPC pellets (Figure 7.5A).

Intriguingly, for NECM groups, pellets from PL were smallest in size at both time points while those from FNPE were the largest (Figure 7.4B); the FNPE pellets also contained the highest GAGs content analyzed by biochemistry (Figure 7.5B). The enhanced DNA content in FNPE and ANPE pellets was also shown at both day 10 and day 21. The chondrogenic index (ratio of GAG to DNA content) of FNPE pellets is almost 2-fold of PL pellets. Stronger staining for sulfated GAGs by Alcian Blue and immunostaining for collagen II also showed the same trend, which was 
that PL expansion down-regulated while DECM expansion upregulated chondrogenesis in NPCs with FNPE being the highest (Figure 7.4B).

Down-regulation of hypertrophic, catabolic and senescent markers in NPC-derived DECM rejuvenated pellets

Our real-time PCR data also suggested that expression of hypertrophic markers (COLX, RUNX2, $A L P L, M M P 13)$ was up-regulated in SECM pretreated NPCs, while down-regulated in NECM expanded NPCs compared to their own respective PL control. Similarly, the catabolic matrix genes that associated with inflammatory (COX2, MMP3, ADAMTS4, ADAMTS5, TIMP1) were also down-regulated in NECM expanded NPCs but up-regulated in SECM pretreated NPCs. The senescence marker genes (CASP3, P53, SIRT1, BMI1) also showed similar trend (Figure 7.6). 


\section{DISCUSSION}

Low back pain is often related to intervertebral disc (IVD) degeneration and herniation that results from a progressive loss of proteoglycans and water content in the nucleus pulposus (NP). Autologous disc cell-based therapy is a promising approach for IVD regeneration. Unfortunately, the quantity and quality of the autologous herniated NP cells (NPCs) is limited and compromised. The current in vitro expansion of NPCs is insufficient. Our previous studies have shown the rejuvenation of porcine NPCs by SDSC-deposited SECM, which significantly enhanced NPC proliferation and redifferentiation into chondrocyte like cells. ${ }^{16 ; 17}$ In this study, for the first time, we have shown that human NPCs could be rejuvenated by its own deposited matrix, especially the young matrix. Although the proliferative potentials of human NPCs can be rejuvenated by both SDSC- and NPC-deposited DECMs, the NPC-deposited NECM is superior to SDSC-derived DECM in enhancing the redifferentiated chondrogenic potentials in herniated NPCs.

In this study, the NP tissue that we collected from patients was the part of the herniated disc, which could be the degenerated NP tissue. There have been only few studies evaluated the quality of these NPCs. Up-regulated senescence associated markers as well as decreased telomere length and loss of replicative potential have been shown in degenerated human IVD ${ }^{19-21}$ or with progressing age. ${ }^{22}$ Hegewald et al. observed significant signs of dedifferentiation and degeneration as well as very limited regenerative potential for cells harvested from herniated disc tissue of patients aged around 45-year old. ${ }^{23}$ Ciapetti et al. suggested that the tissue in the degenerated disc is disorganized and the paucity of cells out of cluster/chondron association make the IVD-derived cells an unreliable source for disc regeneration. ${ }^{24}$ Oppositely, degenerated porcine NPC had been shown to have a higher colony-forming rate and a higher proliferation rate though the differentiation towards chondrogenic lineage is lower than the healthy NPC in vitro. ${ }^{25}$ Degenerated human NPC also exhibited regenerative potentials when treated with TGF $\beta 3$ and dexamethasone by Abbott et al.. ${ }^{26}$ Our characterization of the proliferative and chondrogenic potential evaluation also supported that adequate proliferation and redifferentiation potentials were possessed in human NPCs from herniated disc. This provided a precious opportunity for application of autologous NPCs in future patients.

We also observed the expression of MSC surface marker in NPCs from herniated disc and their significantly enhanced potentials to be rejuvenated towards more proliferative and redifferentiation especially after the NPC-derived NECM expansion. It is plausible that these NPCs possess mesenchymal stem cell (MSC) like stemness. However, it is still debatable whether NP tissue, especially the degenerated NP tissue contains MSCs. A potential stem cell niche was proposed in the IVD in four different species. ${ }^{27}$ Blanco et al. suggested that MSCs 
existed in human degenerated NP and exhibited similar properties except the adipogenic potential as bone marrow-derived stem cells that came from the same subjects. ${ }^{28}$ Although further investigation is needed before we reach a conclusion, the further promoted the yield of cell number and proteoglycan synthesis in NPCs during redifferentiation especially by the young NECM matrix suggested that the three-dimensional DECM could serve as an ex vivo expansion system or "niche" for rejuvenating these NPCs from herniated disc.

Interestingly, the rejuvenated NPC redifferentiated pellets showed lower expression of hypertrophic, catabolic and senescent marker genes. The altered NPCs feature behavior during IVD degeneration include increased hypertrophic differentiation, ${ }^{29}$ increased catabolic metabolism and decreased anabolic metabolism ${ }^{30-33}$ and induced cell death. ${ }^{34}$ Addition of growth factors such as TGF $\beta 1,{ }^{35}$ TGF $\beta 3$ and dexamethasone, ${ }^{36}$ IGF-1 and BMP-7, ${ }^{37: 38}$ have been shown to increase the expression of proteoglycans and collagens in degenerated NPCs in vitro. However, the confirmation of the effect of these growth factors treatment in vivo and detailed dose-dependent study as well as long-term safety study in large animal model are still higly anticipated as suggested by Masuda et al. ${ }^{39}$ Our data indicated that the three-dimensional DECMs, especially young matrix could serve as expansion system for providing larger quantity of high quality NPCs without administration of exogenous growth factors.

The application of acellularized NPC derived matrix for rejuvenating NPC is promising. The unique combination, quantity and organization of ECM components give rise to the tissue-specific structure and function. This is nowhere more evident than in this study that no attempt to emulate native ECM is better than the native ECM itself. Similarly, Mercuri et al. also showed that acellular porcine NP hydrogel could serve as scaffold for promoting NP regeneration when combined with human adipose-derived stem cells. ${ }^{40 ; 41}$ Also NPC-derived acellular matrix facilitated the bone marrow-derived MSC differentiation towards NPC-like lineages. ${ }^{42}$ Our previous study also showed that DECM deposited by porcine NPC also benefited SDSC viability and guided its differentiation to NP lineage. ${ }^{17}$ As a tissue-specific DECM, it serves as a scaffold for rejuvenating herniated NPCs, especially the fetal NPC-derived young matrix.

Our previous studies indicated that porcine NPCs can be rejuvenated by porcine SDSCdeposited DECM towards more proliferative and chondrogenic potential. ${ }^{16,17}$ In this study, we did not observed the enhanced chondrogenesis in redifferentiated potential in NPCs. One of the possible explanations is the difference between porcine NPCs and human NPCs. Laminin is found to be highly expressed in immature NP tissue. Chen et al. suggested that with age, this unique laminin decreased both in porcine and human NPCs. ${ }^{43}$ The immunostaining of 3-month old porcine and 2-year old human showed some positive staining of laminin, but none were 
observed in 24-month old porcine and 35-year old human. As laminin is an essential component of basement membrane surrounding the notochord during notochord formation and differentiation, the presence of laminin and receptors is unique to NP tissue of IVD. Also a soft ( $<720 \mathrm{pa}$ ) and laminin containing ECM substrate has been proved to promote the immature NPC morphology, cell-cell interactions, and proteoglycan synthesis. ${ }^{44}$ Our recent proteomic data of SDSC deposited SECMs suggested that laminin is missing. ${ }^{18}$ Based on above evidence, we highly suspected that the absence of laminin in SECMs is probably responsible for the unidentified enhancement of chondrogenesis in NPCs. The further investigation is ongoing.

Our next step is to perform the microarray analysis of gene expression changes in three NPCs that expanded on different substrates and proteomics of both young and old NECMs. The identification of significantly changed genes could suggest important signaling pathways that manipulate the rejuvenation of NPCs by the NECMs. The critical component within the NECMs could be identified by proteomics data and facilitate future applications of biomaterials in NP tissue engineering and regeneration. Our purpose is to determine specific genes involved in DECM reprogramming and/or rejuvenation so as to find specific signal transduction pathways. Elucidating the underlying mechanism will help commercialize this technology in the near future, which could make clinical application of large-scale expansion of high-quality NP cells from degenerated disc patients a reality. 


\section{REFERENCES}

1. Macfarlane GJ, Thomas E, Groft PR et al. Predictors of early improvement in low back pain amongst consulters to general practice: the influence of pre-morbid and episode-related factors. Pain 1999;80:113-9.

2. Luoma K, Riihimäki $H$, Luukkonen $R$ et al. Low back pain in relation to lumbar disc degeneration. Spine 2000;25:487-92.

3. Salminen JJ, Erkintalo MO, Pentti $\mathrm{J}$ et al. Recurrent low back pain and early disc degeneration in the young. Spine 1999;24:1316-21.

4. Parke WW, Schiff DC. The applied anatomy of the intervertebral disc. Orthop Clin North Am 1971;2:309-24.

5. Humzah MD, Soames RW. Human intervertebral disc: structure and function. Anat Rec 1988;220:337-56.

6. Beard HK, Ryvar R, Brown R et al. Immunochemical localization of collagen types and proteoglycan in pig intervertebral discs. Immunology 1980;41:491-501.

7. Pearce RH, Grimmer BJ, Adams ME. Degeneration and the chemical composition of the human lumbar intervertebral disc. J Orthop Res 1987;5:198-205.

8. Mwale F, Roughley P, Antoniou J. Distinction between the extracellular matrix of the nucleus pulposus and hyaline cartilage: a requisite for tissue engineering of intervertebral disc. Eur Cell Mater 2004;8:58-63.

9. Ganey T, Libera J, Moos $\vee$ et al. Disc chondrocyte transplantation in a canine model: a treatment for degenerated or damaged intervertebral disc. Spine 2003;28:2609-20.

10. Gruber HE, Johnson TL, Leslie K et al. Autologous intervertebral disc cell implantation: a model using Psammomys obesus, the sand rat. Spine 2002;27:1626-33.

11. Hohaus $C$, Ganey TM, Minkus $Y$ et al. Cell transplantation in lumbar spine disc degeneration disease. Eur Spine J 2008;17 Suppl 4:492-503.

12. Evans C. Potential biologic therapies for the intervertebral disc. J Bone Joint Surg Am 2006;88A(Suppl. 2):95-8.

13. Kluba $T$, Niemeyer $T$, Gaissmaier $C$ et al. Human anulus fibrosis and nucleus pulposus cells of the intervertebral disc: effect of degeneration and culture system on cell phenotype. Spine 2005;30:2743-8.

14. Tsai TT, Guttapalli A, Oguz E et al. Fibroblast growth factor-2 maintains the differentiation potential of nucleus pulposus cells in vitro: implications for cell-based transplantation therapy. Spine 2007;32:495-502.

15. He F, Chen X, Pei M. Reconstruction of an in vitro tissue-specific microenvironment to rejuvenate synovium-derived stem cells for cartilage tissue engineering. Tissue Eng Part $A$. 2009;15:3809-21. 
16. He F, Pei M. Rejuvenation of nucleus pulposus cells using extracellular matrix deposited by synovium-derived stem cells. Spine (Phila Pa 1976). 2012;37:459-69.

17. Pei M, Shoukry M, Li $\mathrm{J}$ et al. Modulation of in vitro microenvironment facilitates synoviumderived stem cell-based nucleus pulposus tissue regeneration. Spine (Phila Pa 1976) 2012;37:1538-47.

18. Li J, Hansen KC, Zhang $Y$ et al. Rejuvenation of chondrogenic potential in a young stem cell microenvironment. Biomaterials. 2014;35:642-53.

19. Gruber HE, Ingram JA, Norton $\mathrm{HJ}$ et al. Senescence in cells of the aging and degenerating intervertebral disc: immunolocalization of senescence-associated beta-galactosidase in human and sand rat discs. Spine(Phila Pa 1976). 2007;32:321-7.

20. Heathfield SK, Le Maitre CL, Hoyland JA. Caveolin-1 expression and stress-induced premature senescence in human intervertebral disc degeneration. Arthritis Res. Ther. 2008;10:R87.

21. Le Maitre CL, Freemont AJ, Hoyland JA. Accelerated cellular senescence in degenerate intervertebral discs: a possible role in the pathogenesis of intervertebral disc degeneration. Arthritis Res. Ther. 2007;9:R45.

22. Jeong SW, Lee JS, Kim KW. In vitro lifespan and senescence mechanisms of human nucleus pulposus chondrocytes. Spine J. 2014;14:499-504

23. Hegewald AA, Endres M, Abbushi $A$ et al. Adequacy of herniated disc tissue as a cell source for nucleus pulposus regeneration. J Neurosurg Spine. 2011;14:273-80.

24. Ciapetti G, Granchi D, Devescovi V et al. Ex vivo observation of human intervertebral disc tissue and cells isolated from degenerated intervertebral discs. Eur Spine J. 2012;21 Suppl 1:S10-9.

25. Mizrahi O, Sheyn D, Tawackoli $W$ et al. Nucleus pulposus degeneration alters properties of resident progenitor cells. Spine J. 2013;13:803-14.

26. Abbott RD, Purmessur D, Monsey RD et al. Regenerative potential of TGF $\beta 3+$ Dex and notochordal cell conditioned media on degenerated human intervertebral disc cells. J Orthop Res. 2012;30:482-8.

27. Henriksson $\mathrm{H} 1$, Thornemo $\mathrm{M}$, Karlsson $\mathrm{C}$ et al. Identification of cell proliferation zones, progenitor cells and a potential stem cell niche in the intervertebral disc region: a study in four species. Spine (Phila Pa 1976). 2009;34:2278-87.

28. Blanco JF1, Graciani IF, Sanchez-Guijo FM et al. Isolation and characterization of mesenchymal stromal cells from human degenerated nucleus pulposus: comparison with bone marrow mesenchymal stromal cells from the same subjects. Spine (Phila Pa 1976). 2010;35:2259-65.

29. Rutges JP, Duit RA, Kummer JA et al. Hypertrophic differentiation and calcification during intervertebral disc degeneration. Osteoarthritis Cartilage. 2010;18:1487-95. 
30. Le Maitre CL, Freemont AJ, Hoyland JA. Localization of degradative enzymes and their inhibitors in the degenerate human intervertebral disc. J Pathol. 2004;204:47-54.

31. Pockert AJ, Richardson SM, Le Maitre CL et al. Modified expression of the ADAMTS enzymes and tissue inhibitor of metalloproteinases 3 during human intervertebral disc degeneration. Arthritis Rheum. 2009;60:482-91.

32. Vo NV, Hartman RA, Yurube $T$ et al. Expression and regulation of metalloproteinases and their inhibitors in intervertebral disc aging and degeneration. Spine J. 2013;13:331-41.

33. Patel KP, Sandy JD, Akeda K et al. Aggrecanases and aggrecanase-generated fragments in the human intervertebral disc at early and advanced stages of disc degeneration. Spine (Phila Pa 1976). 2007;32:2596-603.

34. Ding F, Shao ZW, Xiong LM. Cell death in intervertebral disc degeneration. Apoptosis. 2013 Jul;18(7):777-85.

35. Wang SL, Yu YL, Tang CL et al. Effects of TGF- $\beta 1$ and IL-1 $\beta$ on expression of ADAMTS enzymes and TIMP-3 in human intervertebral disc degeneration. Exp Ther Med. 2013 ;6:1522-26.

36. Kim JS, Ellman MB, An HS et al. Insulin-like growth factor 1 synergizes with bone morphogenetic protein 7-mediated anabolism in bovine intervertebral disc cells. Arthritis Rheum. 2010;62:3706-15.

37. Liang CZ, Li H, Tao YQ et al. Dual release of dexamethasone and TGF- $\beta 3$ from polymeric microspheres for stem cell matrix accumulation in a rat disc degeneration model. Acta Biomater. 2013;9:9423-33.

38. Chaofeng W, Chao Z, Deli W et al. Nucleus pulposus cells expressing hBMP7 can prevent the degeneration of allogenic IVD in a canine transplantation model. J Orthop Res. 2013;31:1366-73

39. Masuda K, Oegema TR Jr, An HS. Growth factors and treatment of intervertebral disc degeneration. Spine (Phila Pa 1976). 2004;1;29:2757-69.

40. Mercuri JJ, Gill SS, Simionescu DT. Novel tissue-derived biomimetic scaffold for regenerating the human nucleus pulposus. J Biomed Mater Res A. 2011;96:422-35.

41. Mercuri JJ, Patnaik S, Dion G et al. Regenerative potential of decellularized porcine nucleus pulposus hydrogel scaffolds: stem cell differentiation, matrix remodeling, and biocompatibility studies. Tissue Eng Part A. 2013;19:952-66.

42. Yuan M, Yeung CW, Li YY et al. Effects of nucleus pulposus cell-derived acellular matrix on the differentiation of mesenchymal stem cells. Biomaterials. 2013;34:3948-61.

43. Chen J, Jing L, Gilchrist CL et al. Expression of laminin isoforms, receptors, and binding proteins unique to nucleus pulposus cells of immature intervertebral disc. Connect Tissue Res. 2009;50(5):294-306. 
44. Gilchrist CL, Darling EM, Chen J et al. Extracellular matrix ligand and stiffness modulate immature nucleus pulposus cell-cell interactions. PLoS One. 2011;6:e27170. 


\section{FIGURE LEGENDS}

Figure 7.1 (A) Cell morphology of passage 2 NPC during expansion on plastic flasks (PL) or fetal and adult SDSC derived DECM (SECM) (FE and AE) for two passages. Cell number was counted $(B)$ and proliferation index was analyzed by flow cytometry (C).

Figure 7.2 (A) Cell morphology of passage 2 NPC during expansion on plastic flasks (PL) or fetal and adult NPC derived DECM (NECM) (FNPE and ANPE) for two passages. Cell number was counted $(B)$ and proliferation index was analyzed by flow cytometry (C).

Figure 7.3 Mesenchymal stem cell surface markers (CD29, CD90 and CD105) were analyzed by flow cytometry after expansion on three different subtrates from both SECM (A) and NECM (B).

Figure 7.4 Histology and immunostaining analysis of SECM (A) or NECM (B) pre-expanded NPCs pellets after 10 or 21 days chondrogenic induction. Gross appearance of the pellets, alcian blue staining for sulfated GAGs and immunostaining collagen II were displayed at both time points.

Figure 7.5 Biochemistry analysis for GAGs and DNA content in SECMs expanded NPCs (A) or NECMs expanded NPCs (B) were measured at day 0,10 and 21. DNA content of NPC pellets changes was normalized by the content of pellets at day 0 . Chondrogenic index (the ratio of GAG to DNA) indicated the degree of chondrogenic differentiation of NPCs.

Figure 7.6 Real-time PCR to examine the hypertrophic (COLX, RUNX2, ALPL, MMP13, VEGFA), catabolic metaboism (COX2, MMP3, ADAMTS4, ADAMTS5, TIMP1) and senescence (CASP3, $P 16, P 21, P 53, S I R T 1, B M I 1)$ gene markers was tested in SECM expanded NPC pellets (A) and NECM expanded NPC pellets (B). 
Figure 7.1

A

PL

FE

AE
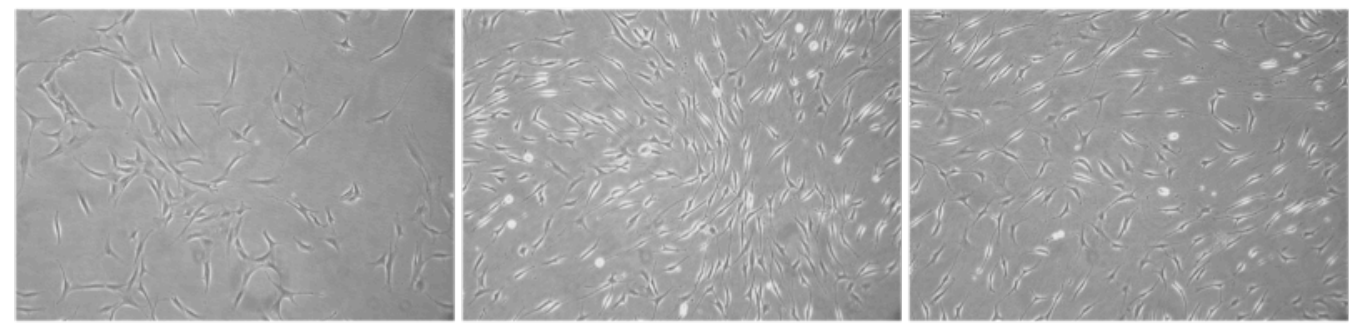

B

C

PL

FE

AE
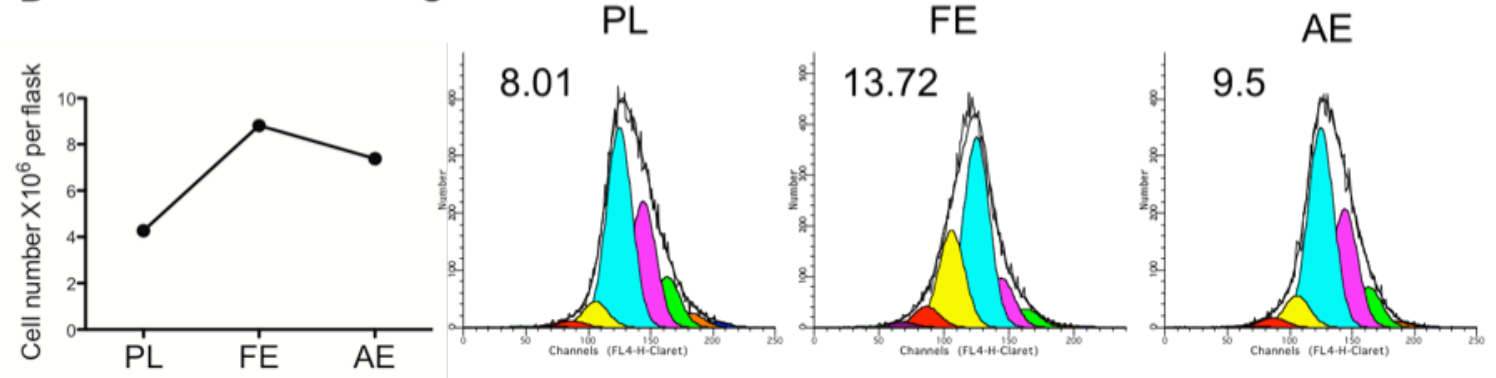
Figure 7.2

A

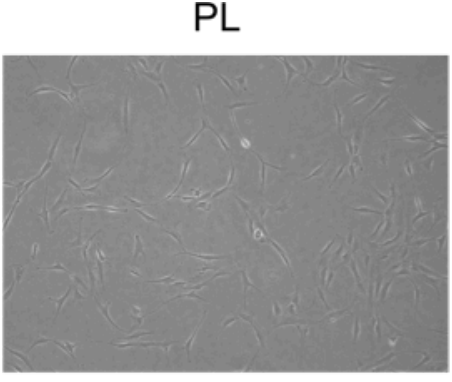

B

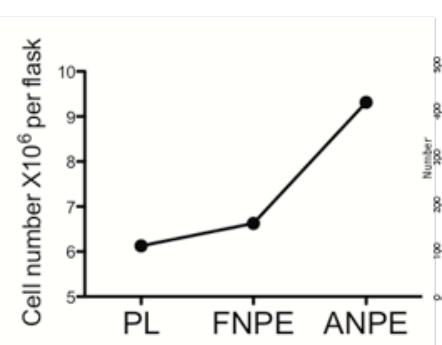

FNPE
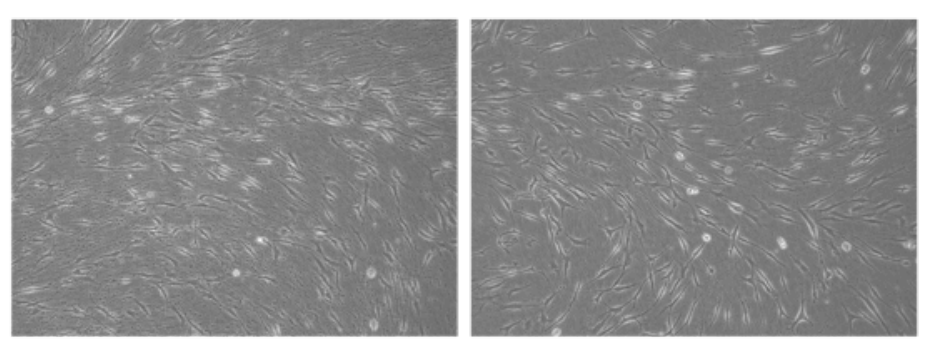

PL

5.36

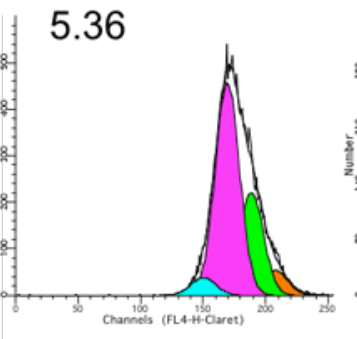

FNPE

ANPE

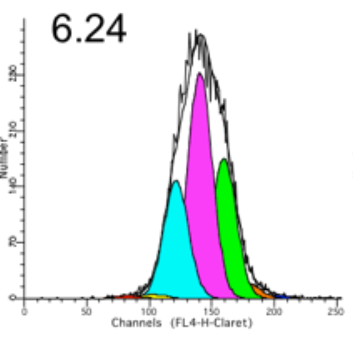

9.45

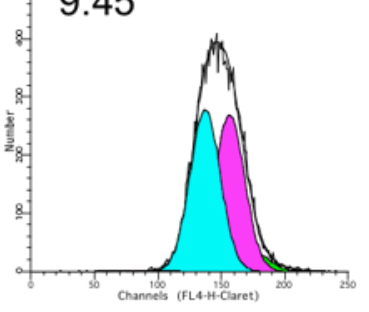




\section{Figure 7.3}

A
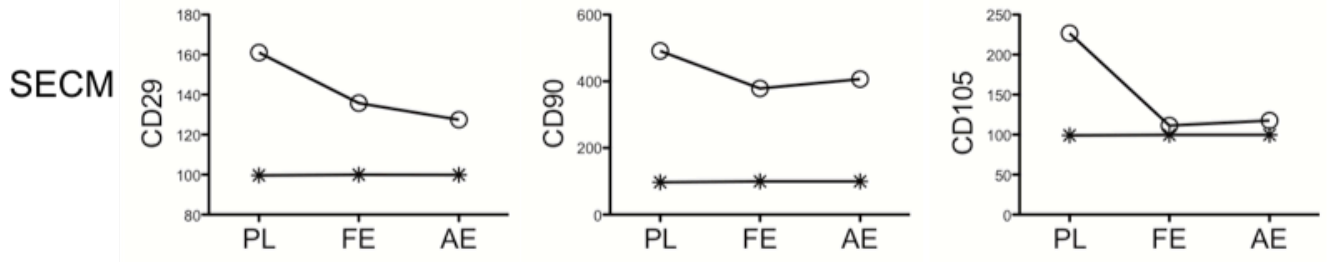

B
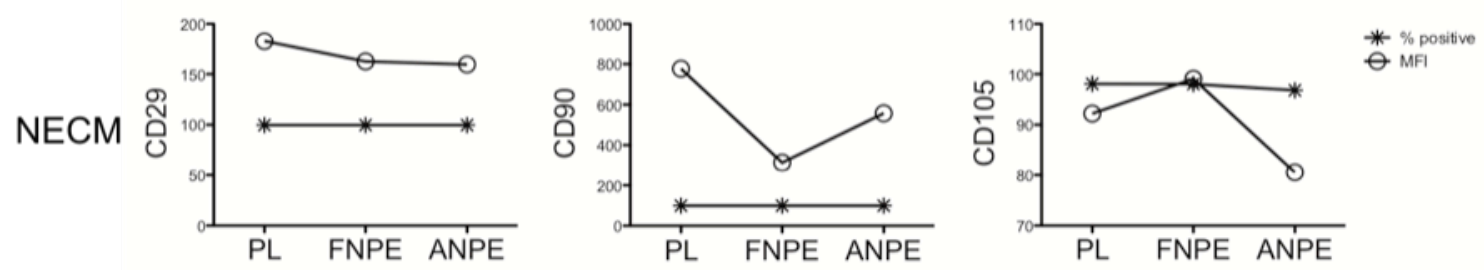
Figurer 7.4

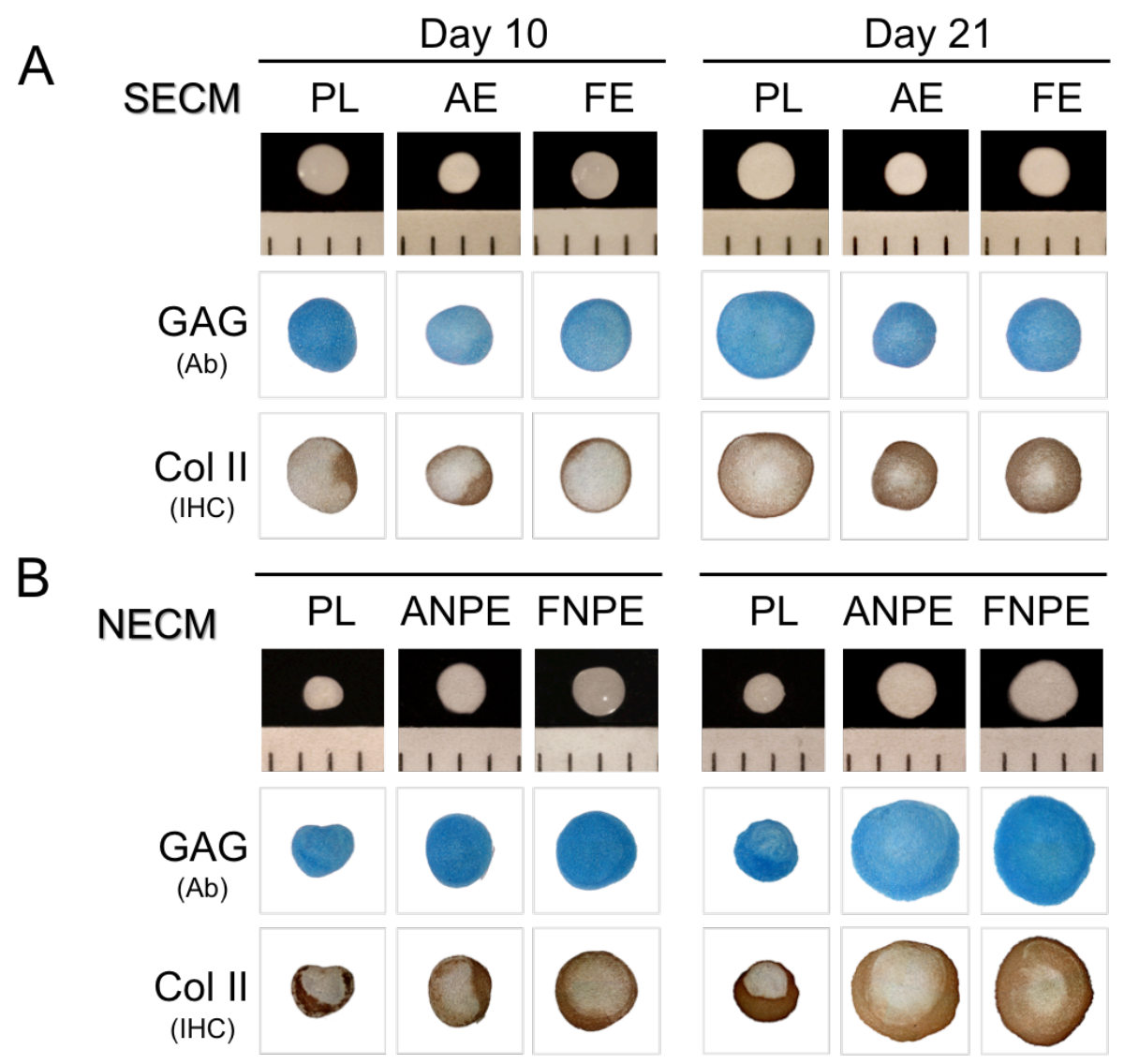


Figure 7.5

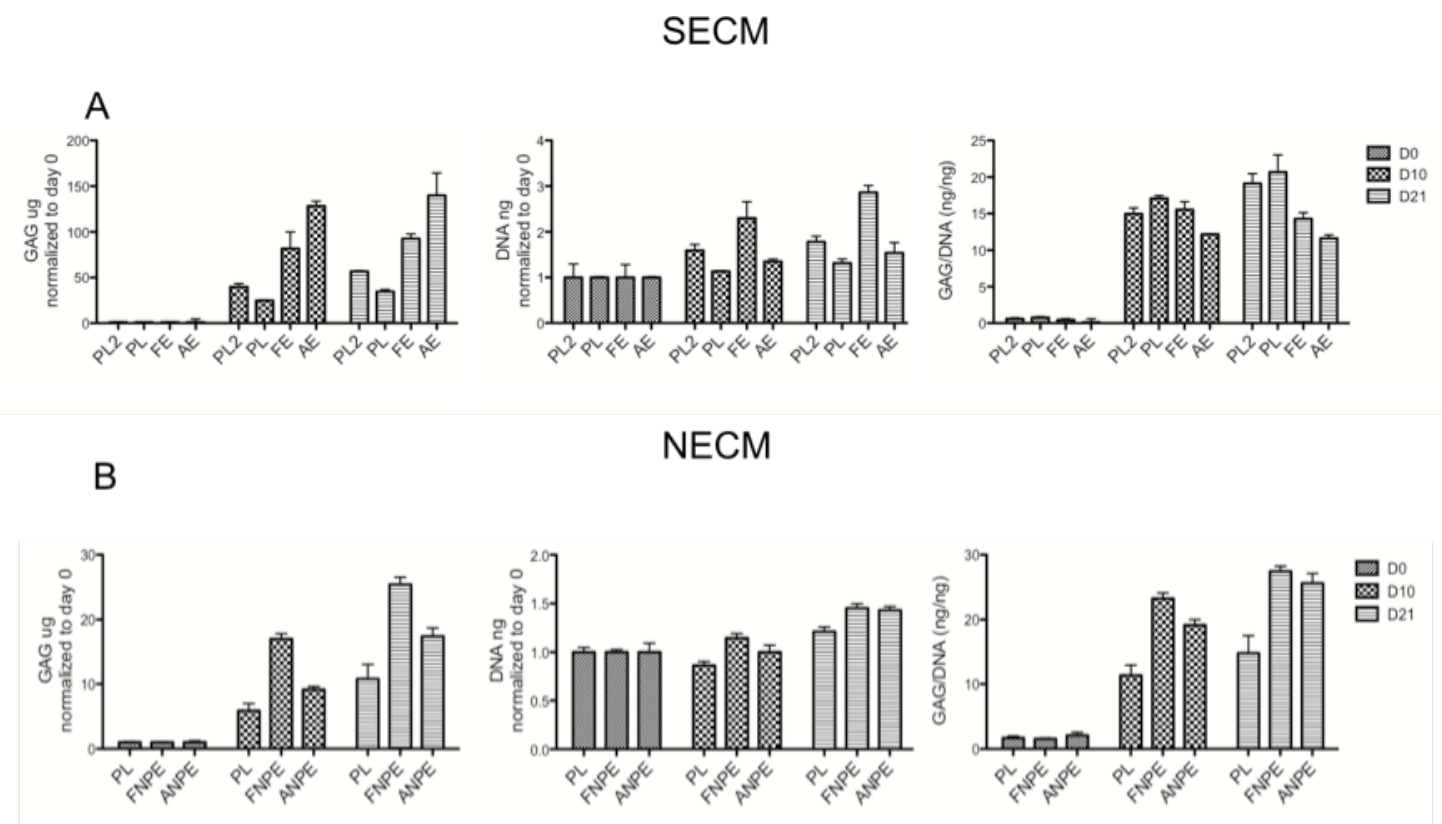


Figure 7.6
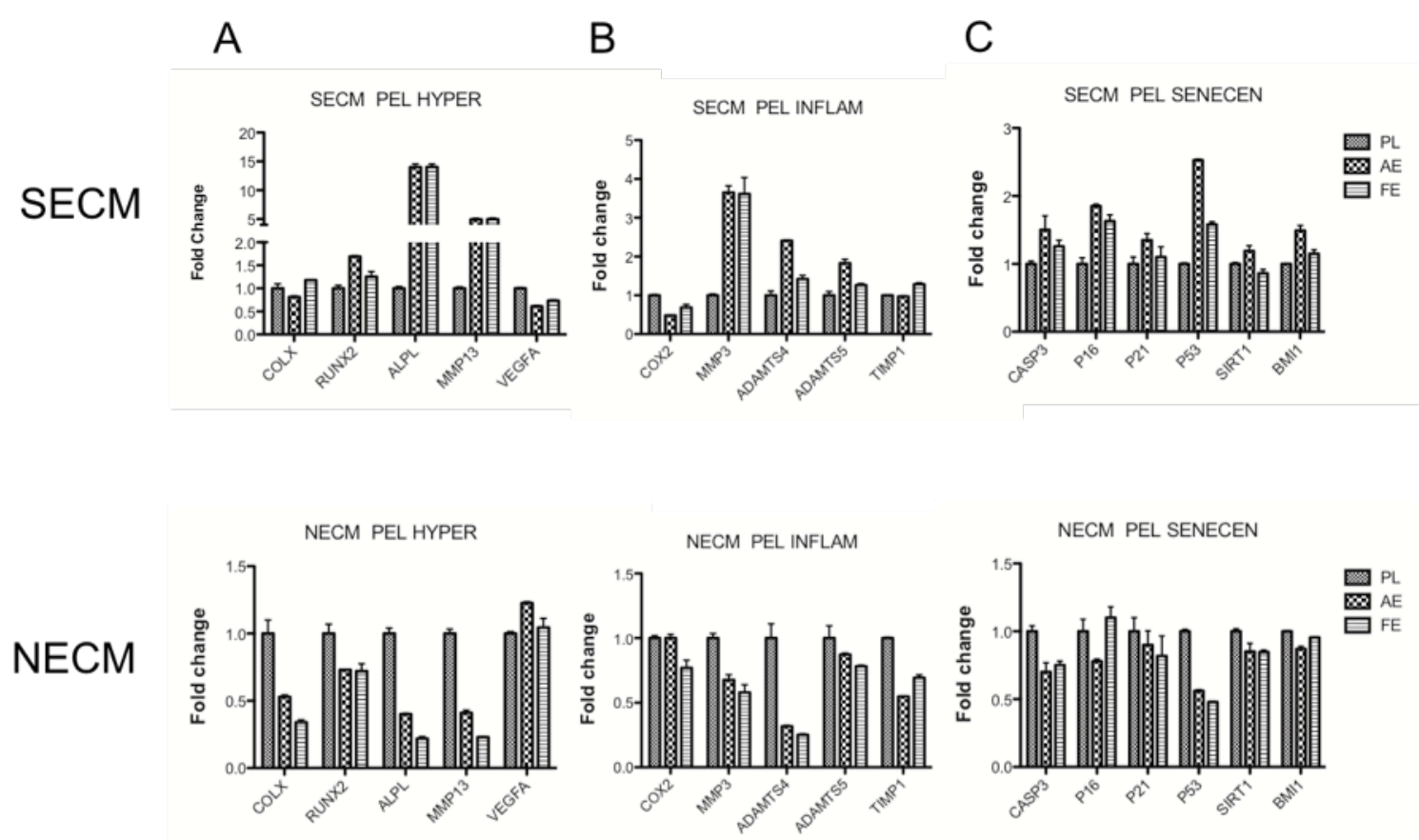


\section{CHAPTER 8: GENERAL DISCUSSION}

The objectives of this dissertation were to investigate the effect of conventional methods and the novel DECM expansion system on SDSCs for facilitating chondrogenesis and explore the potential cell sources of DECM; to characterize the rejuvenating effect of fetal SDSC deposited young DECM on adult SDSCs and its potential mechanisms; to apply the young DECM expansion system to the rejuvenation of primary NPCs from herniated human discs. The longterm goal is to develop an efficient ex vivo expansion system with proliferation and chondrogenic potential rejuvenating capacities, which can provide a large quantity of high quality cells for cartilage engineering. The central hypothesis is that DECM deposited by human primary cells or stem cells can serve as an excellent ex vivo expansion system for cartilage regeneration. Due to the shortage of autologous chondrocytes, it is critical to identify a tissue-specific stem cell for chondrogenesis from various sources. The DECM based ex vivo stem cell expansion system has shown promising potential in maintaining stemness and facilitating chondrogenesis but it could be optimized. Understanding of the rejuvenation mechanism of DECM has moved forward through biophysical and biochemical analysis. The involvement of signaling pathways and potential epigenetic mechanisms are also subjected to scrutiny.

\subsection{Synovium Derived Stem Cells are a Tissue-Specific Stem Cell for Chondrogenesis}

Adult stem cells are undifferentiated cells found among differentiated cells in a tissue or organ that can renew themselves and can differentiate to yield some or all of the major specialized cell types of the tissue or organ. The search for adult stem cells began in the 1950s, when researchers first discovered two populations in bone marrow. One population is the hematopoietic stem cells and the other is bone marrow stromal stem cells [also called BMSCs]. The MSC is known to be able to give rise to a variety of cell types, among them osteocytes, chondrocytes, adipocytes, and other kinds of connective tissue cells. A wide variety of MSCs have been isolated from a number of different tissues and organs, suggesting that the homeostatic maintenance of most tissues is capable of regeneration and repair and is ultimately mediated by such tissuespecific stem cells. The tissue-specific stem cell is derived from a known tissue type and can respond to organ-specific signals when recruited to that organ; in other words, the differentiation potential reflects the local cell population. ${ }^{1 ; 2}$

Recently, SDSCs have been proposed as tissue-specific stem cells for chondrogenesis for the following reasons. First, synovium and cartilage share an adjacent anatomical location. The synovium is a fluid-filled cavity that surrounds joint cartilage and tendons and facilitates smooth movement of joints. Unsurprisingly, chondrocytes and SDSCs share a similar gene expression 
profile. ${ }^{3}$ SDSCs, like chondrocytes, have been shown to accumulate type II collagen and express the gene for proteoglycan 4 , but do not accumulate large amounts of type $X$ collagen. ${ }^{4 ; 5}$ Although type $X$ collagen is a marker of hypertrophy, it is sometimes expressed by deep-zone chondrocytes. Also, the cells of the synovium and articular cartilage develop from the same pool of precusor cells and remain in close relationship into adulthood. ${ }^{6-8}$ Second, synovium can serve as a stem cell niche/microenvironment for stem cells to reside and functions in conjunction with nurturing cells to retain pluripotency, prevent apoptosis, and inhibit excessive cell replication. ${ }^{9} \mathrm{~A}$ recent study from Kurth et al. demonstrated that a slow-cycling, MSC-like cell population existed in murine knee joints, which spread out through synovium, in both the intimal layer and subintimal layer. ${ }^{10}$ Upon injury, the synovium and cartilage function together in the absence of medical intervention, further demonstrating the tissue-specific capacity of SDSCs. Third, our recent study also showed porcine SDSC-derived DECM can provide a three-dimensional environment for promoting proliferation and chondrogenic potential without a concomitant increase in adipogenesis and osteogenesis. ${ }^{11}$ In Chapter 3, addition of FGF-2 during cell expansion promoted not only SDSC chondrogenic potential but also hypertrophic marker expression. However, expansion on DECM deposited by SDSCs could enhance chondrogenic potential without increase of hypertrophy. As shown in Chapter 4, the tissue-specificity of SDSC could be further enhanced by DECMs as demonstrated by increased chondrogenic but not osteogenic and adipogenic potentials. Interestingly, in Chapter 6 we discovered that young DECM derived from fetal SDSC rejuvenated adult SDSCs with higher proliferation and chondrogenic and adipogenic but not osteogenic potential. The most feasible explanation is that fewer tissue-specific signals were provided by young DECM than adult DECM. Also SDSCs have been reported to possess superior chondrogenic and adipogenic potentials rather than osteogenic potential. ${ }^{12}$

\subsection{Reconstruction and Optimization of Decellularized Stem Cell Matrix Based Ex Vivo Expansion System for Cartilage Degeneration}

A stem cell niche is a specific site in adult tissues where stem cells reside and undergo selfrenewal and differentiation by producing large numbers of progeny. Ever since the concept of "niche" was proposed by Schofield in 1978 to describe the physiologically limited microenvironment of bone marrow in which the hematopoietic stem cells reside, ${ }^{13}$ the niche hypothesis has been supported by a variety of co-culture experiments in vitro. ${ }^{14-17}$ Structurally, the niche is formed by supporting cells that provide a microenvironment for stem cells and the signals emanating from the supporting cells. ${ }^{18-20}$ However, it still remains a major challenge to accurately define the precise cellular components and anatomical structure of the niche. 
The ECM comprises a scaffold of collagens and other structural proteins that are interlaced with proteoglycans which, together, control the local mechanical environment and contribute to the "stem cell niche" microenvironment through their own signaling moieties and their ability to bind growth factors, cytokines, enzymes, and other diffusible molecules. Compared to traditional 2D culture, culturing stem cells in 3D environments provides another dimension for external mechanical inputs and for cell adhesion, which dramatically affects integrin ligation, cell contraction, and associated intracellular signaling. ${ }^{21 ; 22}$ Furthermore, the 3D environment might be necessary to model morphogenetic and remodeling events that occur over larger-length scales. The mechanisms by which nanotopographic cues derived from ECM influence stem cell proliferation and differentiation are not well investigated yet but appear to involve changes in cytoskeletal organization and structure, potentially in response to the geometry and size of the underlying features of the ECM. That is, changes in the feature size of the substrate may influence the clustering of integrins and other cell adhesion molecules, thus altering the number and distribution of focal adhesions. The composition and function of adhesions characterized in 3D matrices derived from tissues or cell culture were demonstrated to be different from focal and fibrillar adhesions characterized on 2D substrates in their content of $\alpha_{5} \beta_{1}$ and $\alpha_{1} \beta_{3}$ integrins, paxillin, other cytoskeletal components, and tyrosine phosphorylation of $F A K .{ }^{23}$ Relative to $2 \mathrm{D}$ substrates, 3D matrix interactions also display enhanced cell biological activities and narrowed integrin usage. Similarly, in recent years, the importance of ECM has been recognized due to the application of decellularized tissue matrix in organ or tissue regeneration. ${ }^{24-30}$ Partially, it is because of the highly conservative nature of ECM components between species. Different from the above studies, we deposited ECM using stem cells and decellularized it for reconstructing this ex vivo microenvironment for cartilage engineering due to its demand of a large quantity of high quality cells. Our first success came from the porcine SDSC deposited DECM, which enhanced the proliferation and chondrogenic potential when applied as an expansion system compared to traditional expansion on plastic flask for porcine SDSC. ${ }^{11}$ Human SDSC (both fetal and adult SDSC) deposited DECM also exhibited the same effect as shown in Chapter 4, Chapter 5 and Chapter 6 . The investigation of the DECMs deposited by adipose and urine derived stem cells and dermal fibroblasts in Chapter 4 also showed that, despite the differences in these DECMs, all were able to enhance the self-renewal and chondrogenic potential compared to the $2 \mathrm{D}$ culture. It not only demonstrated the advantage of 3D DECMs over 2D plastic culture in facilitating ex vivo expansion but also suggested that there are common core components among all these DECMs. The exploration of these similarities in future studies would benefit the development of an ex vivo expansion system for cartilage engineering.

Communication within the niche is essential for the maintenance of proper stem cell function and for determining the rate of stem cell self-renewal. Soluble factors may act locally or may diffuse 
throughout the niche to direct stem cell fate decisions. Studies indicate that supporting cells, which are located adjacent to stem cells, secrete soluble factors that are required for maintaining stem cell identity and for specifying stem cell self-renewal. ${ }^{31-33}$ Soluble factors, such as growth factors and cytokines, are important for the initiation and control of stem cell differentiation. A wide variety of soluble growth factors, such as FGF- $2,{ }^{34}$ TGF $-\beta,{ }^{35}$ vascular endothelial growth factor, and hepatocyte growth factor, ${ }^{36}$ bind to a component of ECM, which greatly slows their diffusion and therefore serves to fine-tune their local concentrations and gradients. ${ }^{35 ; 36}$ Matrix binding can create locally higher concentrations of autocrine growth factors, ${ }^{37}$ allowing smaller amounts of the factor to signal more effectively. ${ }^{38}$ In this dissertation, we also investigated the influence of soluble growth factor, FGF-2, on SDSC stemness in Chapter 3. We showed that addition of FGF-2 during cell expansion significantly increased SDSC proliferation and chondrogenic potential. The combination of DECM with FGF-2 further enhanced the proliferation and chondrogenic potential in recellularized SDSCs, suggesting a synergistic effect between them. However, unlike DECM, the addition of FGF-2 also significantly increased the expression of hypertrophic markers (type $\mathrm{X}$ collagen).

The physiological condition, including oxygen tension, is an important component of the stem cell microenvironment and has been shown to play a role in regulating both embryonic and adult stem cells. Low oxygen tensions (hypoxia) maintain undifferentiated states of embryonic, hematopoietic, mesenchymal, and neural stem cell phenotypes and also influence proliferation and cell-fate commitment. Despite the presence of a decreased osteogenic and chondrogenic potential when induced to differentiate in hypoxic conditions, ${ }^{39}$ adipose stem cells exhibited increased chondrocytic markers when expanded in hypoxic conditions and differentiated in normoxic cultures. ${ }^{40}$ The effect of hypoxia in committing adipose stem cells to chondrocytes is

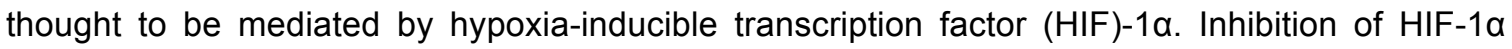
leads to decreased chondrogenic potential, normal osteogenic potential, and enhanced adipogenic potential. ${ }^{41}$ The role of hypoxia and HIF-1a in cell differentiation is tissue-specific, because HIF-1a maintains the stem cells in an undifferentiated state, inhibits differentiation of mesenchymal cells into osteoblasts, adipocytes, and myocytes, and stimulates differentiation into chondrocytes. ${ }^{42-45}$ These data support the role of oxygen tension as an important factor in the determination of cell fate and maintenance of stemness in adipose and bone marrow derived MSCs. In Chapter 3, application of low oxygen level (5\%) in combination with FGF-2 or DECM during expansion significantly promoted proliferation with strong chondrogenic potential, suggesting the maintenance of stemness by hypoxia. One limitation of this study is that expression of HIF-1 $\alpha$ was not analyzed. In Chapter 5, we also investigated the influence of hypoxia during pellet culture for chondrogenesis. Our data showed that low oxygen level 
increased the pellet size, GAG content, and chondrogenic marker expression after a 14 day induction. Thus, the low oxygen level in pellet culture for chondrogenesis is established.

\subsection{Biophysical and Biochemical Explanations of Decelluarized Extracellular Matrix}

Another key challenge in stem cell research is to learn how to direct the differentiation of stem cells toward specific fates. Other than the components of the ECM, a variety of cues including biophysical factors, such as the stiffness of ECM and extrinsic mechanical factors as well as cell shape changes, are also capable of influencing stem cell proliferation, self-maintenance, and differentiation toward specific cell phenotypes. Recently, the elasticity of the matrix microenvironment was identified as regulating stem cell fate. By changing the stiffness of the substrate, human MSCs could be directed along neuronal, muscle, or bone lineages. ${ }^{46}$ Since then, substrate stiffness has been applied to modulate the proliferation and differentiation of embryonic stem cells ${ }^{47 ; 48}$ as well as certain types of adult MSCs. ${ }^{49 ; 50}$ The Ras superfamily, especially the Rho subfamily members that are well known to regulate the cytoskeleton, cell growth, and transcription, is reported to be involved in substrate stiffness sensing. ${ }^{51}$ Rhostimulated contractility drives stress fiber and focal adhesion formation and the up-regulation of $\alpha$ smooth muscle actin correlates with contractility on a rigid substrate. ${ }^{52 ; 53}$ RhoA and downstream Rho kinase (ROCK) also mediate substrate rigidity-regulated $\mathrm{Ca}^{2+}$ oscillation, which determines the physiological functions of human MSCs. ${ }^{54}$ Rac1 is another Rho family protein that can be activated by myosin inhibition, which also has provided evidence for the critical role of contractility in substrate sensing. ${ }^{55 ; 56}$ Understanding has increased about how underlying matrix stiffness can

guide stem cells toward a specific developmental lineage, ${ }^{46 ; 57}$ but matrix stiffness alone is likely to be insufficient to achieve complete terminal differentiation. ${ }^{46}$ In order to understand how DECM exhibits influence on recellularized cells, we measured the elasticity of different DECMs and of cells expanded on different substrates in Chapter 4 and Chapter 6. Not surprisingly, all the DECM expanded cells exhibited a lower elasticity compared to plastic flask expanded cells. The maintained or enhanced stemness in the DECM expanded cells could be due to its elasticity mimicking the in vivo niche. Additionally, the lower elasticity of fetal SDSC DECM compared to adult SDSC DECM also resulted in a lower elasticity in recellularized adult SDSCs in Chapter 6, which could explain the enhanced rejuvenating effect by young DECM. In Chapter 4, we also compared the differences of elasticity in four different DECMs and cells expanded on them. As expected, SDSCs expanded on all DECMs exhibited lower elasticity than cells expanded on plastic flasks. However, the elasticity does not match the enhanced chondrogenic potential in cells, which confirmed that matrix stiffness is not sufficient to determine lineage differentiation. Alternatively, matrix stiffness could be an underlying mediator of growth factors, such as TGF $\beta$ driven processes, regulating the equilibrium between storage and release of a host of matrix- 
bound growth factors. ${ }^{58}$ Although matrix stiffness is not the most effective at driving a specific lineage differentiation, it is an important determinant and co-factor for directing cell differentiation induced by soluble biochemical factors. Stem cells need to integrate microenvironmental cues from both soluble biochemical factors and ECM to regulate differentiation.

In this dissertation, we also employed scanning electron microscopy to observe the morphology of cells and the substrates (plastic flasks or DECMs) and interactions between them in Chapter 4 and Chapter 6. The most striking difference is between the cells expanded on plastic flasks and DECMs. The well-spread and enlarged morphology accompanied with proliferation arrest signified the development of senescence. The less spread and spindle shaped cells expanded on DECMs showed a higher proliferation rate and chondrogenic potential in the later stage. Cell shape is defined within the niche by the constraints imposed by the surrounding ECM on cells during development and adulthood. ${ }^{59 ; 60}$ Alterations in adhesive interactions and crosstalk between the ECM and the cells work to define each other. Evidence suggests that physical control of cell shape alone can act as a potent regulator of cell signaling and lineage differentiation. ${ }^{61}$ As suggested in a recent review, a thorough understanding of the physical properties of ECM could facilitate the development of biomaterials to display and deliver stem cell regulatory signals in a precise and near-physiological fashion, and serve as a powerful artificial microenvironment in which to study and instruct stem cell fate both in vitro and in vivo. ${ }^{62}$

ECM is primarily composed of various collagens, laminins, and glycoproteins serving as substrates for a myriad of adhesion molecules including integrins, cadherins, and discoidin domain receptors. Cell-matrix interaction-induced signaling constitutes a critical determinant of cell behavior, making ECM composition a key factor in the stem cell niche. In Chapter 6, we applied proteomics to analyze the components of SDSC DECM from young and old donors. We identified interesting discrepancies in the composition of these matrices, such as young matrix contains more fibrillin-2, clusterin, and tenascin $\mathrm{C}$ and old matrix possesses more biglycan, decorin, dermatoponin, elastin, periostin, thrombospondin-1, and TGF- $\beta 1$. Existing literature has shown that the young matrix contains proteins involved in cell proliferation while the old matrix possesses components that prefer cell differentiation and apoptosis. One of the future directions to investigate the mechanism is to focus on a specific protein that may influence the cells the most. Identification of the critical protein would benefit the development of biomaterials for cartilage engineering. Interestingly, we found no laminin in young or old matrix. We also confirmed our proteomics data with immunofluorescence staining. Full characterization of DECM using biophysical and biochemical analysis will offer great opportunities to biomaterials technologies, which can be designed to act as carriers for local delivery of stem cells, supporting cells, or molecular niche cues. 


\subsection{Signaling Pathways Involved in the Rejuvenating Effect of Decellularized Extracellular Matrix}

The rejuvenating effect of DECM was mainly manifested in maintaining and promoting stemness of recellularized cells. MAPK and Wnt signaling pathways are two key pathways involved in cell proliferation and chondrogenic potential. As a major family of ECM receptors that transmit information from the matrix to the cells, integrins play a role as key mediators for cell proliferation. Integrin-mediated cell adhesion is required for cell motility and affects cell proliferation. ${ }^{63 ; 64}$ Ligands present in ECM, such as vitronectin, fibronectin, laminin, and collagen, are recognized by specific integrins, such as integrin $\alpha_{5} \beta_{1}$ for fibronectin. ${ }^{65}$ Integrin-ECM interaction can activate signaling cascades, such as ERK1/2, MAPK, PI3-K, and AKT. ${ }^{66 ; 67}$ It is agreed that sustained ERK activation requires cooperative signaling between receptor tyrosine kinases and integrins. ${ }^{64}$ The induction of cyclin D1 mRNA has most frequently been attributed to the activation of ERKs. ${ }^{68}$ However, only a sustained ERK signal is not sufficient to induce cyclin D1 protein. PI3-K is also required for the expression and stability of cyclin D1. ${ }^{69 ; 70}$ in addition, FAK is an important regulator of cyclin D1. Overexpression of wild-type and dominant negative FAK cDNAs showed that integrin-dependent phosphorylation of FAK plays an important role in phosphorylation of ERK and induction of cyclin D1. ${ }^{71}$

The Wnt/ $\beta$-catenin pathway is related to stem-cell self-renewal and proliferation. Maruyama et al. found that, besides directly regulating renewal and proliferation, activation of $\beta$-catenin also alters the lineage commitment of MSCs to differentiate into chondrocytes through cooperating with FGF receptor 1 and balancing between BMP and FGF signaling pathways. ${ }^{72}$ Since Wnt signaling is also involved in inhibiting adipogenesis of MSCs through $\beta$-catenin dependent and independent pathways, ${ }^{73}$ tumor necrosis factor-alpha (the activator of the NF-kB pathway) inhibits adipogenesis by the $\beta$-catenin/TCF4-dependent pathway. ${ }^{74}$ Interactions between NF-kB and $\beta$ catenin/TCF pathways also play a part in regulating MSC proliferation and differentiation. ${ }^{75}$ However, balance among signaling pathways is more important in regulating MSCs through lineage differentiation, as well as maintaining stemness. Coordination between Wnt signals and other secreted signals contributes to the regulation of stem cell self-renewal in tissue microenvironments. ${ }^{76}$ Wnt signals are not only involved in ECM-mediated enhancement of stem cell proliferation, but also contribute to retaining or promoting differentiation potential. Czyz and Wobus reported evidence that the interaction of stem cells with ECM via integrins determines the expression of the signaling molecules BMP-4 and Wnt-1, resulting in the activation of the mesodermal and neuroectodermal lineage, respectively. ${ }^{77}$ Defective Wnt signaling, however, 
affects ECM synthesis, possibly being responsible for the etiology of the segmental premature aging disease Hutchinson-Gilford Progeria because mice exhibit skeletal defects and apoptosis in major blood vessels proximal to the heart. ${ }^{78}$ This study provided insights into the role of Wnt signaling and ECM in aging.

Wnt signaling plays an important role in chondrocyte maturation. Wnt inhibitors were reported to promote chondrogenic differentiation of human MSCs. ${ }^{79}$ Moreover, Wnt signaling may play a "dual" role in chondrogenesis, depending on the specific Wnt ligand responsible for the signaling and the development stage when Wnt is engaged. During chondrogenesis in the chicken limb, Wnt5a delays the maturation of chondrocytes while Wnt4 accelerates the process. ${ }^{80}$ Like Wnt5, Wnt7a also induces a chondro-inhibitory effect, which involves the MAPK pathway and activator protein-1 transcriptional activity. ${ }^{81} \mathrm{Wnt} 14$, another member of the Wnt family, is expressed in the chondrogenic region and has been reported to arrest and even reverse chondrogenic differentiation. ${ }^{82} \beta$-catenin, the central player in canonical Wnt signaling, is required during the early differentiation and late-stage maturation of chondrocytes, but the canonical pathway inhibits the progression of chondrocyte differentiation. Constitutively active $\beta$-catenin can prevent chicken chondrocytes from differentiation by down-regulating Sox9 and type II collagen; ${ }^{83}$ meanwhile, mice with elevated $\beta$-catenin activity resulting from secreted frizzled-related protein deficiency exhibit accelerated chondrocyte maturation. ${ }^{84}$

To the best of our knowledge, there has been no study investigating MAPK and Wnt signaling in 3D DECM expanded cells and followed condensation and chondrogenesis. In Chapter 6, we found that MAPK (especially ERK, JNK, and p38) and Wnt signaling were actively involved in young ECM-mediated adult cell expansion and chondrogenic differentiation. The down-regulation of $p$-ERK in young ECM expanded adult SDSCs indicated a decrease in cell senescence. The increase of $p$-ERK in cell condensation and decrease in 10-day chondrogenic induction could be explained by the dual role of $p$-ERK in promoting chondrogenesis in the early stage and inhibiting it in the later stage. Our data also showed that the canonical Wnt3a signal is downregulated in ECM treated adult SDSCs and remained at a comparable level during chondrogenesis with plastic expanded adult SDSCs. In contrast, Wnt5a and Wnt11, the non-canonical signals, were dramatically up-regulated in ECM treated adult SDSCs, especially in the young ECM group. The same trend was observed in chondrogenic induced pellets as well.

Two tumor-suppressor proteins, p53 and pRB, are the central activating pathway of senescence. Senescence stimuli activate $p 53$, which then induces pRB related senescence by activating $p 21$, the transcriptional target of $p 53$. This senescence is reversible by the subsequent inactivation of p53. ${ }^{85}$ The p53-p21-pRB pathway has also been demonstrated as playing a more important role in senescent nucleus pulposus chondrocytes in vivo. ${ }^{86}$ In addition, the p53/p21 pathway is 
activated by excessive activation of Wnt/ $\beta$-catenin signaling, which leads to MSC senescence as well. ${ }^{87}$ The induction of caveolin 1 up-regulates p53 and p21 and down-regulates pRB. Caveolin overexpression also activates the p38 MAPK pathway, suggesting that both of these pathways are involved in mediating chondrocyte senescence. ${ }^{88}$ Caveolin 1 overexpression has been shown to be responsible for loss of adipogenic differentiation abilities in senescent human MSCs. ${ }^{89}$ Consistently, a decreased level of p21 and caveolin 1 expression was observed in low-density seeding SDSC along with the retained the stemness in Chapter 2. Low-density seeding of SDSCs also expressed lower levels of p-ERK and p-JNK but a higher level of p38 MAPK expression.

\subsection{Decellularized Stem Cell Matrix: A Potential In Vitro Model of Epigenetic Application for Cartilage Regeneration}

Decellularized tissue matrix has proven to be beneficial in regenerative medicine $;^{90}$ it serves as a biological scaffold for selective cell types allowing increased proliferation. The characterization of decellularized cartilage ECM suggested that it is not only a complex $3 D$ structure full of biochemical signals, but also a mechanotransduction device. ${ }^{91}$ This attribute makes decellularized cartilage ECM a perfect candidate for cartilage tissue engineering. Encouraging preliminary animal and clinical data have been reported. ${ }^{92-94}$ More interestingly, DECM deposited by human MSCs (DSCM) could be used as an in vitro expansion system. ${ }^{95}$ DSCM promoted cell attachment, spreading, migration, proliferation, and the maintenance of responses to differentiation signals. ${ }^{96}$ The rejuvenating effect of DSCM has been observed in not only adult

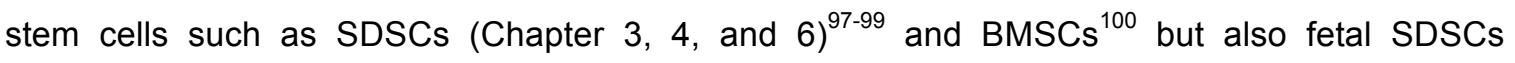
(Chapter 5) and primary cells such as articular chondrocyte ${ }^{101 ; 102}$ and nucleus pulposus cells (Chapter 7). ${ }^{103 ; 104}$ In this dissertation, we also found that DSCM deposited by fetal SDSCs provided a robust rejuvenating effect in promoting adult SDSC proliferation and chondrogenic capacities in Chapter 6. ${ }^{105}$ The increased proliferative and chondrogenic potentials may possibly provide large quantities of high quality cells in an autologous implantation strategy, which has been encouraged by a recent minipig study in which DSCM-expanded SDSCs were injected intraarticularly to treat partial-thickness cartilage defects. ${ }^{106}$

Other than the mechanisms mentioned above, the connections of environmental cues to chromatin and associated signaling factors that are involved in early epigenetic regulation of cartilage regeneration have also been proposed. Several potentially related environmental factors including aging, growth factors, hypoxia, inflammatory factors, mechanics, and oxidative stress that may serve as epigenators (a signal that emanates in the cellular environment and initiates an intracellular pathway that triggers expression of the epigenetic phenotype) in cartilage regeneration have been proposed. ${ }^{107}$ The rejuvenation effect of DSCM is supported by its 
excellent ability in managing environmental factors. DSCM deposited by fetal SDSCs aided in the protection of expanded cells from senescence in Chapter $5 .{ }^{108}$ DSCM expanded SDSCs showed robust resistance to hydrogen peroxide-induced oxidative stress. ${ }^{99}$ Our unpublished data suggested that DSCM expanded SDSCs exhibited an up-regulated ability to resist IL-1 $\beta$ mediated inflammation. The proteomics data in Chapter 6 showed that DSCM is also rich in growth factors and acts as a reservoir for the needs and demands of the cell. ${ }^{105}$ The addition of hypoxia and FGF-2 in the DSCM expansion system improved expanded SDSC proliferative and chondrogenic potentials in Chapter $3 .^{98}$ The presence of hypoxia alone also enhanced the rejuvenating effect of the DECM on nucleus pulposus cells. ${ }^{103}$

While the mechanisms involved in DSCM rejuvenation remain unclear, Choi et al. showed that the restoration of senescent human diploid fibroblasts by matrix was regulated by epigenetic mechanisms; both $\mathrm{Ku}$ and SIRT1 were induced during restoration and were required for senescent cells to return to a youthful phenotype. ${ }^{109}$ Our microarray data also showed that both miR-140 and miR-145 were dramatically down-regulated during cell expansion and up-regulated during chondrogenic differentiation in DSCM pretreated SDSCs accompanied with enhanced proliferative and chondrogenic potentials, suggesting a pivotal role of miR-140 and miR-145 in DSCM mediated SDSC rejuvenation mechanisms (unpublished data). In response to environmental stimuli, miR-140 targeted multiple genes to play different roles during chondrogenic differentiation, endochondral bone formation, and osteoarthritis pathogenesis, as summarized by Hong and Reddi. ${ }^{110}$ Interestingly, miR-140 has been reported to target chemokine (CXC motif) ligand 12 (CXCL12) and ADAMTS-5 in equine cord blood-derived MSCs; ${ }^{111}$ its overexpression protected cartilage from antigen-induced arthritis and maintained cartilage homeostasis in a knockout mouse model. ${ }^{112}$ It also stimulated in vitro chondrogenesis by upregulating SOX9 and ACAN in human MSCs. ${ }^{113}$ SOX9 has been suggested as a downstream target gene of miR-145 or miR-449a, which directly or indirectly represses SOX9 and cartilage matrix gene expression in human primary chondrocytes, BMSCs, and a murine embryonic mesenchymal cell line C3H10T1/2. ${ }^{114-116}$

In conclusion, we demonstrated that decellularized stem cell matrix is superior to conventional methods and provides a better microenvironment for ex vivo expansion of SDSCs while maintaining its stemness. Decellularized matrix derived from young stem cells could rejuvenate adult stem cells toward proliferation and chondrogenesis. This novel expansion system could also be applied to restore the proliferative and redifferentiation potentials in herniated nucleus pulposus cells as well. 


\section{REFERENCES}

1. Jiang $\mathrm{Y}$, Jahagirdar $B N$, Reinhardt $R L$ et al. Pluripotency of mesenchymal stem cells derived from adult marrow. Nature. 2002;418:41-9.

2. Horie M, Sekiya I, Muneta $T$ et al. Intra-articular injected synovial stem cells differentiate into meniscal cells directly and promote meniscal regeneration without mobilization to distant organs in rat massive meniscal defect. Stem Cells. 2009;27:878-87.

3. Klein $\mathrm{T}$, Malada J, Sah $\mathrm{R}$ et al. Tissue engineering of articular cartilage with biomimetric zones. Tissue Eng Part A. 2009;15:143-57.

4. Pei $\mathrm{M}, \mathrm{He} F$, Kish $\vee$ et al. Engineering of functional cartilage tissue using stem cells from synovial lining: a preliminary study. Clin Orthop Relat Res. 2008;466:1880-9.

5. Schumacher BL, Hughes CE, Kuettner KE et al. Immunodetection and partial cDNA sequence of the proteoglycan, superficial zone protein, synthesized by cells lining synovial joints. J Orthop Res. 1999;17:110-20.

6. Archer CW, Dowthwaite GP, Francis-West P. Development of synovial joints. Birth Defects Res C Embryo Today. 2003;69:144-55.

7. Bandara G, Georgescu HI, Lin CW et al. Synovial activation of chondrocytes: evidence for complex cytokine interactions. Agents Actions. 1991;34:285-8.

8. Pacifici M, Koyama E, Iwamoto M et al. Development of articular cartilage: what do we know about it and how may it occur? Connect Tissue Res. 2000;41:175-84.

9. Moore K, Lemischka I. Stem cells and their niches. Science 2006;311:1880-5.

10. Kurth T, Dell'Accio F, Crouch $V$ et al. Functional mesenchymal stem cell niches in adult mouse knee joint synovium in vivo. Arthritis Rheum 2011;63:1289-300.

11. He F, Chen XD, Pei M. Reconstruction of an in vitro tissue-specific microenvironment to rejuvenate synovium-derived stem cells for cartilage tissue engineering. Tissue Eng Part $A$ 2009;15:3809-21.

12. Sakaguchi $\mathrm{Y}$, Sekiya I, Yagishita $\mathrm{K}$ et al. Comparison of human stem cells derived from various mesenchymal tissues: superiority of synovium as a cell source. Arthritis Rheum. 2005;52:2521-9.

13. Schofield R. The relationship between the spleen colony-forming cell and the haemopoietic stem cell. Blood Cells 1978;4:7-25.

14. Dexter TM, Moore MA, Sheridan AP. Maintenance of hemopoietic stem cells and production of differentiated progeny in allogeneic and semiallogeneic bone marrow chimeras in vitro. $J$ Exp Med 1977; 145:1612-6.

15. Li W, Johnson SA, Shelley WC et al. Hematopoietic stem cell repopulating ability can be maintained in vitro by some primary endothelial cells. Exp Hematol. 2004;32:1226-37. 
16. Moore KA, Ema H, Lemischka IR. In vitro maintenance of highly purified, transplantable hematopoietic stem cells. Blood 1997;89:4337-47.

17. Rios M, Williams DA. Systematic analysis of the ability of stromal cell lines derived from different murine adult tissues to support maintenance of hematopoietic stem cells in vitro. $J$ Cell Physiol 1990;145:434-43.

18. Li L, Xie T. Stem cell niche: Structure and function. Annu Rev Cell Dev Biol 2005;21:605-31.

19. Lin H. The stem-cell niche theory: Lessons from flies. Nat Rev Genet 2002;3:931-40.

20. Spradling A, Drummond-Barbosa D, Kai T. Stem cells find their niche. Nature 2001;414:98104.

21. Roskelley CD, Desprez PY, Bissell MJ. Extracellular matrix-dependent tissue-specific gene expression in mammary epithelial cells requires both physical and biochemical signal transduction. Proc Natl Acad Sci USA 1994;91:12378-82.

22. Knight $\mathrm{B}$, Laukaitis $\mathrm{C}$, Akhtar $\mathrm{N}$ et al. Visualizing muscle cell migration in situ. Curr Biol 2000;10:576-85.

23. Cukierman E, Pankov R, Stevens DR et al. Taking cell-matrix adhesions to the third dimension. Science 2001;294:1708-12.

24. Atala A, Vacanti JP, Peters CA et al. Formation of urothelial structures in vivo from dissociated cells attached to biodegradable polymer scaffolds in vitro. $J$ Urol 1992;148:65862.

25. Choi JS, Kim BS, Kim JY et al. Decellularized ex-tracellular matrix derived from human adipose tissue as a potential scaffold for allograft tissue engineering. $J$ Biomed Mater Res $A$ 2011;97:292-9.

26. Dequach JA, Yuan SH, Goldstein LS et al. Decellularized porcine brain matrix for cell culture and tissue engineering scaffolds. Tissue Eng Part A 2011;17:2583-92.

27. Ott HC, Matthiesen TS, Goh SK et al. Perfusion-decellularized matrix: using nature's platform to engineer a bioartificial heart. Nat Med 2008;14:213-21.

28. Petersen TH, Calle EA, Zhao L et al. Tissue-engineered lungs for in vivo implantation. Science 2010;329:538-41.

29. Ponce Marquez S, Martinez VS, Mclntosh Ambrose W et al. Decellularization of bovine corneas for tissue engineering applications. Acta Biomater 2009;5:1839-47.

30. Zhou P, Lessa N, Estrada DC et al. Decellularized liver matrix as a carrier for the transplantation of human fetal and primary hepatocytes in mice. Liver Transpl 2011;17:41827.

31. Kiger AA, Jones DL, Schulz $C$ et al. Stem cell self-renewal specified by JAK-STAT activation in response to a support cell cue. Science 2001;294:2542-5.

32. Tulina N, Matunis E. Control of stem cell self- renewal in drosophila spermatogenesis by JAK-STAT signaling. Science 2001;294:2546-9. 
33. Xie T, Spradling AC. Decapentaplegic is essential for the maintenance and division of germline stem cells in the drosophila ovary. Cell 1998;94:251-60.

34. Chintala SK, Miller RR, McDevitt CA. Basic fibroblast growth factor binds to heparan sulfate in the extracellular matrix of rat growth plate chondrocytes. Arch Biochem Biophys 1994;310:180-6.

35. Paralkar VM, Vukicevic S, Reddi AH. Transforming growth factor beta type 1 binds to collagen IV of basement membrane matrix: Implications for development. Dev Biol 1991;143:303-8.

36. Ruhrberg $C$, Gerhardt $H$, Golding $M$ et al. Spatially restricted patterning cues provided by heparin-binding VEGF-A control blood vessel branching morphogenesis. Genes Dev 2002;16:2684-98.

37. Tschumperlin DJ, Dai G, Maly IV et al. Mechanotransduction through growth-factor shedding into the extracellular space. Nature 2004;429:83-6.

38. Swartz MA. Signaling in morphogenesis: Transport cues in morphogenesis. Curr Opin Biotechnol 2003;14:547-50.

39. Malladi $\mathrm{P}, \mathrm{Xu} \mathrm{Y}, \mathrm{Chiou} \mathrm{M}$ et al. Effect of reduced oxygen tension on chondrogenesis and osteogenesis in adipose-derived mesenchymal cells. Am J Physiol Cell Physiol 2006;290: C1139-46.

40. $\mathrm{Xu} Y$, Malladi $\mathrm{P}$, Chiou $\mathrm{M}$ et al. In vitro expansion of adipose- derived adult stromal cells in hypoxia enhances early chondrogenesis. Tissue Eng 2007;13:2981-93.

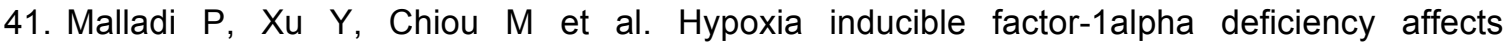
chondrogenesis of adipose-derived adult stromal cells. Tissue Eng 2007;13:1159-71.

42. Gustafsson MV, Zheng $X$, Pereira $T$ et al. Hypoxia requires notch signaling to maintain the undifferentiated cell state. Dev Cell 2005;9:617-28.

43. Lin Q, Lee YJ, Yun Z. Differentiation arrest by hypoxia. J Biol Chem 2006;281;30678-83.

44. Sainson RC, Harris AL. Hypoxia-regulated differentiation: Let's step it up a notch. Trends Mol Med 2006;12:141-3.

45. Salim A, Nacamuli RP, Morgan EF et al. Transient changes in oxygen tension inhibit osteogenic differentiation and Runx2 expression in osteoblasts. J Biol Chem 2004;279: 40007-16.

46. Engler AJ, Sen S, Sweeney HL et al. Matrix elasticity directs stem cell lineage specification. Cell 2006;126:677-89.

47. Evans ND, Minelli C, Gentleman E et al. Substrate stiffness affects early differentiation events in embryonic stem cells. Eur Cell Mater 2009;18:1-13.

48. Jacot JG, Kita-Matsuo $H$, Wei KA et al. Cardiac myocyte force development during differentiation and maturation. Ann N Y Acad Sci 2010;1188:121-7. 
49. Leipzig ND, Shoichet MS. The effect of substrate stiffness on adult neural stem cell behavior. Biomaterials 2009;30:6867-78.

50. Saha K, Keung AJ, Irwin EF et al. Substrate modulus directs neural stem cell behavior. Biophys J 2008;95:4426-38.

51. Peyton SR, Putnam AJ. Extracellular matrix rigidity governs smooth muscle cell motility in a biphasic fashion. J Cell Physiol 2005;204:198-209.

52. Chrzanowska-Wodnicka M, Burridge K. Rho-stimulated contractility drives the formation of stress fibers and focal adhesions. J Cell Biol 1996;133:1403-15.

53. Hinz B, Celetta G, Tomasek JJ et al. Alpha-smooth muscle actin expression upregulates fibroblast contractile activity. Mol Biol Cell 2001;12:2730-41.

54. Kim TJ, Seong J, Ouyang $M$ et al. Substrate rigidity regulates $\mathrm{Ca}+$ oscillation via RhoA pathway in stem cells. J Cell Physiol 2009;218:285-93.

55. Griffin MA, Sen S, Sweeney HL et al. Adhesion-contractile balance in myocyte differentiation. J Cell Sci 2004;117:5855-63.

56. Pelham RJ Jr, Wang Y. Cell locomotion and focal adhesions are regulated by substrate flexibility. Proc Natl Acad Sci USA 1997;94:13661-5.

57. Peyton SR, Ghajar CM, Khatiwala CB et al. The emergence of ECM mechanics and cytoskeletal tension as important regulators of cell function. Cell Biochem Biophys 2007;47:300-20.

58. Wells RG, Discher DE. Matrix elasticity, cytoskeletal tension, and TGF-beta: the insoluble and soluble meet. Sci Signal 2008;1:pe13.

59. Chen CS, Mrksich M, Huang S et al. Geometric control of cell life and death. Science 1997;276:1425-8.

60. Folkman J, Moscona A. Role of cell shape in growth control. Nature 1978;273:345-9.

61. Wozniak MA, Chen CS. Mechanotransduction in development:a growing role for contractility. Nature Rev Mol Cell Biol 2009;10:34-43.

62. Lutolf MP, Gilbert PM, Blau HM. Designing materials to direct stem-cell fate. Nature 2009;462:433-41.

63. Hynes RO. Integrins: bidirectional, allosteric signaling machines. Cell 2002;110:673-87.

64. Schwartz MA, Assoian RK. Integrins and cell proliferation: regulation of cyclin-dependent kinases via cytoplasmic signaling pathways. J Cell Sci 2001;114:2553-60.

65. Loeser RF. Chondrocyte integrin expression and function. Biorheology 2000;37:109-16.

66. Brockbank EC, Bridges $\mathrm{J}$, Marshall $\mathrm{CJ}$ et al. Integrin beta1 is required for the invasive behavior but not proliferation of squamous cell carcinoma cells in vivo. $\mathrm{Br} J$ Cancer 2005;92:102-12.

67. Sanders MA, Basson MD. Collagen IV- dependent ERK activation in human Caco-2 intestinal epithelial cells requires focal adhesion kinase. J Biol Chem 2000;275:38040-7. 
68. Roovers K, Assoian RK. Integrating the MAP kinase signal into the $\mathrm{G} 1$ phase cell cycle machinery. Bioessays 2000;22:818-26.

69. Gille H, Downward J. Multiple ras effector pathways contribute to $G(1)$ cell cycle progression. J Biol Chem 1999;274:22033-40.

70. Takuwa N, Fukui Y, Takuwa Y. Cyclin D1 expression mediated by phosphatidylinositol 3kinase through mTOR-p70(S6K)-independent signaling in growth factor-stimulated NIH 3T3 fibroblasts. Mol Cell Biol 1999;19:1346-58.

71. Zhao JH, Reiske H, Guan JL. Regulation of the cell cycle by focal adhesion kinase. J Cell Biol 1998;143:1997- 2008.

72. Maruyama T, Mirando AJ, Deng CX et al. The balance of WNT and FGF signaling influences mesenchymal stem cell fate during skeletal development. Sci Signal 2010;3:ra40.

73. Kennell JA, MacDougald OA. Wnt signaling inhibits adipogenesis through beta-catenindependent and -inde- pendent mechanisms. J Biol Chem 2005;280:24004-10.

74. Cawthorn WP, Heyd F, Hegyi $\mathrm{K}$ et al. Tumour necrosis factor-alpha inhibits adipogenesis via a beta- catenin/TCF4(TCF7L2)-dependent pathway. Cell Death Differ 2007:14:1361-73.

75. Hyun Hwa C, Hye Joon J, Ji Sun S et al. Crossregulation of beta-catenin/Tcf pathway by NFkappaB is mediated by Izts2 in human adipose tissue- derived mesenchymal stem cells. Biochim Biophys Acta 2008;1783:419-28.

76. Klapholz-Brown Z, Walmsley GG, Nusse YM et al. Transcriptional program induced by Wnt protein in human fibroblasts suggests mechanisms for cell cooperativity in defining tissue microenvironments. PLoS One 2007;2:e945.

77. Czyz J, Wobus A. Embryonic stem cell differentiation: the role of extracellular factors. Differentiation 2001;68:167-74.

78. Hernandez L, Roux KJ, Wong ES et al. Functional coupling between the extracellular matrix and nuclear lamina by Wnt signaling in progeria. Dev Cell 2010;19:413-25.

79. Im GI, Quan Z. The effects of Wnt inhibitors on the chondrogenesis from human mesenchymal stem cells. Tissue Eng Part A 2010;16:2405-13.

80. Hartmann C, Tabin CJ. Dual roles of Wnt signaling during chondrogenesis in the chicken limb. Development 2000;127:3141-59.

81. Tufan AC, Daumer KM, DeLise AM et al. AP-1 transcription factor complex is a target of signals from both $\mathrm{WnT}-7 \mathrm{a}$ and $\mathrm{N}$-cadherin-dependent cell-cell adhesion complex during the regulation of limb mesenchymal chondrogenesis. Exp Cell Res 2002;273:197-203.

82. Hartmann C, Tabin CJ. Dual roles of Wnt signaling during chondrogenesis in the chicken limb. Development 2000;127:3141-59.

83. Ryu JH, Kim SJ, Kim SH et al. Regulation of the chondrocyte phenotype by beta-catenin. Development 2002;129:5541-50. 
84. Gaur T, Rich L, Lengner CJ et al. Secreted frizzled related protein 1 regulates Wnt signaling for BMP2 induced chondrocyte differentiation. J Cell Physiol 2006;208:87-96.

85. Beausejour CM, Krtolica A, Galimi F et al. Reversal of human cellular senescence: roles of the p53 and p16 pathways. EMBO J 2003;22:4212-22.

86. Kim KW, Chung HN, Ha KY et al. Senescence mechanisms of nucleus pulposus chondrocytes in human intervertebral discs. Spine J 2009;9:658-66.

87. Zhang DY, Wang HJ, Tan YZ. Wnt/beta-catenin signaling induces the aging of mesenchymal stem cells through the DNA damage response and the p53/p21 pathway. PLoS One 2011;6:e21397.

88. Dai SM, Shan ZZ, Nakamura H et al. Catabolic stress induces features of chondrocyte senescence through over-expression of caveolin 1: possible involvement of caveolin 1induced down-regulation of articular chondrocytes in the pathogenesis of osteoarthritis. Arthritis Rheum 2006;54:818-31.

89. Park JS, Kim HY, Kim HW et al. Increased caveolin-1, a cause for the declined adipogenic potential of senescent human mesenchymal stem cells. Mech Ageing Dev 2005;126:551-9.

90. Badylak SF, Weiss DJ, CaplanA et al. Engineered whole organs and complex tissues. Lancet 2012;379:943-52.

91. Benders KE, van Weeren PR, Badylak SF et al. Extracellular matrix scaffolds for cartilage and bone regeneration. Trends Biotechnol 2013;31:169-76.

92. Cole BJ, Farr J, Winalski CS et al. Outcomes after a single-stage procedure for cell-based cartilage repair: a prospective clinical safety trial with 2-year follow-up. Am J Sports Med 2011;39:1170-9.

93. Kang $\mathrm{H}$, Peng J, Lu $\mathrm{S}$ et al. In vivo cartilage repair using adipose-derived stem cell-loaded decellularized cartilage ECM scaffolds. J Tissue Eng Regen Med 2012. DOI: 10.1002/term.1538

94. Yang Q, Peng J, Guo Q et al. A cartilage ECM-derived 3-D porous acellular matrix scaffold for in vivo cartilage tissue engineering with $\mathrm{PKH} 26$-labeled chondrogenic bone marrowderived mesenchymal stem cells. Biomaterials 2008;29:2378-87.

95. Pei M, Li JT, ShoukryM et al. A review of decellularized stem cell matrix: a novel cell expansion system for cartilage tissue engineering. Eur Cell Mater 2011;22:333-43; discussion 343.

96. Lin $\mathrm{H}$, Yang $\mathrm{G}$, Tan $\mathrm{J}$ et al. Influence of decellularized matrix derived from human mesenchymal stem cells on their proliferation, migration and multi-lineage differentiation potential. Biomaterials 2012;33:4480-9.

97. He F, Chen X, Pei M. Reconstruction of an in vitro tissue-specific microenvironment to rejuvenate synovium-derived stem cells for cartilage tissue engineering. Tissue Eng Part $A$ 2009;15:3809-21. 
98. Li J, M Pei. Optimization of an in vitro three-dimensional microenvironment to reprogram synovium-derived stem cells for cartilage tissue engineering. Tissue Eng Part A 2011;17: 703-12.

99. Pei $\mathrm{M}$, Zhang $\mathrm{Y}, \mathrm{Li} \mathrm{J}$ et al. Antioxidation of decellularized stem cell matrix promotes human synovium-derived stem cell-based chondrogenesis. Stem Cells Dev 2013;22:889-900.

100. Pei M, He F, Kish VL. Expansion on extracellular matrix deposited by human bone marrow stromal cells facilitates stem cell proliferation and tissue-specific lineage potential. Tissue Eng Part A 2011;17:3067-76.

101. Pei M, F He. Extracellular matrix deposited by synovium-derived stem cells delays replicative senescent chondrocyte dedifferentiation and enhances redifferentiation. J Cell Physiol 2012;227:2163-74.

102. Pei M, He F, Wei L. Three-Dimensional Cell Expansion Substrate for Cartilage Tissue Engineering and Regeneration: A Comparison in Decellularized Matrix Deposited by Synovium-Derived Stem Cells and Chondrocytes. J Tissue Sci Eng 2011;2:104.

103. Pei M, Shoukry M, Li J et al. Modulation of in vitro microenvironment facilitates synoviumderived stem cell-based nucleus pulposus tissue regeneration. Spine (Phila $\mathrm{Pa}$ 1976) 2012;37:1538-47.

104. He F, M Pei. Rejuvenation of nucleus pulposus cells using extracellular matrix deposited by synovium-derived stem cells. Spine (Phila Pa 1976) 2012;37:459-69.

105. Li J, KC Hansen, Y Zhang et al. Rejuvenation of chondrogenic potential in a young stem cell microenvironment. Biomaterials 2014;35:642-53.

106. Pei M, F He, J Li et al. Repair of large animal partial-thickness cartilage defects through intraarticular injection of matrix-rejuvenated synovium-derived stem cells. Tissue Eng Part $A$ 2013;19:1144-54.

107. Li J, Ohliger J, Pei M. Significance of Epigenetic Landscape in Cartilage Regeneration from the Cartilage Development and Pathology Perspective. Stem Cells Dev. 2014 Feb 20. doi:10.1089/scd.2014.0002.

108. Li J, He F, Pei M. Creation of an in vitro microenvironment to enhance human fetal synovium-derived stem cell chondrogenesis. Cell Tissue Res 2011;345:357-65.

109. Choi HR, a Cho K, Kang HT et al. Restoration of senescent human diploid fibroblasts by modulation of the extracellular matrix. Aging Cell 2011;10:148-57.

110. Hong E, Reddi AH. MicroRNAs in chondrogenesis, articular cartilage, and osteoarthritis: implications for tissue engineering. Tissue Eng Part B Rev 2012;18:445-53.

111. Buechli ME, Lamarre J, Koch TG. MicroRNA-140 expression during chondrogenic differentiation of equine cord blood-derived mesenchymal stromal cells. Stem Cells Dev 2013;22:1288-96. 
112. Miyaki S, Sato T, Inoue A, et al. MicroRNA-140 plays dual roles in both cartilage development and homeostasis. Genes Dev 2010;24:1173-85.

113. Karlsen TA, Jakobsen RB, Mikkelsen TS et al. microRNA-140 targets RALA and regulates chondrogenic differentiation of human mesenchymal stem cells by translational enhancement of SOX9 and ACAN. Stem Cells Dev 2014;23:290-304

114. Martinez-Sanchez A, Dudek KA, Murphy CL. Regulation of human chondrocyte function through direct inhibition of cartilage master regulator SOX9 by microRNA-145 (miRNA-145). $J$ Biol Chem 2012;287:916-24.

115. Paik $S$, Jung HS, Lee $S$ et al. miR-449a regulates the chondrogenesis of human mesenchymal stem cells through direct targeting of lymphoid enhancer-binding factor-1. Stem Cells Dev 2012;21:3298-08.

116. Yang B, Guo $\mathrm{H}$, Zhang $\mathrm{Y}$ et al. MicroRNA-145 regulates chondrogenic differentiation of mesenchymal stem cells by targeting Sox9. PLoS One 2011;6:e21679. 


\title{
CURRICULUM VITAE
}

\section{JINGTING LI}

\author{
EDUCATION AND TRAINING \\ 2009-2014 Ph.D. in Exercise Physiology, Stem Cell and Tissue Engineering \\ Department of Orthopaedics, West Virginia University \\ 2009-2014 Graduate Research Assistant \\ Department of Orthopaedics, West Virginia University \\ 2007-2009 Medical Information Officer \\ Pfizer, Inc., Beijing, China \\ 2005-2007 M.S. in Pharmacology \\ Basic Medical School of Wuhan University, Wuhan University, Wuhan, China \\ 2000-2005 Doctor of Medicine (M.D.) \\ Basic Medical School of Wuhan University, Wuhan University, Wuhan, China
}

\section{FELLOWSHIPS AND AWARDS}

2014 Outstanding Doctor of Philosophy

2012 Poster Presentation Award, E. J. Van Liere Convocation and Research Day, West Virginia University

2009-2014 Graduate Research Assistant Fellowship, West Virginia University

\section{PROFESSIONAL ASSOCIATIONS}

2009-present Member, Orthopaedic Research Society (ORS)

Member, International Society of Stem Cell Research (ISSCR)

Member, Tissue Engineering and Regenerative Medicine International Society

(TERMIS)

2005-present Member, The Medical Council of China

\section{MEDIA}

http://www.sciencenews.org/view/feature/id/342561/description/Cartilage Creation

http://www.connexoncreative.com/publications/archives/ECM230.aspx

http://www.mdlinx.com/orthopedics/news-article-test.cfm/5130346 
http://www.extracellularmatrixnews.com/issue/volume-5-09-mar-13/\#reviews

\section{TEACHING AND MENTOR EXPERIENCE}

2005-2007 Teaching Assistant, Experimental course on Pharmacology

Basic Medical School of Wuhan University, Wuhan University, Wuhan, China

MENTOR, mentoring for medical/PhD student since 2010.

\section{SKILL}

Primary stem cell isolation, Stem Cell culture, Lineage Differentiation, Animal handling

Real-time PCR, Western blot, Biochemistry, Immunohistology, Scanning Electron Microscopy,

Confocal microscopy, Atomic force microscopy, Flow cytometry, Microarray, Proteomics, MicroCT

Microsoft Office, Image J, Photoshop 


\section{PEER-REVIEWED PUBLICATIONS}

1. Li JT, Hansen KC, Zhang Y, Dong CB, Dinu C, Pei M. Rejuvenation of chondrogenic potential in a young stem cell microenvironment. Biomaterials 2014;35(2):642-53. PMID: 24148243. (IF: 7.604)

2. Li JT, Ohliger J, Pei M. Significance of epigenetic landscape perception in cartilage regeneration. Stem Cell Dev, 2014. PMID: 24555773. doi:10.1089/scd.2014.0002. (IF: 4.670)

3. Li JT, Campbell D, Bal G, Pei M. Can arthroscopically harvested synovial stem cells be preferentially sorted using SSEA4 antibody for cartilage, bone and adipose regeneration? Arthroscopy, 2014;30(3):352-361. (In press) (IF: 3.103)

4. Li JT, Pei M. Decellularized stem cell matrix: a novel approach for autologous chondrocyte-based cartilage repair. In: Stem Cells and Cancer Stem Cells, Volume 12. Hayat MA (ed.), Springer, 2014. doi: 10.1007/978-94-017-8032-2_10

5. Pei M, Li JT, Zhang Y, Liu GH, Wei L, Zhang YY. Immobilized trophic stimulation from urine-derived stem cells revitalizes human bone marrow stromal cells from replicative senescence. Cell Tissue Research, 2014. (In press)

6. Shoukry M, Li JT, Pei M. Reconstruction of an in vitro "niche" for the transition from intervertebral disc development to nucleus pulposus regeneration. Stem Cells Dev 2013;22(8):1162-76. PMID: 23259403. (IF: 4.670) (Highlighted in journal cover)

7. Pei M, Zhang Y, Li JT, Chen D. Antioxidation of Decellularized Stem Cell Matrix Promotes Human Synovium-Derived Stem Cell-Based Chondrogenesis. Stem Cells Dev 2013;22(6):889-900. PMID: 23092115. (IF: 4.670)

8. Pei M, He F, Li JT, Tidwell J, Jones A, Barry M. Repair of large animal partial-thickness cartilage defects using matrix rejuvenated synovium-derived stem cells. Tissue Eng Part A 2013;19(9-10):1144-54. PMID: 23216161. (IF: 4.065)

9. Li JT, Pei M. Cell senescence: a challenge in cartilage engineering and regeneration. Tissue Eng Part B 2012;18(4):270-87. PMID: 22273114. (IF: 4.065)

10. Li JT, Jones B, Zhang Y, Pei M. Low density expansion rescues human synoviumderived stem cells from replicative senescence. Drug Deliv Transl Res 2012;2(5):363-74.

11. Pei M, Shoukry M, Li JT, Daffner S, France J, Emery SE. Modulation of in vitro microenvironment facilitates synovium-derived stem cell-based nucleus pulposus tissue regeneration. Spine 2012;37(18):1538-47. PMID: 22391443. (IF: 2.159)

12. Pei $M^{*}$, Li JT, Shoukry M, Zhang Y. A Review of Decellularized Stem Cell Matrix: a Novel Cell Expansion System for Cartilage Tissue Engineering. Eur Cell Mater 2011;22:333-43. PMID: 22116651. (IF: 4.558) (cited by 15) 
13. Li JT, He F, Pei M. Creation of an in vitro microenvironment to enhance human fetal synovium-derived stem cell chondrogenesis. Cell Tissue Res 2011;345(3):357-65. PMID: 21805113. (IF: 3.677)

14. Li JT, Pei M. Optimization of an in vitro three-dimensional microenvironment to reprogram synovium-derived stem cells for cartilagetissue engineering. Tissue Eng Part A 2011;17(5-6):703-12. PMID: 20929284. (IF: 4.065) (cited by 25)

15. Ping J, Li JT, Liao ZX, Shang L, Wang H. Indole-3-carbinol inhibits hepatic stellate cells proliferation by blocking NADPH oxidase/reactive oxygen species/p38 MAPK pathway. Eur J Pharmacol 2011;650(2-3):656-62. PMID: 21044624. (IF: 2.592) (cited by 11)

16. Pei M, Chen DM, Li JT, Wei L. Histone Deacetylase 4 promotes TGF- $\beta 1$-induced synovium-derived stem cell chondrogenesis but inhibits chondrogenically differentiated stem cell hypertrophy differentiation. Differentiation 2009;78(5):260-8. PMID: 19716643. (IF: 2.855) (cited by 21)

17. Li JT, Liao ZX, Ping J, Xu D, Wang H. Molecular mechanism of hepatic stellate cell activation and antifibrotic therapeutic strategies. J Gastroenterol 2008;43(6):419-28. PMID: 18600385. (IF: 3.788) (cited by 71)

\section{MANUSCRIPTS IN PREPARATION, UNDER REVIEW AND REVISION}

1. Zhang Y, Li JT, Pei M. Preconditioning with p38 MAPK inhibitor boosts matrix-expanded human synovium-derived stem cells in chondrogenic potential through corsstalk with the non-canonical Wnt signaling pathway. Adv Mater, 2014 (Under review)

2. Li JT, Zhang Y, Pei M. Adult stem cell microenvironment facilitated fetal synovium-derived stem cells chondrogenic differentiation. (In preparation)

3. Li JT, McConda DB, Clovis NB, Danley SE, Pei M. Repair of osteoporotic rat calvarial defects using allogenic adipose stem cells with poly (lactic-co-glycolic acid) scaffold. (In preparation)

4. Li JT, Pei M. Deciphering the role of decellularized extracellular matrix in enhancing human synovium-derived stem cell chondrogenesis. (In preparation)

5. Li JT, Pei M. A comparison in rejuvenation of human nucleus pulposus cells from herniated disc by synovium-derived stem cell and nucleus pulposus cells deposited decellularized matrix. (In preparation)

\section{CONFERENCE PRESENTATIONS:}

1. Li JT, Hansen KC, Zhang Y, Dong CB, Dinu C, Pei M. Define The Rejuvenating Effect Of Young Matrix Microenvironment In Stem Cell Chondrogenic Potential. 60 ${ }^{\text {th }}$ Annual Meeting of the Orthopaedic Research Society. Hyatt Regency, New Orleans, Louisiana (2014). Poster\#: 0446. March 15-18. (Poster presentation) 
2. Li JT, Pei M. Is Laminin Required For Decellularized Stem Cell Matrix Mediated Human Nucleus Pulposus Rejuvenation? $60^{\text {th }}$ Annual Meeting of the Orthopaedic Research Society. Hyatt Regency, New Orleans, Louisiana (2014). Poster\#: 1636. March 15-18. (Poster presentation)

3. Pei M, Li JT, Zhang Y, Pizzute T. Contribution of FGF2 versus FGF10 to synoviumderived stem cell expansion and tri-lineage differentiation and potential mechanisms. $60^{\text {th }}$ Annual Meeting of the Orthopaedic Research Society. Hyatt Regency, New Orleans, Louisiana (2014). Poster\#: 384. March 15-18. (Poster presentation)

4. Zhang Y, Li JT, Pei M. Preconditioning with p38 MAPK inhibitor boosts matrix-expanded human synovium-derived stem cells in chondrogenic potential. $60^{\text {th }}$ Annual Meeting of the Orthopaedic Research Society. Hyatt Regency, New Orleans, Louisiana (2014). Poster\#: 1636. March 15-18. (Poster presentation)

5. Zhang Y, Li JT, Pei M. Sb203580 facilitates decellularized stem cell matrix -expanded human synovium-derived stem cells in chondrogenic potential in IL-1beta inflammatory condition. $60^{\text {th }}$ Annual Meeting of the Orthopaedic Research Society. Hyatt Regency, New Orleans, Louisiana (2014). Poster\#: 1206. March 15-18. (Poster presentation)

6. Li JT,Dong CB, Dinu C, Pei M. MicroRNA-Mediated Rejuvenation of Adult Stem Cells through Young Stem Cell Matrix for Chondrogenesis. 59 ${ }^{\text {th }}$ Annual Meeting of the Orthopaedic Research Society. Henry B Gonzalez Convention Center, San Antonio, Texas (2013). Jan 26-29. Trans ORS 38:57. (Oral presentation)

7. Pei M, Li JT, Shoukry M, Zhang YY. Decellularized matrix from urine stem cells benefits human bone marrow stromal cell chondrogenesis. $59^{\text {th }}$ Annual Meeting of the Orthopaedic Research Society. Henry B Gonzalez Convention Center, San Antonio, Texas (2013). Jan 26-29. Trans ORS 38:773. (Poster presentation)

8. Li JT, Dong CB, Dinu C, Pei M. MicroRNA-Mediated Engineering a Tissue-Specific Microenvironment for Reprogramming Synovium-Derived Stem Cell Chondrogenesis. $59^{\text {th }}$ Annual Meeting of the Orthopaedic Research Society. Henry B Gonzalez Convention Center, San Antonio, Texas (2013). Jan 26-29. Trans ORS 38:673. (Poster presentation)

9. Zhang Y, Li JT, Pei M. Decellularized Matrix Benefits Expanded Human Stem Cell Chondrogenesis in Resistance to an Inflammatory Environment. 59th Annual Meeting of the Orthopaedic Research Society. Henry B Gonzalez Convention Center, San Antonio, Texas (2013). Jan 26-29. Trans ORS 38:470. (Poster presentation)

10. Li JT, McConda D, Clovis N, Smith S, Pei M. Repair of Osteoporotic Rat Calvarial Defects using Poly(lactic-co-glycolic acid) with Adipose Stem Cells. 59 ${ }^{\text {th }}$ Annual Meeting of the Orthopaedic Research Society. Henry B Gonzalez Convention Center, San Antonio, Texas (2013). Jan 26-29. Trans ORS 38:780. (Poster presentation) 
11. Li JT, Zhang Y, Kish VL, Pei M. Decellularized Stem Cell Matrix: A "Fountain of Youth" for Human Adult Stem Cell-Based Cartilage Regeneration. 2012 E. J. Van Liere Convocation and Research Day, WVU, March 9. (second place in basic science poster presentation)

12. Zhang Y, Li JT, Kish VL, Pei M. Decellularized Stem Cell Matrix Protects Adult Stem Cell-Based Chondrogenesis from Oxidative Stress. 2012 E. J. Van Liere Convocation and Research Day, WVU, March 9. (Poster presentation)

13. Jones B, Li JT, Zhang Y, Pei M. Low density monolayer expansion rescues human synovial stem cells from replicative senescence. 2012 E. J. Van Liere Convocation and Research Day, WVU, March 9. (Oral presentation)

14. Li JT, Zhang Y, Kish VL, Pei M. Young microenvironment rejuvenates aged human synovium-derived stem cells toward chondrogenesis. $58^{\text {th }}$ Annual Meeting of the Orthopaedic Research Society.Moscone West Convention Center, San Francisco, CA (2012). Feb 4-7. Trans ORS 37:1748. (Poster presentation)

15. Zhang Y, Li JT, Kish VL, Pei M. Extracellular matrix rescues human synovium-derived stem cells from oxidative stress and enhances expanded stem cell chondrogenesis. $58^{\text {th }}$ Annual Meeting of the Orthopaedic Research Society. Moscone West Convention Center, San Francisco, CA (2012). Feb 4-7. Trans ORS 37:1747. (Poster presentation)

16. Li JT, He F Y, Kish VL, Pei M. True or false: a tissue-specific microenvironmentfavors human synovium-derived stem cell chondrogenesis. $58^{\text {th }}$ Annual Meeting of the Orthopaedic Research Society.Moscone West Convention Center, San Francisco, CA (2012). Feb 4-7. Trans ORS 37:1749. (Poster presentation)

17. Pei M, He F, Li JT, Tidwell JE, Jones AC, McDonough EB. Decellularized stem cell matrix rejuvenates synovium-derived stem cellsfor cartilage regeneration and repair of partical-thickness cartilage defects. $58^{\text {th }}$ Annual Meeting of the Orthopaedic Research Society.Moscone West Convention Center, San Francisco, CA (2012). Feb 4-7. Trans ORS 37:671. (Poster presentation)

18. Pei M, Shoukry M, Li JT. Modulation of an in vitro tissue-specific microenvironment to facilitate nucleus pulposus tissue regeneration. $58^{\text {th }}$ Annual Meeting of the Orthopaedic Research Society.Moscone West Convention Center, San Francisco, CA (2012). Feb 47. Trans ORS 37:2101. (Poster presentation)

19. Li JT, Jones B, Zhang Y, Pei M. Low seeding density favors human synovium-derived stem cell proliferation and multi-lineage differentiation capacity. $58^{\text {th }}$ Annual Meeting of the Orthopaedic Research Society.Moscone West Convention Center, San Francisco, CA (2012). Feb 4-7. Trans ORS 37:1750. (Poster presentation) 
20. Li JT, Pei M. Decullarized matrices modulate human synovium-derived stem cell chondrogenesis. ISSCR $9^{\text {th }}$ Annual Meeting 2011 Toronto, Ontario Canada (Poster Presentation)

21. Li JT, He F, Kish VL, Pei M. Does decellularized matrix provide a tissue-specific microenvironment to enhance human synovium-derived stem cell chondrogenesis? 2011 E. J. Van Liere Convocation and Research Day, WVU, March 10-11. (Poster presentation)

22. Li JT, Pei M. Optimization of an in vitro 3-D microenvironment to reprogram synoviumderived stem cells for chondrogenesis. $56^{\text {th }}$ Annual Meeting of the Orthopaedic Research Society.New Orleans (2010). Trans ORS 35:774. (Poster presentation)

23. Pei M, Li JT. Sequential application of extracellular matrix and low oxygen to improve human synovium-derived stem cell chondrogenesis. TERMIS-EU 2010, Galway, Ireland, $13^{\text {th }}-17^{\text {th }}$ June 2010. (Oral presentation)

24. Pei $\mathrm{M}$, Li JT, He F. Reconstruct an in vitro 3-D microenvironment to reprogram synovium-derived stem cells for chondrogenesis. TERMIS-EU 2010, Galway, Ireland, $13^{\text {th }}-17^{\text {th }}$ June 2010. (Poster presentation)

25. Li JT, Pei M. Optimization of an in vitro 3-D microenvironment to reprogram synoviumderived stem cells for chondrogenesis. 2010 E. J. Van Liere Convocation and Research Day, WVU, April 20-21. (Poster presentation) 